\title{
Experimental Investigation of Mechanical Behaviour of Hybrid Bolted/Bonded Joints for Aircraft
}

\author{
by
}

JiHyun Kim

A thesis submitted to the Faculty of Graduate and Postdoctoral Affairs in partial fulfillment of the requirements for the degree of

\author{
Master of Applied Science \\ in \\ Aerospace Engineering
}

Carleton University

Ottawa, Ontario

(C) 2016

JiHyun Kim 


\begin{abstract}
The hybrid bolted/bonded joint is an emerging aircraft structural joint configuration that is expected to have two advantages over traditional joint configurations: 1) improved joint strength over the traditional joints and 2) fail-safe design. However, previous studies found no advantages from the bolted/bonded joints mainly due to the adhesive stiffness. Using stiff adhesive resulted in two joints behaving independently. The objective of this thesis is to experimentally investigate the mechanical behaviour of the hybrid bolted/bonded joint with the softer paste adhesive.

This thesis verifies the measurement technique, Digital Image Correlation (DIC), which is introduced to the research group for the first time. The DIC technique is verified with the axial extensometer by measuring displacement and strain fields from the simple aluminum test coupon. Additionally, the DIC technique with the instrumented bolt, which is the classic measurement technique to obtain shear load in the bolt, is examined in the bolted/bonded joint configuration. Lastly, the DIC technique is used to investigate the surface strain field changes in different joint configurations. Unique observations are made in each joint configuration, and are presented in this thesis.
\end{abstract}




\section{ACKNOWLEDGEMENTS}

I would like to thank my supervisor, Dr. Jeremy Laliberté for giving me the opportunity. Without his support and sharing his knowledge, it would not be possible to finish the research.

I also would like to acknowledge the external supervisor, Mr. Rick Cole at the National Research Council-Institute for Aerospace Research (NRC-IAR). I learned a lot from his extensive knowledge in the composite structure joints and his warm welcome always made me happy to work at NRC.

I would like to express the gratitude to the technical staff at Mechanical and Aerospace Engineering Department, Carleton University: Alex Proctor, who was always happy to work with and did not hesitate whenever I asked for unreasonable request, Kevin Sangster for always teaching me how to work efficiently, Ian Lloy for always teaching me how to work safely at the machine shop, and Steve Truttmann for extensive knowledge in experiments and supports at the structure lab. Without them, I would not be able to finish a single experiment.

I would like to thank Pedro Lopez-Cruz for helping my part of the project and sharing valuable knowledge, Kobye Bodjona from McGill University, Canada for providing his excellent instrumented bolt, and Shashank Pant for always giving me advice when I was at NRC.

Lastly, I would like to express deep gratitude to my family, especially my mother for the ultimate sacrifice, and friends, who listened to my meaningless grumbling. 


\section{TABLE OF CONTENTS}

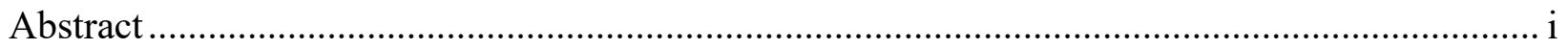

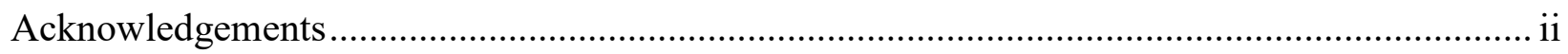

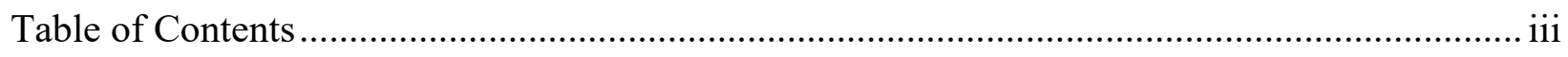

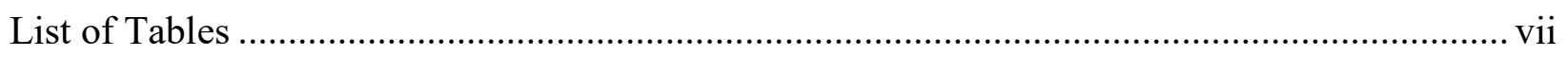

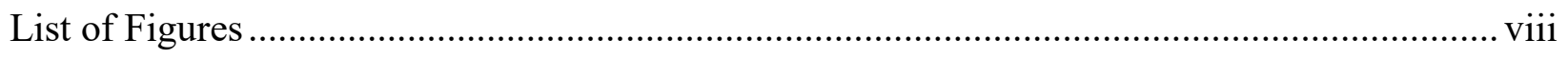

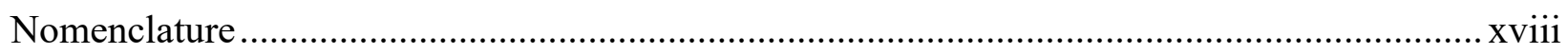

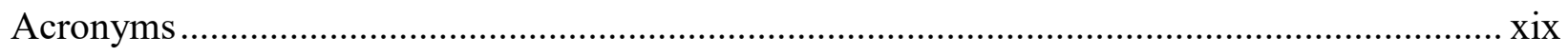

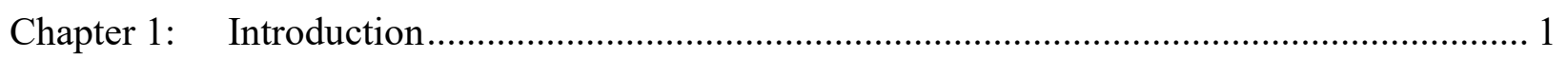

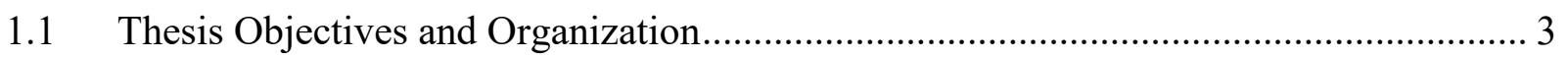

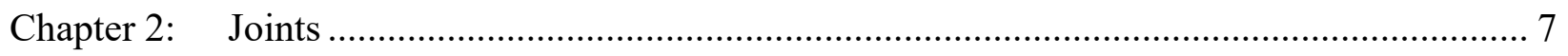

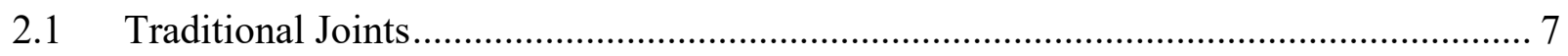

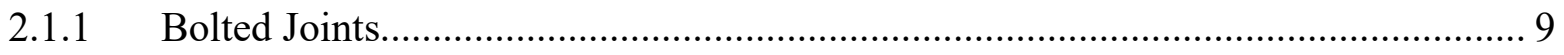

2.1.2 Adhesively Bonded Joints.............................................................................. 12

2.2 Hybrid Bolted/Bonded Joints ............................................................................... 18

2.3 Experimental Application to the Joint Study ………................................................ 22 
Chapter 3: Digital Image Correlation (DIC)

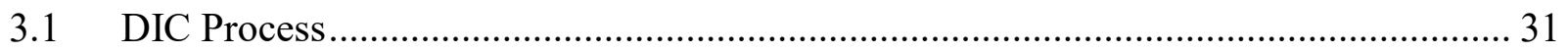

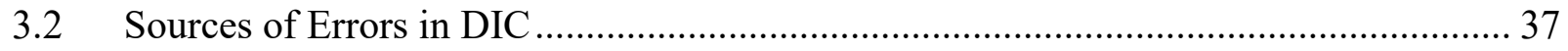

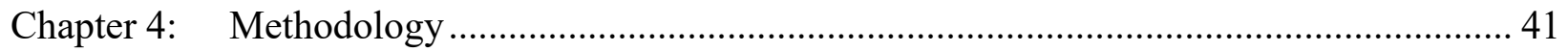

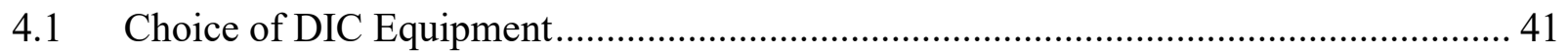

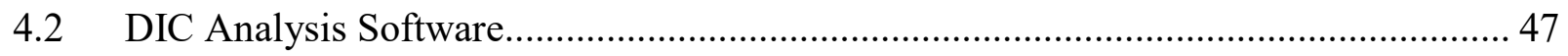

4.3 Camera Software Program and Camera Operation ................................................ 49

4.4 Manufacturing of Composite Bolted/Bonded Joints ........................................... 51

4.4.1 Test Coupon Design............................................................................. 51

4.4.2 Preparation of Composite Adherends .............................................................. 54

4.4.3 Bonding Process of Composite Laminates .................................................. 59

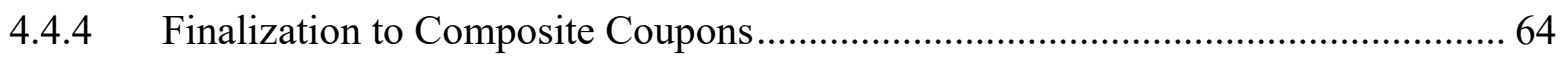

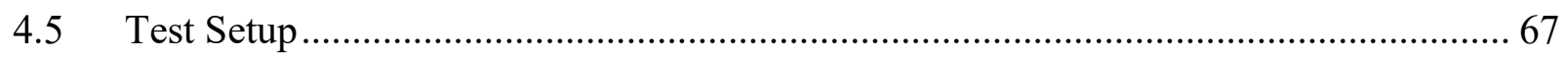

4.5.1 Test Series 1 - Investigation of DIC Configuration ....................................... 68

4.5.2 Test Series 2 - Instrumented Bolt Testing ............................................. 71

4.5.3 Test Series 3 - Investigation of the DIC technique to measure load sharing in

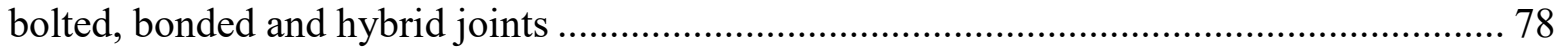


Chapter 5: Experimental Results 84

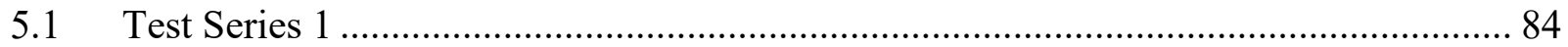

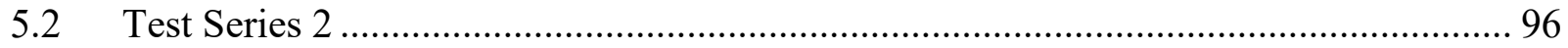

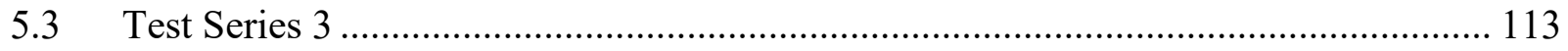

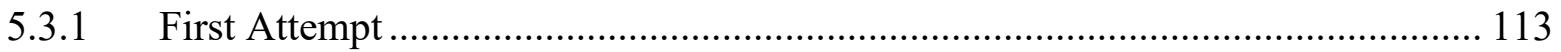

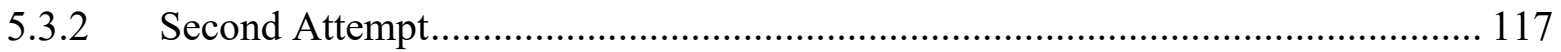

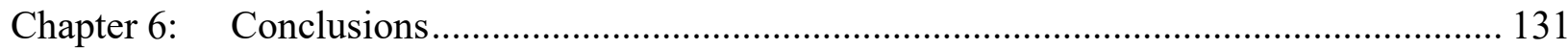

Chapter 7: Recommendations and Future Work ...................................................... 134

7.1 Three-Dimensional Digital Image Correlation (3D-DIC).................................... 135

7.2 2D-DIC Technique Measurement on the Edge of the Joints .................................. 136

7.3 Shape Sensing Technique using Fibre Optic Sensors .......................................... 138

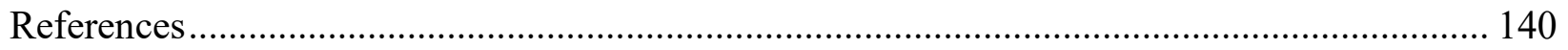

Appendix A. Technical Specification of Cameras ...........................................................

Appendix B. Dimensions of Test Coupons ........................................................................

Appendix C. Model Numbers and Serial Numbers ..................................................... VIII

Appendix D. Bolt Shear Load Calculation ................................................................ IX

Appendix E. $\quad$ Applied Load versus Axial Strain from Test Series 3 ................................... X 


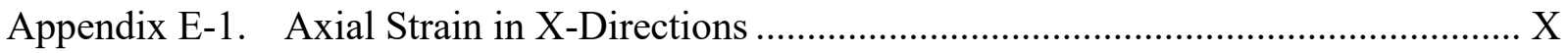

Appendix E-2. Axial Strain in Y-Direction....................................................................

Appendix E-3. Axial Strain from Various Locations in the Bolted Joint............................ XIV

Appendix E-4. Axial Strain from Various Locations in the Bonded Joint......................... XIV

Appendix E-5. Axial Strain from Various Locations in the Bolted/Bonded Joint ................XV 


\section{LIST OF TABLES}

Table 2.1: Bond strength with different surface treatments (Stelmack, 2008) ……...................... 8

Table 4.1: Camera model considered for the research (Canon Canada Inc., n.d.; Olympus

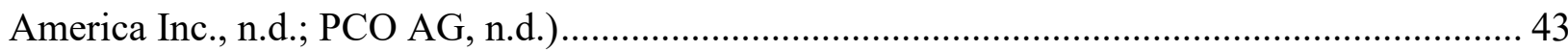

Table 4.2: Geometry requirement for the composite bolted joint (ASTM D5961/D5961M - 13,

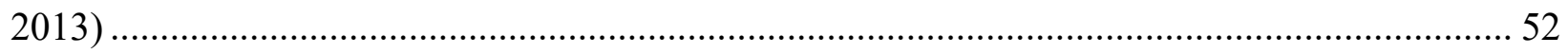

Table 4.3: Dimensions of three different CFRP bolted/bonded joint test coupons ....................... 53

Table 5.1: DIC analysis setting (Test series 1 with an aluminum test coupon with no extension

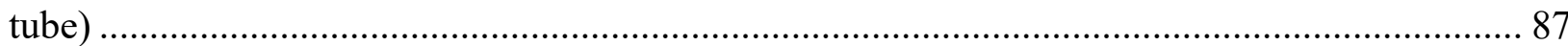

Table 5.2: DIC analysis Settings (bolted/bonded joint with a smaller overlap and the

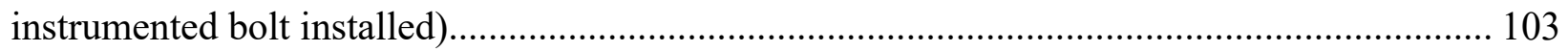

Table 5.3: DIC analysis setting (CFRP bolted joint) ............................................................. 120

Table 5.4: DIC analysis setting (CFRP bonded joint with a hole)............................................. 120

Table 5.5: DIC analysis setting (CFRP bolted/bonded joint) …………………………............. 121

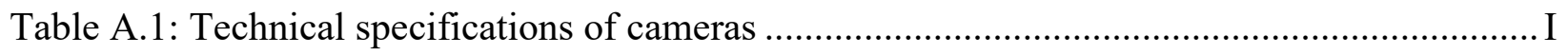

Table C.1: Equipment model number and serial number ...................................................... VIII 


\section{LIST OF FIGURES}

Figure 1.1: Increase in composite materials usage for aircraft structures over time (U.S.

Government Accountability Office, 2011) .................................................................. 1

Figure 2.1: Failure modes of bolted joints (Hart-Smith, 1976) ............................................ 10

Figure 2.2: Load paths of bolted joints due to friction (green) and stress into the bolt (red) ....... 11

Figure 2.3: Composite bonded joint configuration (Hart-Smith, 2003). Reprinted with permission

Figure 2.4: Load path in a single lap bonded joint 14

Figure 2.5: Estimate of stress distribution over the length of the adhesive layer in a single lap joint using Goland and Reissner model (Lopez-Cruz, 2016) ..... 14

Figure 2.6: Shear Failure. (a) cohesive failure (b) adhesive failure (adapted from Heslehurst, 2013)

Figure 2.7: Peeling failure (a) cohesive failure (b) adhesive failure (adapted from Heslehurst, 2013) 15

Figure 2.8: Failure steps in a single lap bonded joints with brittle adherends (adapted from HartSmith, 1974) 16

Figure 2.9: The effect of the adhesive thickness (da Silva et al., 2006) Reprinted with permission. 
Figure 2.10: Tensile stress-strain curve of Hysol EA9361 at different loading rates (da Silva et al.

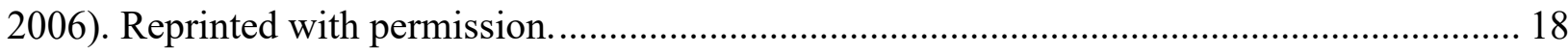

Figure 2.11: Effect of adhesive modulus on the bolt load transfer (Kelly, 2005). Reprinted with

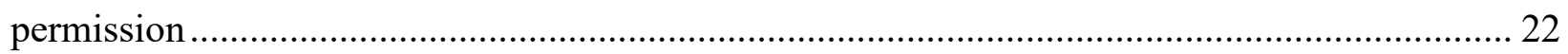

Figure 3.1: Example of DIC analysis from present research .................................................... 28

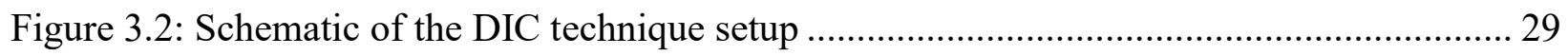

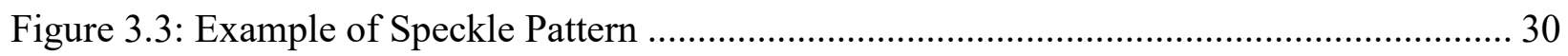

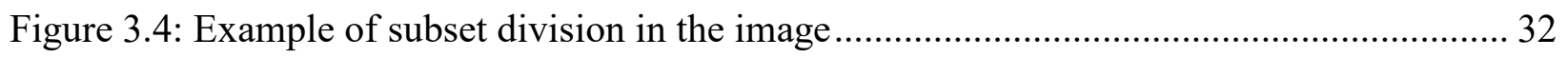

Figure 3.5: An example of reference and deformed images ..................................................... 33

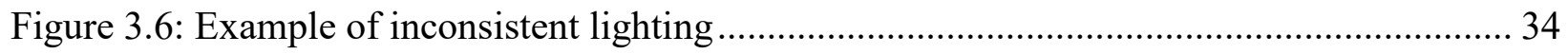

Figure 3.7: Example of correlation coefficient of Figure 3.1 …………………....................... 35

Figure 3.8: Out-of-plane displacement occurred during the static tensile load test...................... 38

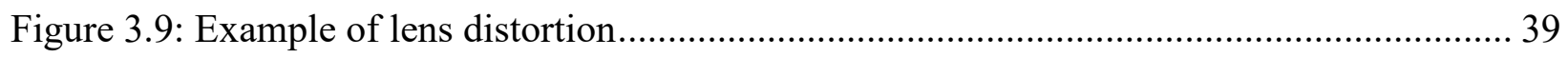

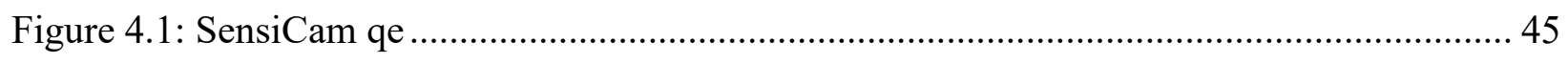

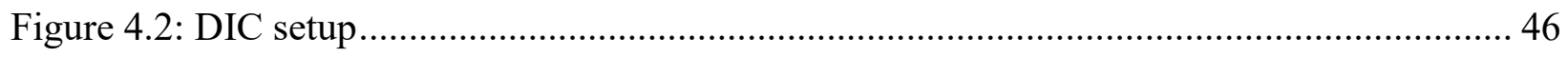

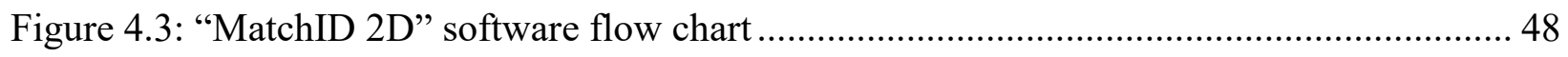

Figure 4.4: Schematic image of camera framing time setting (Cooke Co., 2002) ....................... 50 
Figure 4.5: The difference between 8-bit and 16-bit depths

Figure 4.6: Schematic image of vacuum bagging 56

Figure 4.7: Vacuum bagging process for curing laminate 1 56

Figure 4.8: Vacuum bagging process for curing laminate 2 57

Figure 4.9: Vacuum bagging process for curing laminate 3 57

Figure 4.10: Recommended cure cycle for CYCOM 5320 (modified from Cytec Solvay Group, 2015) 58

Figure 4.11: Actual temperature change in the laminate during initial curing process 58

Figure 4.12: The result of ultrasonic scanning of cured laminate. 59

Figure 4.13: Grit blasting process. 60

Figure 4.14: Plates following grit blasting with piano wires attached 62

Figure 4.15: Adhesive applied to the plate 62

Figure 4.16: Vacuum bagging process. 64

Figure 4.17: Completely cured bonded plates 64

Figure 4.18: Image showing delamination at the exit of composite panel (modified from Durão, Tavares, de Albuquerque, Marques, \& Andrade, 2014) 65

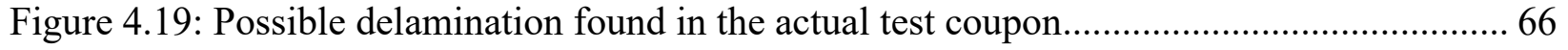


Figure 4.20: The magnified picture of the completed notch.

Figure 4.21: The test coupon after the completion of manufacturing. 67

Figure 4.22: DIC verification with extensometer 69

Figure 4.23: Speckle pattern applied to the aluminum test coupon surface 70

Figure 4.24: Instrumented Bolt 72

Figure 4.25: Rosette used in the instrumented bolt (EA-13-062TV-350E) 73

Figure 4.26: The Wheatstone bridge configuration (Kuphaldt, n.d.). 73

Figure 4.27 The schematic image of the finite element model..... 74

Figure 4.28: First test coupon (bolted joint) with the instrumented bolt 75

Figure 4.29: Second test coupon (bolted/bonded joint) with the instrumented bolt 76

Figure 4.30: Schematic drawing of second and third test coupons. 77

Figure 4.31: Picture of the last test coupon taken by DIC equipment 78

Figure 4.32: Three test coupons with different configurations. (a) bolted joint (b) bonded joint with a hole (c) bolted/bonded joint . 78

Figure 4.33: Hi-Lok ${ }^{\circledR}$ titanium pin with protruding shear head, Hi-Lok ${ }^{\circledR}$ titanium collar, and washer 79

Figure 4.34: Side view of the CFRP bolted joint .............................................................. 80 
Figure 4.35: Sleeve fastener, its collar, and washer. 80

Figure 4.36: Side view of CFRP bolted/bonded joint with sleeve fasteners 81

Figure 4.37: Applied load versus stroke curve showing the comparison between Hi-Lok fasteners and sleeve fasteners (modified from Lopez-Cruz, 2016)...... 82

Figure 5.1: The FOV of the aluminum test coupon from the first round and the AOI (blue) and the reference subset (yellow) for the analysis 85

Figure 5.2: Area for measuring average strain $\left(\varepsilon_{\mathrm{yy}}\right)$ from the first test 86

Figure 5.3 Schematic image of determining the virtual strain gage size 87

Figure 5.4: Applied load versus stroke curve from the test series 1 88

Figure 5.5: Displacement change over time 89

Figure 5.6: Stress versus axial strain curve (aluminum test coupon with no extension tube) ...... 90

Figure 5.7: The percentage difference between DIC and extensometer data (aluminum test coupon with no extension tube)

Figure 5.8: Comparison between DIC pictures of the first and the second tests ..... 92

Figure 5.9: the AOI (blue) and the reference subset (yellow) setup of the second test with aluminum test coupon 93

Figure 5.10: Area for measuring average strain $\left(\varepsilon_{y y}\right)$ from the second test 93 
Figure 5.11: Stress versus axial strain curve (aluminum test coupon with $13 \mathrm{~mm}$ extension tube)

Figure 5.12: The difference between DIC and extensometer data in percentage (aluminum test coupon, the extension tube added to the camera)

Figure 5.13: Applied load versus stroke curve (aluminum bolted joint)

Figure 5.14: Applied load versus voltage output from the instrumented bolt (aluminum bolted joint). 97

Figure 5.15: Applied load versus bolt shear load in the centre of the bolt (aluminum bolted joint)

Figure 5.16: Applied load versus stroke curve (CFRP bolted/bonded joint with large overlap area). 99

Figure 5.17: Applied load versus bolt shear load in near the centre of the through thickness of the joint (CFRP bolted/bonded joint with large overlap area) 100

Figure 5.18: Applied load versus stroke curve (bolted/bonded joint with small overlap area) .. 101

Figure 5.19: Applied load versus bolt shear load in near the centre of the through thickness of the joint (narrower bolted/bonded CFRP joint). 101

Figure 5.20: FOV and AOI (blue) of the specimen with speckle pattern (left) and the area (white) that the average shear strain values were extracted (right) 103 
Figure 5.21: Applied load versus surface shear strain from DIC and FEA model 104

Figure 5.22: Applied load versus the shear load in the centre of the bolt. 106

Figure 5.23: Out-of-plane displacement captured during the test. 107

Figure 5.24: Shear strain change due to different strain window size 108

Figure 5.25: The shear strain extractions points from the FEA model 109

Figure 5.26: The shear strain extractions points from the DIC analysis. 109

Figure 5.27: Finite Element Analysis vs. Digital Image Correlation $\left(90^{\circ}\right)$ 111

Figure 5.28: Finite Element Analysis vs. Digital Image Correlation $\left(0^{\circ}\right)$ 111

Figure 5.29: Finite Element Analysis vs. Digital Image Correlation $\left(60^{\circ}\right)$ 112

Figure 5.30: Finite Element Analysis vs. Digital Image Correlation (30) 112

Figure 5.31: Possible manufacturing defects caused unexpected failure behaviour of the joint 113

Figure 5.32 Load versus stroke curve of the failed specimen (CFRP bolted/bonded joint) ....... 115

Figure 5.33: The bolt response from the first attempt (CFRP bolted/bonded joint)..... 115

Figure 5.34: Failed surface of the joints during the first attempt. 116

Figure 5.35: Applied load versus stroke curve of three test coupons 118 
Figure 5.36: The difference in the stroke between the bonded joint with a hole and the bolted/bonded joint 119

Figure 5.37: FOV, AOI (blue), and the reference subset (red) for the bolted joint (left), the bonded joint with a hole (centre), and the bolted/bonded joint (right)

Figure 5.38: Shear strain around the bolt showing the "butterfly" pattern

Figure 5.39: The data extraction area for the bolted joint (left), the bonded joint with a hole (centre), and the bolted/bonded joint (right) in the butterfly region

Figure 5.40: The data extraction area for the bolted joint (left), the bonded joint with a hole (centre), and the bolted/bonded joint (right) from the points lying $45^{\circ}$ axis. 122

Figure 5.41: The data extraction area for the bolted joint (left), the bonded joint with a hole (centre), and the bolted/bonded joint (right) from the points lying $60^{\circ}$ axis

Figure 5.42: Load versus shear strain $\left(\gamma_{\mathrm{xy}}\right)$ comparison of three different joints in the butterfly

region

Figure 5.43: Load versus shear strain $\left(\gamma_{\mathrm{xy}}\right)$ comparison of three different joints in the $45^{\circ}$ axis 125

Figure 5.44: Load versus shear strain $\left(\gamma_{x y}\right)$ comparison of three different joints in the $60^{\circ}$ axis 125

Figure 5.45: Direction of the displacement vector in the bolted joint 126

Figure 5.46: Direction of the displacement vector in the bonded joint 126

Figure 5.47: Direction of the displacement vector in the bolted/bonded joint 127 
Figure 5.48: Load versus shear strain obtained from various locations in the bolted joint 129

Figure 5.49: Load versus shear strain obtained from various locations in the bonded joint ...... 129

Figure 5.50: Load versus shear strain obtained from various locations in the bolted/bonded joint 130

Figure 7.1: 3D-DIC equipment. (LaVision, 2016) 136

Figure 7.2: Example of DIC technique used on the edge of the joint (Lopez-Cruz, 2016) ........ 137

Figure 7.3: Fibre optic shape sensing technology (Beam S., 2014) 139

Figure E.1: Applied load versus axial strain $\left(\varepsilon_{x x}\right)$ of three different joints in the butterfly region $\mathrm{X}$

Figure E.2: Applied load versus axial strain $\left(\varepsilon_{x x}\right)$ of three different joints in the $45^{\circ}$ axis X

Figure E.3: Applied load versus axial strain $\left(\varepsilon_{x x}\right)$ of three different joints in the $60^{\circ}$ axis XI Figure E.4: Applied load versus axial strain $\left(\varepsilon_{y y}\right)$ comparison of three different joints in the butterfly region. XII

Figure E.5: Applied load versus axial strain $\left(\varepsilon_{y y}\right)$ comparison of three different joints in the $45^{\circ}$ axis XII

Figure E.6: Applied load versus axial strain $\left(\varepsilon_{y y}\right)$ comparison of three different joints in the $60^{\circ}$ axis XIII

Figure E.7: Applied load versus axial strain $\left(\varepsilon_{x x}\right)$ in the bolted joint. XIV 
Figure E.8: Applied load versus axial strain $\left(\varepsilon_{y y}\right)$ in the bolted joint......

Figure E.9: Applied load versus axial strain $\left(\varepsilon_{x x}\right)$ in the bonded joint XV

Figure E.10: Applied load versus axial strain $\left(\varepsilon_{y y}\right)$ in the bonded joint .....................................

Figure E.11: Applied load versus axial strain $\left(\varepsilon_{x x}\right)$ in the bolted/bonded joint ........................ XVI

Figure E.12: Applied load versus axial strain $\left(\varepsilon_{y y}\right)$ in the bolted/bonded joint ........................ XVI 


\section{NOMENCLATURE}

Symbols Description Units

$\xi \quad$ Shape function in horizontal direction $\quad N / A$

$\eta \quad$ Shape function in vertical direction $\quad N / A$

$f_{m} \quad$ Ensemble average of reference and deformed subsets in $\quad N / A$ horizontal direction

$g_{m} \quad$ Ensemble average of reference and deformed subsets in $\quad N / A$ vertical direction

$e \quad$ Distance from the edge to the centre of the bolt $\mathrm{mm}$

d Bolt diameter $\mathrm{mm}$

w Joint overlap width $\mathrm{mm}$

$l$ Joint overlap length $\mathrm{mm}$

$l_{0} \quad$ Gauge length of axial extensometer $\mathrm{mm}$

$l_{d} \quad$ Deformed length of axial extensometer $\mathrm{mm}$

$\varepsilon \quad$ Strain $\mathrm{mm} / \mathrm{mm}$

E Modulus of Elasticity $\quad G P a$

$\sigma$ Stress $\quad \mathrm{MPa}$

F Load or Force $N$ 


\section{ACRONYMS}

2D-DIC Two Dimensional Digital Image Correlation

3D-DIC Three Dimensional Digital Image Correlation

AOI Area of Interest

ASTM American Society for Testing and Materials

BCSPLINE Bicubic Spline

CC Cross Correlation

CCD Charge-Coupled Device

CFRP Carbon Fibre Reinforced Plastic

CMOS Complementary Metal-Oxide-Semiconductor

COMP Composite project code used in CRIAQ

CRIAQ Consortium for Research and Innovation in Aerospace in Québec

DIC Digital Image Correlation

DSLR Digital Single Lens Reflex

FAA Federal Aviation Administration

FEA Finite Element Analysis

FOV Field of View

FPS Frames per Second

FRP Fibre Reinforced Plastic

GFRP Glass Fibre Reinforced Plastic

LED Light-emitting Diode

NRC-IAR National Research Council - Institute for Aerospace Research

PSSD Parametric Sum of Squared

RPM Rotation per Minute

SSD Sum of Squared Difference

VSG Virtual Strain Gage

ZNSSD Zero-Mean Normalized Sum of Squared 


\section{Chapter 1: INTRODUCTION}

Composite materials have been increasingly used in commercial aircraft structures as can be seen in Figure 1.1. The main advantage of composite materials is to reduce weight while retaining the strength of traditional structural materials. By saving weight, aircraft in the same size can carry more passengers or fly farther distances. According to Boeing's data for aircraft structures, substituting the structural materials achieved weight savings of $20 \%$ compared to aluminum materials (Hale, 2006). Further weight saving is possible by optimizing of substructure components, such as joints in composite structures. For example, 2.4 million fasteners are used to assemble a single Boeing 787 Dreamliner (Herring, 2014). Millions of fasteners can add significant weight to the aircraft and increase assembly costs and complexity. Thus, there is a necessity in reducing the number of fasteners required and/or the size of each fastener.

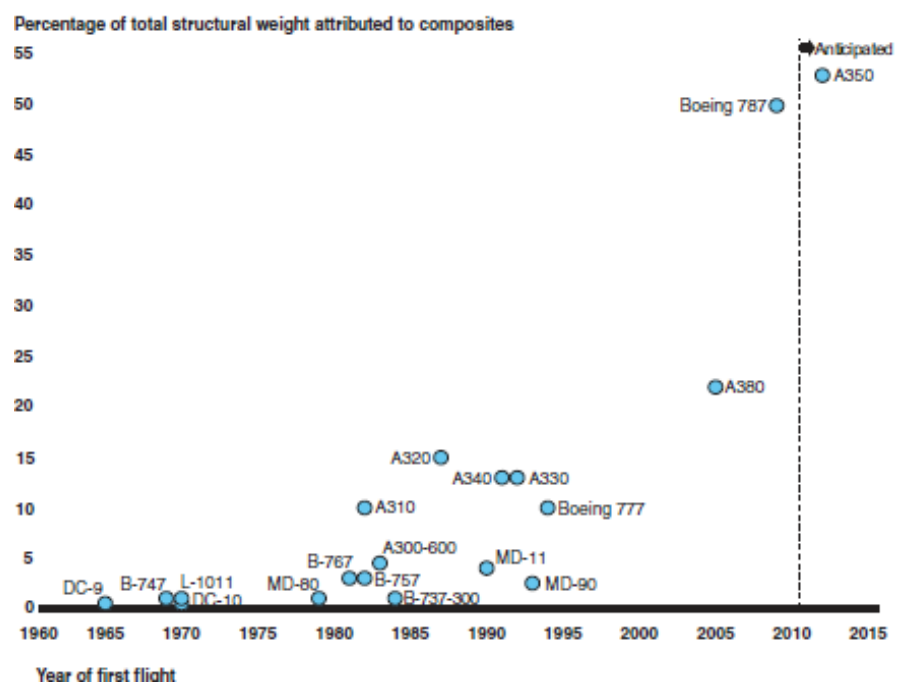

Figure 1.1: Increase in composite materials usage for aircraft structures over time (U.S. Government Accountability Office, 2011) 
The hybrid bolted/bonded joints are studied because they should have a longer service life by sharing load transfer between the fastener and adhesive - resulting in lower stresses within each separate load path joint. If a longer service life is not the main design goal, then hybrid joints may also permit smaller fasteners or fewer fasteners. Also, the fasteners and adhesive can act as redundant load paths for each other, which means that one load path can still retain structural integrity until the next maintenance interval, inspection, and repair (Federal Aviation Administration, 2009). However, previous studies showed analytically or experimentally that the hybrid bolted/bonded joint did not act as intended (Hart-Smith, 1985; Vallée, Tannert, Meena, \& Hehl, 2013). The studies showed that the adhesive layer in the bolted/bonded joint is always the major load path as a higher share of the load always through the stiffer path, thus, the previously studied hybrid joint has the same behaviour as a purely bonded joint until the adhesive layer fails and then the fasteners would contribute. In other words, each part of the hybrid joint acts separately so that the expected advantages of the bolted/bonded joint could not be fully achieved. The COMP-506 Project - Design of Hybrid Bolted/Bonded Joints, sponsored by Consortium for Research and Innovation in Aerospace in Québec (CRIAQ), with McGill University, École polytechnique de Montréal, L3MAS, Delastek and Bombardier Aerospace, was initiated by these findings (CRIAQ, 2013). The overall goal of the project is to investigate the behaviour of the bolted/bonded joints and offer an optimal way to design the bolted/bonded joints from the findings.

The role of Carleton University is to investigate the behaviour of the hybrid bolted/bonded joint experimentally. The bolted/bonded joint test coupons were 
manufactured at National Research Council Aerospace Composites Laboratory, Ottawa, Canada and tested in the Mechanical and Aerospace Engineering Structures Laboratory at Carleton University, Ottawa, Canada.

The behaviour of the joints was investigated by the measurement technique called Digital Image Correlation (DIC). Digital Image Correlation is a non-invasive measurement technique, which provides the displacement and the strain fields by analyzing a series of pictures taken at a certain interval. The technique has been widely used in various fields as well as the studies of the joints and anisotropic materials, such as the composite materials (Backman, Li, \& Sears, 2011; Hild \& Roux, 2006). The DIC technique is particularly useful when anisotropic materials are tested because the fullfield data is more useful than the point data since the point data can miss unusual behaviour in certain locations. Furthermore, different post-test analyses using the DIC technique can be performed with saved pictures to prevent from repeating the entire experiments. Time and material savings are possible compared to the traditional measurement techniques, such as strain gages.

\subsection{Thesis OBJECTIVES AND ORGANIZATION}

The goal of this thesis research is to investigate the mechanical behaviour of the composite hybrid bolted/bonded joint. In order to achieve the thesis goal, estimating the contribution of the bolt to load transfer in the hybrid bolted/bonded joint was to be investigated. A commonly used technique to measure the load transferred through the bolt is an instrumented bolt. An instrumented bolt is a specially designed and machined 
bolt that the strain gages installed to measure the shear or tensile load transmitted by the bolt. However, the instrumented bolt is not usable in the present research because the required design bolt size is too small to be instrumented. Therefore, the DIC technique was chosen as an alternative approach.

This thesis reviews the previous studies of bolted, bonded, and bolted/bonded joints (Chapter 2). The DIC process is covered to provide a better understanding of how this technique functions and the application of the DIC technique observed from the previous studies is also covered (Chapter 3). The experimental setup for validating the DIC technique and verifying the goal of the thesis is discussed (Chapter 4). Following the discussion of the experimental results (Chapter 5), research conclusions are presented (Chapter 6). Lastly, recommendations from the present work and future studies are discussed (Chapter 7). 
The thesis work is explained and divided into the following chapters

\section{Chapter 1: Introduction}

\section{Chapter 2: Joints}

This chapter covers the previous studies and their observations of bolted, bonded, and bolted/bonded joints in composite structures. Also, the failure modes and load paths of the bolted and bonded joints are also covered. The experimental measurement technique to study the joints is also covered.

\section{Chapter 3: Digital Image Correlation}

This chapter covers the DIC technique process, the sources of errors in the DIC technique.

\section{Chapter 4: Methodology}

This chapter covers the manufacturing of the bolted/bonded joint test coupons, DIC equipment selection, and experimental setup

\section{Chapter 5: Experimental Results}

This chapter covers findings from the DIC equipment verification tests using both a homogeneous aluminum test coupon (no joint) and joint coupons with various configurations. The comparison of results between a bolted joint, a bonded joint with a hole, and a bolted/bonded joint are also explained. 


\section{* Chapter 6: Conclusion}

This chapter summarizes key findings from the tests performed during the research and proposes recommendations for improving the DIC technique and future research considerations. 


\section{Chapter 2: JOINTS}

This chapter discusses previous studies of composite bolted and bonded joints. It focuses on how the bolted and the bonded joints fail and what factors cause the failure of these joints. Following the review of traditional joints, additional studies on composite hybrid bolted/bonded joints are reviewed. This section focuses on the positive potentials of the bolted/bonded joints found in the previous studies. Lastly, the experimental measurement techniques for studying the joints is discussed.

\subsection{TRADITIONAL JOINTS}

Two traditional joint types are used in composite aircraft structures; mechanically fastened (e.g. bolted or riveted) joints and bonded joints. Traditionally, bolted or riveted joints have been used because installing, replacing, and inspecting them is relatively straightforward and requires techniques and skills similar to the mechanical fastening of metals. However, the disadvantages of bolted or riveted joints include:

1) maintenance time to replace;

2) overall weight increase of the aircraft and;

3) higher peak loads and stress concentrations.

Stress concentrations are an important concern, if the structure experiences higher load than the design point, it can lead to a shorter service life than predicted.

A bonded joint experiences less stress concentration compared to the bolted joints because the load transfer from one structure to another is through the entire bonded area. However, it is harder to inspect a bonded joint when compared to a bolted joint because 
the adhesive layer is hidden between the adherends. Federal Aviation Administration (FAA) (2009) specifically stated that the reliable non-destructive inspection technique must be established to inspect the bonded joint (Federal Aviation Administration, 2009). Without specialized equipment, such as ultrasonic equipment, it may not be possible to detect the initiation of failure. Furthermore, the bonding procedure has a great impact on its service life. A surface treatment is of particular importance since it affects the shear adhesive strength. Table 2.1 demonstrates that the bond strength of a same bonded joint can be increased from 3.07 MPa to $19 \mathrm{MPa}$ with a proper surface treatment. Due to this significant effect of surface preparation, FAA specified the surface preparation as the consideration that must be controlled during the bonding process. (Federal Aviation Administration, 2009).

Table 2.1: Bond strength with different surface treatments (Stelmack, 2008)

\begin{tabular}{|c|c|c|c|}
\hline Adherend & Treatment & Adhesive & Shear Strength \\
\hline \multirow{3}{*}{ Aluminum } & As Received & & $3.07 \mathrm{MPa}$ \\
\cline { 2 - 2 } & Vapor Degreased & \multirow{4}{*}{ Epoxy } & $5.77 \mathrm{MPa}$ \\
\cline { 2 - 2 } & Grit Blast & & $12.07 \mathrm{MPa}$ \\
\cline { 2 - 2 } & Acid Etch & & $19.00 \mathrm{MPa}$ \\
\hline
\end{tabular}

Studies conducted the traditional joints are reviewed and discussed in this chapter. This chapter begins by summarizing the findings of the studies focused on the relationship between the design and failure modes of the bolted and the bonded joints. Then, the findings of the hybrid bolted bonded joint studies are discussed. 


\subsubsection{BOLTED JOINTS}

The bolted joints have a long application history in engineering structures. The composite bolted joints have particular factors determining the bolted joint strength and the failure modes: 1) the adherend laminate and 2) the fibre stacking sequences. In this section, the effect of each factor on the composite bolted joint is discussed.

Assuming that the bolt does not fail before the adherend failure and all bolts are identical, then the adherend strength is the main contributor to the joint bearing strength. Fibre reinforced composite materials have orthotropic or directional properties, such as strength and stiffness, which are defined by the fibre direction. Collings (1977) studied the effect of the different laminate to the bearing strength. A single bolted joint with cross-ply laminate adherends consisting of only $0^{\circ}$ and $90^{\circ}$ plies had about $11 \%$ lower bearing strength than the same single bolted joint with quasi-isotropic composite laminate adherends consisting of $0^{\circ}$ and $\pm 60^{\circ}$ plies (Collings, 1977).

Failure modes commonly observed in the composite bolted joints are schematically shown in Figure 2.1. 


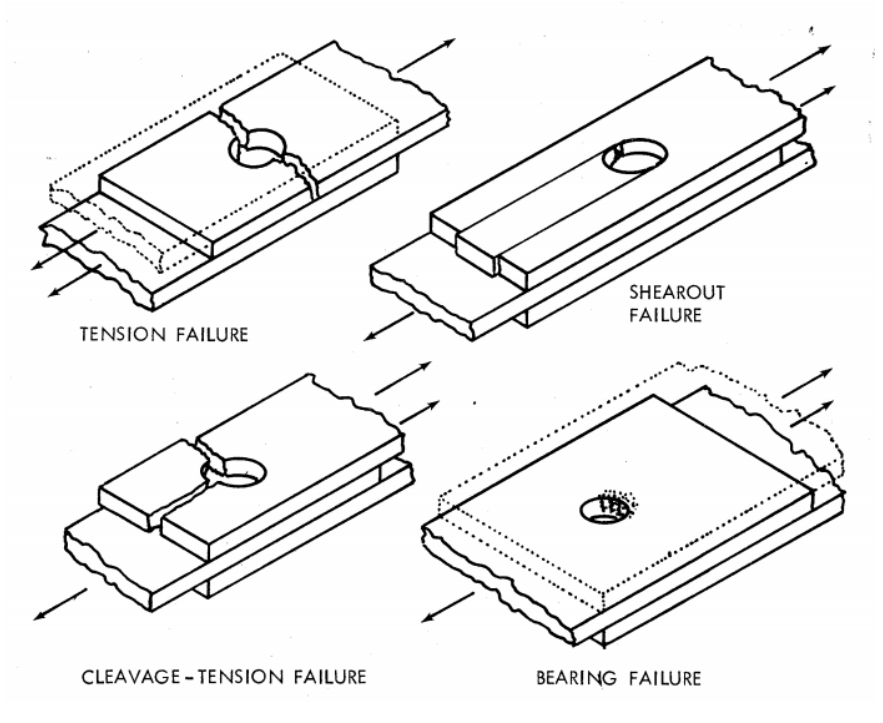

Figure 2.1: Failure modes of bolted joints (Hart-Smith, 1976)

The initiation of each failure mode of fibre reinforced composite materials occurs in different locations. A bearing failure mode is considered a non-catastrophic failure, where the delamination occurs between $0^{\circ}$ and $90^{\circ}$ interfaces or matrix cracking in $90^{\circ}$ or $45^{\circ}$ plies. It is non-catastrophic because the structures are still held by the bolt when the bearing failure occurs. A tension failure mode and a shearout failure mode are considered as catastrophic failure modes as the structure cannot be held after either failure occurs. The tension failure mode usually occurs at $90^{\circ}$ layer with no indication until $90 \%$ of a failure load. The shearout failure mode occurs after $0^{\circ}$ layer experiences micro-buckling and causes larger matrix failure in the laminate at $95 \%$ of the failure load (Camanho, Bowron, \& Matthews, 1998).

For a double-lap joint configuration with carbon fibre reinforced plastic (CFRP) adherends, a net tension failure occurs when the overlap width is equivalent to between three to four bolt diameters. This failure stress is much lower than the laminate' ultimate 
strength, which indicates a significant stress concentration. The bearing failure occurs when the overlap width is equivalent to six bolt diameters. It indicates the geometry influences the failure mode of the bolted joint (Hart-Smith, 1976).

When a bolted joint is loaded, two load paths exist as described in Figure 2.2. The first load path is the bolt. The other path is the friction between adherends. The load transfer by friction is significant until the bolt deforms enough to touch the hole. The effect of friction is significant to the bolted joint strength. The analytical model of pinned joints indicated the friction coefficient between adherends increased from 0.2 to 0.5 with a reduced ultimate load by about 27\% (Yavari, Rajabi, Daneshvar, \& Kadivar, 2009). Assuming that the surface finish for all test coupons is the same, then the torque applied to install a bolt must be controlled since a compressive force from the bolt will be the main contributor to varying the friction between the adherends.

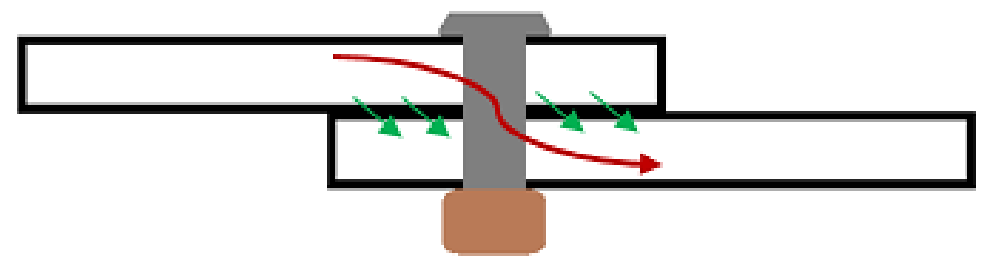

Figure 2.2: Load paths of bolted joints due to friction (green) and stress into the bolt (red)

In summary, the composite bolted joint strength is affected by the laminate configurations since the configuration affects the adherend strength. Also, each failure mode in the composite joint is initiated in a different location. Therefore, knowing the type of failure mode will help to assume the failure initiation point. The joint geometry also influences which type of failure modes should be expected. Since the strength may 
be significantly lower in a certain failure mode, it is necessary to control the geometry to avoid the failure at much lower stress.

\subsubsection{ADHESIVELY BONDED JOINTS}

An adhesively bonded joint is another type of joints commonly used in aircraft structures. The bonded joint is commonly used for secondary aircraft structure rather than for primary structures because Civil Aviation Authorities will not presently certify the primary structures with only bonded joints even though Federal Aviation Administration (FAA) strictly stated the requirement for the bonded joint structures (Pantelakis \& Tserpes, 2013; Federal Aviation Administration, 2009). However, the bonded joint is still a promising joint configuration for less stress concentration and weight reduction.

Different bonded joint configurations exist as can be seen in Figure 2.3.

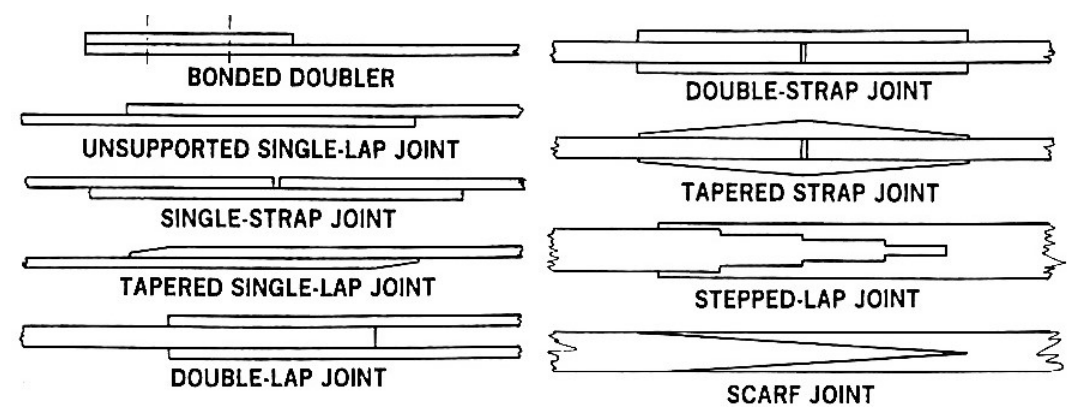

Figure 2.3: Composite bonded joint configuration (Hart-Smith, 2003). Reprinted with permission

The choice of configurations depends on the design details of the structures. For example, double-lap joints are not employed in structures with thick aderends because the bond load due to using thicker adherends increases more rapidly against the bond 
capacity. The scarf joint or the stepped-lap joint is recommended over the double-lap joint when thick adherends are to be used (Hart-Smith, 1974). On the other hand, the ASTM standards, such as D3165 - 07 'Standard Test Method for Strength Properties of Adhesives in Shear by Tension Loading of Single-Lap-Joint Laminated Assemblies' or D5868 - 01 'Standard Test Method for Lap Shear Adhesion for Fiber Reinforced Plastic (FRP) Bonding', suggest using a test coupon with a single-lap joint configuration for better understanding of the adhesive behaviour. Furthermore, manufacturing complexity affects the optimal design configuration to use. The load transferring through a single-lap bonded joint causes a secondary bending due to load eccentricity, which induces the peel stress in the adhesive layer (Kelly, 2005). Hence, a double-lap joint configuration is also often used for reduced peel stress effect by avoiding load eccentricity.

The load applied to a bonded joint is transferred through the entire adhesive layer as can be seen in Figure 2.4. The load induces shear stress in the adhesive layer, and it becomes the principal load transfer mechanism of the adhesive layer. Shear stress concentration does not occur in the adhesive layer during transferring of the load. However, several analytical models indicated that there is a region, where the peel stress and adhesive shear stress in the single-lap bonded joint are higher at the free-edge of the adherends (Goland \& Reissner, 1944; Volkersen, 1938; Hart-Smith, 1974). 


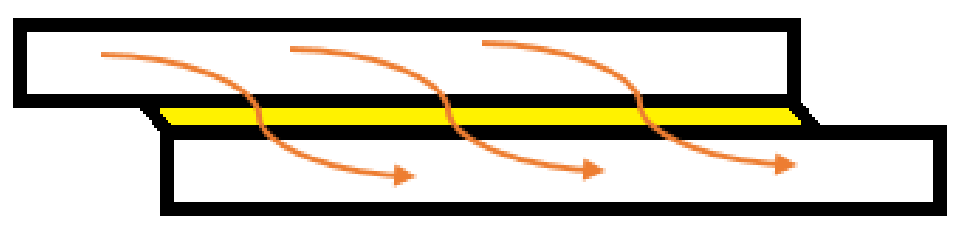

Figure 2.4: Load path in a single lap bonded joint

The analytical model developed by Goland and Reissner (1944) in Figure 2.5

shows a general sense of stress distribution in the adhesive layer. It can be seen that both stresses near the edges are significantly higher. Although the model does not take into account stress through the bond thickness and the stress-free condition, it reasonably describes the stress distribution in the bonded joint. Kumar et al. (2013) experimentally proved that both adhesive shear and peel stresses agreed with Goland and Reissner's model except the stress-free region (Kumar, Bhat, \& Murthy, 2013). These high stress regions near the edge of the single-lap joint are the location where the adhesive failure usually initiates.

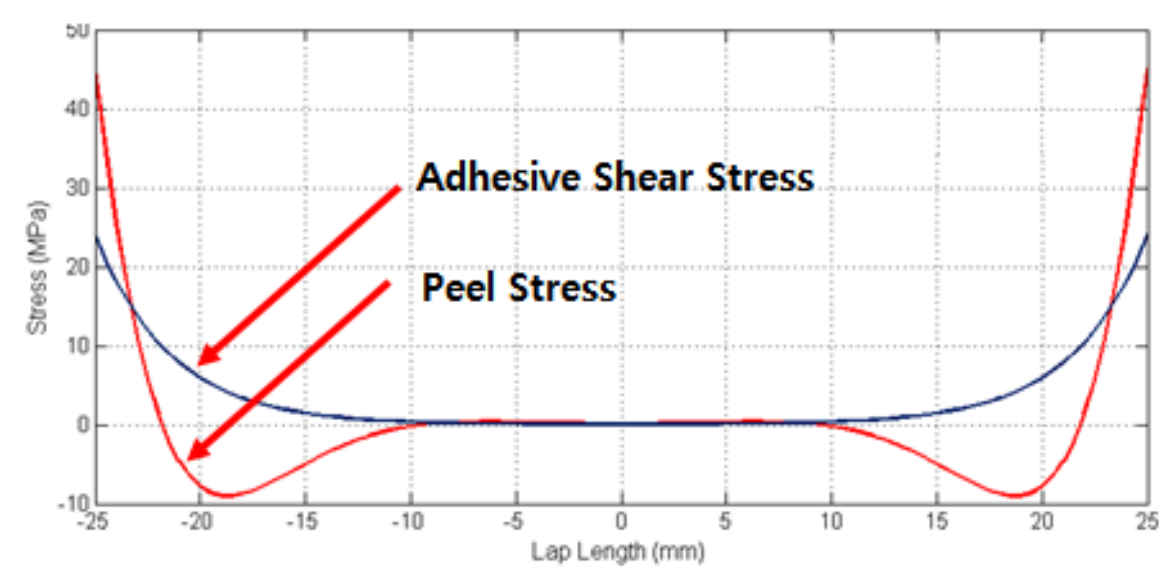

Figure 2.5: Estimate of stress distribution over the length of the adhesive layer in a single lap joint using Goland and Reissner model (Lopez-Cruz, 2016) 
There are two primary failure modes observed in adhesively bonded joints: cohesive failure and adhesive failure. Hart-Smith (1974) defined a well-designed joint when the joint failed in an adherend far from the joint area. Also, the adhesive layer in the well-designed joint should fail in a cohesive manner when the stress exceeds the designed adhesive strength according to his study (Hart-Smith, 1974). If the bonded joint fails between the adherend and the adhesive layer because the adhesive is not perfectly bonded to the adherends due to poor surface finish, then the adhesive will fail in an adhesive manner. This failure case happens below the joint design strength. Therefore, the adhesive failure is considered as an unfavorable failure mode (Heslehurst, 2013). Figure 2.6 and Figure 2.7 illustrate the failure modes seen in a single-lap bonded joint.

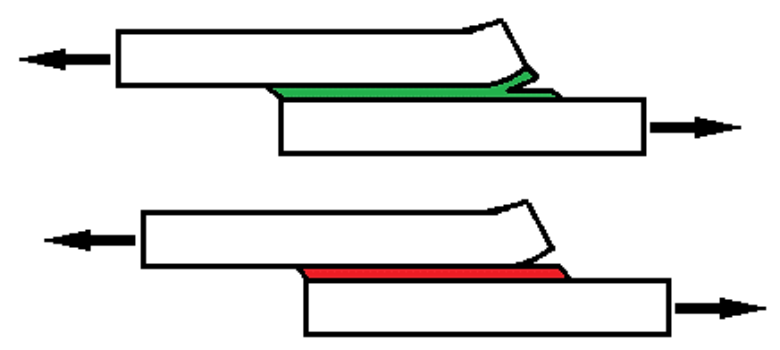

Figure 2.6: Shear Failure. (a) cohesive failure (b) adhesive failure (adapted from Heslehurst, 2013)

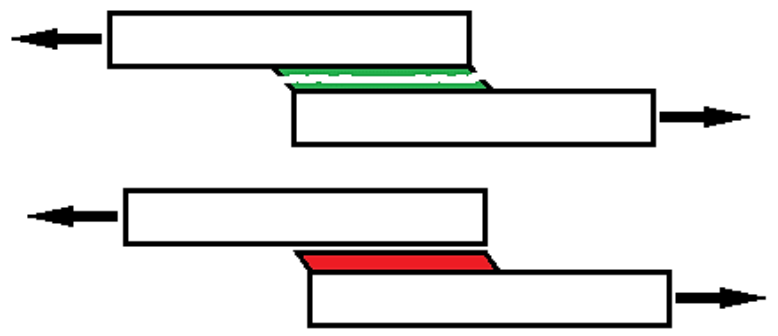

Figure 2.7: Peeling failure (a) cohesive failure (b) adhesive failure (adapted from Heslehurst, 2013) 
As the single-lap joint starts to be loaded, both adherends at the bonded region start to bend due to load eccentricity causing the stress concentration near the ends of the adhesive as described in the second image of Figure 2.8.

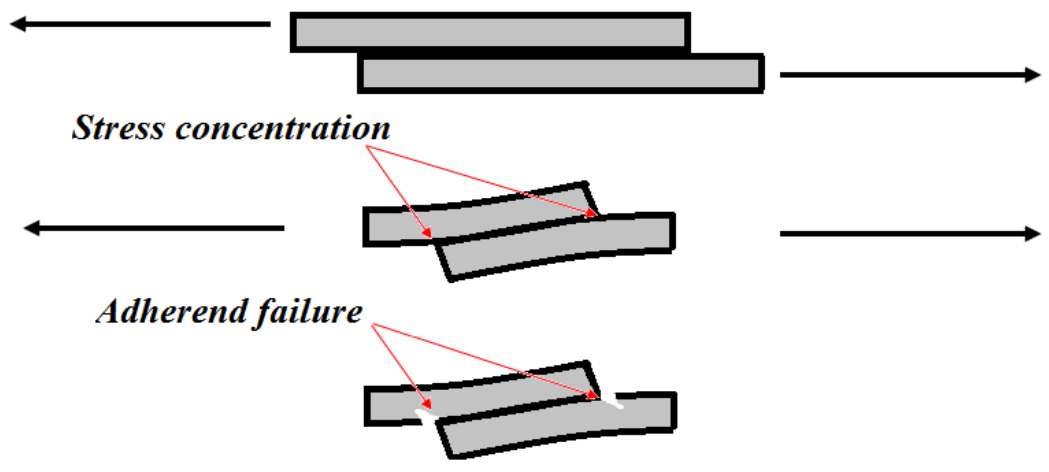

Figure 2.8: Failure steps in a single lap bonded joints with brittle adherends (adapted from HartSmith, 1974)

These ends are the locations, where the failure initiation occurs due to interlaminar tensile stress. This is a particular concern for joints with CFRP adherends and high strength adhesive because CFRP adherends are susceptible to through-thickness loads. This failure is schematically described in the last image of Figure 2.8. Therefore, it is important to reduce stress concentration at the free ends of the joint. The adhesive can be formed into a unique shape at these locations, or lower strength adhesive can be used to reduce the stress concentration at the free ends (da Silva \& Banea, 2009).

Adhesive thickness affects the failure modes of the bonded joint. According to the study by da Silva et al. (2009), a failure of thin adhesive is dominated by the stress concentration at the edges. However, the failure of thick adhesive is influenced by global yield behaviour rather than the stress concentration at the edges and occurs at lower 
applied loads (da Silva, et al. 2009). In other words, the thicker adhesive is likely to have lower joint strength if the same materials are used in the structure as can be seen in Figure 2.9.

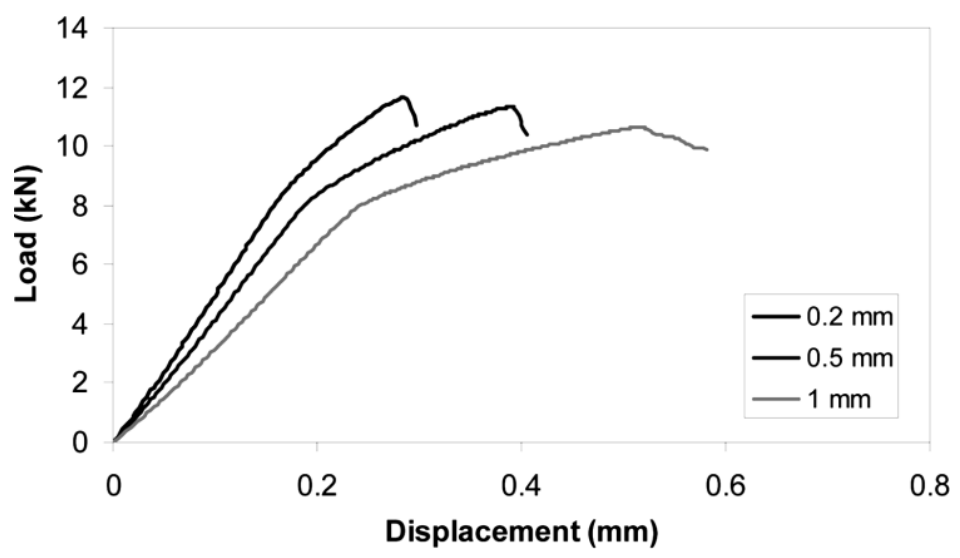

Figure 2.9: The effect of the adhesive thickness (da Silva et al., 2006) Reprinted with permission.

According to Figure 2.10, the rate at which the ductile adhesive material is loaded also affects its strength or its capability to transfer the load. This is due to the viscoelastic material behaviour that is more sensitive to the strain-loading. This effect is not considerable when the ductile adhesive is tested below the glass-transition temperature, which the adhesive tends to behave in a brittle manner (da Silva et al., 2006). The chosen adhesive, Hysol ${ }^{\circledR}$ EA 9361, has low glass transition temperature, and it is to be used at the temperature of $-192^{\circ} \mathrm{C}$ (Oluseyi et al., 2004). When the ASTM standard test procedure is followed, the loading rate is not considered because the standard limits the load or displacement rate to a certain value. For example, the ASTM standard D3165 - 07 requires the rate of $1.27 \mathrm{~mm} / \mathrm{min}$. However, when a non-standard test setup is performed, 
the strength change due to different loading rate must be considered in the bonded joint with viscoelastic adhesive.

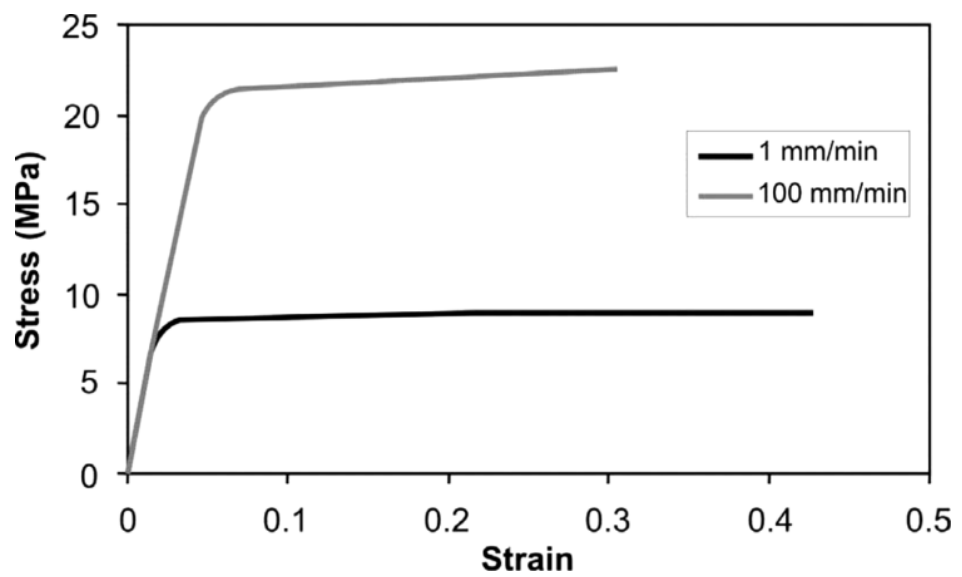

Figure 2.10: Tensile stress-strain curve of Hysol EA9361 at different loading rates (da Silva et al. 2006). Reprinted with permission.

\subsection{HYBRID BOLTED/BONDED JOINTS}

Most studies of bolted/bonded joints have indicated two possible advantages of using the configuration over traditional configurations. First, the bolted/bonded joint can be used for a fail-safe design. Secondly, the bolted/bonded joint configuration may be utilized to provide higher overall joint strength.

Hart-Smith (1985) studied multi-bolted stepped lap bolted/bonded joints analytically. It was found that the load transferred through the bolt is insignificant compared to the load transferred through the adhesive layer when the stiffness of bolt load path is far less stiff than that of adhesive load path. This finding was interesting 
since it indicates that the adhesive layer and the bolts do not act simultaneously for load transfer, so the benefit of using bolted/bonded joints cannot be achieved. However, it was also suggested that bolted/bonded joints should be used as a part of the fail-safe design, which is still advantageous over traditional joint configurations (Hart-Smith, 1985).

Vallée et al. (2013) studied the joint strength of the multi-bolted double-lap bolted/bonded joint configuration. They joined a pipe and a lamella together, which both were made of glass fibre reinforced plastic (GFRP). According to the results from both analytical and experimental studies, the bolted/bonded joints had only $5 \%$ increase in total load capacity over the adhesively bonded joints and 100\% increase over the bolted joints in the identical geometry (Vallée et al., 2013). Similar to the conclusion by HartSmith, the total load capacity of the bolted/bonded joint had only minimal improvements over the adhesively bonded joints. However, the load versus stroke curve indicates that the adhesively bonded joint failed in a brittle manner and lost joining capabilities while the bolted/bonded joint had a similar failure but sustained loads after the brittle failure because of the bolts holding the test coupon. This supports the possibility of bolted/bonded joints as a fail-safe design.

Moroni et al. (2010) studied the energy absorptions in different joint configurations. The energy absorption in his study meant the area of the load versus stroke curve. It was found that the hybrid welded/bonded joints had more than seven times higher energy absorption compared to bonded joints. The load versus stroke curve showed there was no difference in the maximum joint load between the welded/bonded 
and the bonded joints. However, it indicated again the high load capacity of the entire joint (Moroni, Pirondi, \& Kleiner, 2010).

Although the previously mentioned studies found that there was no improvement in the joint strength, other researchers found a possibility of improving hybrid joint strength in certain specific configurations. Di Franco (2013) studied single-riveted singlelap bolted/bonded joints with cross-ply CFRP as one adherend and aluminum plate as the second adherend. The study found that the bolted/bonded joint with properly post-cured adherend showed $10 \%$ increase in a maximum load capacity over the bonded joint with the same properly post-cured adherends. Also, it was found that the bolted/bonded joint with CFRP that had not been post-cured showed $28 \%$ increase in a maximum load capacity over the bonded joint with the same CFRP adherend that had not been postcured. With the angle-ply adherend, the bolted/bonded joint with post-cured CFRP adherend showed 16\% increase in the load capacity (Di Franco, Fratini, \& Pasta, 2013). The study indicates that the joint strength of the bolted/bonded joint can be improved significantly. Also, it is better to have bolted/bonded joint configuration when there is a manufacturing defect due to a large increase in the maximum load capacity according to the study.

Robinson and Kosmatka (2012) studied multi-bolted scarf bolted/bonded joints. Strain gages were installed on the surface near each row of bolts. It was found that the strain distribution between bonded and bolted/bonded joints was almost identical to each other. However, the bonded joint failed at $580 \mathrm{kN}$ while the bolted/bonded joint failed at 
$2260 \mathrm{kN}$, which is almost $400 \%$ increase in the maximum load capacity (Robinson \& Kosmatka, 2012).

The joint strength capability is dependent on the geometry of the joint, adhesive properties, adherend properties. Stewart and Stewart (1997) showed that the stacking sequence in the composite laminate also affected the joint strength. The location of $0^{\circ} \mathrm{ply}$ affected the laminate tension stress thus inducing damages at lower load level (Stewart \& Stewart, 1997).

However, these previous studies still showed the same pattern as Hart-Smith (1985) pointed out that the bolted/bonded joint behaves exactly same as the bonded joint until the adhesive fails. The true purpose of using the bolted/bonded joint make both joints share the load simultaneously so that the stress to each joint is reduced. Kelly (2005) investigated the effect of various parameters in the hybrid joints using a computational analytical model. The model suggests that adhesive thickness, adherend thickness, overlap length, and width-to-bolt diameter ratio all affect the amount of load transferred through the bolt. Also, the adhesive modulus and ductility both affect the load transfer mechanism as can be seen in Figure 2.11. Furthermore, the load transferred by the bolt increases in a size restricted model when an adhesive with lower elastic modulus or higher ductility is used (Kelly, 2005). 

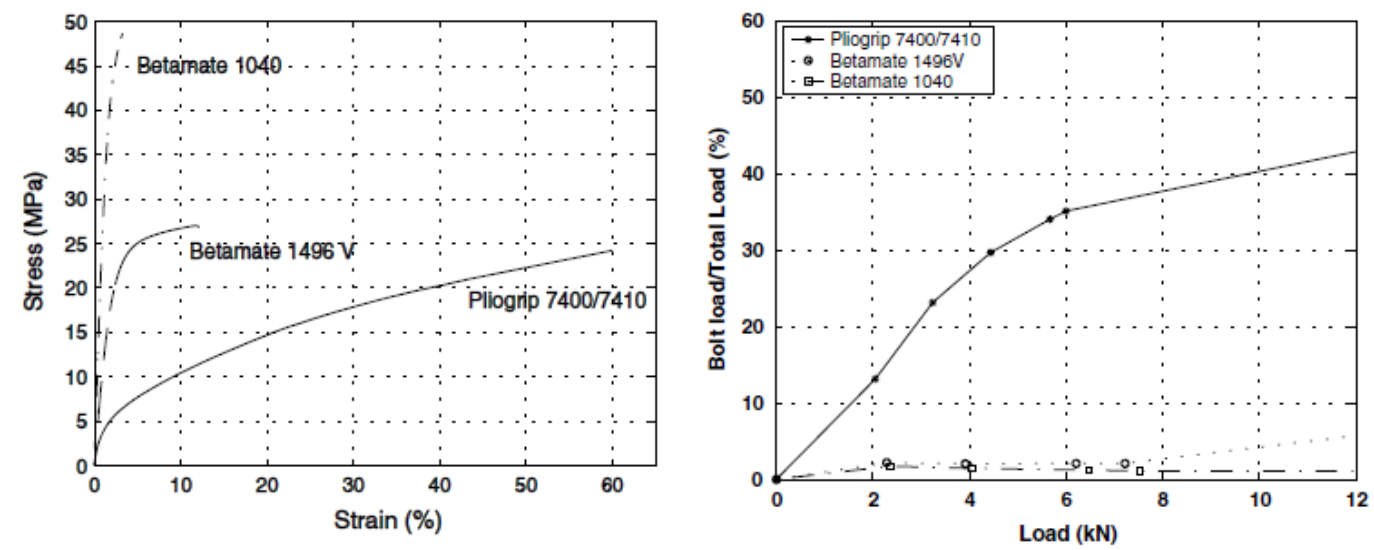

Figure 2.11: Effect of adhesive modulus on the bolt load transfer (Kelly, 2005). Reprinted with permission

In summary, the previous studies are not in agreement that the bolted/bonded joint is superior or inferior to the traditional joints by meeting both theoretical advantages. However, a few studies indicated that a higher strength using the bolted/bonded joint is still possible. More specifically, the more flexible adhesive is recommended to increase the load sharing between two load paths in the bolted/bonded joints.

\subsection{EXPERIMENTAL APPLICATION TO THE JoINT STUDY}

The interest in this thesis was to estimate experimentally the load transfer through the bolt in the bolted/bonded joint. However, it is difficult to measure the load transferred by the bolt in the bolted/bonded joint experimentally because the load path of the bolt is hidden inside of the joint. This difficulty led most studies to estimate the bolt load transfer by analytical models or performing experiments with limited geometries. There 
are only a few studies attempted to obtain the load transfer from the experiment. Most studies of the bolted/bonded joints focused on the failure modes and the failure load. This information is good enough to understand the maximum load capacity of the bolted/bonded joint, but it does not give detailed information on how the joint behaves during loading.

The most widely used direct approach to obtaining the load transferred through the bolt is using an instrumented bolt. Kelly (2005) showed the bolt load in the composite bolted/bonded joint using a specially designed instrumented bolt. The titanium hi-torque lockbolt was modified to accommodate two strain gage rosettes, and they were connected to form a Wheatstone bridge configuration. The data from the instrumented bolt was consistent, and it matched with the analytical model (Kelly, 2005). The limitation of these instrumented bolts is the size and removing the material from the bolt. According to the design of the bolt, the diameter was $15 \mathrm{~mm}$. This is three times larger than the bolt chosen for this research. Also, the bolt has to be machined to install the rosettes. Poor machinability of titanium is well-known (Pramanik, 2013). In other words, manufacturing the instrumented bolt from the titanium bolt will be expensive. With the size and the material of the bolt, it will be difficult to design the instrumented bolt using the bolt chosen for this research. Furthermore, removing a small amount of material in the small size bolt may affect the strength and geometrical stiffness.

Other techniques to study bolted/bonded joints include adopting novel sensor technologies. Camanho et al. (2005) performed the experiment by placing piezoelectric acoustic emission transducers on the single-shear lap joint with bonded inserts. $\mathrm{He}$ 
attempted to catch the failure moment from the acoustic emission result by comparing it to the load versus stroke curve. It was found that the moment of failure from the comparison and predicted the failure process. However, this study focused on catching the failure moment using the acoustic emission transducers (Camanho, Tavares, de Oliveira, Marques, \& Ferreira, 2005). This type of sensors may be good for catching the event in the joint, but it still does not give full information, such as the failure location.

Since the traditional techniques used for joint mechanical studies have limitations, other techniques were considered in this research. Due to the size limitation, an indirect measurement technique was developed. Among the indirect measurement techniques, the DIC was chosen for this research because its potential has been highlighted in previous studies. The DIC technique started as a displacement measurement technique (Sutton, Wolters, Peters, Ranson, \& McNeill, 1983). Also, some studies proved the role of the DIC technique as a failure detector. In other words, the DIC technique can be used for detecting the failure and measuring the displacement simultaneously. Furthermore, the DIC technique was already used to understand joint behaviour by comparing strain fields from different joint configurations with steel adherends (Sadowski, Kneć, \& Golewski, 2010).

Any damage in the adhesive layer can cause stress concentrations near the damaged area, and it ultimately affects the adherends. Kumar et al. (2013) studied the detectability of damage induced in the GFRP single-lap bonded joint using twodimensional DIC (2D-DIC). It was compared the strain field of the undamaged GFRP single-lap bonded joint to the strain field of the same joint with the damage induced in the 
adhesive layer both obtained from the DIC technique. It was concluded that the DIC technique caught the damage in the adhesive layer, which was hidden by the adherends. It indicates that the change in the adhesive layer affects adherends, and the DIC technique can catch the change from the adherends (Kumar et al., 2013).

Backman et al. (2011) studied the stresses of the adhesive layer in the bonded joint using 2D-DIC and compared the result to a finite element model. Good agreement was observed between the experimental and the analytical data except in the local region, where the failure was observed due to local displacement discontinuity (Backman, Li, \& Sears, 2011).

Corr et al. (2007) used the DIC technique to observe the mechanical behaviour of the CFRP embedded concrete specimen. In their study, the DIC technique was used for measuring the displacement of the specimen. The technique also captured the moment of cracking by detecting a significant jump in the displacement data. Their study indicates that the DIC technique can be used for the displacement measurement technique and the failure detector in the specimen for the single test (Corr, Accardi, Graham-Brady, \& Shah, 2007). Comer et al. (2013) concluded there is a potential to prove analytical, computational models from the three-dimensional (3D-DIC) technique. Also, the technique detected that fracture occurred in the adhesive layer during the experiment, supporting the DIC technique as an adhesive failure detector (Comer, Katnam, Stanley, \& Young, 2013).

The use of DIC is not limited to test coupon configurations, such as a single-lap joint. Fedele et al. (2009) used a test coupon, which configured the GFRP Z-stringer 
attached to the GFRP plate. This study did not use the DIC technique to measure displacement or strain fields, but it used the DIC technique to track the non-linear failure in the adhesive layer between the plate and the stringer and adapted it to the finite element model (Fedele, Raka, Hild, \& Roux, 2009). Furthermore, it indicates that the technique is not limited to measuring the displacement or the strain field from the front surface of the specimen, but any surface can be chosen for performing the DIC technique. Lastly, the progressive failure of the adhesive layer can be observed from sequential pictures of the area of interest.

Yao et al. (2005) compared the strain values obtained from 2D-DIC to those from strain gages using a composite material pressure vessel. The strain change was induced by increasing the inner pressure of the vessel, and it was measured from the outer surface of the pressure vessel. They concluded that the strain values measured using DIC were close to the strain values from the strain gages in all directions with only $5 \%$ errors (Yao, Meng, Jin, \& Yeh, 2005).

In summary, the DIC technique is not intended to directly measure the load transfer through the bolt since it is mainly used for measuring the surface displacement or strain fields. However, even if the DIC technique cannot directly measure the load transfer through the bolt, it is expected to obtain valuable information such as failure location, highest strain region, and strain fields differences due to different joint configurations using the DIC technique. Furthermore, if the DIC technique can capture the common behaviour of different joint configurations, the test may be standardized for observing in-test behaviour of the joint coupons. 


\section{Chapter 3: Digital IMAGE CORRELATION (DIC)}

One way to evaluate mechanical properties is to measure the strain of test coupons under tensile or compressive loading. Resistance strain gages have long been commonly used to obtain strain data, but one disadvantage of strain gages is that they provide point strain data at the location, where the gage is installed.

When strain data is needed from more than one point of interest on a specimen, a full-field measurement technique is a better choice. Photoelasticity is a classic example of long-standing full-field strain measurement technique (Post, 1979). It is to measure the strain distribution in a test coupon by using the birefringence effect (Phillips, 2008). The photoelasticity technique is still used in many studies, and further improving the technique is ongoing by adopting automated computing technologies to calculate strains from photoelastic strain field images (Ayatollahi \& Nejati, 2011; Ramesh, Gupta, \& Kelkar, 1997; Ramesh, Kasimayan, \& Neethi Simon, 2011). However, the photoelasticity technique has disadvantages. Firstly, it requires a coating on the surface of the interest, which might be difficult when coating the material is performed by someone with no previous experiences unless a clear model of the actual test coupon is made. Secondly, it gives a clear strain field pattern when the load is applied, but obtaining a strain magnitude from the pattern may require significant calculation efforts. Furthermore, the difficulty with separating the result obtained from the photoelasticity to each principal component is also an issue.

Another full-field measurement technique is DIC, which correlates a series of digital images taken at a regular interval and yields relative displacement or strain fields 
from the correlated images. Figure 3.1 shows an example of the DIC analysis. It visualizes the displacement and the strain fields on the picture so that the fields' changes can be directly compared. The displacement or the strain fields are calculated from the images by dividing the image into a block of pixels, called a subset, and tracking its relative movement to neighbour subsets. The size of subsets is chosen based on the image size and the speckle pattern, which is the pattern randomly applied to the surface. Unlike photoelasticity, the magnitude of each strain can be directly obtained, and simple random speckle pattern is enough compared to the fine surface coating on the surface required (Lava, 2015; McCormick \& Lord, 2010; Pan, Qian, Xie, \& Asundi, 2009).

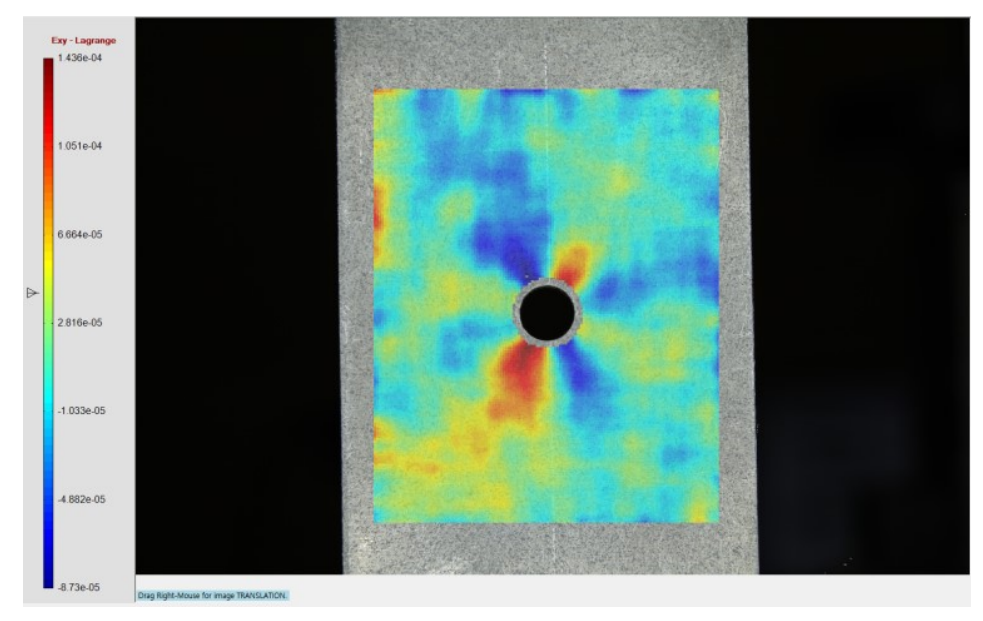

Figure 3.1: Example of DIC analysis from present research

Two basic types of DIC technique exist for strain field analysis: 2D-DIC and 3DDIC. 3D-DIC technique is more beneficial when a significant out-of-plane displacement is expected as it can isolate three-dimensional effects from the in-plane measurement. The problem with 3D-DIC is the requirement of longer process time and higher cost for the specialized analysis software. 
The DIC technique setup is simple. It can be performed with a computer station, a camera system, and the light source. Figure 3.2 shows the schematic of the DIC setup.

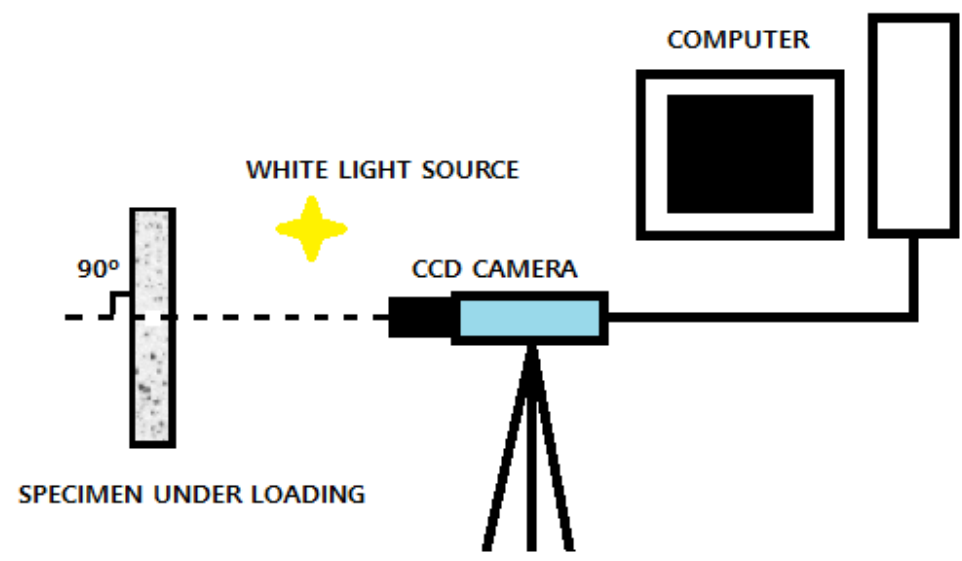

Figure 3.2: Schematic of the DIC technique setup

A computer station controls a camera system, such as photo size, and the time between picture frames, and calculates the displacement or the strain fields using a dedicated analysis software. Since camera technology has been advanced, any camera works for DIC. Lava et al. (2014) introduced a lab program using a regular webcam can for static tensile tests with a hyperelastic material to perform 2D-DIC (Lava, Coppieters, Van Hecke, Van Houtte, \& Debruyne, 2014). The number of cameras can vary depending on which DIC technique is to be performed. A single camera is used for 2D-DIC while two cameras are required for 3D-DIC. Regardless, the surface of interest has to be in parallel with the camera sensor. If the surface is not parallel to the sensor, image-plane displacement gradients are added to the result of 2D-DIC. It is considered as a source of errors in the DIC technique affecting the computational calculation for obtaining a displacement and strain fields (Sutton, Yan, Tiwari, Schreier, \& Orteu, 2008). 
A random speckle pattern provides every subset to have a different level of contrast and gray intensity. The absolute size of speckle pattern must be chosen with respect to the size of specimen and camera's resolution. There is no absolute speckle size requirement for DIC technique, but it is generally recommended that the size needs to be equivalent to $2-4$ pixels at least (Hua et al., 2011). However, this may not be applicable to every situation, and it is difficult to have an absolute speckle size in reality. Hence, trial and error methods are generally recommended to determine the size of the speckle pattern. Paint droplets or laser is used to generate the speckle pattern on the surface. When the paint is applied as seen in Figure 3.3, there are a few recommendations. First of all, when the high magnification DIC, such as measuring the strain on the adhesive layer, is performed, the airbrush is recommended to make fine patterns. On the other hand, regular spray paint is enough to make speckle pattern. The density of speckle pattern can be controlled instead of the size when the spray paint is used. Secondly, the paint with matte type generates better speckle patterns because the glossy type causes the reflection from the light source.

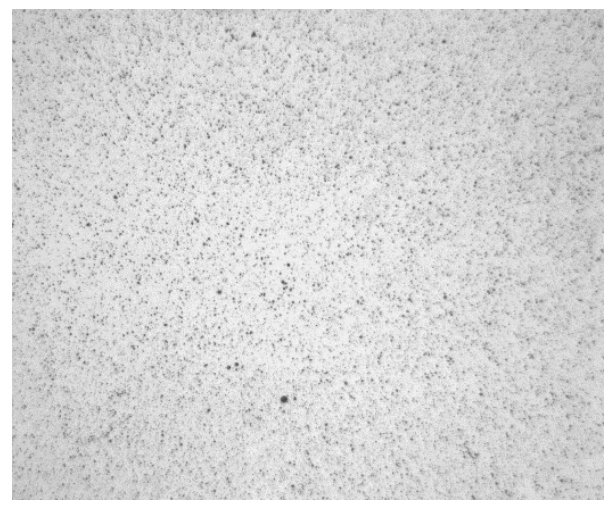

Figure 3.3: Example of Speckle Pattern 
The separate white light source is required to minimize shadow formed on the surface. Since the DIC technique uses a gray intensity for tracking the movement of subsets in the image, any shadow or uneven lighting may cause errors on the result.

\subsection{DIC PROCESS}

The DIC starts with defining the field of view (FOV) and the area of interest (AOI). The FOV is the area captured by the camera image sensor, and this is defined by locating the camera with respect to the specimen. Further definition can be completed by cropping the unnecessary region from the computer software. The AOI is the area, in which the analysis is to be performed. For example, the entire picture in Figure 3.1 is the FOV while the coloured region is the AOI. Appropriately defined FOV and AOI reduce the analysis time and the computational power and yield the perfectly correlated displacement and strain fields. When there is a discontinuity happened due to any crack or any failure in the coupon during the test and included this region for the analysis, the analysis fails to correlate between images and provide the displacement and strain fields with errors. Hence, the area, in which the discontinuity occurred during the test, must be removed from the AOI before running the analysis.

Once the FOV and AOI are defined by the user, the subset size is chosen. The example of the subset defined on the reference image is shown in Figure 3.4. In the black and white image, each individual pixel of the picture will never have unique gray intensity information, which is the reason for defining the subset. 


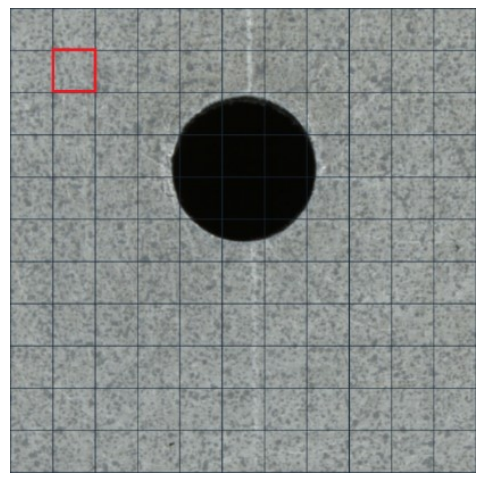

Figure 3.4: Example of subset division in the image

Displacement and strain fields from the DIC technique are calculated by the relative motion of each unique subset to its neighbour subsets. There is no requirement for choosing the subset size, but most computer software manuals recommend the subset to include at least 3 or 4 individual speckles. There are an advantage and a disadvantage of the subset size. When smaller subsets are defined that are close to the recommendation, then more reliable displacement measurement can be obtained. Larger subsets, on the other hand, can provide more reliable correlation since each subset will have more distinctive gray intensity information (Pan et al., 2009). This trade-off must be considered when the subset size is chosen. Once the subset size in the AOI is defined, the analysis software automatically defines the subsets in the AOI. Another parameter to be set at this stage is a step size. The step size can be considered as the assumed number of pixels that the subset expects to be shifted in the next image. The reasonable step size can avoid spending excessive computing time (Robert, Nazaret, Cutard, \& Orteu, 2007).

A correlation criterion needs to be defined after the subset, and the step sizes are chosen. The correlation criterion is used to match the subsets between each subsequent 
image by analyzing the value correlation coefficient and locate the deformed subsets based on the value (Pan, Xie, \& Wang, 2010). For example, the original subset on the left in Figure 3.5 will be deformed into the shape on the right when the load is applied. In the reference subset, the unique gray intensity around the centre of the subset $\mathrm{P}\left(x_{o}, y_{o}\right)$ can be identified. Then, the correlation criterion is used to calculate a correlation coefficient in the deformed image to locate of the deformed subset.
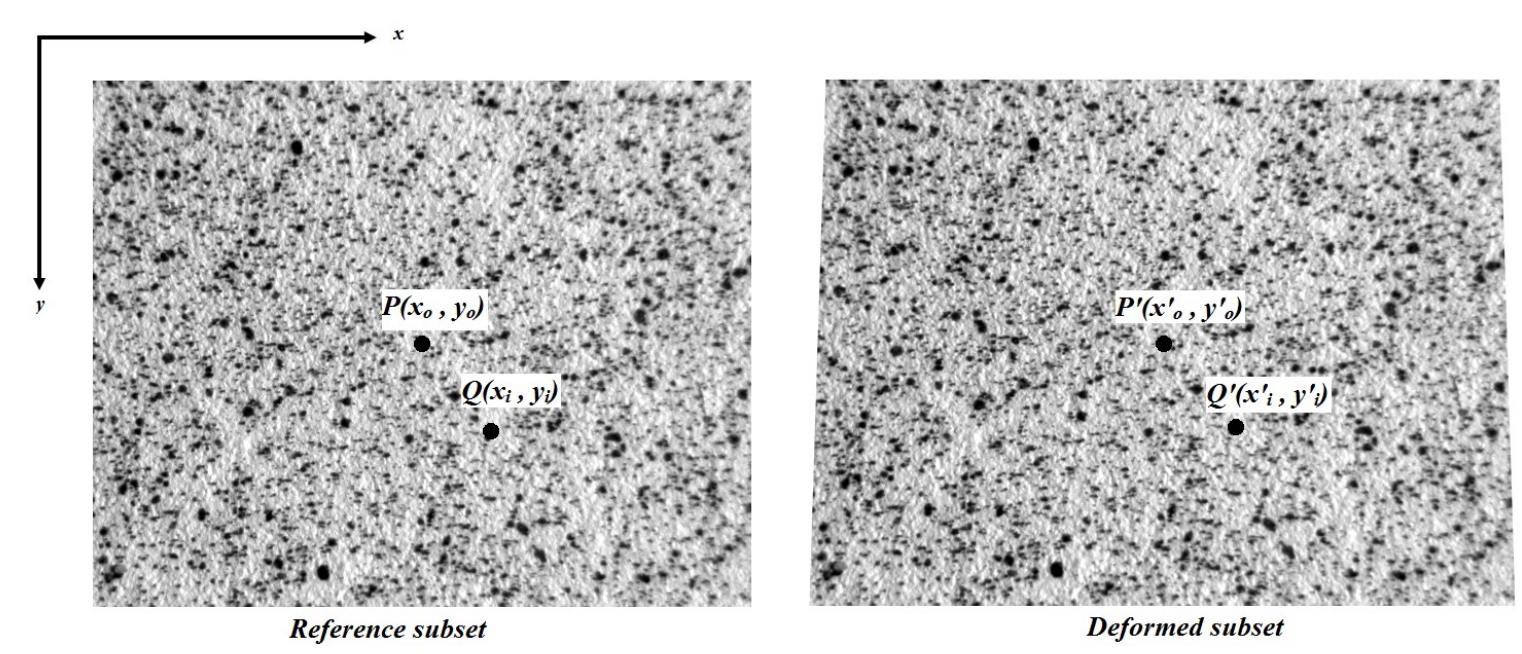

Figure 3.5: An example of reference and deformed images

Different criteria are available:

1) cross-correlation criterion (CC),

2) sum of squared difference criterion (SSD), and

3) parametric sum of squared difference criterion (PSSD) (Pan et al., 2010).

The software used in this research provides three different criteria:

1) cross-correlation criterion,

2) sum of squared difference criterion, and 
3) zero-mean normalized sum of squared differences (ZNSSD), which is the improved version of SSD.

ZNSSD criterion was chosen for this research due to its robust noise-proof performance and insensitivity to lighting inconsistency as seen in Figure 3.6 (Pan et al., 2009).
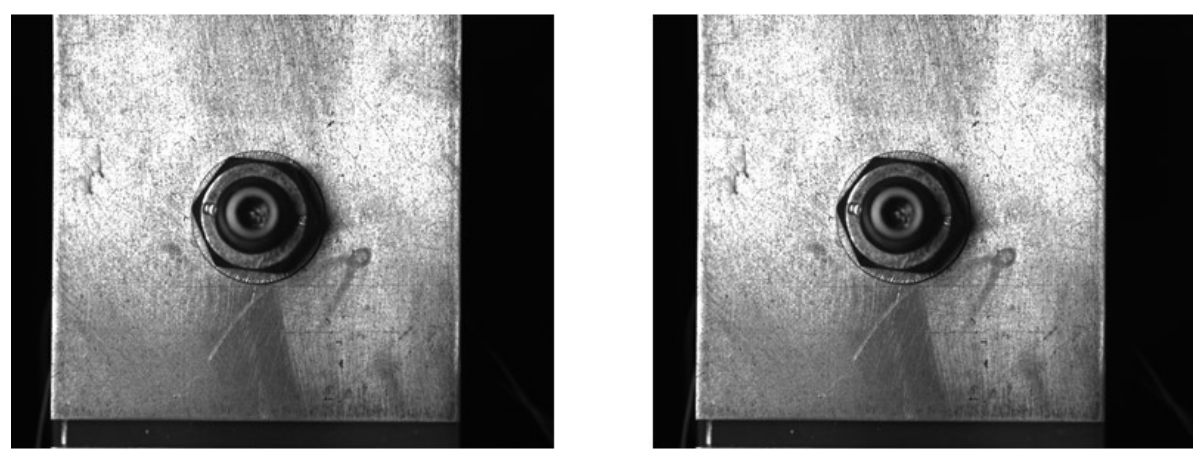

Figure 3.6: Example of inconsistent lighting

In a subset with size of $(2 \mathrm{M}+1)$ by $(2 \mathrm{M}+1)$ pixels, ZNSSD is defined as

$$
C_{Z N S S D}=\sum_{i=-M}^{M} \sum_{j=-M}^{M}\left[\frac{f\left(x_{i}, y_{j}\right)-f_{m}}{\Delta f}-\frac{g\left(x^{\prime}{ }_{i}, y^{\prime}{ }_{j}\right)-g_{m}}{\Delta g}\right]^{2}
$$

Where $f\left(x_{i}, y_{j}\right)$ indicates the reference subset gray intensity, and $g\left(x_{i}^{\prime}, y_{j}^{\prime}\right)$ indicates the deformed subset gray intensity. $f_{m}$ and $g_{m}$ are called the ensemble average of reference and deformed subsets (Pan, Xie, Guo, \& Hua, 2007). $\Delta f$ and $\Delta g$ are the square roots of the sum of the squared difference between gray intensity and the ensemble average.

$$
f_{m}=\frac{1}{(2 M+1)^{2}} \sum_{i=-M}^{M} \sum_{j=-M}^{M} f\left(x_{i}, y_{i}\right)
$$




$$
\begin{gathered}
g_{m}=\frac{1}{(2 M+1)^{2}} \sum_{i=-M}^{M} \sum_{j=-M}^{M} g\left(x_{i}^{\prime}, y_{i}^{\prime}\right) \\
\Delta f=\sqrt{\sum_{i=-M}^{M} \sum_{j=-M}^{M}\left[f\left(x_{i}, y_{i}\right)-f_{m}\right]^{2}} \\
\Delta g=\sqrt{\sum_{i=-M}^{M} \sum_{j=-M}^{M}\left[g\left(x^{\prime}{ }_{i}, y^{\prime}{ }_{i}\right)-g_{m}\right]^{2}}
\end{gathered}
$$

This correlation criterion yields the value in the range 0 to 1 . When the criterion value is close to 1 for the certain subset, then this location is the position of the deformed subset. Figure 3.7 shows the example of the correlation coefficient map in the AOI.

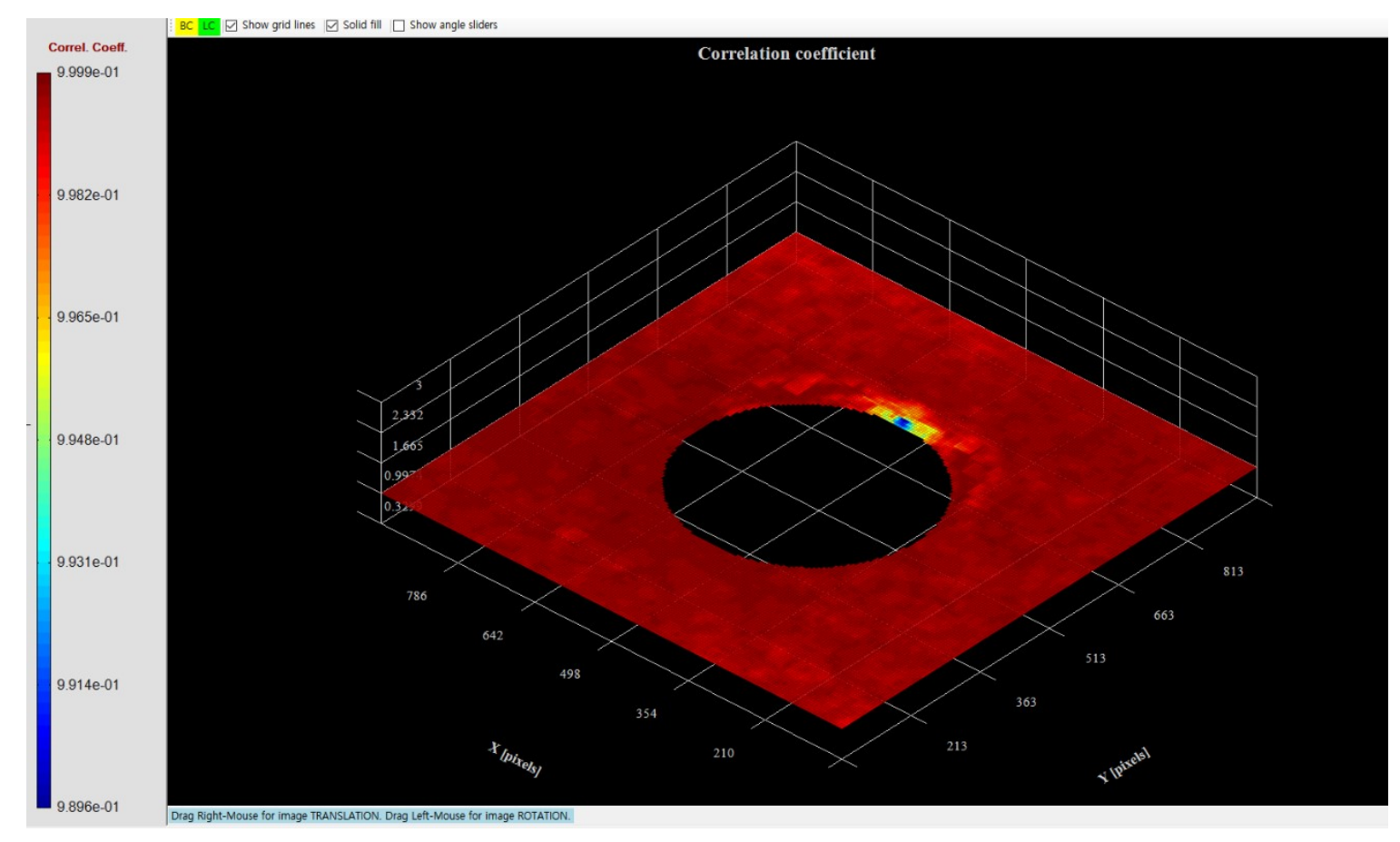

Figure 3.7: Example of correlation coefficient of Figure 3.1

Once the deformed subset is located from the correlation criterion analysis, then a shape function is used to calculate the displacement of the subsets. Three assumptions are 
made the use of shape function in DIC for detecting the displacement of the subset. The first assumption is that the subset in the reference image $f(x, y)$ is deformed to the location $f^{*}\left(x^{*}, y^{*}\right)$ in the subsequently deformed images. Secondly, there is no lighting change between the reference and the deformed images, which will change the gray intensity information. Although the ZNSSD correlation criterion minimizes the effect of inconsistent lighting, no lighting change is still preferred for minimizing errors. Lastly, the discontinuity, such as cracks, between one subset and its neighbour subsets, does not occur. With the assumptions and the information from the correlation criterion, the centre of the deformed subset $\mathrm{P}^{\prime}\left(x_{o}{ }^{\prime}, y_{o}{ }^{\prime}\right)$ can be related to the centre of the reference subset $\mathrm{P}\left(x_{o}, y_{o}\right)$ by using its unique gray intensity pattern and defined the displacement vectors between them. Likewise, the displacement vector and its quantity can be found any point $\mathrm{Q}\left(x_{i}, y_{j}\right)$ in the reference subset and its deformed point $\mathrm{Q}^{\prime}\left(x_{i}{ }^{\prime}, y_{j}{ }^{\prime}\right)$ can be found in the same way (Lu \& Cary, 2000; Pan et al., 2009; Schreier \& Sutton, 2002). The relationship between the reference coordinate and the deformed coordinate in the subset is defined as

$$
\begin{array}{r}
x_{i}^{\prime}=x_{i}+\xi\left(x_{i}, y_{j}\right) \\
y_{j}^{\prime}=y_{j}+\eta\left(x_{i}, y_{j}\right)
\end{array}
$$

The shape functions ( $\xi \& \eta$ ) for translation, rotation, shear, normal strains are

$$
\begin{aligned}
& \xi\left(x_{i}, y_{j}\right)=u+u_{x} \Delta x+u_{y} \Delta y \\
& \eta\left(x_{i}, y_{j}\right)=v+v_{x} \Delta x+v_{y} \Delta y
\end{aligned}
$$

Where $u$ and $v$ are defined as translation motions in $x$ - and $y$-directions (Pan et al., 2009). If the irregular deformations over AOI are expected, high-order terms should 
be included. However, too many high order terms in the shape function will cause numerical errors during the calculation process.

The sub-pixel interpolation must be utilized before the correlation criteria to have a continuous correlation. Correlation criteria are subset based, and they locate the deformed subsets in pixel size movement. When pixels in the deformed subsets moved with sub-pixel levels, the correlation criteria may lose the relative positions of all pixels in the deformed subset. Hence, the interpolation is used to locate these pixels and provide a better correlation between the reference subsets and the deformed subsets. Unlike the shape functions, the interpolation with higher order terms provides higher accuracy and better convergence (Knauss, Chasiotis, \& Huang, 2002; Schreier, Braasch, \& Sutton, 2000). In a simple tensile test, the impact of the interpolation is minimal. However, this minimal effect can be further minimized by choosing the bicubic spline interpolation. Therefore, this interpolation was used for this thesis to minimize numerical errors at the interpolation step (Lava, Cooreman, \& Debruyne, 2010).

\subsection{SOURCES OF ERrors IN DIC}

Although DIC has been used in many applications and can provide good results, there are still some sources of error. All error sources are divided into two categories:

1) errors due to the specimen, loading, and imaging, and

2) numerical errors from algorithms or functions used for the analysis.

Speckle patterns are used to create unique gray intensity patterns in the AOI. The study by Lecompte et al. (2006) found that smaller speckle size must be used in a small 
AOI while a larger speckle size is suitable for a large AOI (Lecompte et al., 2006).

Furthermore, low contrast speckle pattern causes larger standard deviation in the result (Pan, Xie, Wang, Qian, \& Wang, 2008).

When the single-lap joint is loaded, the joint experiences out-of-plane displacement from the secondary bending as shown in Figure 3.8. This out-of-plane displacement particularly affects the in-plane displacement and strain field calculations from the 2D-DIC technique because the 2D-DIC technique does not have a capability of compensating for the out-of-plane displacement effect (Sutton, Yan, Tiwari, Schreier, \& Orteu, 2008).

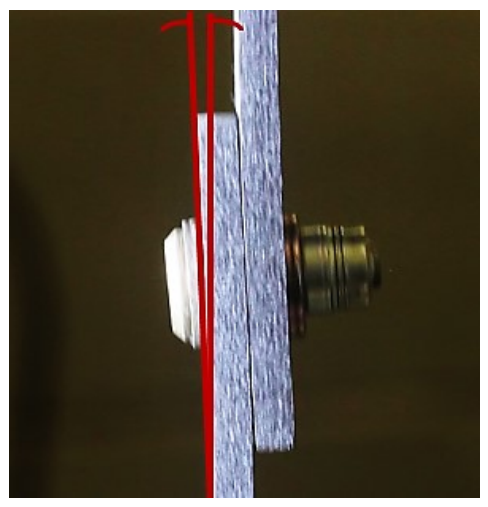

Figure 3.8: Out-of-plane displacement occurred during the static tensile load test

Other factors, such as a non-flat surface, and non-parallelism between the image sensor and the surface, can have the same effect as well. Because these factors except the non-parallelism cannot be easily fixed during the test, it must be considered that the errors always exist due to these factors.

Image distortion due to the lens is another source of errors. Figure 3.9 shows a good example of the distortion effect in the image. The centre of the image does not 
experience much distortion. However, the distortion is more noticeable near the edges.

Since the lens consists of convex and concave lenses to focus a larger field of view onto a small camera sensor area, the distortion of the lens is unavoidable. There are two ways to minimize these errors. One is to use telecentric lenses, and the other is to compensate for distortion effect by the DIC technique software. The telecentric lenses remove the effect of perspective distortion, which is called the parallax effect so that the same object can be seen in the same size regardless of the working distance (Edmund Optics, 2016). The other way is input the lens characterization to the software. The software has a function to obtain the lens characterization with a simple test.

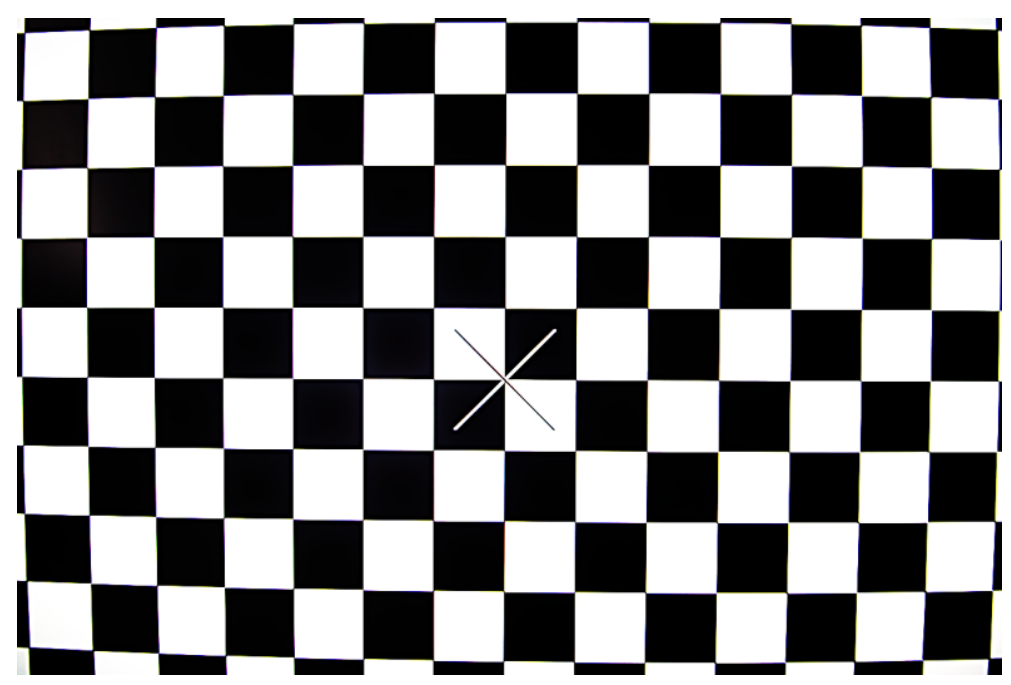

Figure 3.9: Example of lens distortion

Lastly, image noise is another source of errors. The image noise is a random color or contrast information due to different sources, such as shot noise, and thermal noise. The shot noise is caused by photon sensitivity variation in the camera sensor. The thermal noise is due to the camera sensor being hot. When the sensor becomes hotter, it induces 
the current leakage causing the noise (Blanter \& Büttiker, 2000; Quantum Scientific Imaging, Inc, 2008). The scientific cameras are designed to minimize noises, but these noises are unavoidable. According to the study, noises cause random errors in displacement from DIC analysis (Wang, Li, Tong, \& Ruan, 2007).

Numerical errors also occur during the analysis. The most noticeable factor for the user with less experience is the size of subsets. As mentioned earlier, a larger subset size is recommended to make every subset have a unique gray intensity pattern. However, a smaller subset size is better to capture detail information in the displacement field. In other words, choosing the subset size will sacrifice either the detailed information or the uniqueness of gray intensity patterns.

A correlation criterion is also a source of errors due to inconsistent lighting during the experiment. There is no study done to verify which criterion is best for different situations. However, the ZNSSD criterion is affected much less by the test environments compared to other criteria, such as normalized sum-squared difference criterion (NSSD), or cross-correlation criterion (CC) (Tong, 2005).

The sub-pixel interpolation is another source of errors. As mentioned earlier, the high order terms must be included in the interpolation for better accuracy. However, the numerical errors during the calculation are still inevitable. The shape function is also the source of errors. There is no absolute rule to choose the function. It usually depends on the user's experiences or the recommendation by the software manuals. 


\section{Chapter 4: Methodology}

The DIC technique was firstly introduced to the research group, so the equipment for the DIC technique needed to be prepared. The equipment to be prepared included a camera body, an analysis software, and accessories, such as a light stand and tripod. In this chapter, the process of choosing the DIC equipment is covered. Also, the chosen DIC analysis software is briefly introduced. Manufacturing the composite test coupons is covered with detailed information. Lastly, the test setup for all experiments performed during the thesis is covered.

\subsection{CHOICE OF DIC EQuiPMENT}

Digital image correlation equipment selected during the thesis includes a camera body, lenses, light sources, and other accessories. The benefit of DIC is that there is no limitation on the type of camera. As mentioned in Chapter 3, even webcams can be chosen to perform the DIC technique, but these cameras only work for certain purposes. This chapter explains how the DIC equipment was chosen for the research.

A camera body is the equipment, which takes pictures and saves and sends the digital pictures. Different types of camera bodies exist depending on different purposes. Three different camera body types were considered for this research: a conventional digital single lens reflex (DSLR) camera, a compact digital camera, and a scientific camera. Although a scientific camera is the most appropriate type of the research type 
work due to the low level of noise and a high number of frames per second, other two types were also considered at the beginning of the research as they were readily available.

When the study for the camera body began, following requirements were set for the final decision.

1) The camera should be controlled and synchronized by the computer;

2) The camera should not stop taking pictures until the test is completed.

The first requirement is the capability of being controlled and synchronized by a computer that controls a servohydraulic material test frame. Synchronization between the data from the material test frame and the photos taken from the DIC equipment is needed to ensure that the surface change from the DIC picture can be compared to the event detected from the load versus stroke. The pictures synchronized with the load versus stroke can be compared simultaneously, and no assumption is required to compensate time discrepancy.

The second requirement is the ability of the system continuously to store pictures without interruption during the test. There is a special type of memory called a buffer memory, which is needed when transferring the data from a faster system (e.g. image capture sensor) to a slower system (e.g. memory storage). Without buffer memory, possible data losses or delays will be required to transfer which will have a negative effect on the test. When the buffer memory reaches maximum while the data transfer is still ongoing, then the camera system stops taking additional pictures. It means the camera system may stop taking pictures during the experiment when the buffer memory is full. 
Table 4.1: Camera model considered for the research (Canon Canada Inc., n.d.; Olympus America Inc., n.d.; PCO AG, n.d.)

\begin{tabular}{|c|c|c|c|}
\hline $\begin{array}{c}\text { Camera Body } \\
\text { Type }\end{array}$ & Compact Camera & DSLR & Scientific Camera \\
\hline Model & Olympus SP 350 & EOS Rebel XTi & Cooke SensiCam qe \\
\hline Picture & & & \\
\hline
\end{tabular}

One camera model of each of the three types was chosen for the initial comparison. The models chosen for the comparison are shown in Table 4.1, and the technical specification for each camera model can be found in Appendix A. The cameras were chosen based on the availability. First, the chosen compact camera failed to meet both requirements. The compact camera did not have a way to be triggered by the computer system. Also, it was found that the compact camera stopped taking pictures after two frames, which would lead to losing a significant amount of test data. Therefore, the model was ruled out from the further consideration. Next, the DSLR camera was evaluated. Firstly, personal software programmers developed some DSLR trigger software, and they are available for purchase. The common problem with the software is that none of them guarantees to work with MTS system controller since the purpose of the software is to use the camera for astrophotography. Also, the DSLR camera was able to take continuously 30 pictures due to the limited buffer memory. Certainly more image frames can be captured before stopping due to reaching the maximum buffer memory 
against the compact camera. However, it is still problematic if taking pictures is stopped during the test. In the end, only the scientific camera met all of the requirements. However, the selection of the camera must be performed again when different camera models are available. The compact camera and the DSLR for this comparison were outdated models, so there might be better options for the DIC technique.

The scientific camera, which was chosen for this research, can be seen in Figure 4.1. This camera had a few more advantages besides the requirements. First, it can capture pictures with a high number of frames per second (FPS). Although other two cameras also had high FPS and there is no absolute minimum of FPS for the DIC technique, having 10 FPS is still advantageous. Failures in brittle composite materials can be instantaneously captured with this high FPS scientific camera.

Another advantage of using the scientific camera is a Charge-Coupled Device (CCD) sensor with thermo-electrical cooling. Digital camera sensors have electrical charges, and these charges are temperature sensitive. When the camera takes pictures, the sensor temperature increases over time, which increases the noise due to excitation charges. Hence, it is better to control the sensor temperature for minimizing the noise. Furthermore, the CCD sensor has less noise versus the Complementary Metal-OxideSemiconductor (CMOS) sensor although recently developed scientific CMOS cameras are reported to have an equivalent level of sensor noise (Axis Communications AB, 2010). 


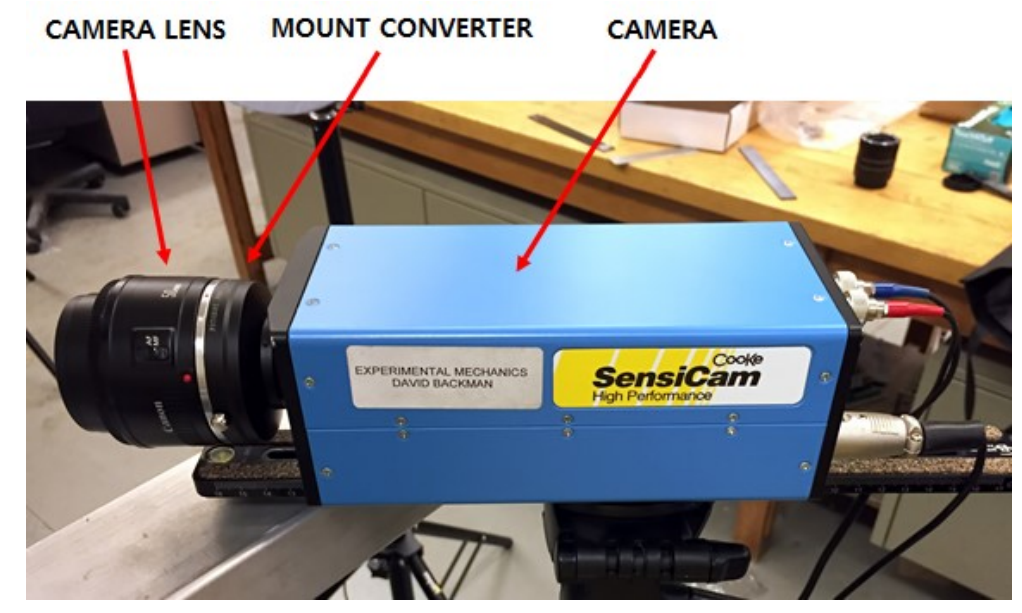

Figure 4.1: SensiCam qe

A camera lens is another essential piece of DIC equipment to collect the light information and focus it on the sensor. Two lenses were used during the research: Canon $50 \mathrm{~mm}$ F1.8 and Tamron 24-70 mm F2.8. These lenses are mounted to Canon's DSLR cameras whereas the scientific cameras have the mount called C-mount. Hence, a Canon to $\mathrm{C}$-mount convert was used. This resulted in a longer focal length, a better quality lens for the same price, and commonly available accessories.

Each lens was used for different applications. The Canon lens has an excellent sharpness in the centre but becomes blurry near the border. This lens is light weight, so adding the extension tube did not cause too much stress to the mount. Hence, this lens was used when the high magnification was necessary, and the area of interest was narrow. High magnification was achieved by an extension tube. The Tamron lens, on the other hand, has an excellent sharpness overall, but this lens weighs about $825 \mathrm{~g}$, which is six times heavier compared to the Canon lens. Adding extension tubes to this lens may cause too much stress to the mount since the lens is significantly heavier than the Canon 
lens. Therefore, it was used when low magnification is enough, but good sharpness is required overall. Other accessories used for the research were a tripod and two Lightemitting Diode (LED) light stands. The completed setup for the DIC measurement technique can be seen in Figure 4.2.

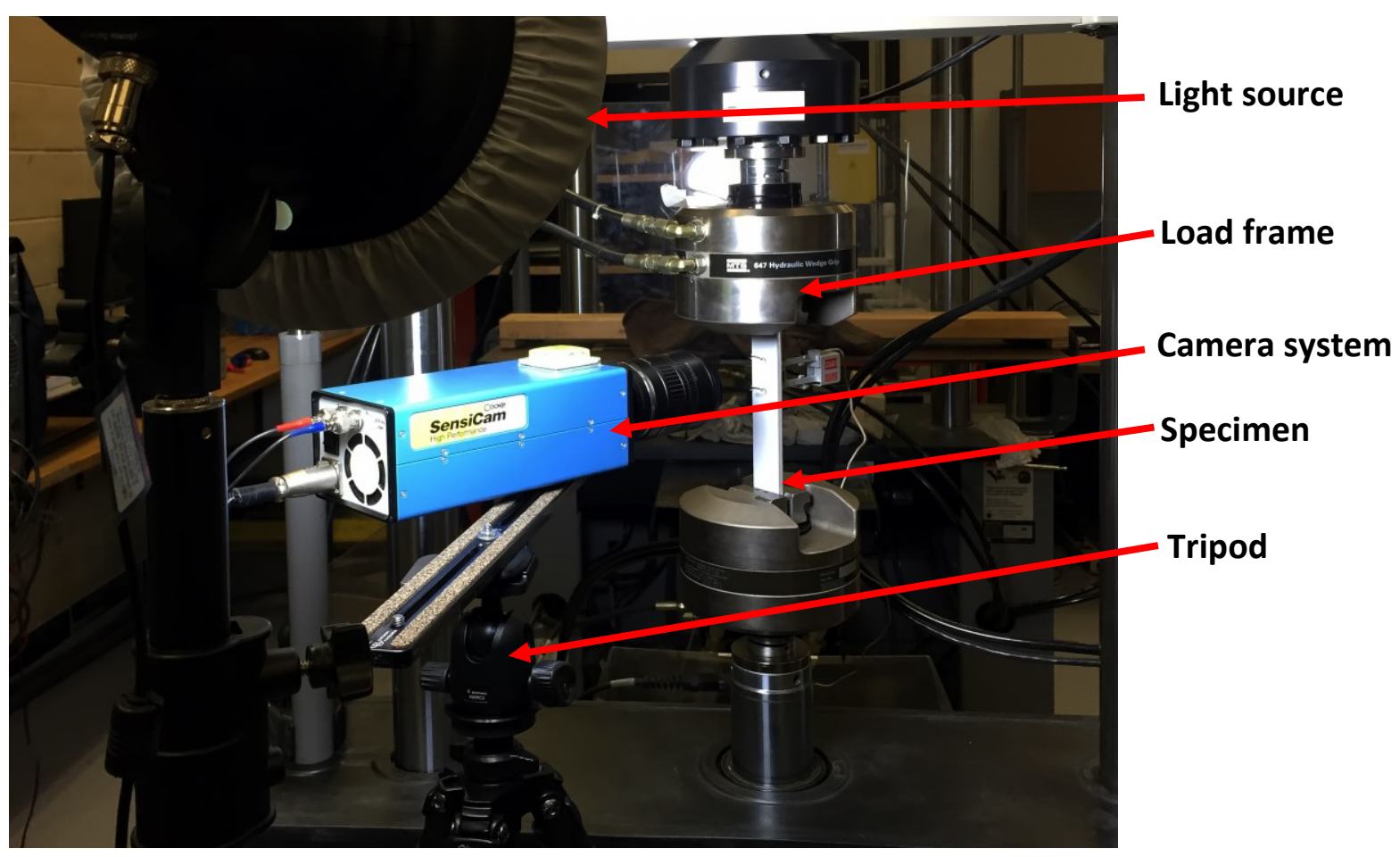

Figure 4.2: DIC setup 


\subsection{DIC ANALYSIS SOFTWARE}

Specialized software is required to carry out the DIC analysis. The pictures taken during the experiment are analyzed by the software and any data, such as displacements, strain, or even stress, can be extracted from the analysis using the software. The software chosen for this research is called "MatchID 2D" developed by University of Leuven, Belgium (MatchID, 2016). The program for this research specifically follows the process shown in Figure 4.3.

The advantage of the program is that it allows users to choose a correlation criterion, a shape function, an interpolation function, and a type of strain measures. By selecting proper criteria and functions, time for analysis can be reduced significantly. Several attempts during the thesis work showed that $25 \%$ of time saving was possible when appropriate options are chosen. Another advantage is that the data extraction can be easily performed. It was found that not all extraction points can yield good results because of the low level of strain or external factors, such as insufficient lighting. Since the analysis can take several hours, fast data extraction capabilities were important to save time and repeat the extraction data from several locations.

The precision of the program is not defined since this depends on the hardware.

One example states that it is possible to have displacement precision of 0.01-pixel movement can be captured when 1-megapixel image with $100 \mathrm{~mm}$ field with measurement is analyzed (Lava, 2015). However, this must be evaluated with chosen hardware setup. 


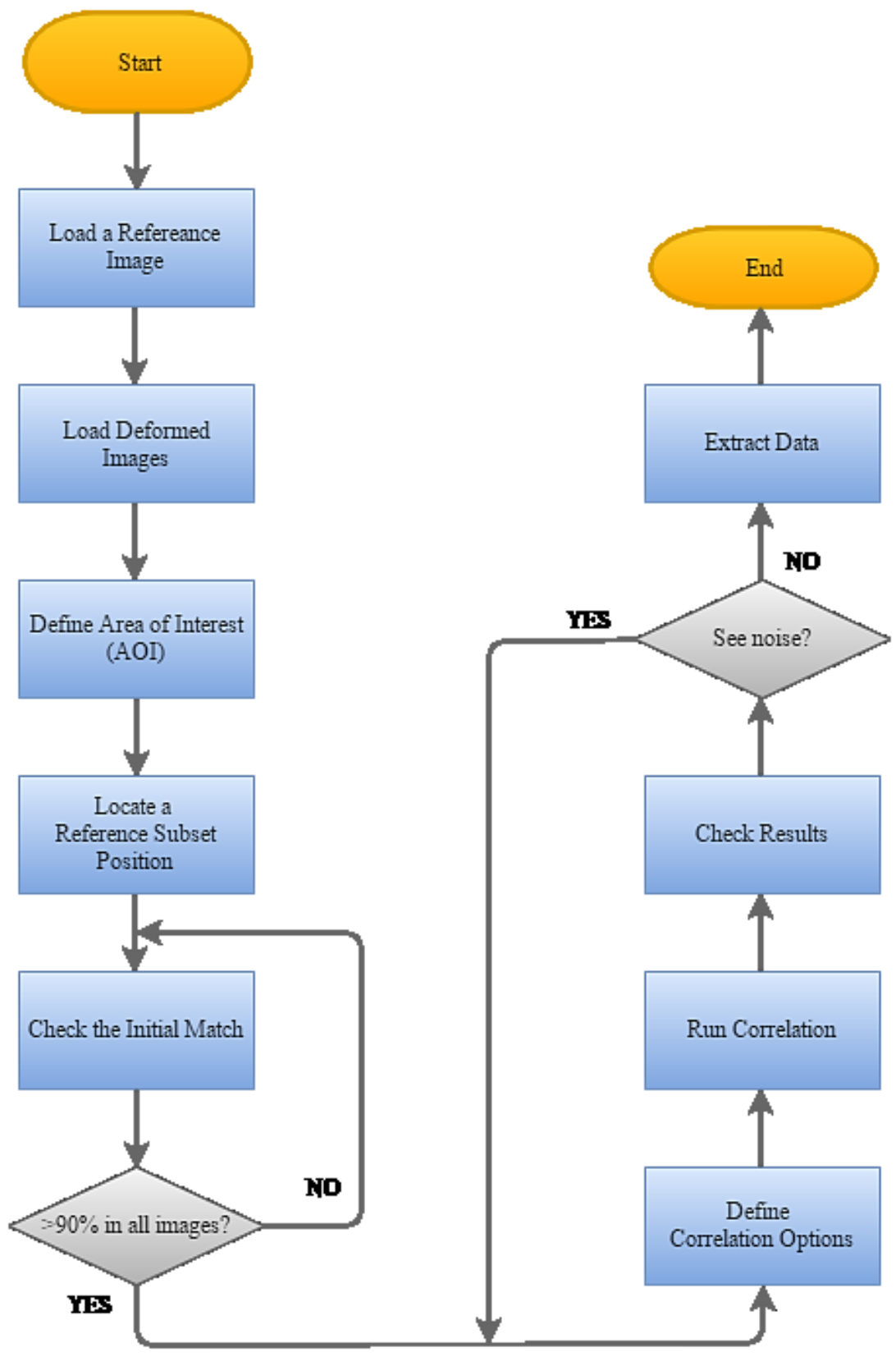

Figure 4.3: "MatchID 2D" software flow chart 


\subsection{CAmera Software Program ANd CAMEra Operation}

The scientific camera comes with the dedicated software for the control. This software also helps to trigger the camera when the FlexTest SE controller (MTS Systems Co.) sends a voltage signal and crop the unnecessary region in the FOV. Setting the FOV is usually performed by moving the camera forward or backward and rotating the camera left or right. However, the sensor has a fixed aspect ratio, which still introduces the unnecessary area in the FOV after physically moving the camera. Therefore, the software can crop this unnecessary region, and it leads to saving time for the analysis and increasing the number of pictures available to store in the memory storage.

In order to operate the camera, the following steps are completed. The first picture is taken manually, and it is used as the reference image for calculating the displacement and the strain fields. Then, the camera is switched to a trigger mode. The camera is triggered by the voltage signal from the FlexTest SE controller (MTS Systems Co.) during the trigger mode. Once the camera is triggered, it takes pictures continuously at the given intervals until the camera uses up all memory storage or is commanded to stop by the software. According to the camera manufacturer, time setting between the frames must be chosen with some factors. Figure 4.4 shows the factors to consider for setting the time. Users can choose delay setting and exposure time; other factors are fixed since they are a systemic time delay. The camera software provides a number of frames per second (FPS) with the settings. 


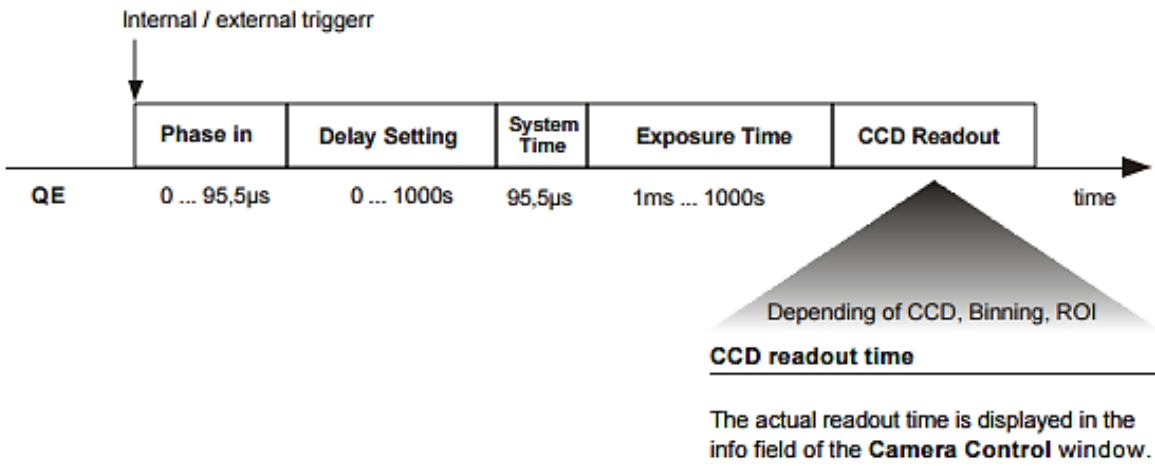

Figure 4.4: Schematic image of camera framing time setting (Cooke Co., 2002)

All pictures are stored in the memory storage; then, they are transferred to the computer. The pictures can be saved to several file formats. Since the DIC analysis software can import any file formats, it does not matter which file format is chosen. The colour depth of images can also be chosen. The colour depth is simply a number of colours that can be described in the image. 16-bit depth is preferred because it can save the same image with a smoother finish as can be seen in Figure 4.5. Unfortunately, the dedicated camera program kept crashing when the 16-bit option was chosen. In general, smoother grey intensity map can be obtained from 16-bit images. The colour depth in black and white will provide a more unique pattern. However, it was assumed that less variation in colour depth would not affect the result minimally since all images were saved in the same format with the same colour depth. 


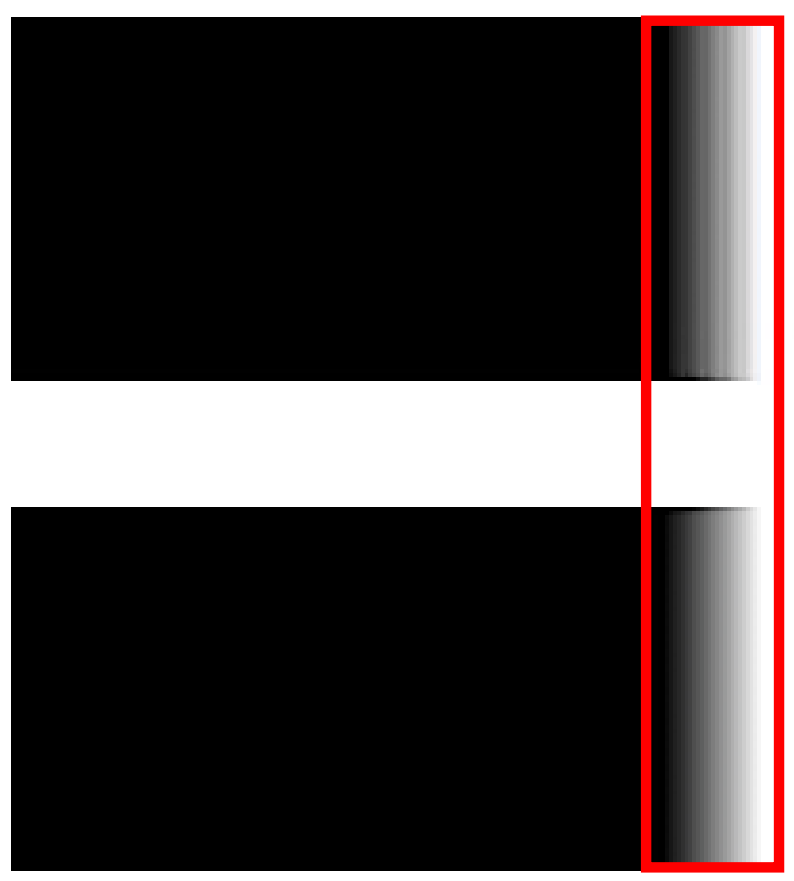

\section{8-bit depth}

\section{6-bit depth}

Figure 4.5: The difference between 8-bit and 16-bit depths

\subsection{Manufacturing OF COMPosite Bolted/Bonded JoInts}

This chapter covers the test coupon design and the detail manufacturing process of the composite bolted/bonded joints. The test coupon design and determination of joint geometry is briefly explained. Also, this chapter provides the detail information about manufacturing process used for the CFRP adherends in this research.

\subsubsection{TEST COUPON DESIGN}

Four different test coupon configurations were used for the experiments:

1) aluminum bolted joint, 
2) CFRP wide overlap test coupon with an $8 \mathrm{~mm}$ diameter hole in the centre of the joint,

3) CFRP small overlap test coupon with an $8 \mathrm{~mm}$ diameter hole in the centre of the joint, and

4) CFRP test coupon configured with $4.76 \mathrm{~mm}$ diameter hole in the centre of the joint.

The purpose of the aluminum bolted joint was to check the function of an instrumented bolt that was used to validate the DIC technique. The bolted joint dimension was followed by the ASTM standard D5961/D5961M - 13, which is a standard test method for bearing response of polymer matrix composite. This standard requires the bolted joint to have a certain ratio between the bolt diameter, the overlap length, the overlap width, and the distance between the diameter and the edge of the joint. Not all dimensions from the standards were referred to design the joint. Table 4.2 shows specific standard parameters followed to design the test coupon. The instrumented bolt diameter was $8 \mathrm{~mm}$. Hence, the joint had $48 \mathrm{~mm}$ overlap width and $48 \mathrm{~mm}$ overlap length. More detailed design information is provided in Appendix B.

Table 4.2: Geometry requirement for the composite bolted joint (ASTM D5961/D5961M - 13, 2013)

\begin{tabular}{|c|c|}
\hline Parameter & Standard \\
\hline \hline Laminate & Quasi-isotropic \\
\hline Edge distance to the centre of the bolt $(e):$ Bolt diameter $(d)$ & $0.5: 1$ \\
\hline Overlap width $(w):$ Bolt diameter $(d)$ & $6: 1$ \\
\hline Overlap length $(l):$ Bolt diameter $(d)$ & $6: 1$ \\
\hline
\end{tabular}


Other three coupon configurations were CFRP bolted/bonded joint with different bolt diameters, overlap lengths, and overlap widths. The ASTM standards do not have an experimental standard for bolted/bonded joint configurations. Therefore, the test coupons were designed by referring to guidelines of ASTM 3165 - 07 and ASTM D5961. The first ASTM standard referred to was ASTM 3165 - 07, which is a standard test method for strength properties of adhesives in shear by tension loading of single-lap-joint laminated assemblies to inspect the bonding characteristics between FRP adherends. Another ASTM standard considered was ASTM D5961/D5961M - 13, which is a standard test method for bearing response of polymer matrix composite laminates. Similar to the approach for the bolted joint, the geometry requirements from ASTM D5961/D5961M - 13 were reviewed and considered in the design process. Table 4.3 shows the final dimensions of three CFRP bolted/bonded joints

Table 4.3: Dimensions of three different CFRP bolted/bonded joint test coupons

\begin{tabular}{|c|c|c|c|}
\hline & Coupon 1 & Coupon 2 & Coupon 3 \\
\hline Laminate & Quasi-isotropic & Quasi-isotropic & Quasi-isotropic \\
\hline$d$ & $8 \mathrm{~mm}$ & $8 \mathrm{~mm}$ & $4.76 \mathrm{~mm}$ \\
\hline$e$ & $14 \mathrm{~mm}$ & $14 \mathrm{~mm}$ & $14.28 \mathrm{~mm}$ \\
\hline$l$ & $28 \mathrm{~mm}$ & $28 \mathrm{~mm}$ & $28.56 \mathrm{~mm}$ \\
\hline$w$ & $48 \mathrm{~mm}$ & $28 \mathrm{~mm}$ & $28.56 \mathrm{~mm}$ \\
\hline
\end{tabular}

Coupon 1 was designed to have same overlap area as the bolted joint, but the overlap length was shortened due to manufacturing issues Coupon 2 was designed after the test result using Coupon 1 had been obtained. Full experimental results can be found in Chapter 5. Coupon 2 was designed to have a smaller overlap area to reduce the size of an adhesive layer for increasing the response from the bolt. Coupon 3 was designed to fit 
the bolt chosen for the project. Since it had a smaller diameter, the overlap length and width, and edge distance were modified accordingly.

\subsubsection{Preparation OF COMPOSITE ADHERENDS}

The manufacturing began by making composite panels. The carbon fibre prepreg used for this research is Cytec's Thornel T-650/35 Pan-based unidirectional fibre preimpregnated with CYCOM 5320 epoxy resin system. This prepreg can be cured either in an autoclave or out-of-autoclave in precision temperature controlled oven. Although the prepreg can be cured out-of-autoclave, it was decided to use the autoclave for better control of pressure and temperature. This decision was to guarantee the curing quality of the laminate by following the cure cycle from the manufacturer. All curing processes were performed by a qualified technician at the National Research Council Aerospace Composites Laboratory in Ottawa. Cutting and drilling procedures were completed at Carleton University. The panels were designed with a total of 24 plies and a balanced, symmetrical quasi-isotropic layup configuration with the following laminate stacking sequence:

$$
[0 / 45 / 90 /-45]_{3 \mathrm{~S}}
$$

Although the quasi-isotropic configuration does not give the highest mechanical properties in a single direction, the laminates with this configuration have identical elastic mechanical properties for all in-plane directions. Also, warping during the curing process can be minimized with the selected a symmetric layup. A heavy duty cutter with cutting 
templates was used to cut the unidirectional prepreg tape. After the cutting had been completed, each ply was stacked according to the stacking sequence. The hand pressure was applied to the laminate using a roller after each ply was stacked. The stacked prepreg was put into a vacuum table to ensure all plies to stick each other and debulk the air trapped between the plies. The $84 \mathrm{kPa}$ vacuum pressure was applied to the stacked prepreg using a vacuum pump at least for 15 minutes. Although this task was not a required process from the manufacturer, it was still performed because the supplied prepreg used for this research was drier than typical prepregs, so the plies did not stick together under normal mechanical pressure. After all plies had been stacked, the plies were left under the same vacuum pressure at least for 24 hours to finish the debulking process.

In order to cure the laminate, the vacuum bagging is required. Vacuum bagging was done with the sequence shown in Figure 4.6. The completely debulked laminate was placed on the large aluminum tool plate and surrounded by edge dam metal strips. These metal strips prevent the cure pressure from compressing the edges of the laminate and decrease the local thickness reduction at the edges as seen in Figure 4.7. On the top of the laminate, a thick metal plate was put to apply additional pressure and prohibit the laminate to deform as seen in Figure 4.8. Thermocouple gauge sensors were installed on one of four laminates and the aluminum tool plate to check the temperature during the curing process. Then, the vacuum bagging was done as Figure 4.9. Once the bag was completely sealed, the air was pulled out from the vacuum bagged plate using the vacuum pump, and the leakage was checked by the pressure drop inside of the bag. The 
pressure was checked by installing the pressure gauge to the vacuum port. The pressure drop was inspected 15 minutes after the gauge was placed.

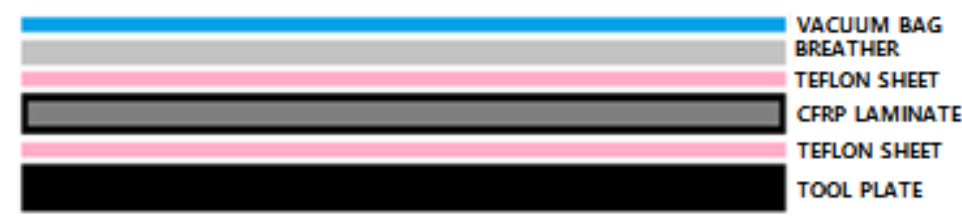

Figure 4.6: Schematic image of vacuum bagging

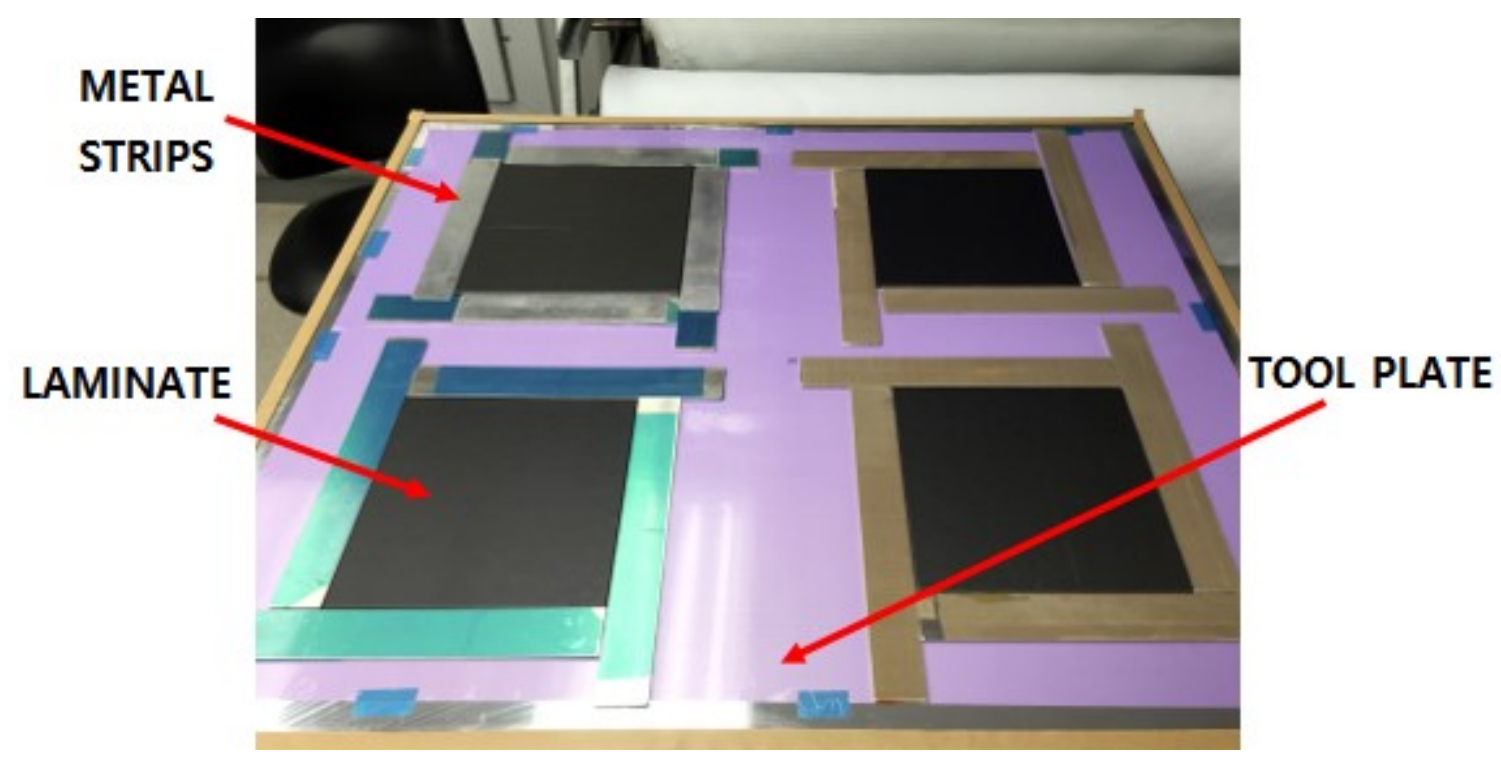

Figure 4.7: Vacuum bagging process for curing laminate 1 


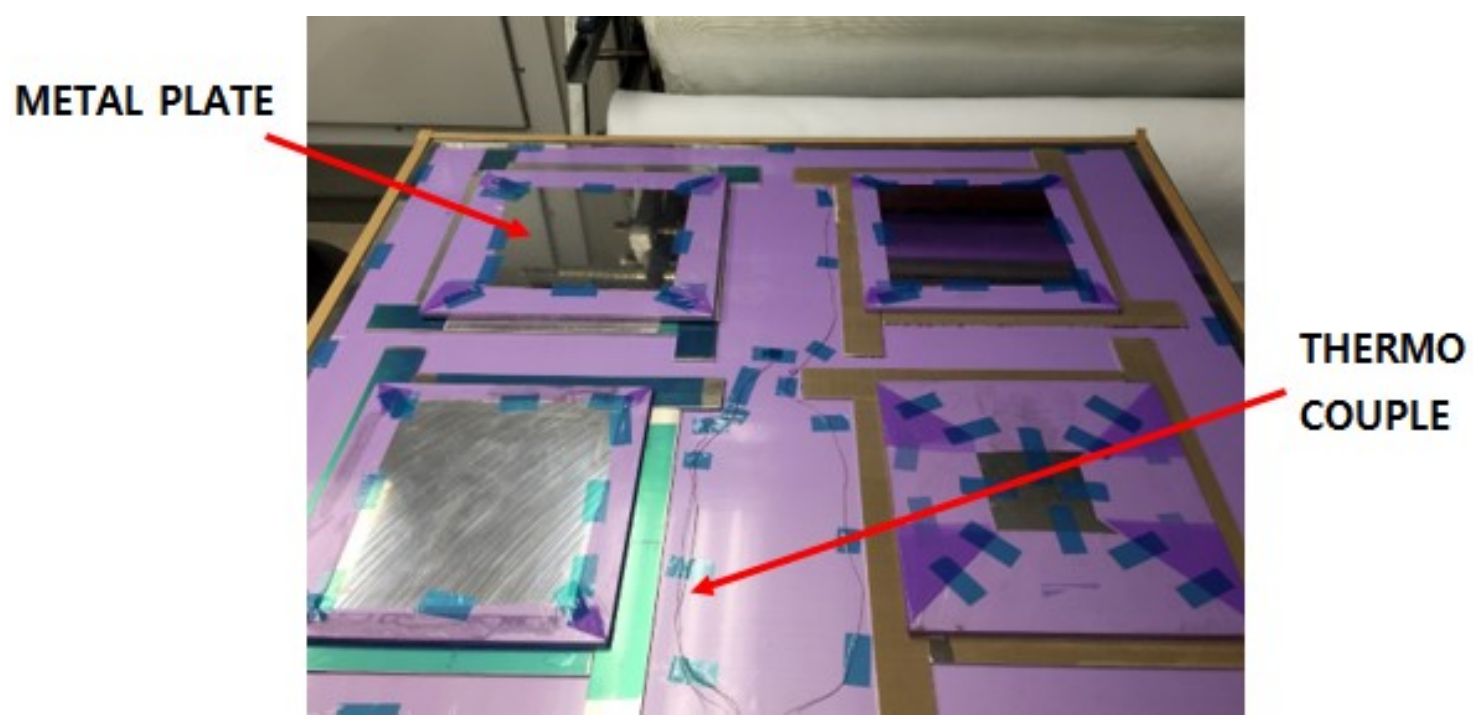

Figure 4.8: Vacuum bagging process for curing laminate 2

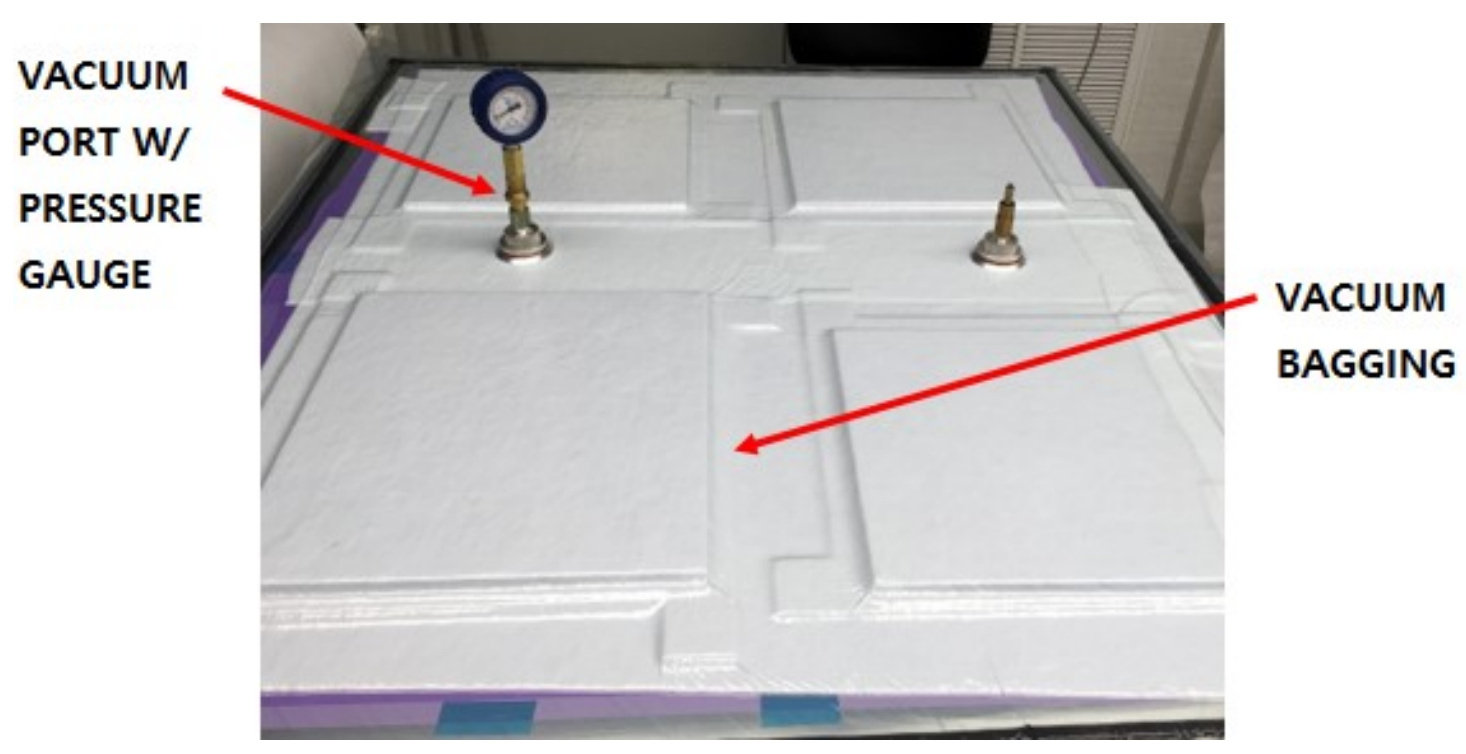

Figure 4.9: Vacuum bagging process for curing laminate 3

The manufacturer recommended three different cure cycles. The cure cycle shown in Figure 4.10 was chosen to cure the laminate. Completely vacuum bagged laminates were placed in the autoclave and cured at the recommended temperature and the 
temperature ramp rates (Cytec Solvay Group, 2015). Figure 4.11 shows the actual temperature change on the surface of the laminate during the initial curing cycle.

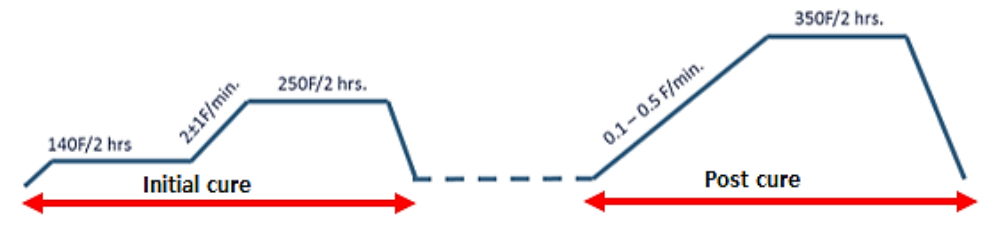

Figure 4.10: Recommended cure cycle for CYCOM 5320 (modified from Cytec Solvay Group, 2015)

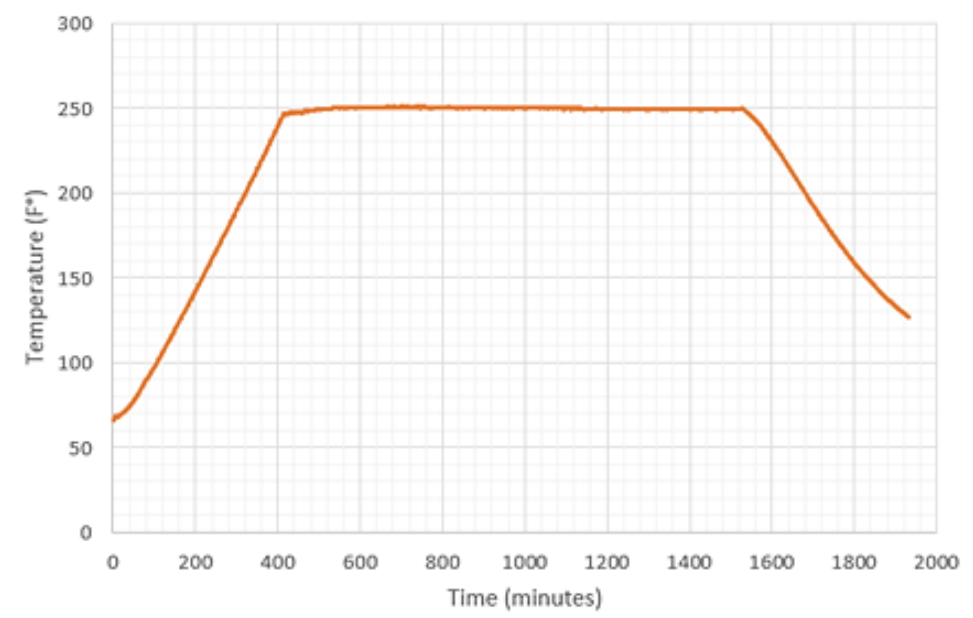

Figure 4.11: Actual temperature change in the laminate during initial curing process

The post cure was also performed in the same autoclave due to the excellent temperature control inside. The pressure in the autoclave did not need to be controlled during the post cure process since the temperature control was the only requirement according to the manufacturer's data sheet (Cytec Solvay Group, 2015). Once the post cure was completed, one laminate was chosen among four for the inspection using ultrasonic C-scan process. The reason for scanning only one laminate was that the laminates, which were stacked in the same way and cured under the same condition on 
the same day, were assumed to have the same final quality. In Figure 4.12, red colour indicates the region where the laminate has no defects, and other colours indicate the possible defects such as delamination or thickness variations. Although the centre showed a possible defect, it was not considered as a problem since this area of the plate would not form part of the overlap region in the joint once the panels were cut. Lastly, the inspected laminates were cut through the centre of the laminate for bonding together.

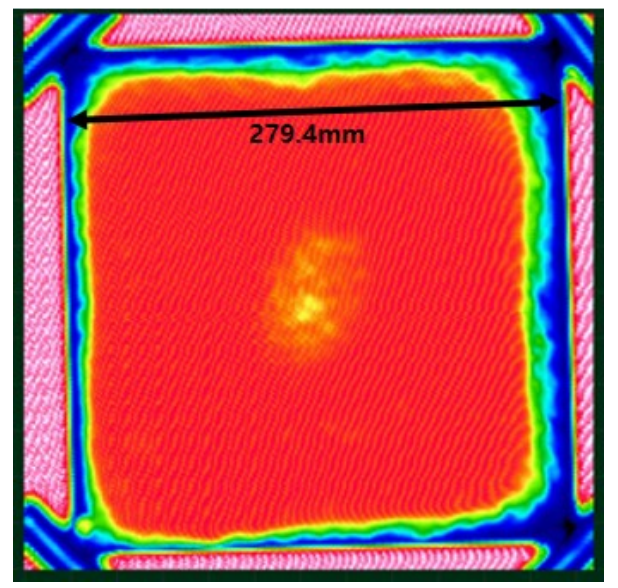

Figure 4.12: The result of ultrasonic scanning of cured laminate

\subsubsection{BONDING PROCESS OF COMPOSITE LAMINATES}

Since the cured laminates were exposed to the lab environment, their surfaces may have been contaminated with foreign substances. Hence, the bonding process began with a surface preparation. Two stages were performed. The first stage was to clean the surface with a suitable solvent. In general, isopropyl alcohol, acetone, or methyl ethyl ketone are used to clean composite plates in industrial settings. Isopropyl alcohol was chosen over methyl ethyl ketone due to environmental and health concerns and over 
acetone since acetone is less effective at cleaning. Each surface was cleaned four times with isopropyl alcohol soaked lint free wipes. The wipe was disposed of after each cleaning step. The wipe was disposed of after each cleaning step. This process was performed in a fume hood. Then the cleaned laminates were moved to the clean room and dried for 45 minutes. Lastly, the sand grit blasting with nitrogen compressed gas was performed on the bonding surfaces as shown in Figure 4.13. After the grit blasting, the panel was cleaned with an air compressor. Primers were not applied to the bonding surface for a chemical modification because epoxy already bonds well with other types of epoxies (da Silva \& Banea, 2009).

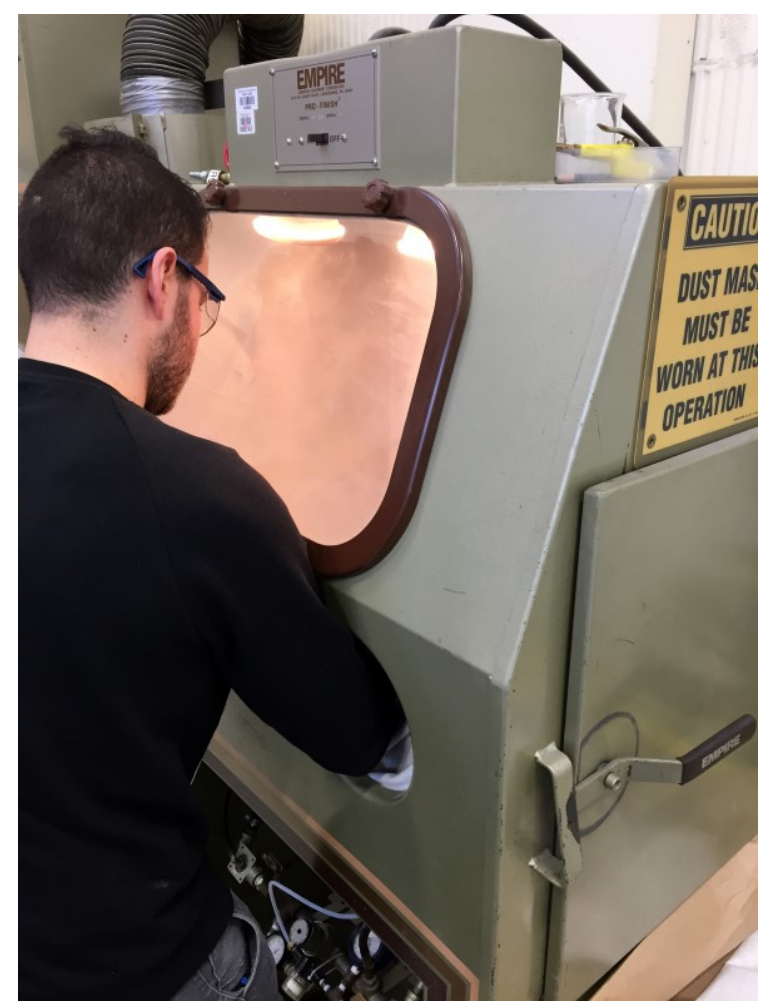

Figure 4.13: Grit blasting process 
The laminates with the surface preparation completed were taken back to the clean room. Piano wires were used to control the thickness to control the thickness. In this thesis, the thickness of the adhesive was limited to only one value of $0.5 \mathrm{~mm}$ to minimize the effect of various adhesive thicknesses. The adhesive thickness, $0.5 \mathrm{~mm}$, was chosen because this was the highest thickness that the project team had been using in other tests and analyses. The wires were cleaned with isopropyl alcohol and the lint free wipes as well to remove oil applied to the wires. Then, they were installed as shown in Figure 4.14. The wires were installed horizontally because this direction had a shorter path for the excessive adhesive to flow out. The wires were located outside of the overlap region since the wire invaded to the overlap region would be considered as a defect. Both wire ends were taped tightly to restrict the movement due to vacuum pressure. The adhesive used for this research was the paste-type adhesive Hysol ${ }^{\circledR}$ EA 9361 (Henkel Co.). This paste adhesive has two parts which must be mixed at a specific weight ratio. A planetary centrifugal mixer, Thinky Mixer ${ }^{\circledR}$ ARE-310 (Thinky Co.), was used for a better mixture of two parts because both components were too viscous to mix manually. The mixed paste adhesive was applied to both bonding surfaces. A large spatula was used to spread the adhesive evenly over the surface. Figure 4.15 shows how the adhesive was applied. 


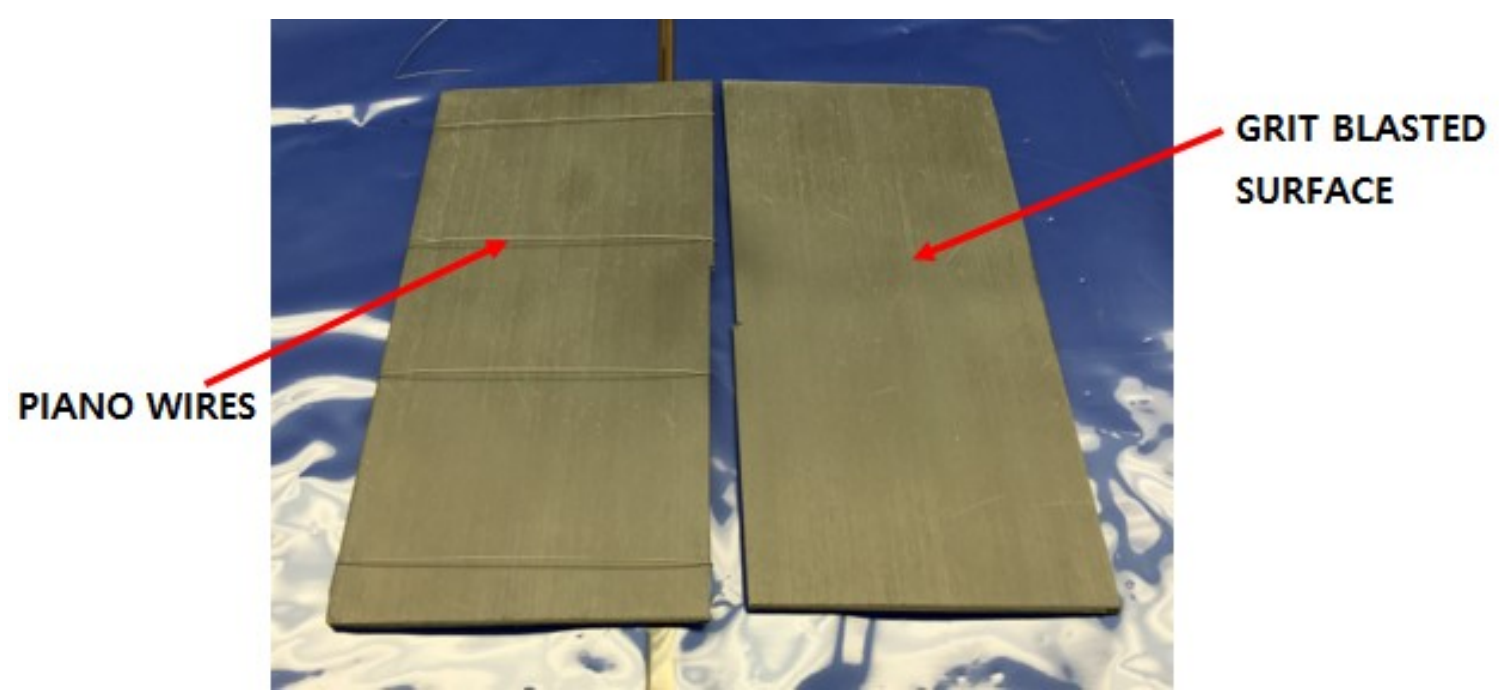

Figure 4.14: Plates following grit blasting with piano wires attached

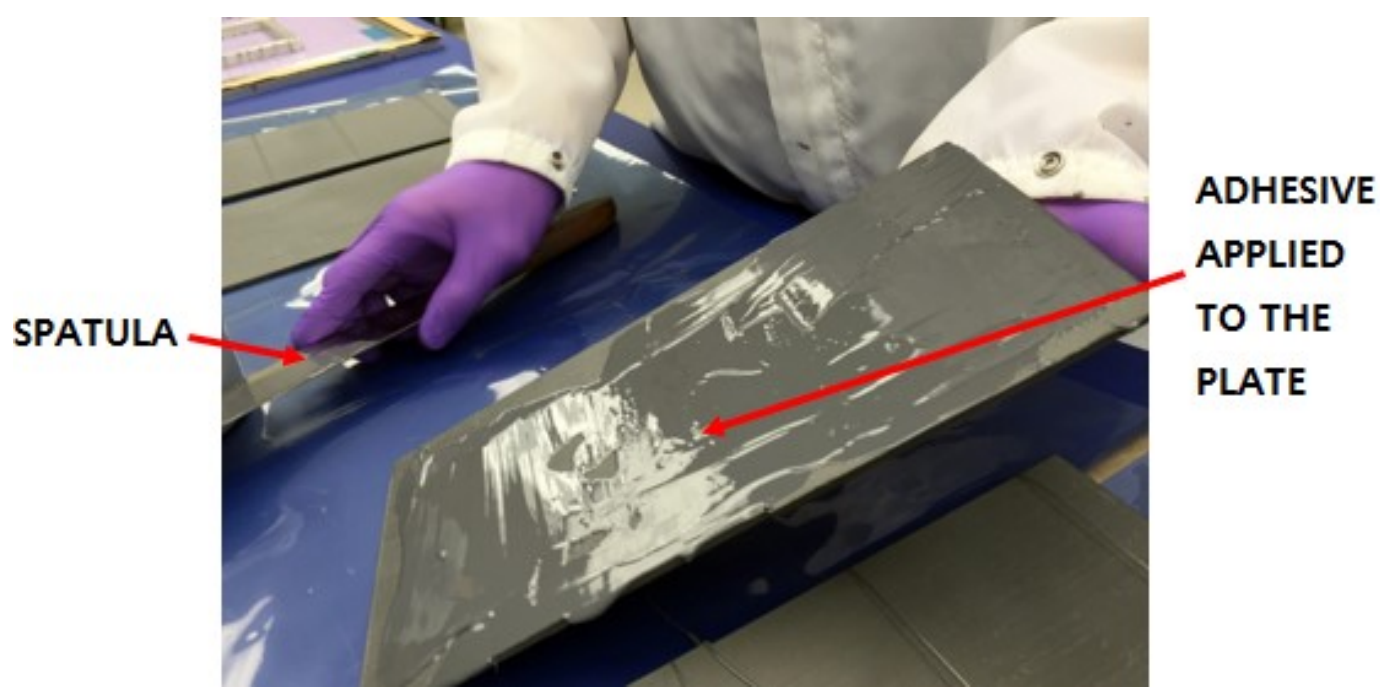

Figure 4.15: Adhesive applied to the plate

Similar to curing the laminate, vacuum bagging was completed to cure the paste adhesive under vacuum as shown in Figure 4.16. The bonded plates were left under vacuum to make excessive adhesive flow out and have the desired adhesive thickness after curing was completed. Metal bars were used to surround the adhesive applied plates. 
Metal bars were used to restrict the plates from being warped. Two long bars seen in Figure 4.17 had triangular shaped channels over the length of the bar to have better adhesive flow. The difference between curing the laminate and curing the adhesive was the use of an autoclave since curing paste adhesive did not require elevated temperatures. According to the manufacturer, the adhesives requires being cured up to seven days for achieving a normal performance (Henkel Corporation Aerospace, 2013). It was found that the initial cure of the adhesive, which is a transition from paste phase to gelation phase, would usually be completed 24 hours after applying to the surface. Hence, the vacuum pressure was applied for 24 hours only; then the plates were left under the vacuum bag at atmospheric pressure for the remaining six days to achieve final cure. The vacuum pressure applied to the bag during the initial cure was about $44 \mathrm{kPa}$. It was found that the full vacuum pressure with a portable vacuum pump, which is about $84 \mathrm{kPa}$, would actually prevent the adhesive flow, so the desired thickness could never be achieved. After several trials, the adhesive cure with a vacuum pressure of $44 \mathrm{kPa}$ yielded the best result. The bonded plates were taken to Carleton Unversity for cutting. 


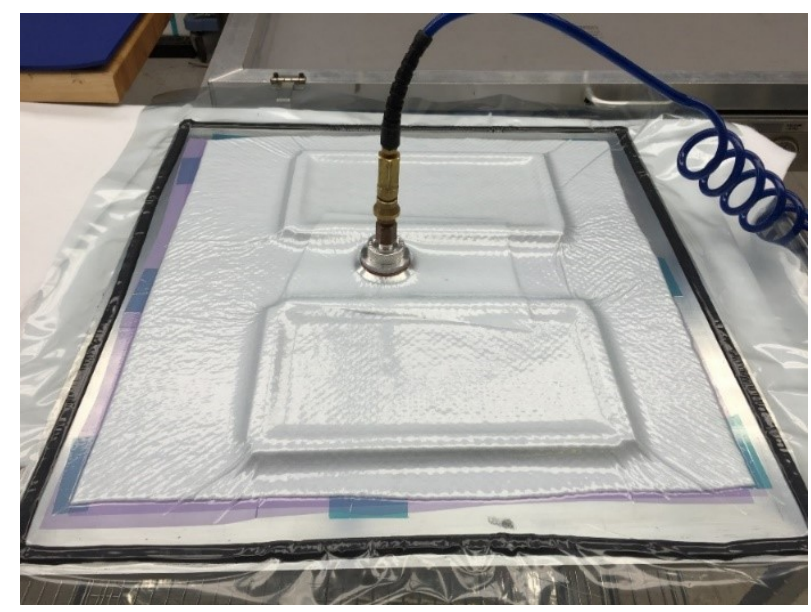

Figure 4.16: Vacuum bagging process

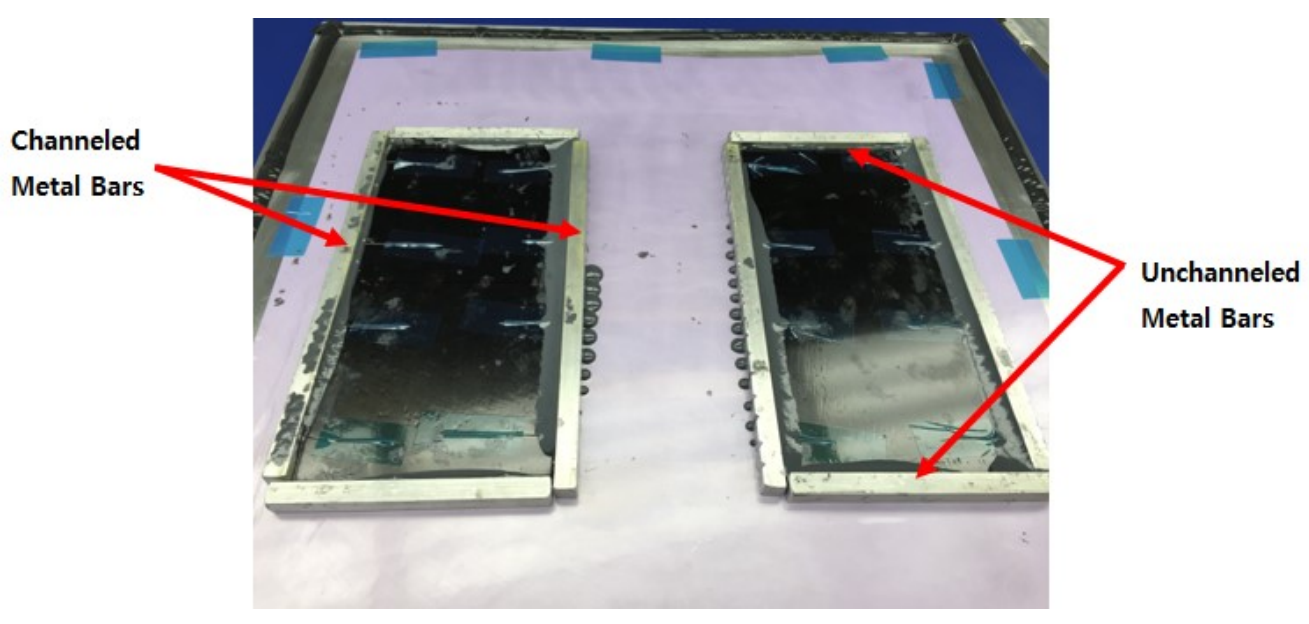

Figure 4.17: Completely cured bonded plates

\subsubsection{FinAlizATION TO COMPOSITE COUPONS}

Fully cured plates were cut into test coupon size with some margins added using a table saw with diamond blades. The margins were added because of the blade width and the blade warp during the cut. Coupons were sanded using 100 grit, 200 grit, and 800 grit 
sandpapers to reduce the edge margin to $1 \mathrm{~mm}$. The length and width were measured with a digital caliper after each sanding. Once the desired dimensions were achieved, the coupons were cleaned with isopropyl alcohol and industrial paper towels.

Bolt holes were drilled in the coupons by a technician at Carleton University Science Technology Centre with two steps to avoid damage such as delamination as shown Figure 4.18. Drilling was chosen over other machining techniques, such as laser or waterjet, because of the cost to make each hole. This damage usually occurs at the exit of drilling rather than the entrance due to the pushing-down effect (Durão, Tavares, de Albuquerque, Marques, \& Andrade, 2014).

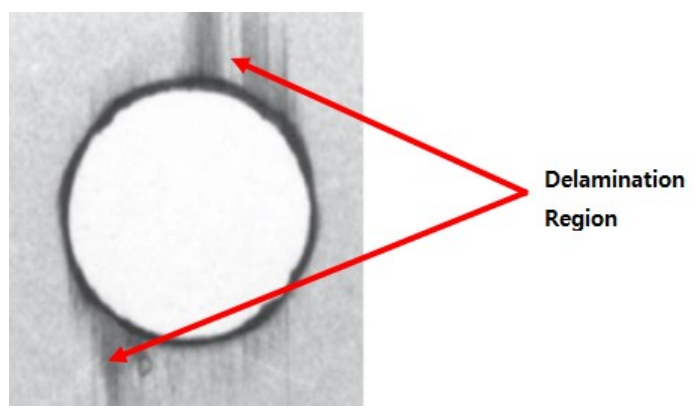

Figure 4.18: Image showing delamination at the exit of composite panel (modified from Durão, Tavares, de Albuquerque, Marques, \& Andrade, 2014)

Minimizing the damage from drilling is important because composite materials always experience strength reduction due to the discontinuity. The drilling was performed with the following recommended procedures to minimize the damage:

1) A slightly smaller than the desired size hole was made with a $135^{\circ}$ split point drill bit with rotational speed up to 800 rotations per minute (RPM); and 
2) A solid carbide straight flute reamer was used to obtain the target diameter hole with rotational speed up to $550 \mathrm{RPM}$

During the process, the aluminum plate was placed under the test coupon as a sacrificial material to minimize the delamination effect. The drilled coupons were visually inspected with magnified pictures as shown in Figure 4.19. Some delaminations were observed, but they were assumed to be minor surface flaws only.

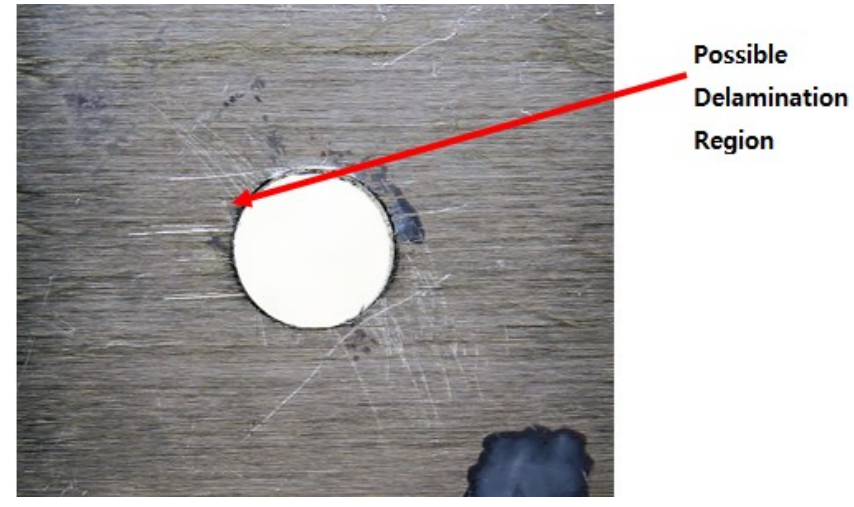

Figure 4.19: Possible delamination found in the actual test coupon

Lastly, making notches to form a single lap joint was performed after drilling. Since the hole needed to be located in the centre of the joint, it had to be drilled as the last step. The same table saw, which was used for cutting the bonded plate into test coupons, equipped with a smaller diameter blade was used to make notches. The notched area was inspected every time after cutting and repeated until the adhesive layer appeared. The completed notch can be seen in Figure 4.20, and the completed test coupon can be seen in Figure 4.21. 


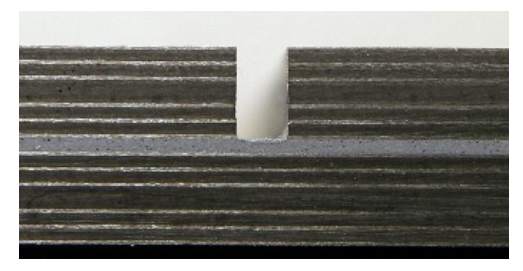

Figure 4.20: The magnified picture of the completed notch

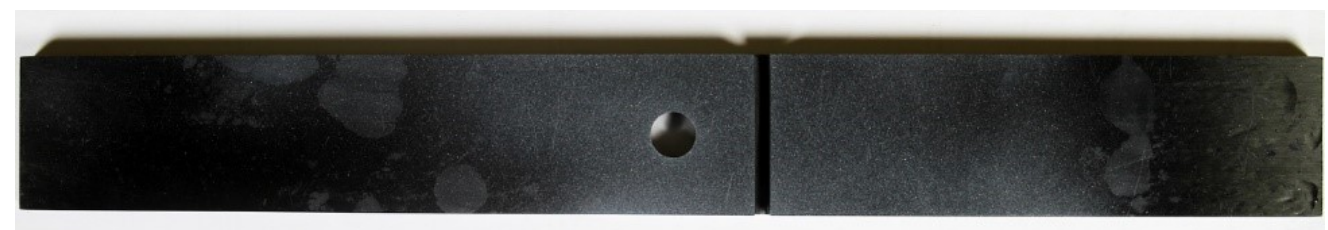

Figure 4.21: The test coupon after the completion of manufacturing

\subsection{Test SETuP}

This section introduces the test setup and the equipment used for each of these series of tests. These tests consisted of:

- Test Series 1 -Investigation of digital image correlation configuration

- Comparison of the strain obtained from the DIC analysis and the conventional axial extensometer

- Tests with and without a camera extension tube while limiting other equipment changes.

- $\quad$ Test Series 2 - Instrumented bolt testing;

- Comparison of results from a strain gage instrumented bolt versus the DIC technique and finite element analysis 
- Three test coupon configurations - aluminum bolted, CFRP bolted/bonded (wider overlap), and CFRP bolted/bonded (narrower overlap)

- Test Series 3 - Investigation of the DIC technique to measure load sharing in CFRP bolted/bonded joints.

- Application of the DIC technique to measure surface strains and correlate them to bolt strains.

- Three composite coupon configurations tested for the comparison purposes - bolted joint, bonded joint with an open hole, and bolted/bonded joint.

\subsubsection{TeSt SERIES 1 - InVESTIGATION OF DiC CONFIGURATION}

This test was performed to validate and get familiar with the DIC analysis process. Although the chosen camera body was already used in some studies (Backman et al., 2011), the camera with other chosen equipment, such as lenses with the converter, was not used for the DIC technique. Therefore, the test was performed to validate the equipment. Getting familiar with the equipment and the computer software for the camera and the analysis was another reason for this test. The test setup can be seen in Figure 4.22. 


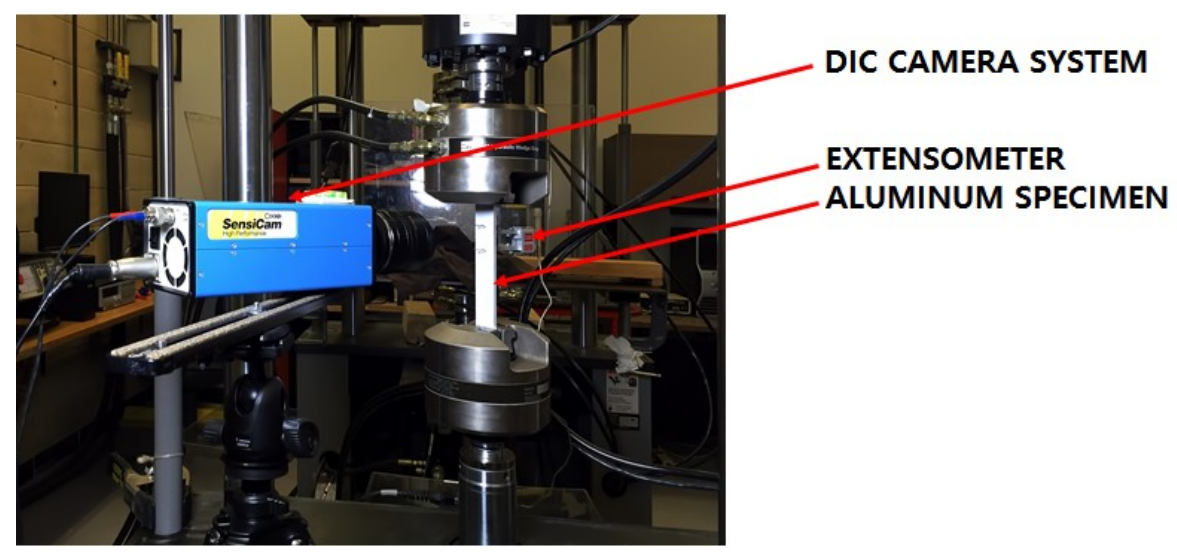

Figure 4.22: DIC verification with extensometer

Test Series 1 was to compare the axial strain data obtained from the DIC technique to the axial strain obtained from a conventional extensometer. The extensometer is the device to measure the strain by measuring the displacement change between two points through a linear voltage displacement transducer. These two contact points are separated from each other by a known initial distance. For this research, the Axial Extensometer 634 (MTS Systems Co.) with $25 \mathrm{~mm}$ gauge length was used. The chosen extensometer is regularly calibrated by the technician at Carleton University. The strain from the extensometer was recorded in the computer via the FlexTest SE controller (MTS Systems Co.). All equipment model numbers and serial numbers can be found in Appendix C. The strain is calculated as deflection per unit of gauge length.

$$
\varepsilon_{\text {extensometer }}=\frac{\Delta l}{l_{o}}=\frac{l_{d}-l_{o}}{l_{o}}
$$

The test coupon was made of a cold-rolled Al 2024-T3 sheet with $4.83 \mathrm{~mm}$ thickness. The length of the coupon was $200 \mathrm{~mm}$, and the width was $30 \mathrm{~mm}$. Aluminum 
alloy was chosen because the material properties are well known. The test coupon was painted with matte white first to reduce the reflection from the metal surface and maximize the contrast to the speckle pattern. The speckle pattern applied to the coupon was in matte black. Spray paint was used to cover the surface and make a random speckle pattern as seen in Figure 4.23. Although the size of the speckle pattern could not be controlled, this random size and distribution ended up giving better random speckle patterns in the image frame.

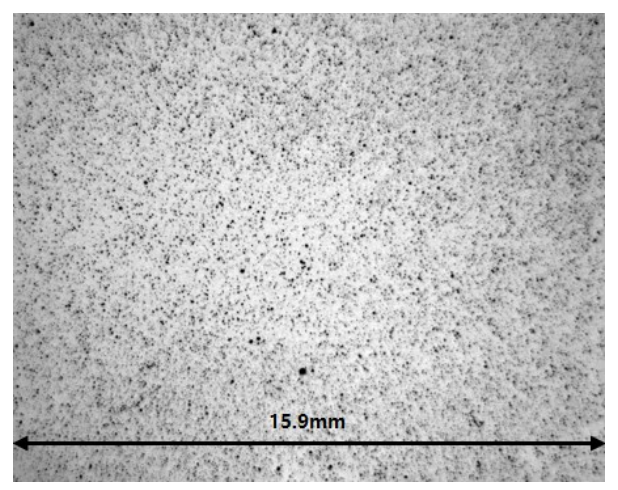

Figure 4.23: Speckle pattern applied to the aluminum test coupon surface

The paint was applied an hour before the test to avoid it being too dry. If the paint is too dry, then the load induces the crack on the painted surface and causes a discontinuity and errors in displacement measurements. The test was performed twice with different equipment. The camera system did not have an extension tube in the first round while the second round had a $13 \mathrm{~mm}$ extension tube added to the camera system, which was the smallest extension tube. It was to find whether increasing magnification under the same condition would give a better result in the displacement and the strain fields. The test was performed under load controlled. The loading ramp rate for both tests 
was set to $6000 \mathrm{~N} / \mathrm{min}$ for reducing the time to reach the maximum level, and a maximum applied a load to $15000 \mathrm{~N}$. The load frame calibration was checked by applying the load to the rectangular steel plate. The applied load was lower than the load equivalent to the yield strength to avoid plastic deformation. The load-stroke displacement variance was checked.

\subsubsection{Test Series 2 - Instrumented Bolt Testing}

This test series used an instrumented bolt and the FEA to validate the DIC technique in the joint configurations. The instrumented bolt shown in Figure 4.24 was a custom-made bolt manufactured by Ph.D. candidate Mr. Kobye Bodjona from McGill University, and the finite element analysis (FEA) model was developed by Ph.D. candidate, Mr. Pedro Lopez-Cruz from Carleton University. The mechanical tests described in this section were all conducted by the author. The purpose of Test Series 2 was to verify whether the DIC technique can detect any change in displacement or strain 
fields when the test coupon experiences a sudden change in load paths.

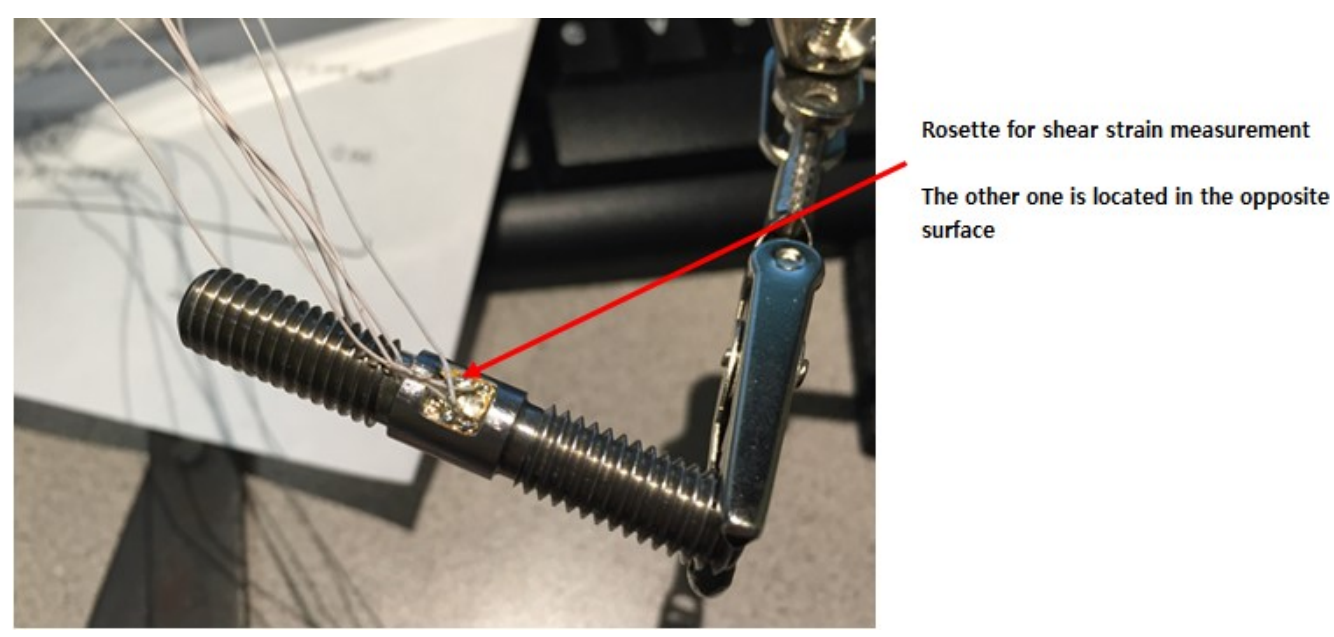

Figure 4.24: Instrumented Bolt

The bolt was manufactured from stainless steel 316 and had $8 \mathrm{~mm}$ diameter. Two strain gage rosettes were located in the centre of the bolt and, on the opposite side of the bolt. The rosette used for the bolt is selected to measure the shear strain. The design of the rosette can be seen in Figure 4.25. Each rosette has two strain gages angled at $\pm 45^{\circ}$. Two rosettes were used to form the Wheatstone bridge configuration. The Wheatstone bridge configuration is the circuit type that four strain gages form the configuration as seen in Figure 4.26. It has advantages in terms of insensitivity to temperature changes and accuracy in measuring strain. The rosettes were connected to the circuit board using thin electrical wires. The purpose of the circuit board is to connect two rosettes in the Wheatstone bridge configuration because the circuit could not be directly formed from the rosettes. The circuit board was connected to P-3 Strain Indicator (Vishay Co.) using the electrical wires. The strain indicator is to obtain the voltage change and to send the 
data to the computer system via FlexTest SE control system (MTS System Co.), which simultaneously records the voltage output with other data channels, such as load, or stroke.

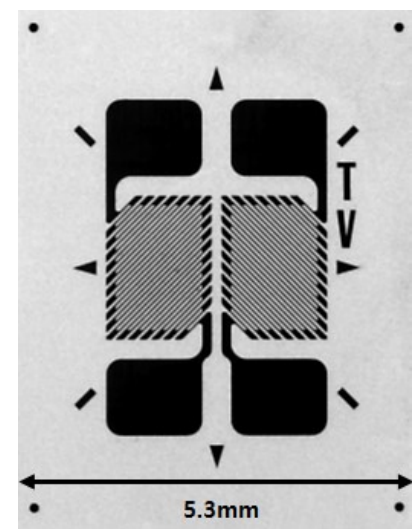

Figure 4.25: Rosette used in the instrumented bolt (EA-13-062TV-350E)

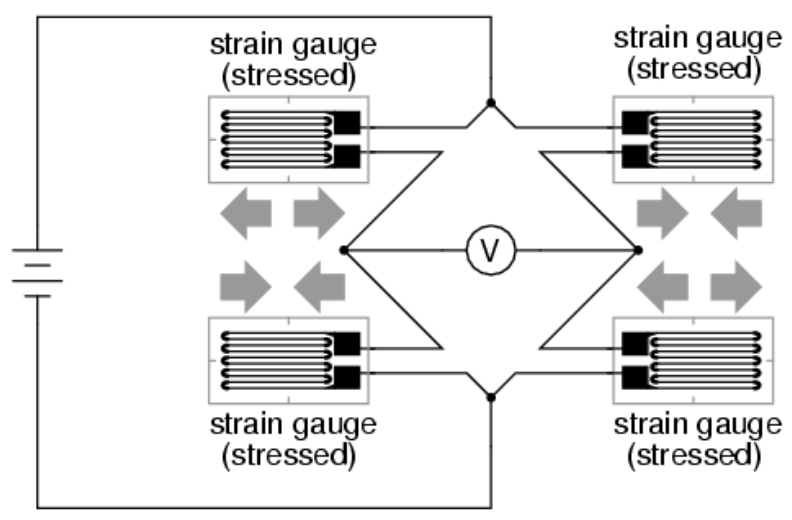

Figure 4.26: The Wheatstone bridge configuration (Kuphaldt, n.d.)

The unique design requires two nuts to be used to install the bolt. The bolt was fastened by finger tightening the nuts. The assumption was made that the amount of torque applied by tightening would be low, so the friction induced due to compression would be negligible. The bolt was chosen instead of purchasing the one from the 
professional manufacturer because the bolt function was checked by Mr. Bodjona and the experimental data was available. Also, the cost to purchase the one from the professional manufacturers had to be considered.

The finite element model is three-dimensional solid model representing the half of the joint as shown in Figure 4.27. More details regarding the finite element model can be found in Lopez-Cruz (2016).

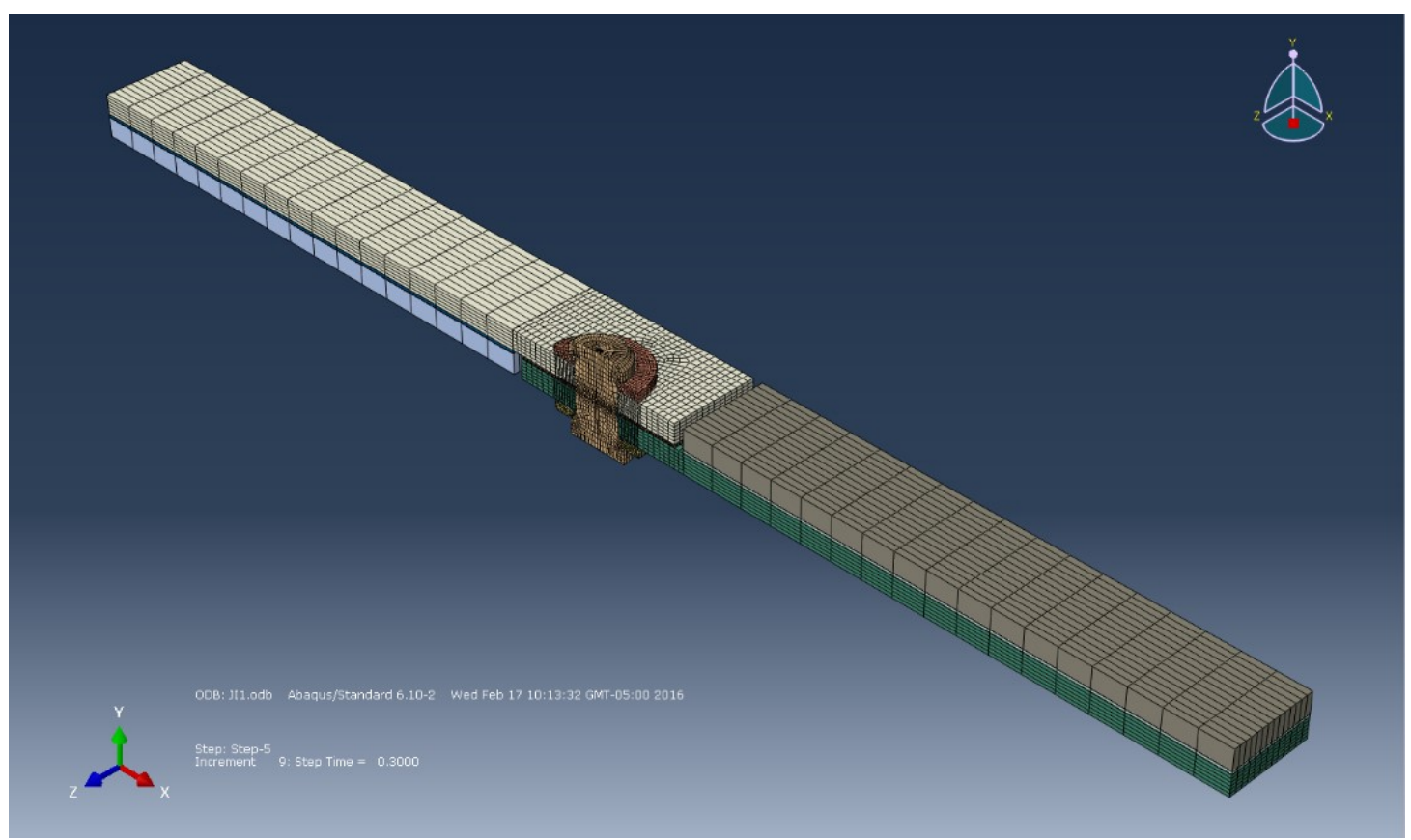

Figure 4.27 The schematic image of the finite element model

Three different test coupons were used for this Test Series.

1) Aluminum bolted joint

2) CFRP bolted/bonded joint with a larger overlap (28 $\mathrm{mm}$ by $48 \mathrm{~mm}$ )

3) CFRP bolted/bonded joint with a smaller overlap ( $28 \mathrm{~mm}$ by $28 \mathrm{~mm}$ ) 
The first test coupon is the aluminum bolted joint. The cold-rolled A1 2024-T3 with $4.83 \mathrm{~mm}$ thickness was used to make the adherends. The aluminum sheet was machined with a milling machine at mechanical and aerospace engineering machine shop at Carleton University. The unique requirement for this bolt to work is to have at least $0.5 \mathrm{~mm}$ spacer between adherends since the bolt was specially designed for the bolted/bonded joints. Fully cured Hysol ${ }^{\circledR}$ EA9361 epoxy was used for the spacer since fully cured epoxy is just a polymer, and it does not adhere to other materials. The average thickness of the spacer was $0.5 \mathrm{~mm}$. The surface friction between the spacer and the adherend was assumed to be same as the surface friction between the adherends. The same material spacers were added to the doublers for matching the overall thickness. The spacers for doublers were bonded using a cyanoacrylate glue. The DIC technique was not performed during the test since this test coupon was used for checking the function of the bolt. The test setup can be seen in Figure 4.28.

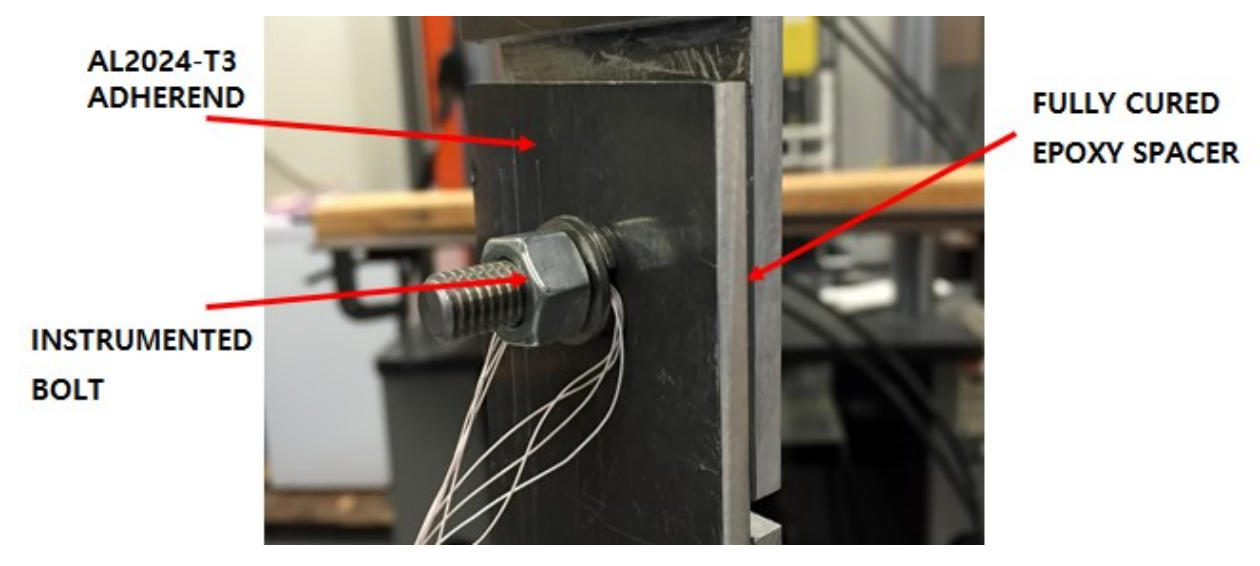

Figure 4.28: First test coupon (bolted joint) with the instrumented bolt

The second test coupon was a CFRP bolted/bonded joint shown in Figure 4.29. The purpose of this trial was to see the response from the instrumented bolt when it 
configured the bolted/bonded joint. The overlap length and width of the joint were 28 $\mathrm{mm}$ by $48 \mathrm{~mm}$ while the original design was to have been $48 \mathrm{~mm}$ by $48 \mathrm{~mm}$ due to incorrect drilling location. The overlap length of $28 \mathrm{~mm}$ was chosen because the wires were put in the adhesive layer to control the adhesive thickness. The maximum length without interfering with the wires was $28 \mathrm{~mm}$. The adhesive thickness was $0.5 \mathrm{~mm}$. Again, the DIC technique was not performed since it was to check the function of the instrumented bolt only.

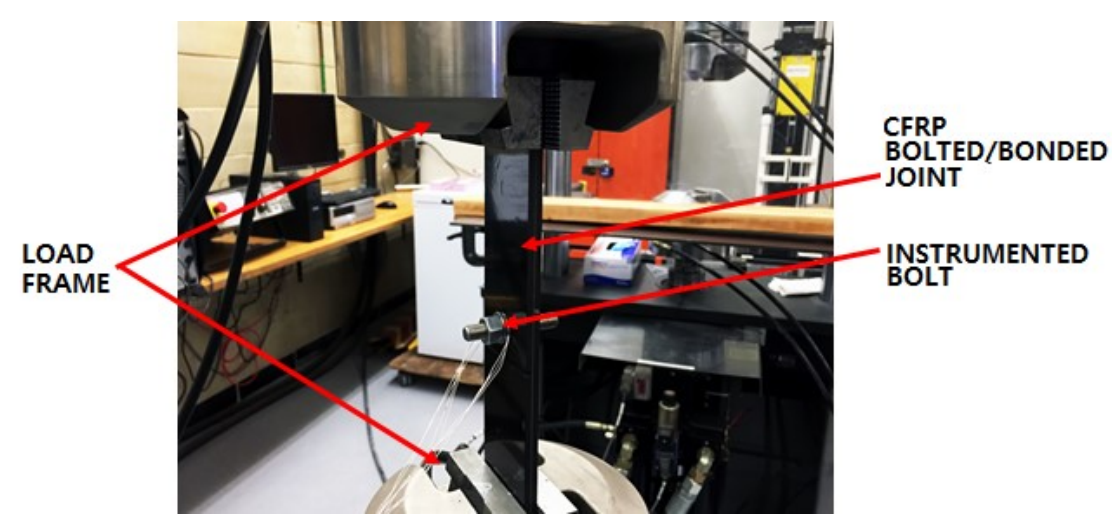

Figure 4.29: Second test coupon (bolted/bonded joint) with the instrumented bolt

The third test coupon was the same CFRP bolted/bonded joint with smaller overlap area. The difference between second and third test coupons can be seen in Figure 4.30. It was determined to reduce the adhesive area since the bolt had a small response when it was installed in the second test coupon. The overlap width and length for this coupon were to have $28 \mathrm{~mm}$ by $28 \mathrm{~mm}$. The DIC technique was attempted in this trial. The DIC technique was attempted to compare the strain pattern from the instrumented bolt to the strain pattern from the DIC technique. One surface was obstructed by the wires 
from the instrumented bolt. Therefore, another surface was used to take pictures for the DIC analysis. Matte white spray paint was used to generate a random speckle pattern.

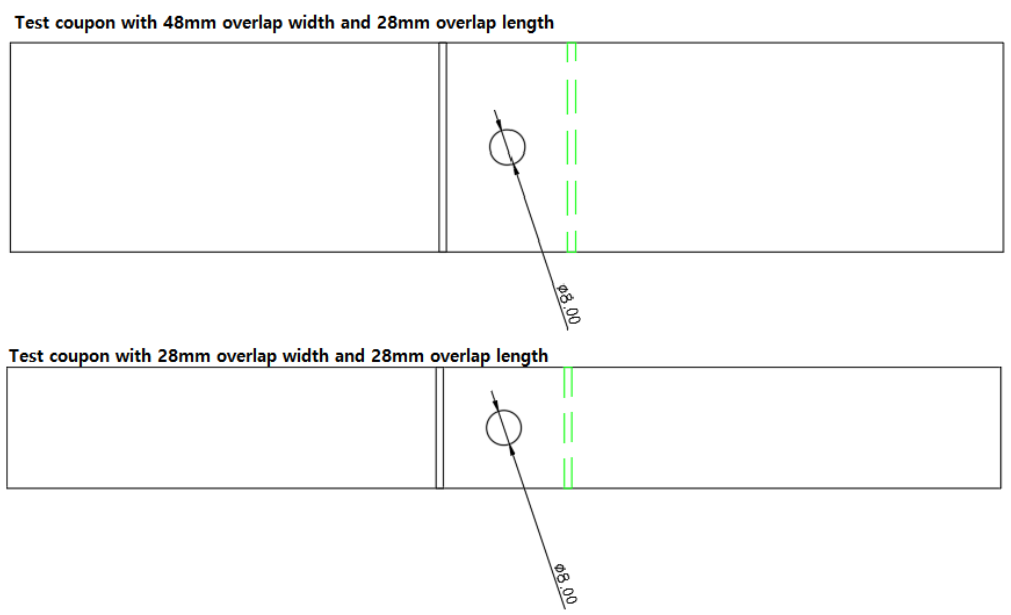

Figure 4.30: Schematic drawing of second and third test coupons

The test did not aim to fail any coupons, which can damage the bolt. Hence, all tests were performed under load-controlled instead of displacement-controlled to avoid inducing the high level of load. Different load setting was applied to each test. For the aluminum bolted joint, the maximum applied load set to $2000 \mathrm{~N}$ with $1000 \mathrm{~N} / \mathrm{min}$ loading rate. The second test had the maximum applied load as $18000 \mathrm{~N}$ with $2000 \mathrm{~N} / \mathrm{min}$ loading rate. The last test had the maximum applied load as $10000 \mathrm{~N}$ with $2000 \mathrm{~N} / \mathrm{min}$. The maximum loads for the second, and the last tests were chosen based on the trial results performed with the same configuration but without the bolt.

Pictures for the DIC analysis were taken every second and saved in an 8-bit bitmap file format. The view of the pictures taken for the analysis is seen in Figure 4.31. 


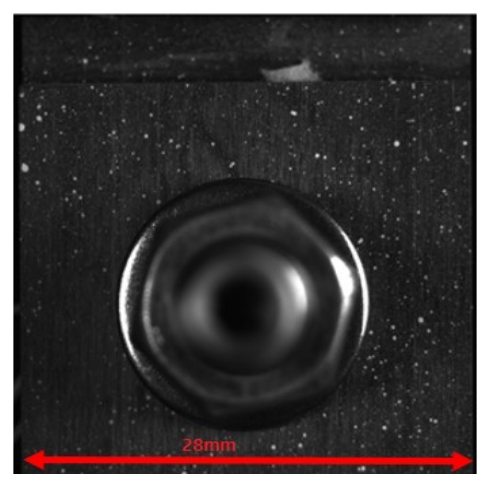

Figure 4.31: Picture of the last test coupon taken by DIC equipment

\subsubsection{TEST SERIES 3 - INVESTIGATION OF THE DIC TECHNIQUE TO MEASURE}

\section{LOAD SHARING IN BOLTED, BONDED AND HYBRID JOINTS}

Test Series 3 was performed after the experimental validation processes were completed. The purpose of this test was to attempt the DIC technique to estimate the load sharing by the bolt in the actual joint configuration. The test was performed by comparing three different joint configurations as shown in Figure 4.32. The surface strain data from the three joint configurations was extracted and compared to each other.

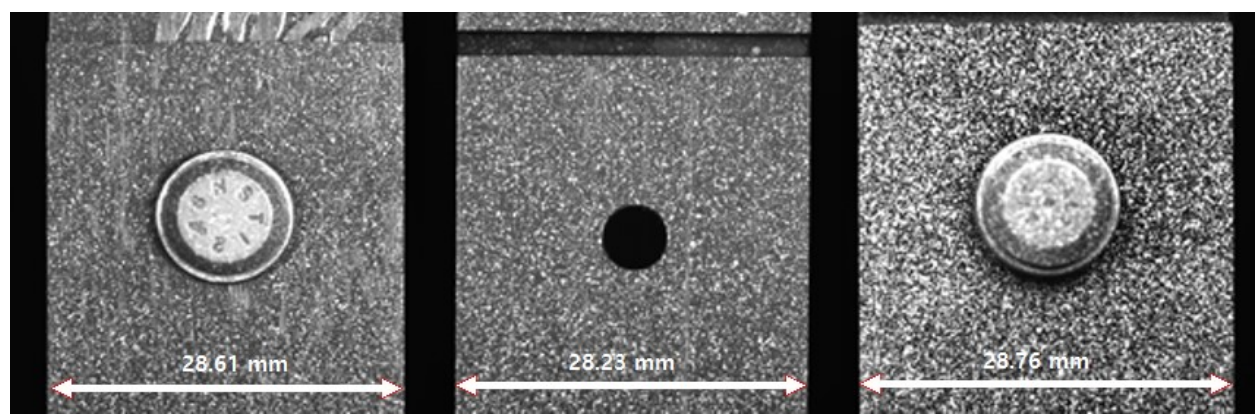

Figure 4.32: Three test coupons with different configurations. (a) bolted joint (b) bonded joint with a hole (c) bolted/bonded joint 
The chosen three configurations were the CFRP bolted joint, the CFRP bonded joint with a hole in the centre, and the CFRP bolted/bonded joint. Each configuration had one test coupon. The bolted joint had a $4.76 \mathrm{~mm} \mathrm{Hi}^{-L_{0}{ }^{\circledR}}{ }^{1}$ titanium pin with protruding shear head and Hi-Lok ${ }^{\circledR}$ titanium collar installed in the centre. The picture can be seen in Figure 4.33. The bolted joint was configured with neat-fit, which means no clearance between the hole and the bolt. Washers were added for filling the gap between the test coupon thickness and the bolt grip length. One washer added to the top and another one on the bottom as can be seen in Figure 4.34.

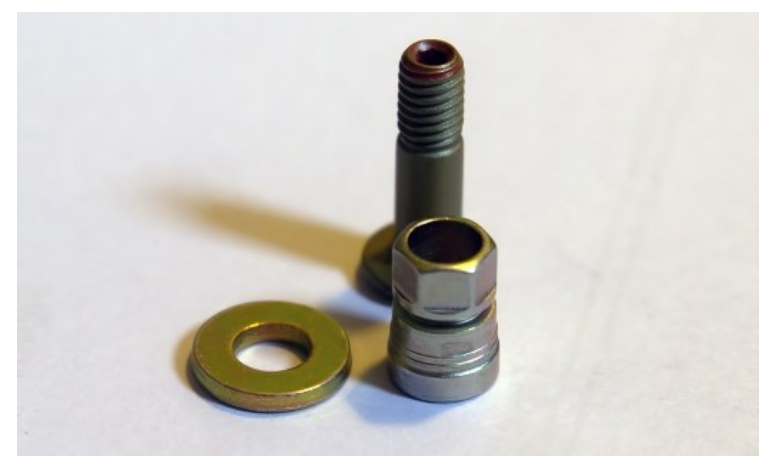

Figure 4.33: Hi-Lok ${ }^{\circledR}$ titanium pin with protruding shear head, Hi-Lok ${ }^{\circledR}$ titanium collar, and washer 


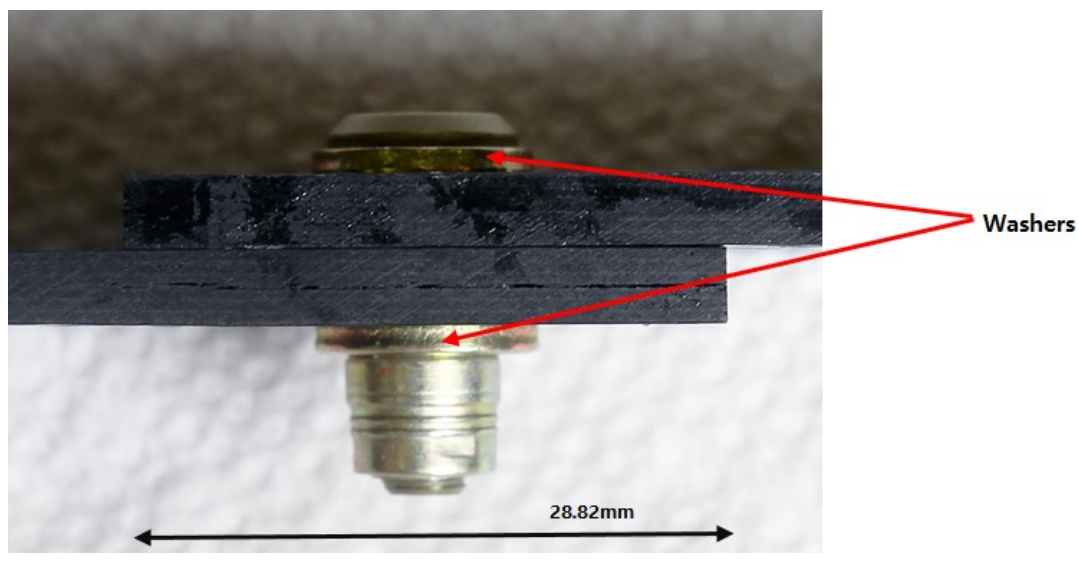

Figure 4.34: Side view of the CFRP bolted joint

The bonded joint had with a $4.76 \mathrm{~mm}$ hole in the centre of the overlap region, but the bolt was not installed. The reason for drilling hole was that the bonded joint without hole shows completely different strain fields, which cannot be compared to other configurations.

The bolted/bonded joint had a $5.26 \mathrm{~mm}$ sleeve fastener in the centre of the overlap instead of the Hi-Lok ${ }^{\circledR}$ fasteners. This sleeve fastener is basically the same $4.76 \mathrm{~mm}$ titanium bolt with a sleeve on it. Similar to the Hi-Lok ${ }^{\circledR}$ pin, there is a special collar for the sleeve fastener as can be seen in Figure 4.35.

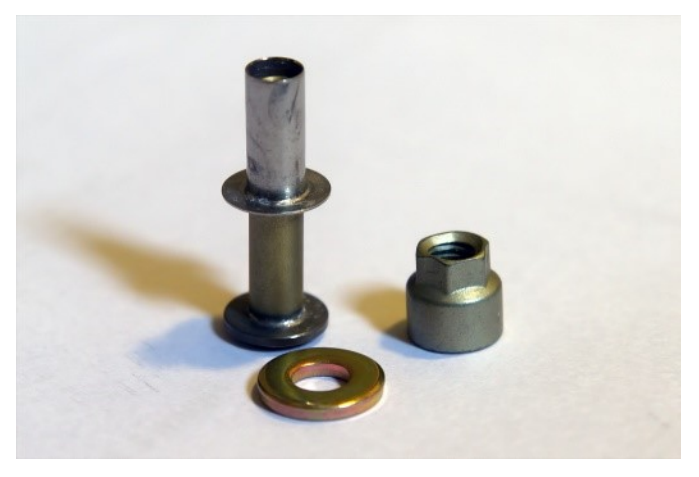

Figure 4.35: Sleeve fastener, its collar, and washer 
Using the sleeve fastener would change the configuration of the bolted joint an interference fit. Two washers were added to the top and one washer to the bottom as shown in Figure 4.36. One additional washer was added because the sleeve fastener grip length was longer than the titanium bolt used in the bolted joint.

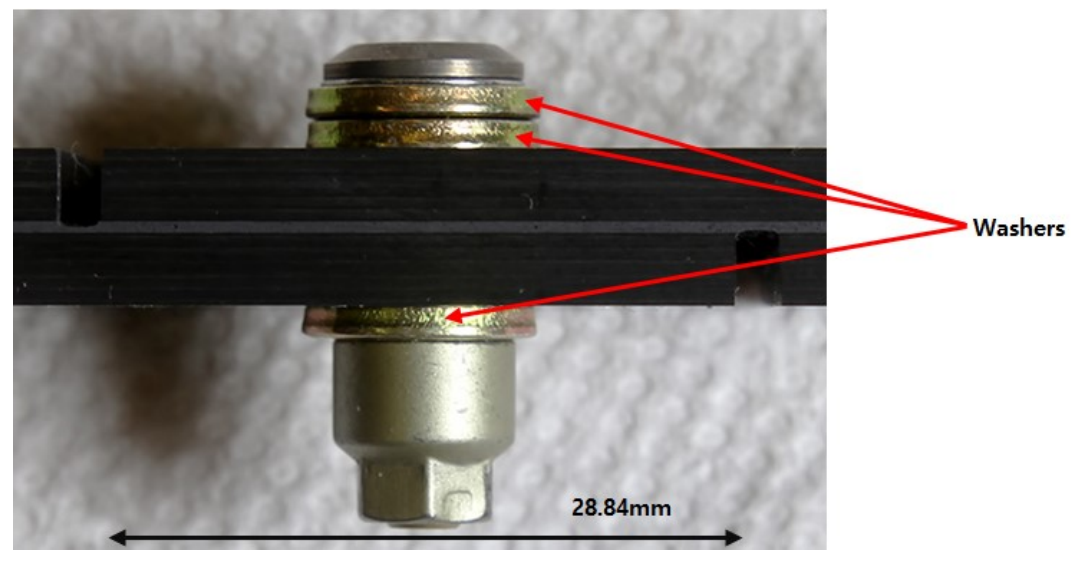

Figure 4.36: Side view of CFRP bolted/bonded joint with sleeve fasteners

All configurations had the $28.56 \mathrm{~mm}$ by $28.56 \mathrm{~mm}$ overlap area with $1 \mathrm{~mm}$ margin of errors. Adhesive thickness for the bonded and the bolted/bonded joints was $0.5 \mathrm{~mm}$. Due to the limitation of quantity, different bolts had to be used for this study. However, these bolts had the same mechanical behaviour in the same bolted/bonded joint configuration. According to the load versus stroke curve in Figure 4.37, the lines between the Hi-Lok ${ }^{\circledR}$ pins and the sleeve fasteners did not have much difference until the failure. Since the test intended to stop before reaching the failure, it was determined to continue regardless of using different bolts. 


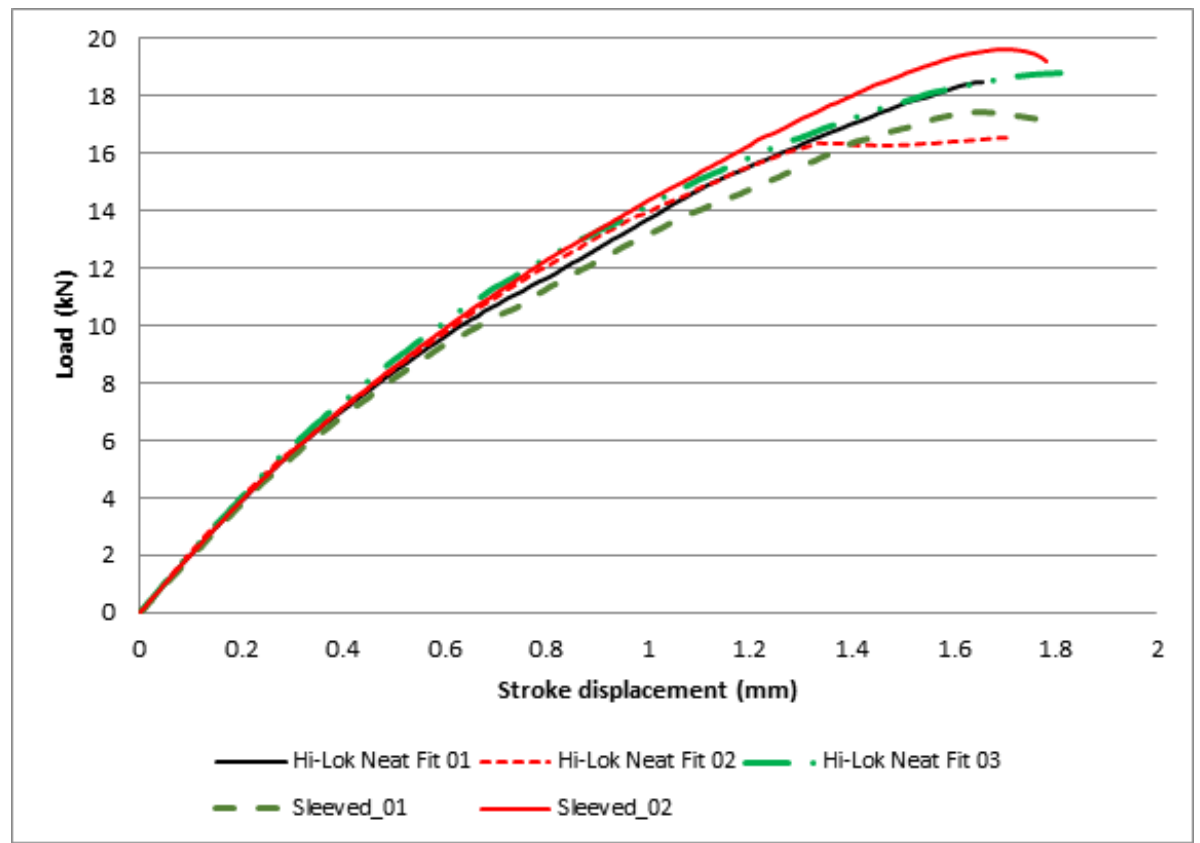

Figure 4.37: Applied load versus stroke curve showing the comparison between Hi-Lok fasteners and sleeve fasteners (modified from Lopez-Cruz, 2016)

According to Figure 4.37, the average failure load was about $18000 \mathrm{~N}$ for the bolted/bonded joints. For this test, it was determined to stop at $12000 \mathrm{~N}$, which is $66 \%$ of the average failure load. There were two reasons for stopping the experiments at the applied load, 12000 N. First, the test coupon will suffer from the significant out-of-plane displacement near the failure load. Since the front surface is interested, too much error will be caused by the out-of-plane displacement. Second, there was a concern about damaging the camera by the debris from the joint because the camera would be placed close to the test coupon. The loading ramp rate was $2000 \mathrm{~N} / \mathrm{min}$. The test was paused every $2000 \mathrm{~N}$ to check the significance of the out-of-plane displacement. The tests were under load-controlled. 
For the DIC technique, a higher number of FPS was also considered, but it was determined to go with 1 FPS due to the limitation of the number of pictures that can be stored. The lens used for this test was Tamron 24-70 mm lens because higher magnification was not necessary, but high clarity in the image was required to obtain the strain values from various locations. All three test coupons were sprayed with white matte spray paint to make random speckle patterns. The pictures were stored in an 8-bit bitmap format. 


\section{Chapter 5: EXPERIMENTAL RESULTS}

This chapter covers the experimental results from three test series. In Test Series 1 , the verification of the equipment prepared for the DIC technique using an aluminum test coupon is discussed. The strain value from the DIC technique was compared to the strain value from the axial extensometer. Test Series 2 discusses the result of the verification of the DIC technique using test coupons with different joint configurations. The instrumented bolt function check was performed with the aluminum bolted joint, and its conclusion is discussed in this chapter. Also, the test result using CFRP bolted/bonded joint for further technique validation is also discussed. Lastly, the test result of the investigation of DIC to measure load sharing in the bolted/bonded joint is presented as obtained from Test Series 3.

\subsection{TEST SERIES 1}

Two data set comparisons were performed for the equipment verification. The first comparison was the displacement comparison between the stroke recorded by the FlexTest SE controller (MTS Systems Co.). and the displacement obtained from the DIC technique. The second comparison was the axial strain $\left(\varepsilon_{y y}\right)$ from the DIC technique was compared to the axial strain $\left(\varepsilon_{y y}\right)$ from the extensometer. Figure 5.1 shows the FOV of the first round and the AOI set for the analysis. 


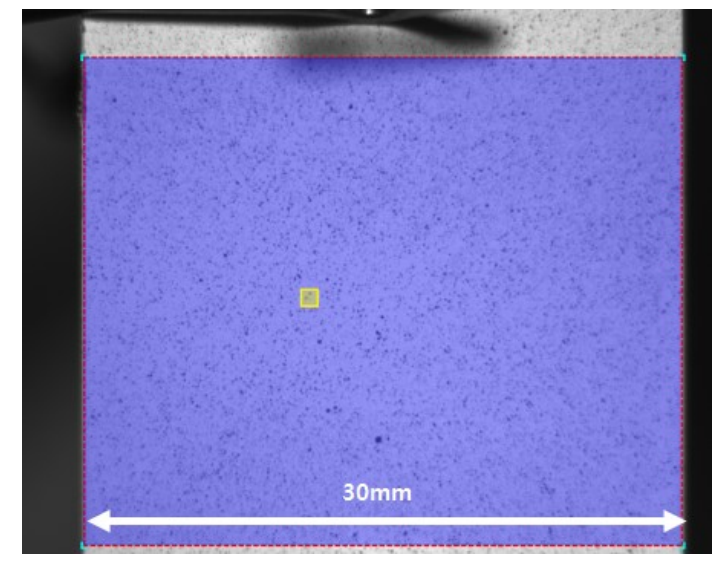

Figure 5.1: The FOV of the aluminum test coupon from the first round and the AOI (blue) and the reference subset (yellow) for the analysis

The specimen covered $85 \%$ of the image frame in horizontal lengthwise. Every 1 pixel was equivalent to $0.02725 \mathrm{~mm}$ in the image. There is no absolute requirement to be met in the pixel-to-actual dimension ratio, but it was checked for the record. Although the AOI for this specimen covered from edge to edge, the strain and displacement results excluded the area near the edge since the analysis yields the result from the relative displacement of subsets as can be seen in Figure 5.2. Near the edge, the relative displacement cannot be obtained because there are not enough subsets near the edge. In general, the software automatically excludes the area near the edge during the analysis. 


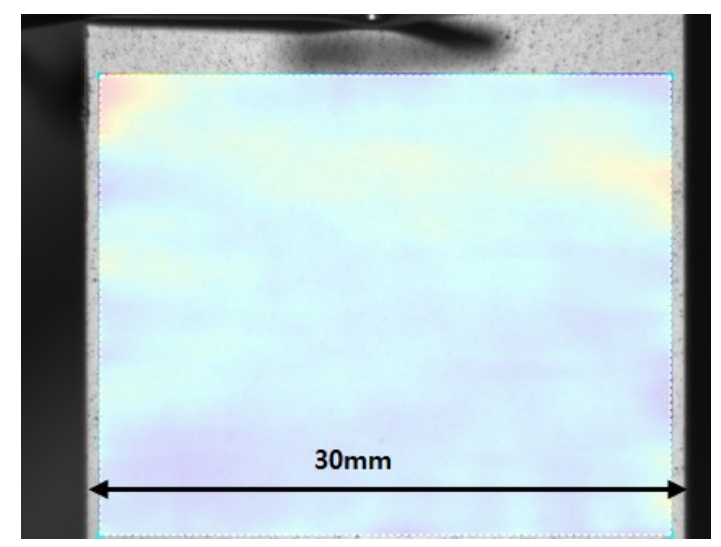

Figure 5.2: Area for measuring average strain $\left(\varepsilon_{y y}\right)$ from the first test

The axial strain $\left(\varepsilon_{y y}\right)$ was extracted from the DIC analysis as the extensometer measures the strain only in this direction. The DIC analysis settings can be found in Table 5.1. All parameters, except parameters explained in the earlier chapter, were left as default or followed the recommendation from the software manual. The strain field is derived from the local polynomial fit. To perform the local polynomial fit, the size of strain window must be set. Virtual Strain Gage (VSG) is schematically shown in Figure 5.3. This is automatically calculated from the other input parameters (MatchID, 2016). 


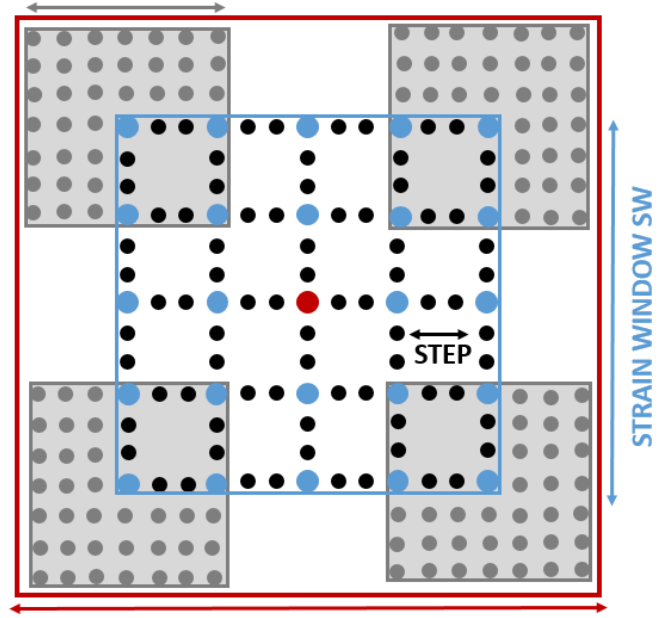

VIRTUAL STRAIN GAUGE VSG

- Strain determination point

Figure 5.3 Schematic image of determining the virtual strain gage size

Table 5.1: DIC analysis setting (Test series 1 with an aluminum test coupon with no extension tube)

\begin{tabular}{|c|c||c|c|}
\hline Parameter & Value & Parameter & Value \\
\hline Subset & 31 pixels & Kernel Size & 5 pixels \\
\hline Step & 7 pixels & Strain & Green-Lagrange \\
\hline Criterion & ZNSSD & Strain Window & 30 pixels \\
\hline Interpolation & BCSPLINE & VSG & 234 pixels \\
\hline Shape Function & Affine & Strain Interpolation & Q4 \\
\hline Prefiltering & Gaussian & & \\
\hline
\end{tabular}

According to the load versus stroke curve recorded by the FlexTest SE controller (MTS Systems Co.) in Figure 5.4, the data increased linearly until the end of the test, which indicates no failure or interruption occurred during the test. 


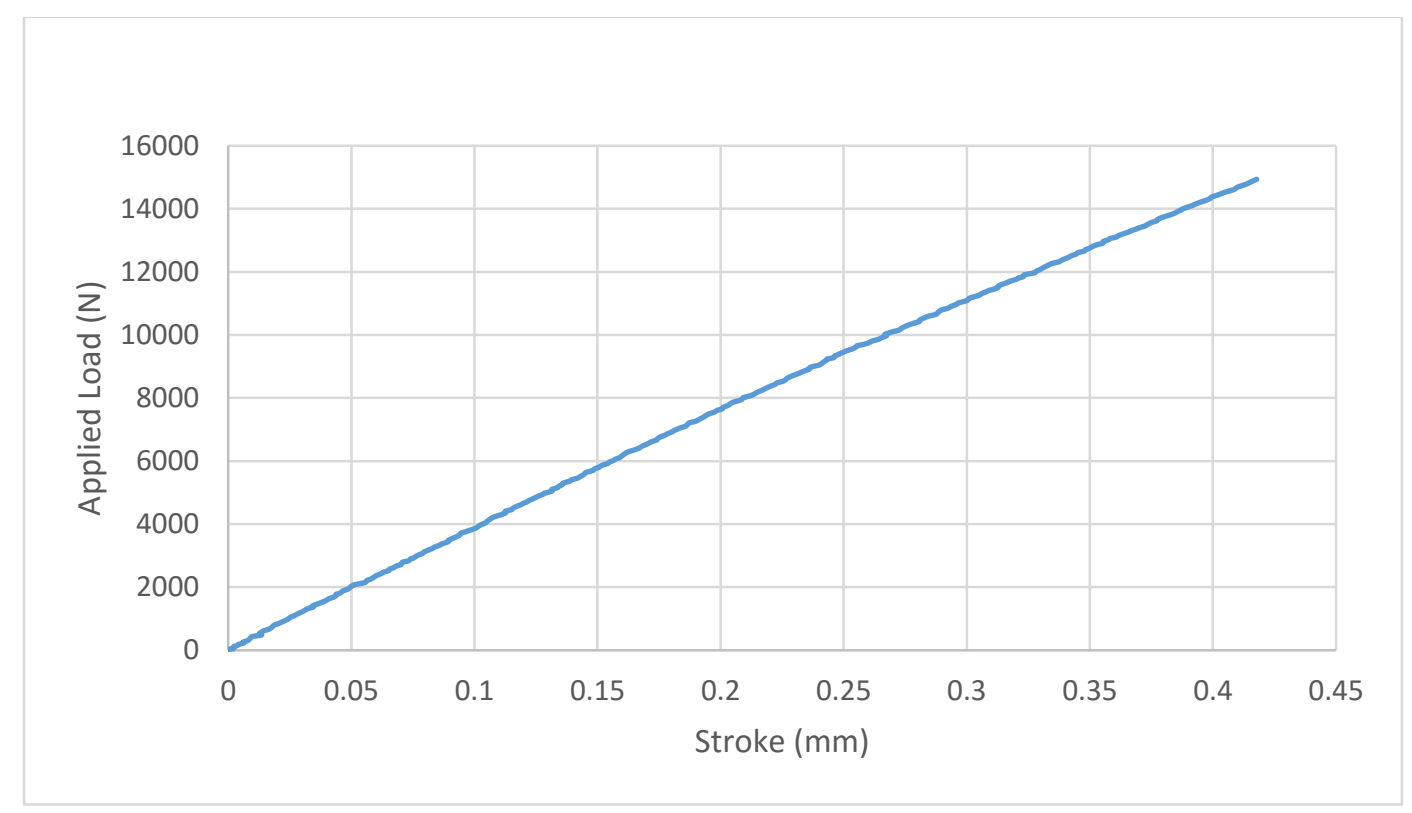

Figure 5.4: Applied load versus stroke curve from the test series 1

Figure 5.5 shows the stroke and the displacement measured from the DIC analysis. The comparison between the stroke and the displacement from the DIC analysis showed that the stroke at 300 seconds is $220 \%$ higher than the displacement obtained from the DIC analysis. The possible reason for the difference is that the grip slippage that occurred during the static tensile test. The specimen was stationary in relation to the grips, but the grips move in relation to the frame. This effect caused an additional displacement, which was recorded together with the actual displacement of the grip. It was not possible to confirm whether the displacement from the DIC analysis was valid because the value of grip slippage could not be obtained to deduct. Hence, the conclusion was made that the direct comparison between displacement data from the DIC analysis and the stroke would be inappropriate to compare. 


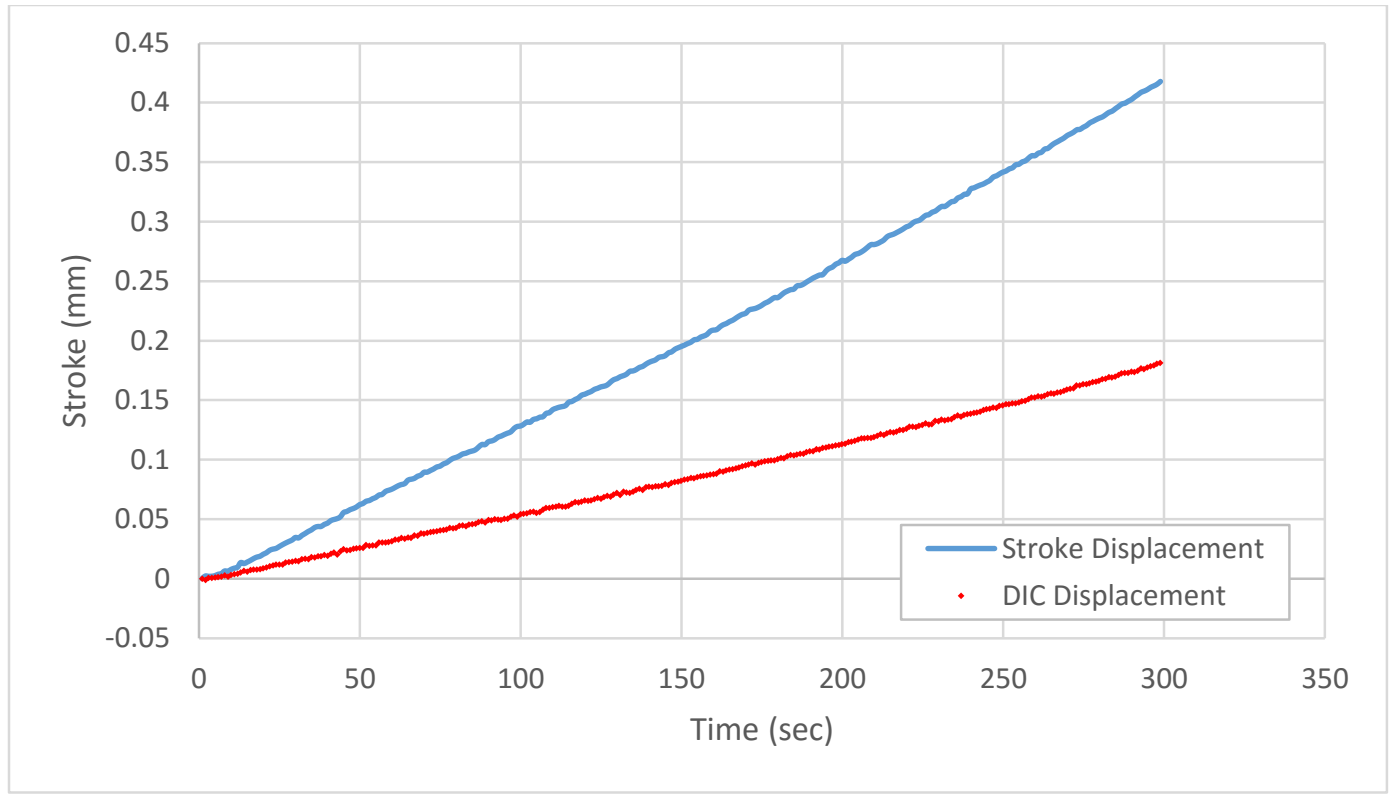

Figure 5.5: Displacement change over time

The axial strain $\left(\varepsilon_{y y}\right)$ had an excellent agreement with the strain data from the extensometer even the distance between the upper limit and the lower limit of the AOI for the DIC analysis was smaller than the gauge length. The average axial strain of the AOI from the DIC analysis was used for the comparison. Figure 5.6 shows the stress axial strain curve obtained from the extensometer and the DIC analysis. Although both data had an excellent overall agreement, there was a minor local disagreement, which could not be explained. The strain data from the extensometer had a steep increase between $170-180$ seconds $(58-63 \mathrm{MPa})$, but this change was not captured either by the DIC analysis or by the load versus stroke curve. It is not clear what caused the jump in the extensometer data. Figure 5.7 shows the percentage difference between two data sets. There were large differences between two data at 30 seconds; then the difference converged to around $2 \%$. Another interesting finding is that the data sets became closer 
after the extensometer experienced the steep increase. Considering that the level of the strain at 30 seconds is 100 microstrain, it may indicate that 100 microstrain is the minimum value that the DIC analysis can accurately detect the strain data.

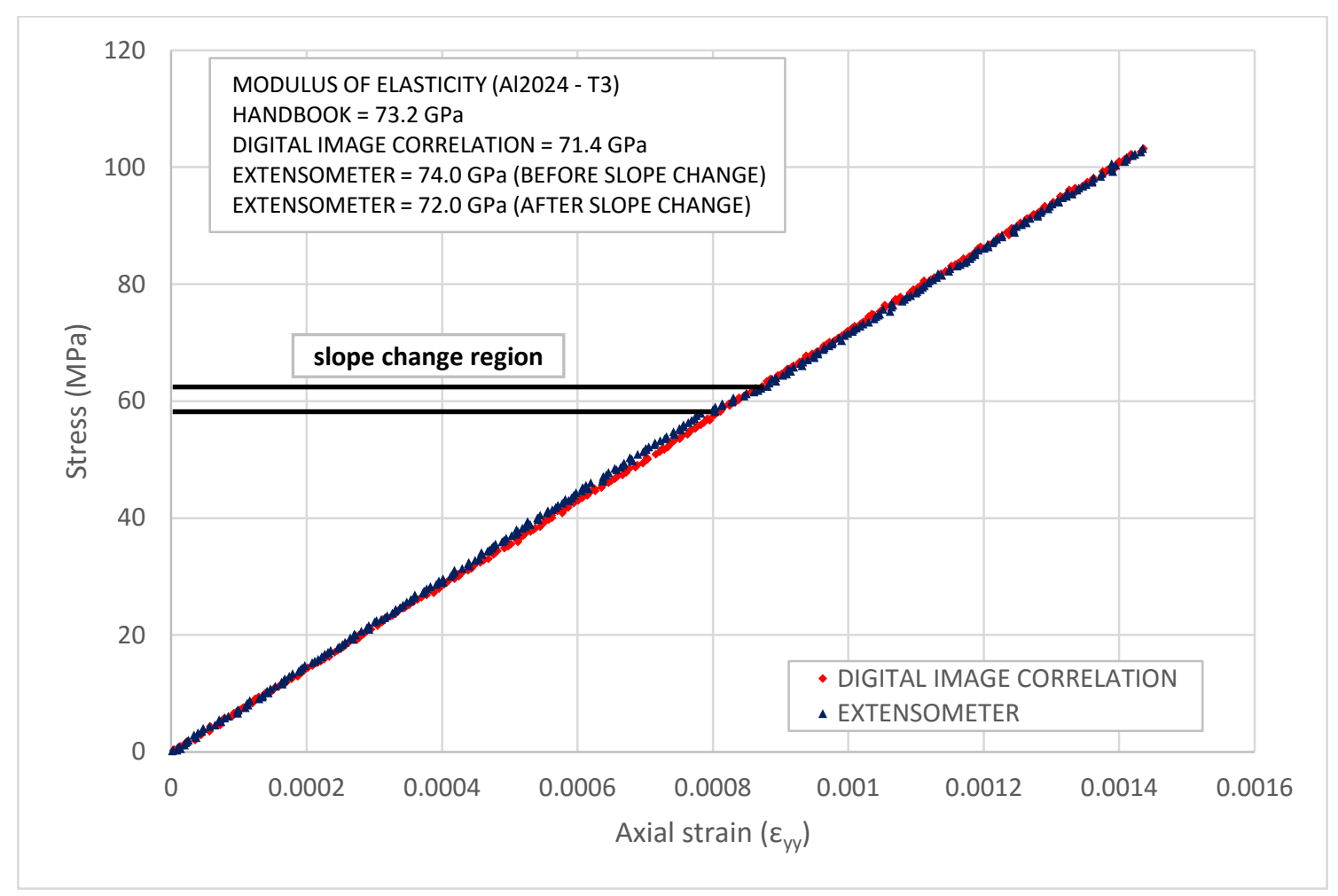

Figure 5.6: Stress versus axial strain curve (aluminum test coupon with no extension tube) 


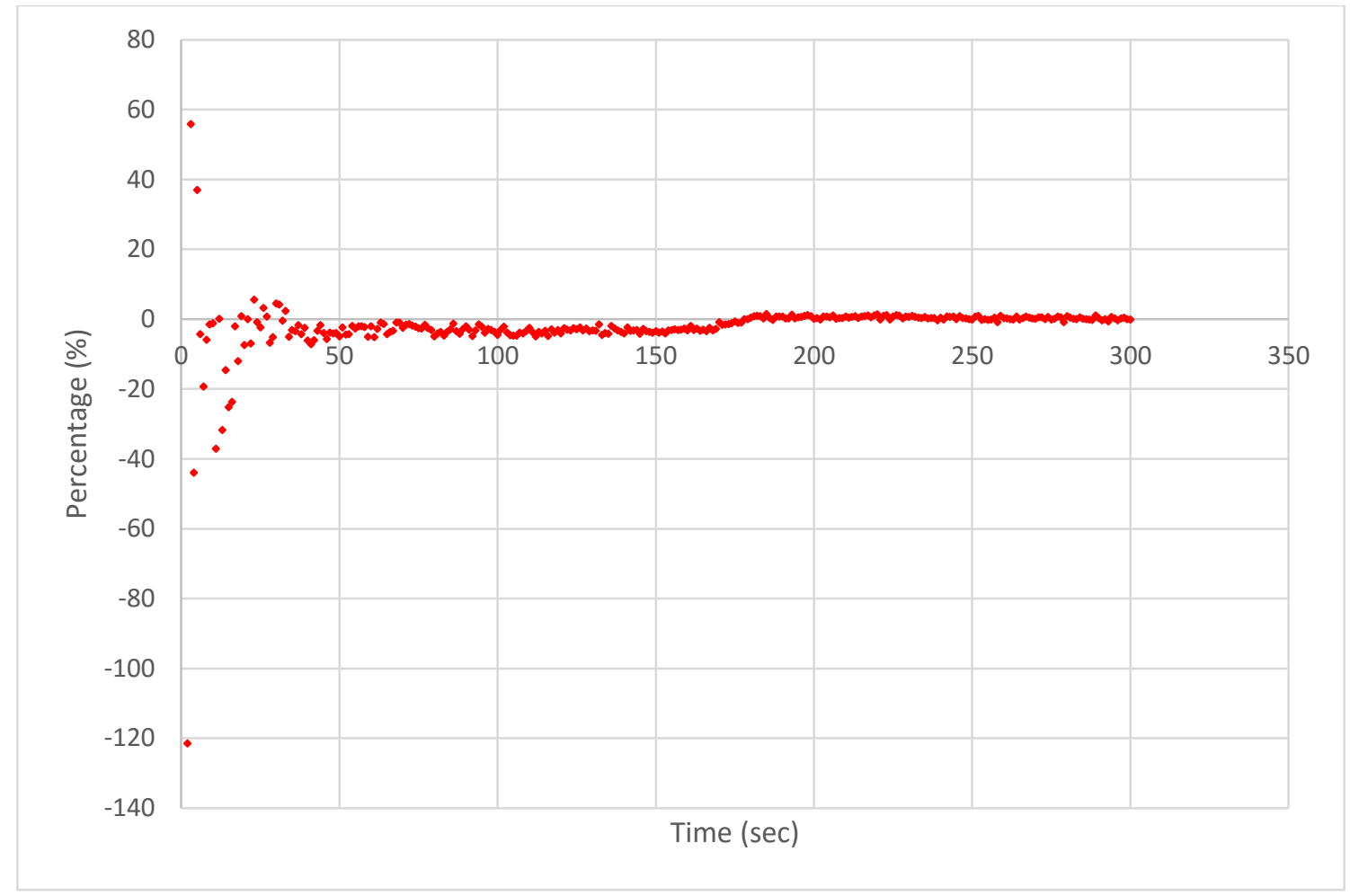

Figure 5.7: The percentage difference between DIC and extensometer data (aluminum test coupon with no extension tube)

The second round was performed after adding the $13 \mathrm{~mm}$ extension tube to the camera system. Again, the purpose of this round was to find out the effect of adding the extension tube on the DIC strain result under the same test condition. The same specimen was used since it did not reach plastic deformation. It was confirmed by the measuring the length of the aluminum test coupon. Adding the extension tube resulted in approximately $30 \%$ magnification in the FOV. Therefore, the FOV covered only about $53 \%$ of the actual specimen horizontally when the camera system was located in the same location. Figure 5.8 shows the approximate size of the FOV of the second round compared to the first trial. The second round had 1 pixel equivalent to $0.01287 \mathrm{~mm}$. It 
means 1 pixel in the second round represents approximately $53 \%$ smaller length than 1 pixel in the first round

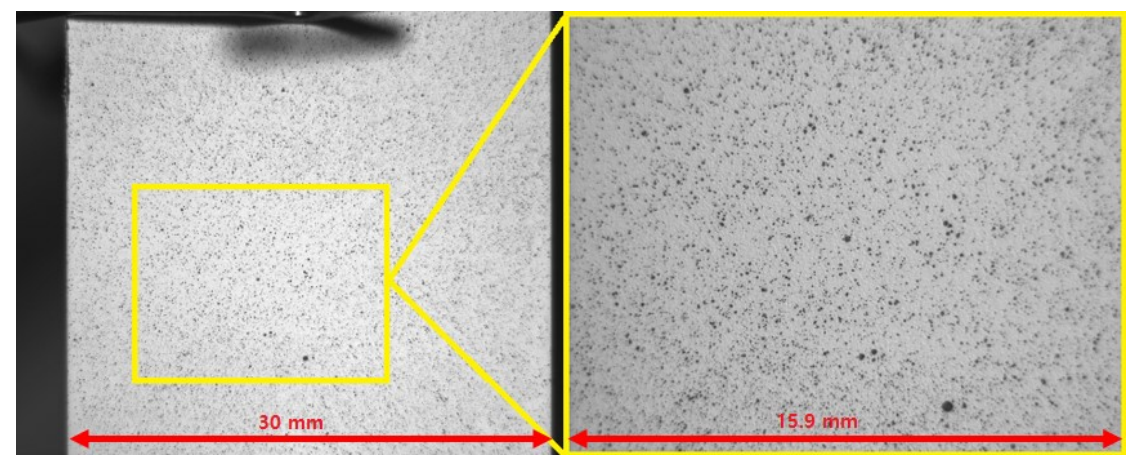

Figure 5.8: Comparison between DIC pictures of the first and the second tests

The AOI for the DIC analysis was narrower than the full FOV because the blurriness around the edges was much worse than the first round. The AOI selection for the second test can be seen in Figure 5.9. Magnification made each speckle pattern look larger than the previous round. At the same time, the finer droplets that could not be observed in the FOV from the first round made denser speckle patterns. These combined effects led to the same setting shown in Table 5.1 from the first round provided a good correlation between the images. 


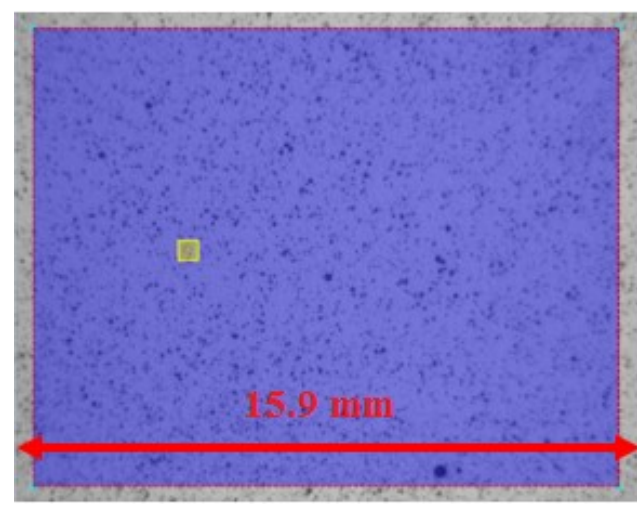

Figure 5.9: the AOI (blue) and the reference subset (yellow) setup of the second test with aluminum test coupon

The average strain was taken from the area selected shown in Figure 5.10. It was found that the effect of changing the equipment was immediately noticeable in the strain result. According to Figure 5.11, the axial strain from the DIC analysis software tends to increase with a higher rate. The probable cause is that the DIC analysis calculates the strain based on the subset displacement result. Further subset movements will lead to higher displacement results ultimately affecting the strain result.

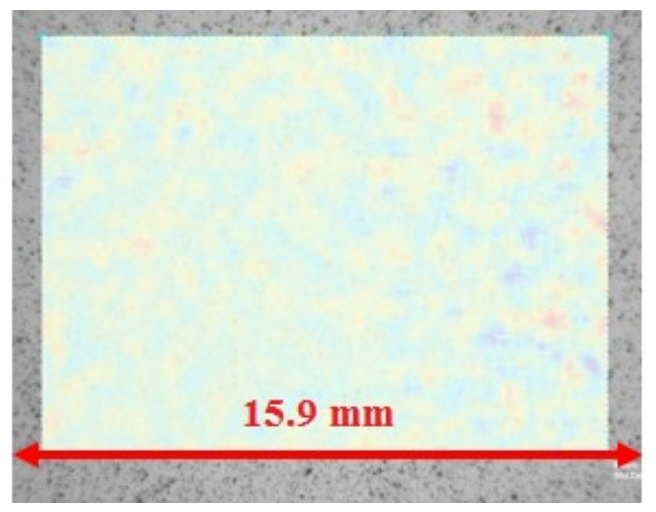

Figure 5.10: Area for measuring average strain $\left(\varepsilon_{y y}\right)$ from the second test 


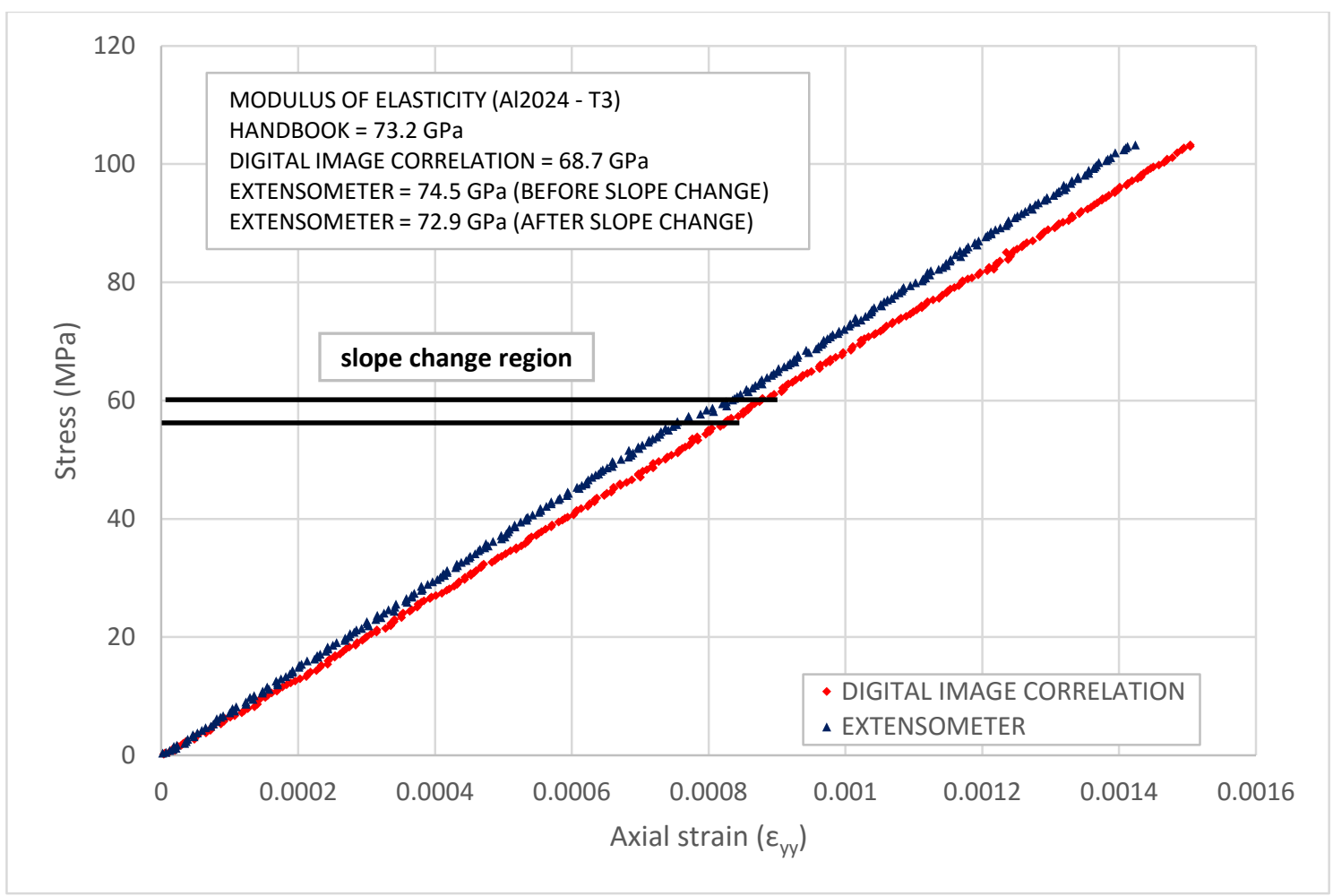

Figure 5.11: Stress versus axial strain curve (aluminum test coupon with $13 \mathrm{~mm}$ extension tube)

The DIC analysis result yielded higher strain than the result from the extensometer, but the difference in axial strain at 300 seconds (105 MPa) was about 100 microstrain according to Figure 5.10. This is only about $7 \%$ higher than the value from the extensometer at 300 seconds according to Figure 5.12. Similar to the result from the first round, the difference in percentage largely scattered until 30 seconds; then it converged to about $10 \%$. The steep increase in the result from the extensometer yielded much smaller percentage difference to about $7 \%$, which the same observed from the first round.

In conclusion, too much magnification may be unnecessary as is can be seen in the observation of the difference between the DIC analysis and the extensometer. 
However, the DIC analysis still provided a good agreement in axial strain with the proven technique. Furthermore, the DIC analysis provided Green-Lagrange strain rather than engineering strain. The difference could be derived from the strain measurements. The comparison between the strain obtained from the DIC analysis and strain obtained from the axial extensometer may not be valid when the large deformation occurs because the discrepancy between these two strain measures increases as the deformation of the material becomes larger.

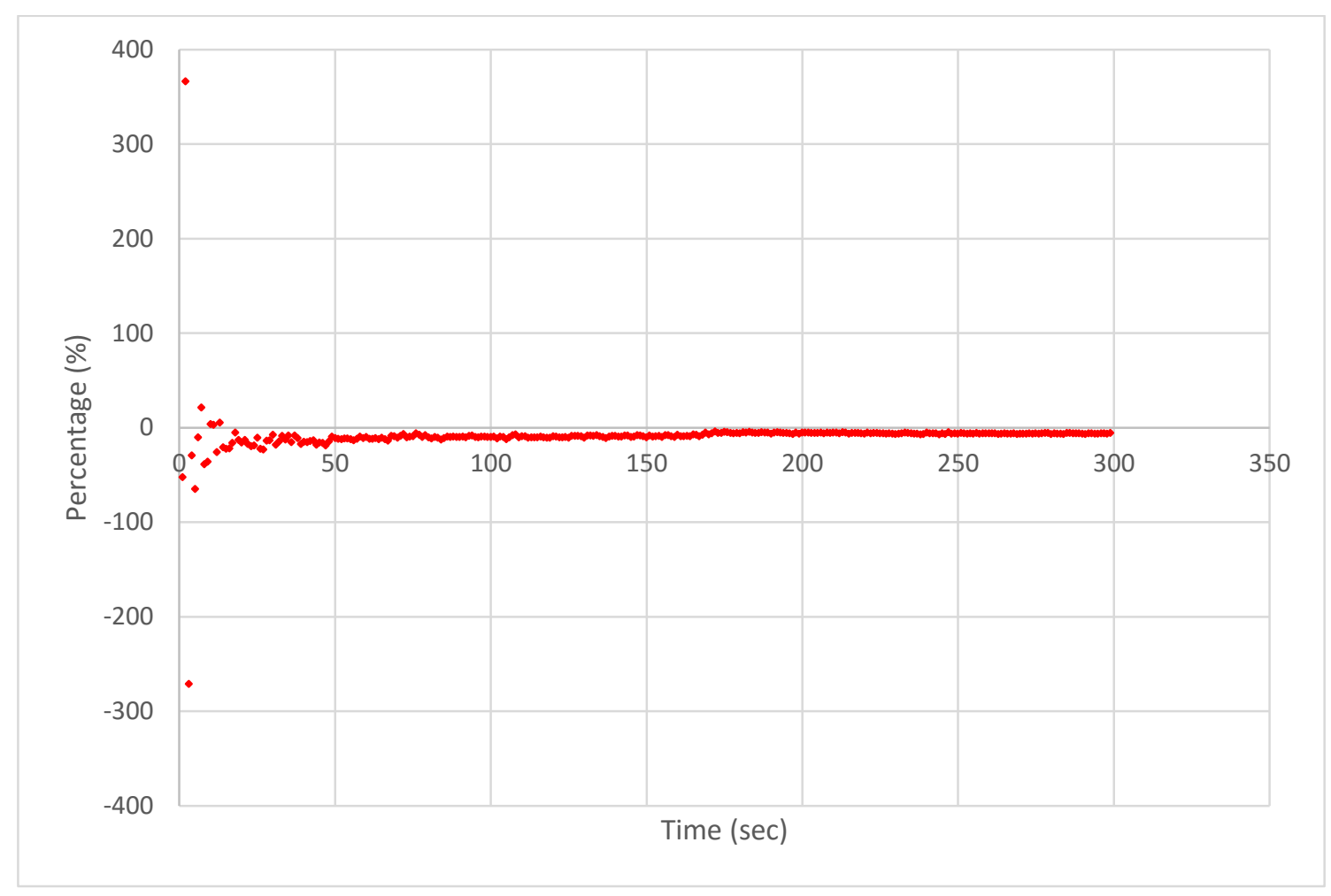

Figure 5.12: The difference between DIC and extensometer data in percentage (aluminum test coupon, the extension tube added to the camera) 


\subsection{TEST SERIES 2}

From the previous test series, it was found that the DIC analysis calculates a good result of axial strain data when the static tensile test is performed with an aluminum alloy test coupon. This test series was performed with the joint, which is more complex than the aluminum test coupon in terms of load transfer mechanism. The goal of the research is to evaluate the DIC technique as a detector of the load transferred by the bolt. Therefore, it was necessary to perform this test with the joint test coupons for validation purposes.

The first stage was to check the function of the instrumented bolt. According to the load versus stroke curve shown in Figure 5.13, there was an abnormal behaviour until the load reached $200 \mathrm{~N}$. It is not clear what actually caused this behaviour in the data since no failure was observed or heard during the test, but a probable cause of the jump could be the clearance between the hole and the bolt. In Figure 5.14, the voltage output from the instrumented bolt also showed that there was a small response until the load reached $200 \mathrm{~N}$. The voltage output showed a steady increase as the load increased past $200 \mathrm{~N}$. 


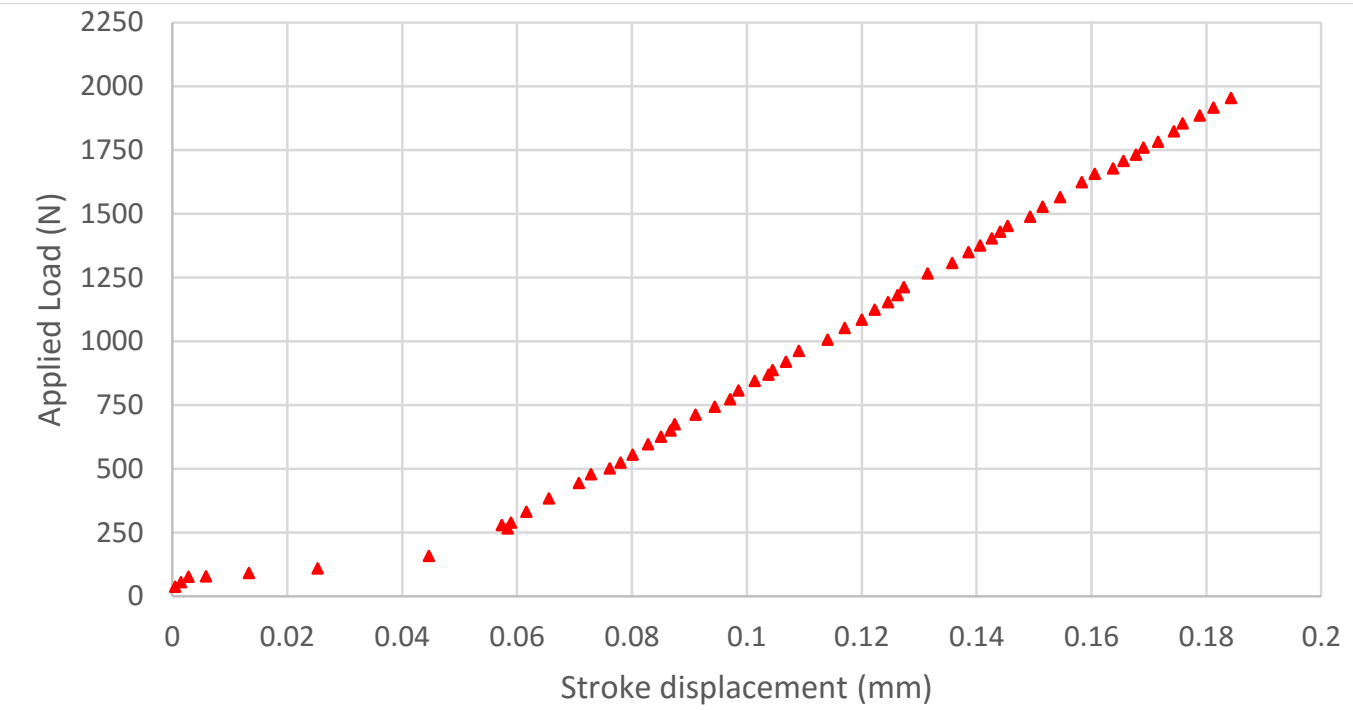

Figure 5.13: Applied load versus stroke curve (aluminum bolted joint)

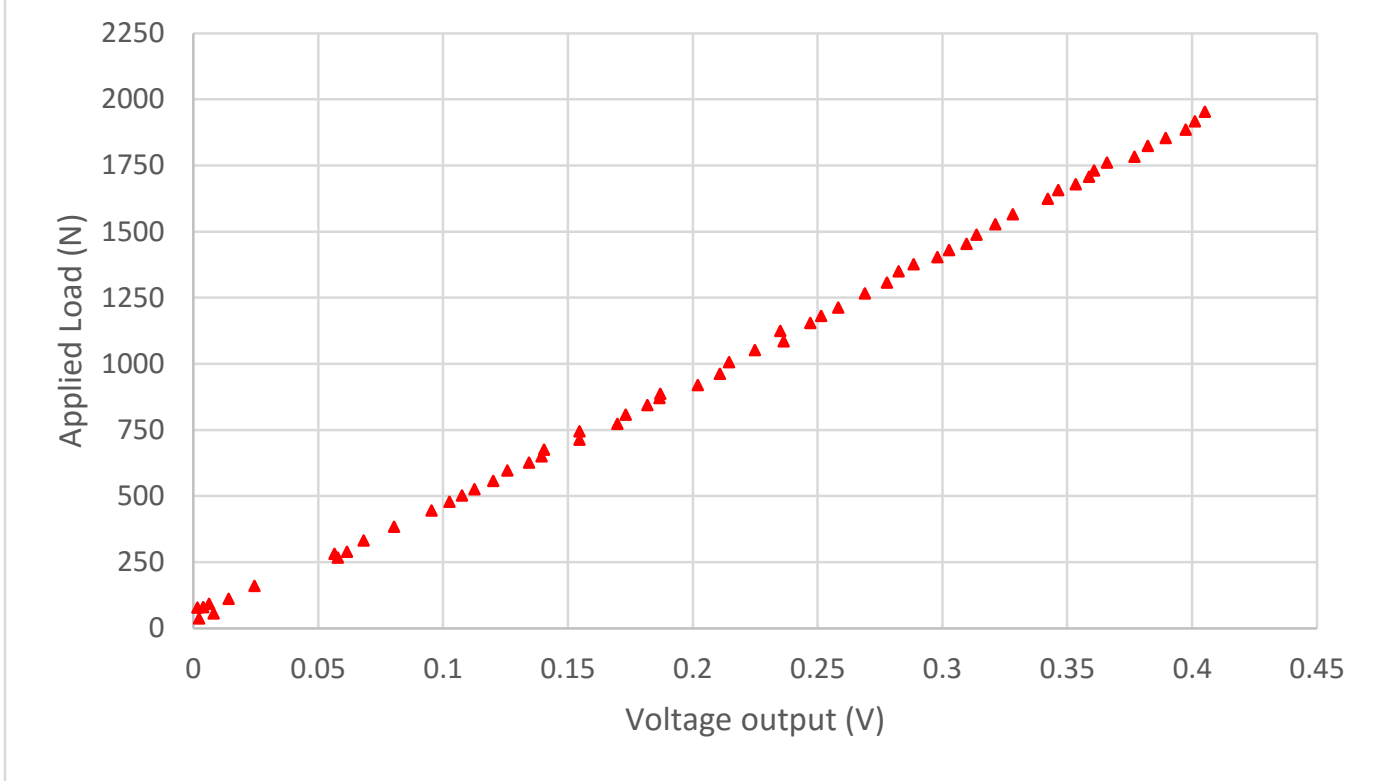

Figure 5.14: Applied load versus voltage output from the instrumented bolt (aluminum bolted joint)

According to Figure 5.15, the shear load to the bolt was obtained from the voltage output. At $2000 \mathrm{~N}$, the shear load caused by the bolt bearing load was about $450 \mathrm{~N}$, which 
is $22.5 \%$ of the total applied load. Since the majority of the load is transferred by the friction at the beginning of the test, the small contribution to the load transfer by the bolt is understandable. Regardless, it was concluded that the bolt was functioning normally and was ready for the next test.

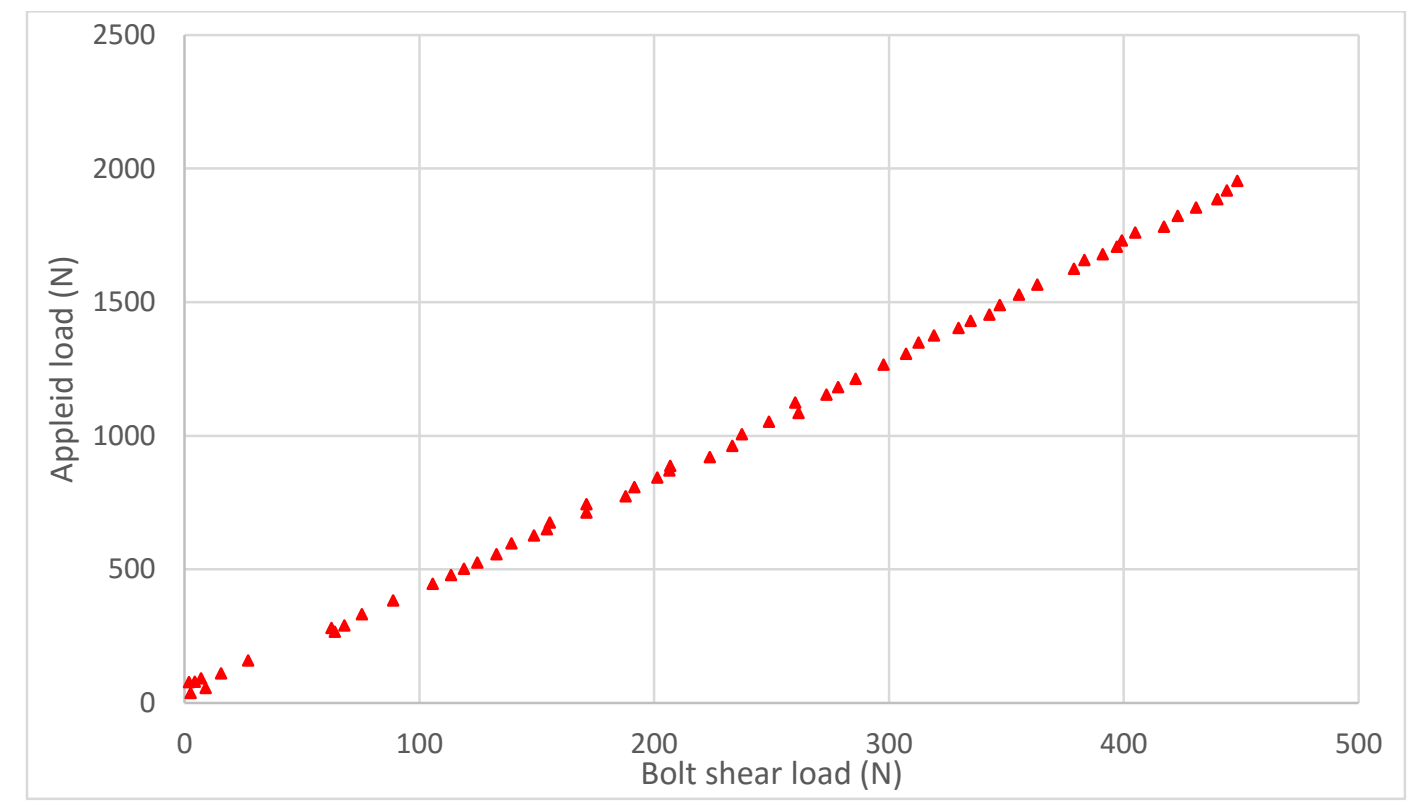

Figure 5.15: Applied load versus bolt shear load in the centre of the bolt (aluminum bolted joint)

After the bolt function check had been completed, the instrumented bolt was installed in the CFRP bolted/bonded joint with a $28 \mathrm{~mm}$ by $48 \mathrm{~mm}$ overlap. An identically configured bonded joint without the bolt installed showed a very small displacement until reaching $18000 \mathrm{~N}$. Therefore, it was determined to pause every 2000 $\mathrm{N}$ for the bolt to respond to small displacement. According to the load versus stroke curve shown in Figure 5.16, the stroke increased linearly until $10000 \mathrm{~N}$; then the stroke increased with a higher rate. However, the voltage output from the instrumented bolt had a contradicting pattern. After passing $4000 \mathrm{~N}$, the voltage output tended to increase 
slower. Furthermore, the shear load in the centre of the bolt was about $200 \mathrm{~N}$ when the applied load was $18000 \mathrm{~N}$ according to Figure 5.17. Therefore, it was decided to attempt another trial with smaller adhesive overlap area, which would increase the contribution of the bolt for the load transfer, before making a conclusion.

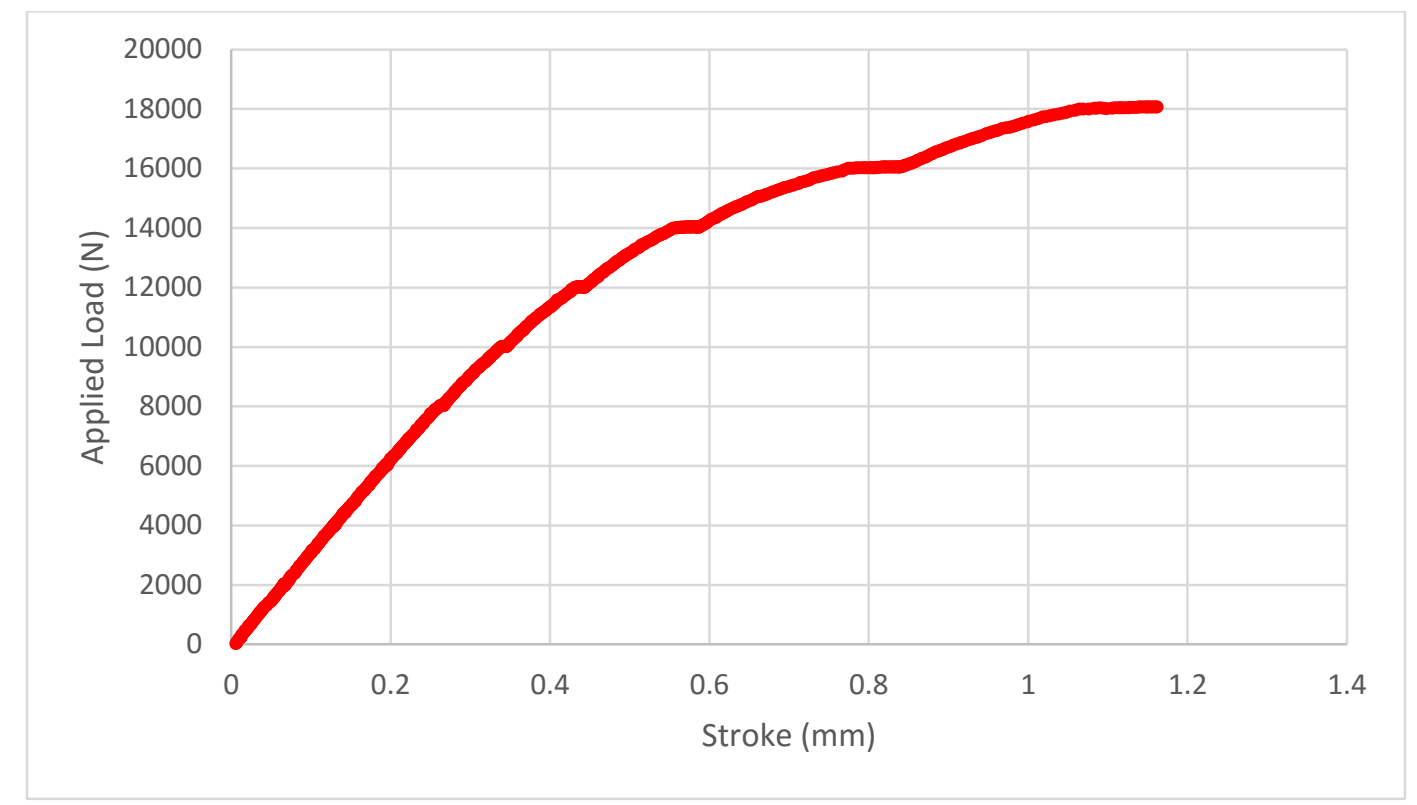

Figure 5.16: Applied load versus stroke curve (CFRP bolted/bonded joint with large overlap area) 


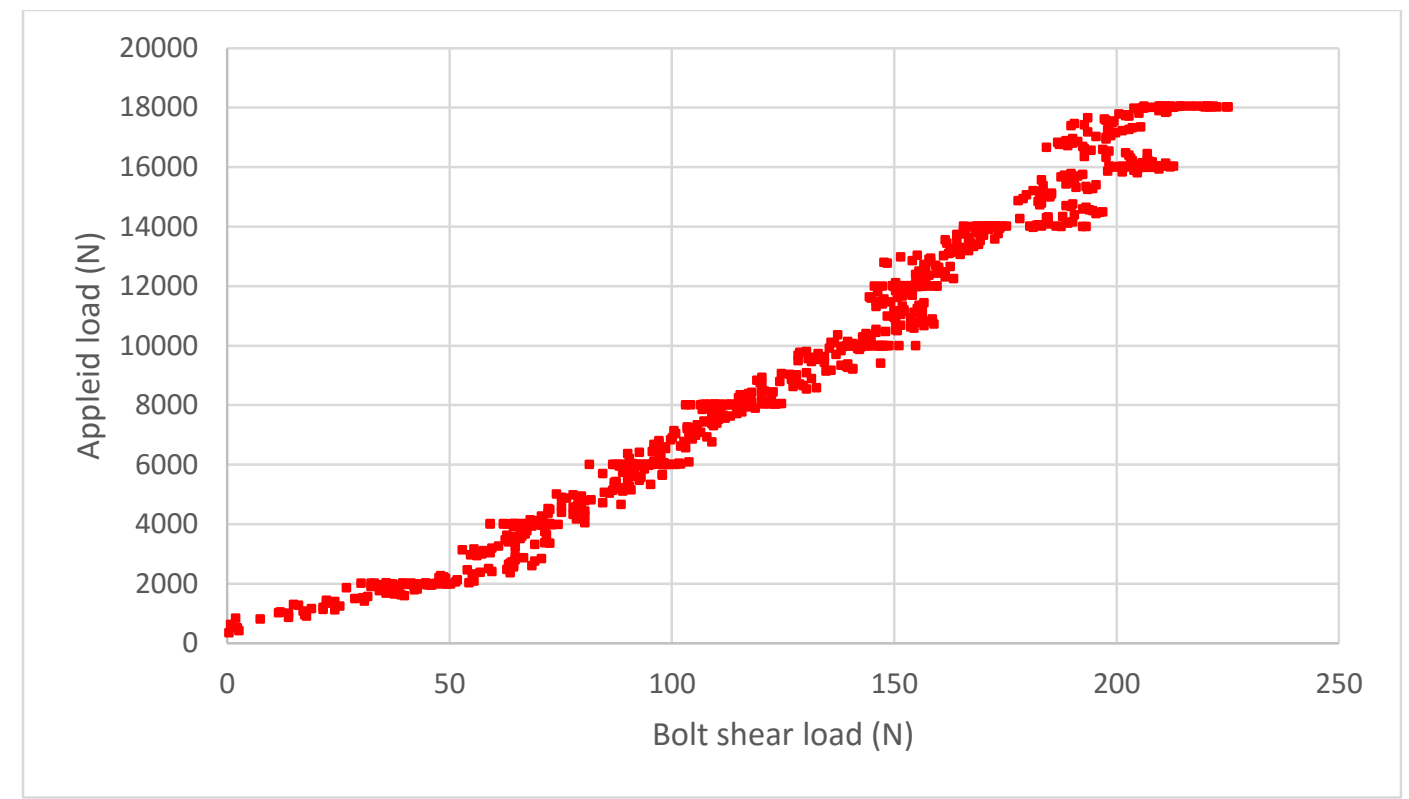

Figure 5.17: Applied load versus bolt shear load in near the centre of the through thickness of the joint (CFRP bolted/bonded joint with large overlap area)

The bolt was installed in the CFRP bolted/bonded joint with a smaller overlap area. According to the load versus stroke curve from the third trial in Figure 5.18, the displacement at $10000 \mathrm{~N}$ was three times higher than the previous test, and the instrumented bolt also had a higher response at the same applied load. As shown in Figure 5.19, the bolt failed to provide acceptable data after the applied load reached 8000 $\mathrm{N}$ because the voltage output reached the upper limit set in the P-3 Strain Indicator (Vishay Co.). Therefore, the data from the instrumented bolt after $8000 \mathrm{~N}$ was unusable. 


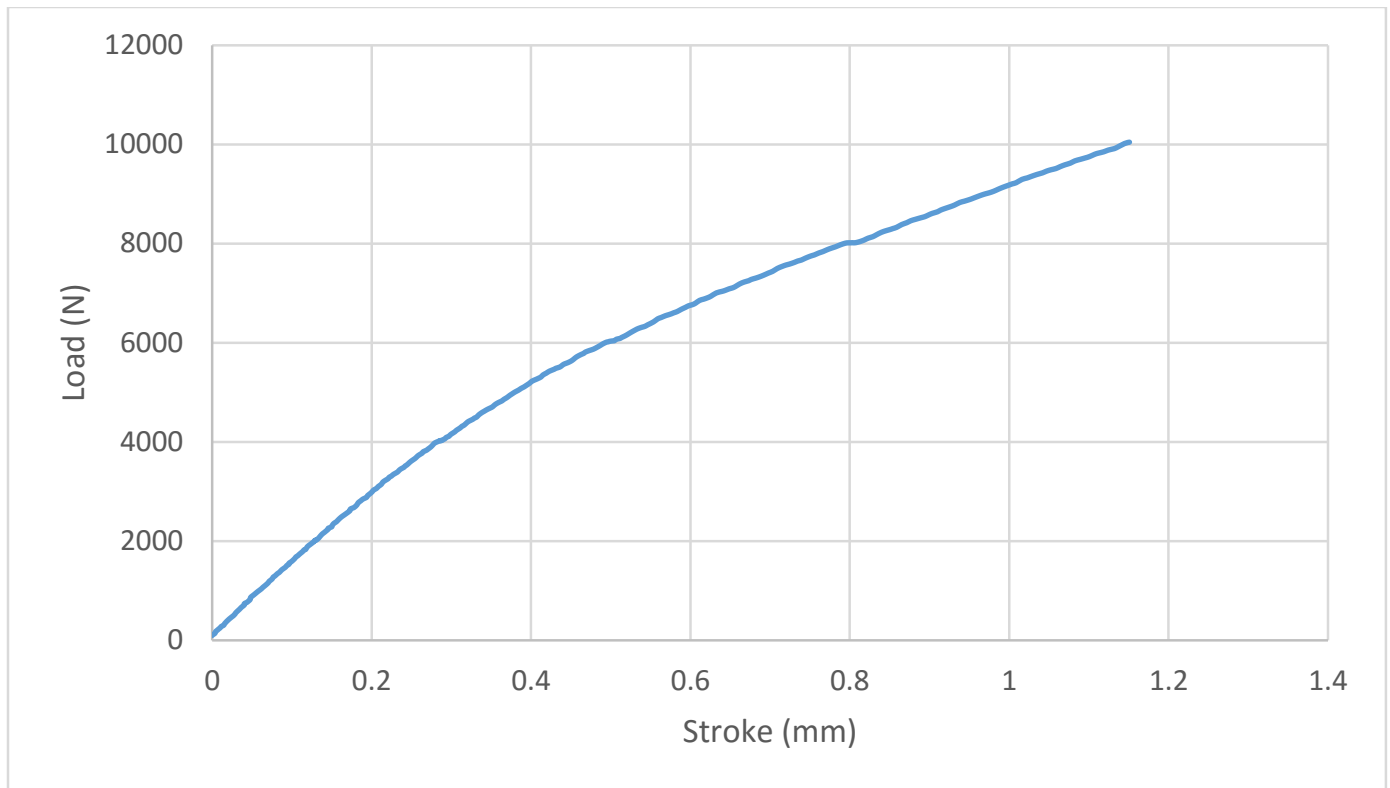

Figure 5.18: Applied load versus stroke curve (bolted/bonded joint with small overlap area)

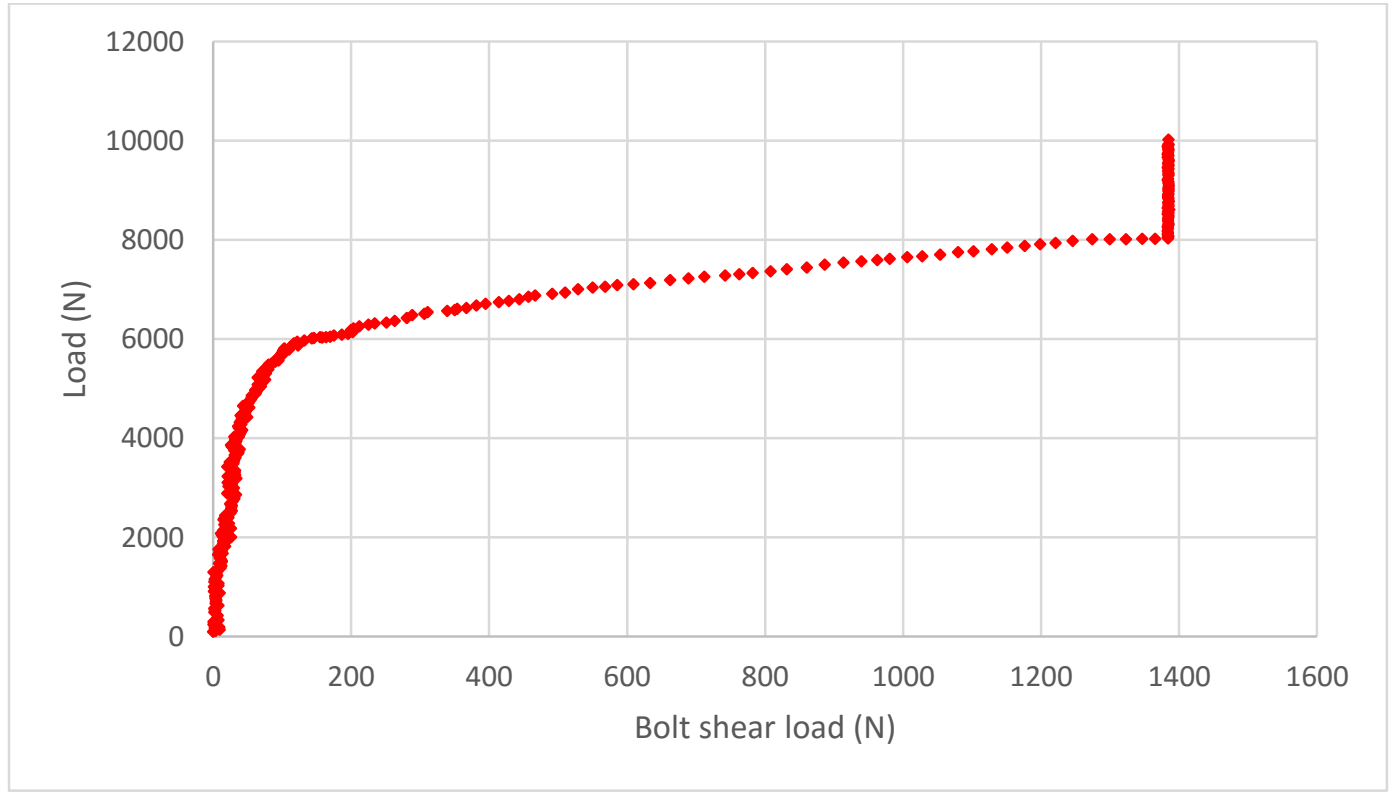

Figure 5.19: Applied load versus bolt shear load in near the centre of the through thickness of the joint (narrower bolted/bonded CFRP joint) 
The shear load in the centre of the bolt obtained from the voltage output is plotted in Figure 5.20. It was found that the load transferred by the bolt at $6000 \mathrm{~N}$ was about $3.3 \%$ of the total applied load; then, it increased to about $17.3 \%$ of the total load at 8000 $\mathrm{N}$. The data from the instrumented bolt indicated higher contributions to the load transfer by the bolt from $6000 \mathrm{~N}$ of the total applied load. Higher contributions by the bolt should affect the surface strains of the adherends.

The DIC technique was attempted to detect this change from the surface of the adherends. Also, results from an FEA model were compared to the experimental shear load from the bolt and the shear strain from the DIC analysis. The FOV and AOI of the specimen were defined as shown in Figure 5.20. The area, where the bolt was located, was removed from the AOI because the bolt was not on the same surface as the adherend surface, which the camera was focused. The DIC analysis was performed with larger subset area than the subset area used in Test Series 1 because the speckle pattern was sparse in the picture, so the large portion of the AOI yielded the low correlation when the smaller subset size was chosen. The rest DIC analysis setting can be found in Table 5.3. 

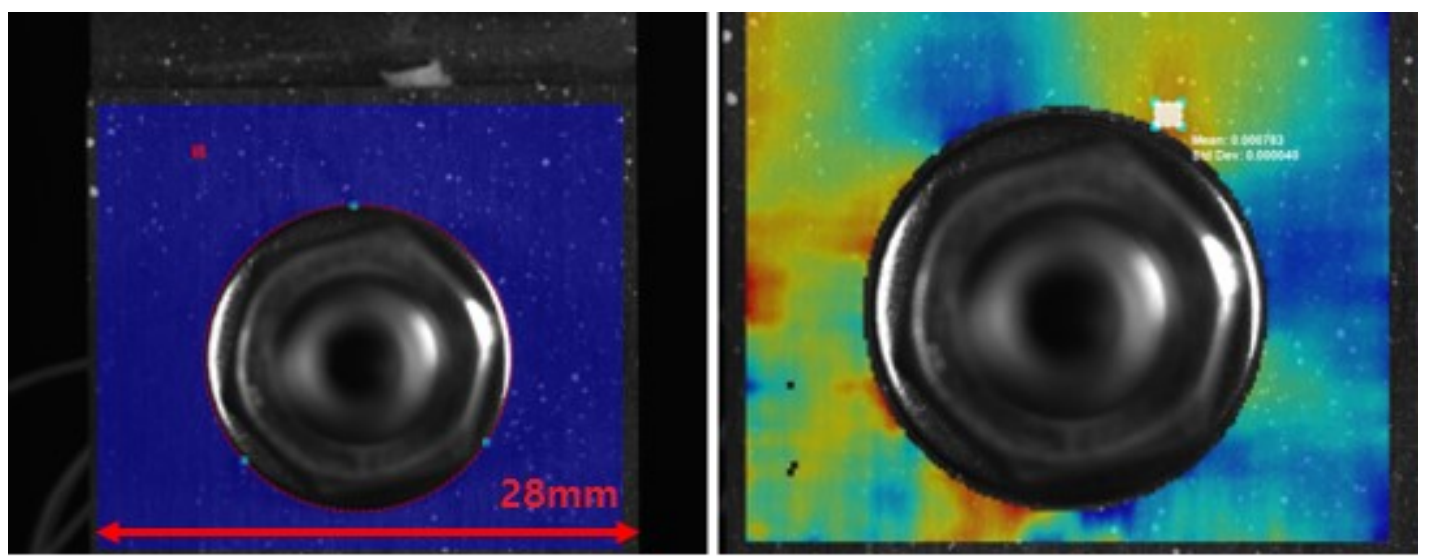

Figure 5.20: FOV and AOI (blue) of the specimen with speckle pattern (left) and the area (white) that the average shear strain values were extracted (right)

Table 5.2: DIC analysis Settings (bolted/bonded joint with a smaller overlap and the instrumented bolt installed)

\begin{tabular}{|c|c||c|c|}
\hline Parameter & Value & Parameter & Value \\
\hline \hline Subset & 39 pixels & Kernel Size & 5 pixels \\
\hline Step & 5 pixels & Strain & Green-Lagrange \\
\hline Criterion & ZNSSD & Strain Window & 35 pixels \\
\hline Interpolation & BCSPLINE & VSG & 189 pixels \\
\hline Shape Function & Affine & Strain Interpolation & Q4 \\
\hline Prefiltering & Gaussian & & \\
\hline
\end{tabular}

Figure 5.20 shows the average surface shear strain of the chosen area, which is marked in the small picture. The area was chosen because it was the location where the highest shear strain occurred. The shear strain $\left(\gamma_{x y}\right)$ was chosen instead of the axial strains because the axial strain $\left(\varepsilon_{x x}\right)$ values were too low and scattered. The axial strain $\left(\varepsilon_{y y}\right)$ values did not show much difference from the shear strain $\left(\gamma_{x y}\right)$. The shear strain was 
taken from the area rather than the point because the strain values from the single point were too scattered to be used. The length of the rectangle was equivalent to $0.5 \mathrm{~mm}$ in the actual specimen. According to Figure 5.21, the DIC analysis captured the surface change due to higher load transfer in the bolt.

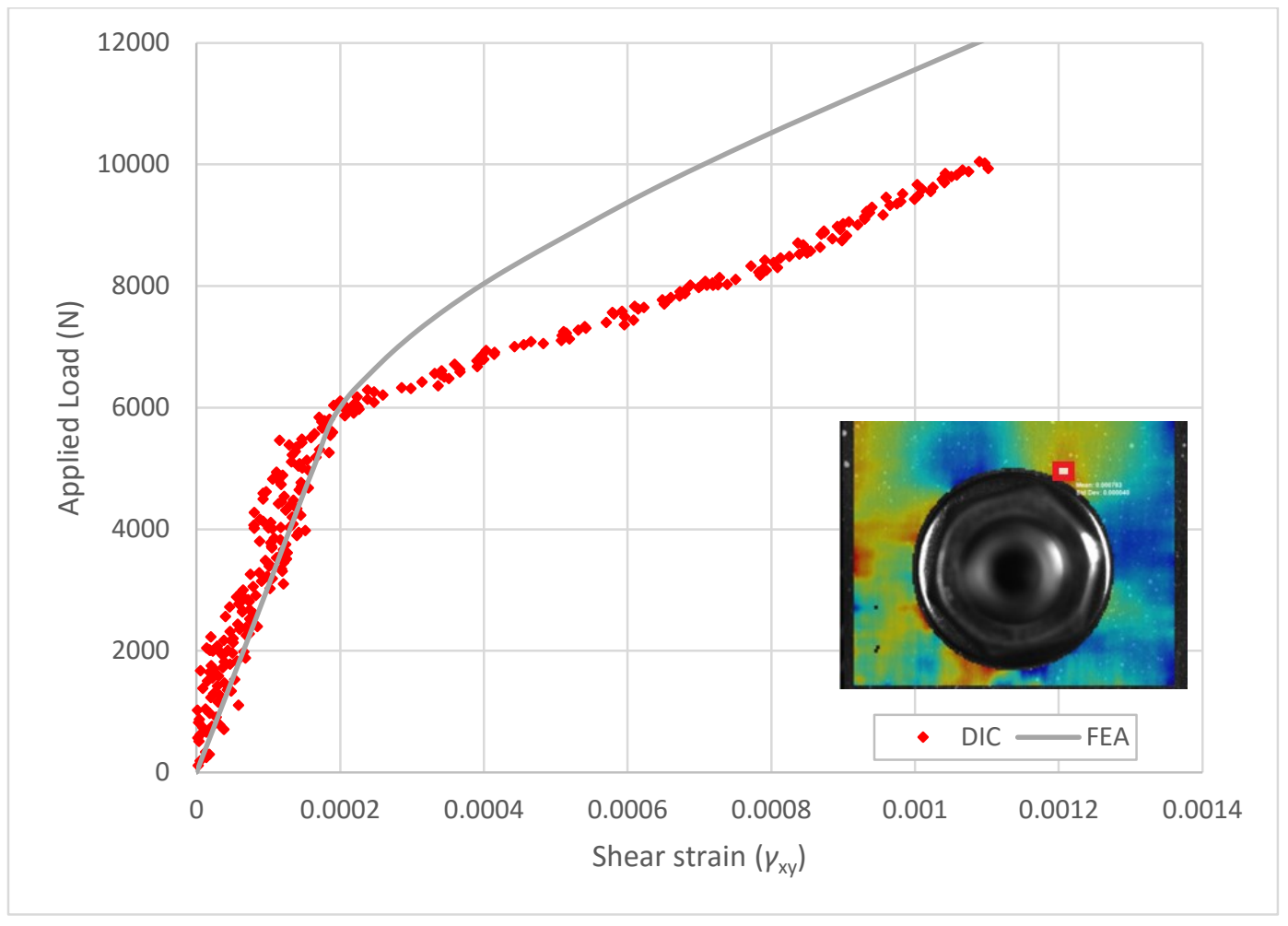

Figure 5.21: Applied load versus surface shear strain from DIC and FEA model

Additionally, both experimental data from DIC and the instrumented bolt were compared to the FEA model. The FEA model strain data was extracted from a single node rather than a small area as with the DIC technique. Furthermore, the FEA model strain was the average shear strain through the thickness of the adherend rather than just the surface strain. Better agreement was found between the DIC analysis and the FEA model when the average shear strain of the adherend from the FEA model was used. 
However, a completely different strain pattern was observed when the surface shear strain from the FEA model was compared. It is understandable since the DIC analysis shows the strain field already affected by the adherend while the FEA model calculates the shear strain of each ply independently. The shear load in the centre of the instrumented bolt was compared to the shear load in the centre of the bolt in the FEA model.

As can be seen in Figure 5.22, both sets of the data showed that the bolt transfers only a small portion of the applied load until 6000 N. A good agreement was found until this point. However, the difference becomes larger after $6000 \mathrm{~N}$, where the bolt starts to act as a major load path in addition to the adhesive. One possible reason for the gap is that this trial was performed with a load-controlled mode, and the load increased slowly, but the FEA model used the material properties obtained from the test based on the ASTM standard D5656, which was performed with a displacement-controlled mode where the load increased more rapidly. Since the paste adhesive, Hysol ${ }^{\circledR}$ EA9361, has a viscoelastic behaviour, the loading rate would cause different material behaviour. Therefore, the different behaviour in the adhesive layer could be the primary reason for the gap between two sets of the data. 


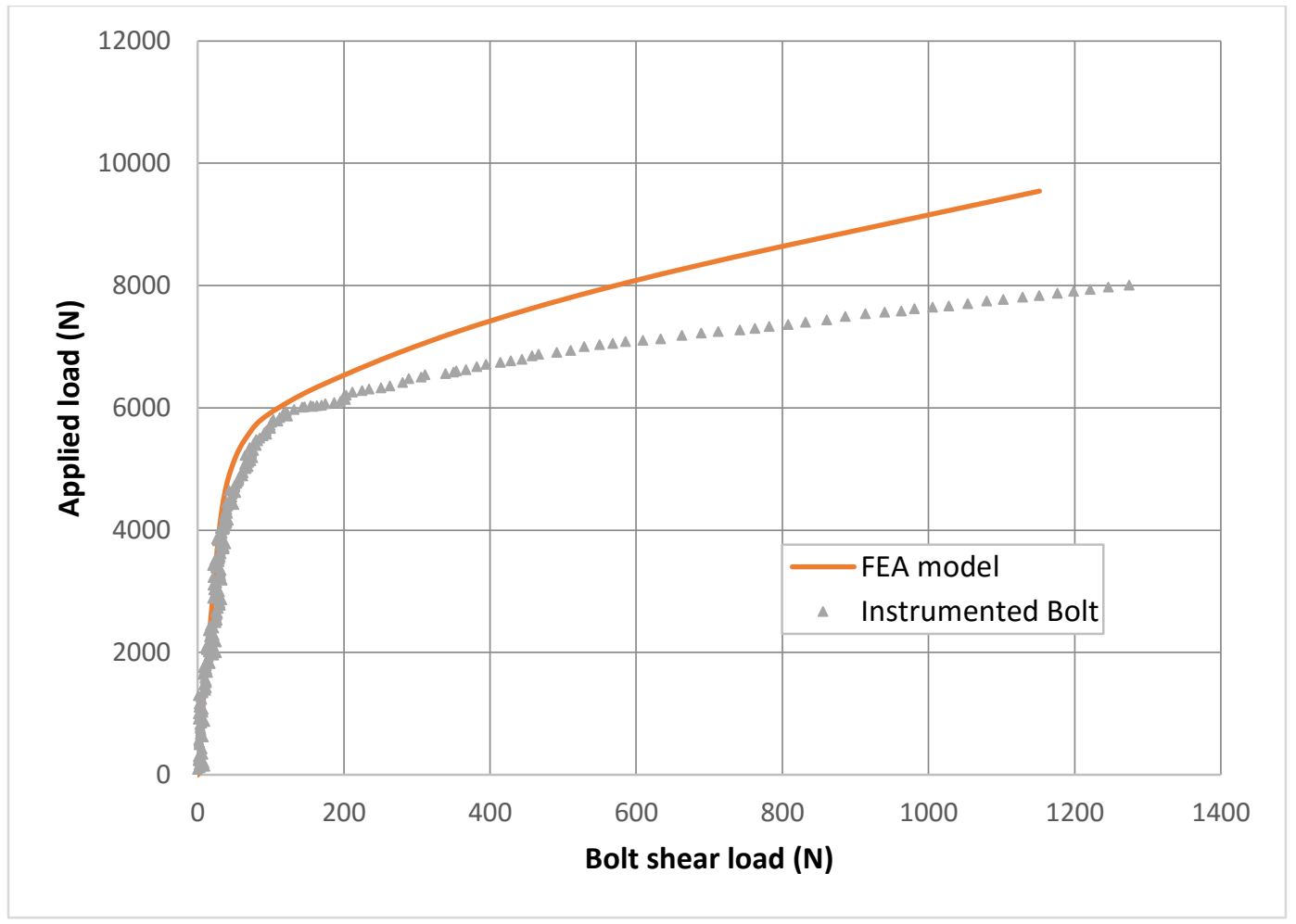

Figure 5.22: Applied load versus the shear load in the centre of the bolt

The data between the FEA model and the DIC analysis also showed a similar pattern to the pattern observed from Figure 5.21. Good agreement was found until 6000 $\mathrm{N}$, where the bolt had a minor role. However, the gap between two data sets became larger after $6000 \mathrm{~N}$. The probable cause of the gap between these two data sets is also a different behaviour of the adhesive layer. According to Figure 5.22, the shear load in the centre of the bolt from the instrumented bolt was much higher than the shear load in the centre of the bolt from the FEA model at the same applied load level. In other words, the adhesive deformation was much higher in the experiment. Therefore, the overall displacement of the adherend should be much higher due to higher deformation of the adhesive, which would yield higher surface strain. Another possible reason is the 
limitation of 2D-DIC. The out-of-plane displacement is inevitable to the single-lap joint configuration due to load path eccentricity as shown in Figure 5.23. The phenomenon causes errors in calculating the displacement and strain fields (Sutton et al., 2008). Lastly, the DIC parameters yield different strain values for the same region. For example, the shear strain plot shift was observed when the different strain window parameter was used. This can be seen in Figure 5.24. Also, Lava et al. (2010) showed that systemic errors can cause the errors in the strain with the range between 50 microstrain and thousands microstrain depending on the DIC analysis parameters (Lava et al., 2010). Assuming all three possible reasons affected the result simultaneously, it is reasonable to conclude the difference is within the margin of errors.

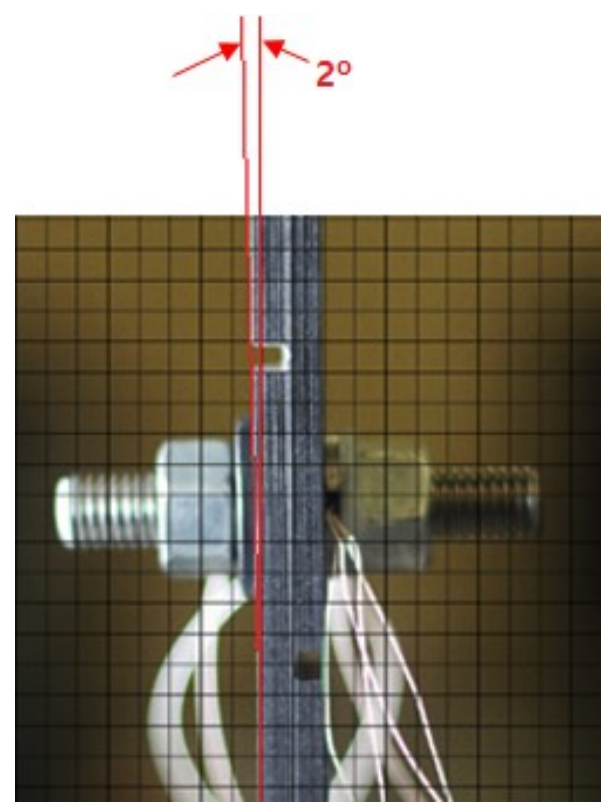

Figure 5.23: Out-of-plane displacement captured during the test 


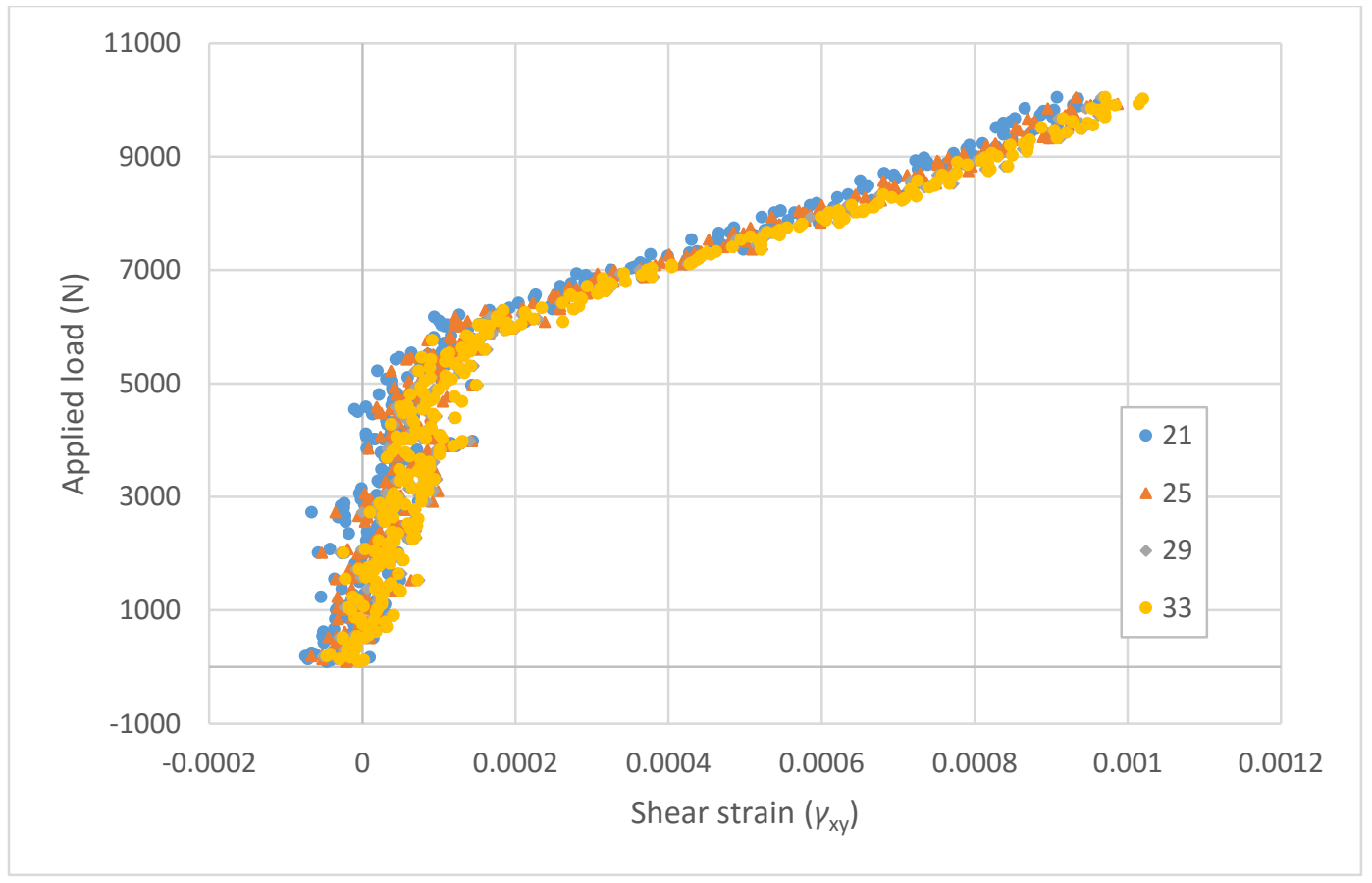

Figure 5.24: Shear strain change due to different strain window size

Shear strain data $\left(\gamma_{\mathrm{xy}}\right)$ was extracted from a few more locations from the FEA model and the DIC analysis to find whether strain data agreements can be found any locations. Four locations were chosen to extract the strains both from the FEA model and the DIC analysis. These locations are shown in Figure 5.25 and Figure 5.26. The reasons for reversed locations was that:

1) The FEA model was intended to be developed as a half model to save time and computational power, and

2) The DIC analysis had more scattered data on the same side as the FEA extraction locations due to lack of speckle pattern. Since the FEA model was assumed that the result would be symmetrical, it was determined to continue to use the reversed location to obtain the strain from the DIC analysis. 
Also, the data was smoothed using the robust local regression method to better highlight the trends.

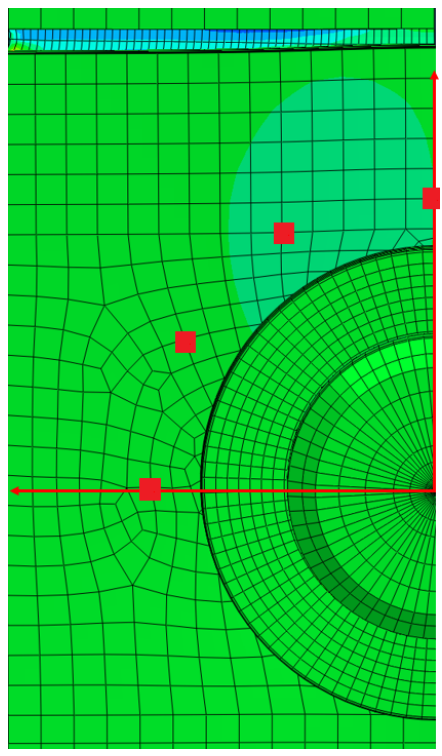

Figure 5.25: The shear strain extractions points from the FEA model

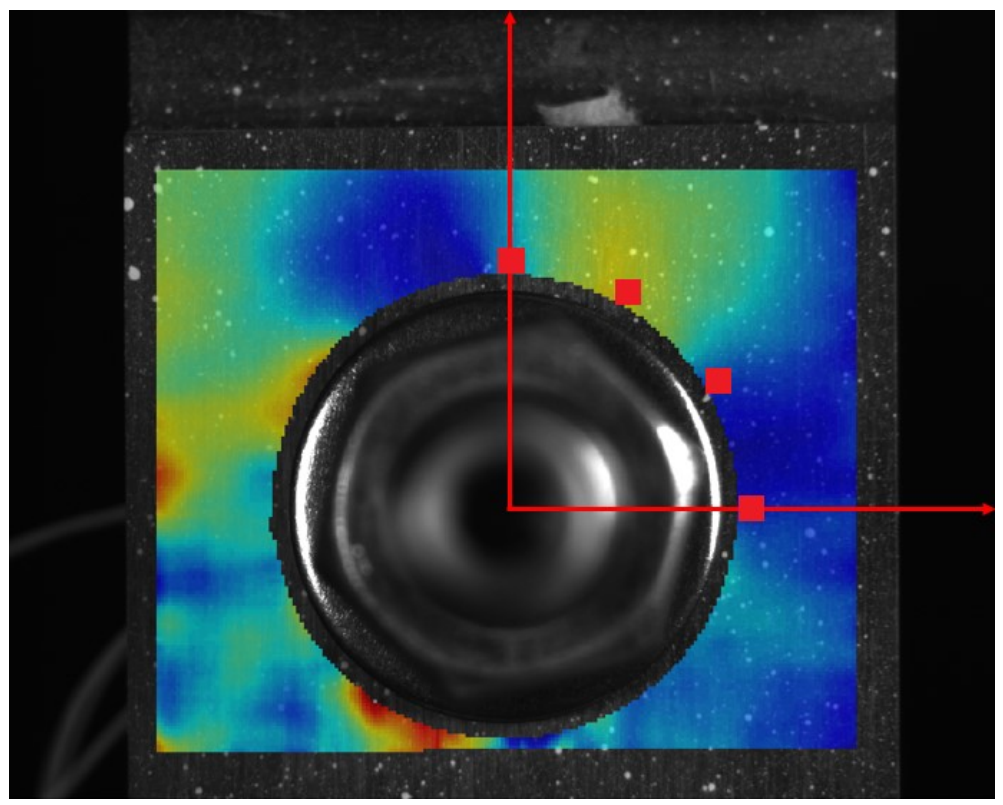

Figure 5.26: The shear strain extractions points from the DIC analysis 
According to Figures 5.27 to 5.30, the shear strain trends from the DIC analysis at $30^{\circ}$ and $60^{\circ}$ showed the similar patterns to the FEA model. However, a disagreement was found between the data from the DIC data analysis and the data from the FEA model at $0^{\circ}$ and $90^{\circ}$. Furthermore, unknown wave patterns were observed in these two graphs, which were not observed from any other graphs. Another interesting observation was that only one data set from the $60^{\circ}$ location was less scattered than other data sets. The reason for the scattered data is that the shear strain in these regions is low so that the sources of errors had a relatively higher effect on the results. The only solution for the scattered data would be using the higher magnification since changing DIC parameters cannot make the scattered data points closer. If the location of interest does not experience a significant level of strain, it is recommended to use higher magnification and focus on the location with sacrificing the strain values.

In conclusion, the DIC provides useful information from the joint configurations, and it was confirmed by comparing to the data from the instrumented bolt and the FEA model. However, not all locations may yield good results due to the sources of errors affecting low strain regions. Therefore, it is recommended to choose high strain regions for studying the joint behaviour or use the higher magnification for the DIC analysis to focus on the specific region of interest. 


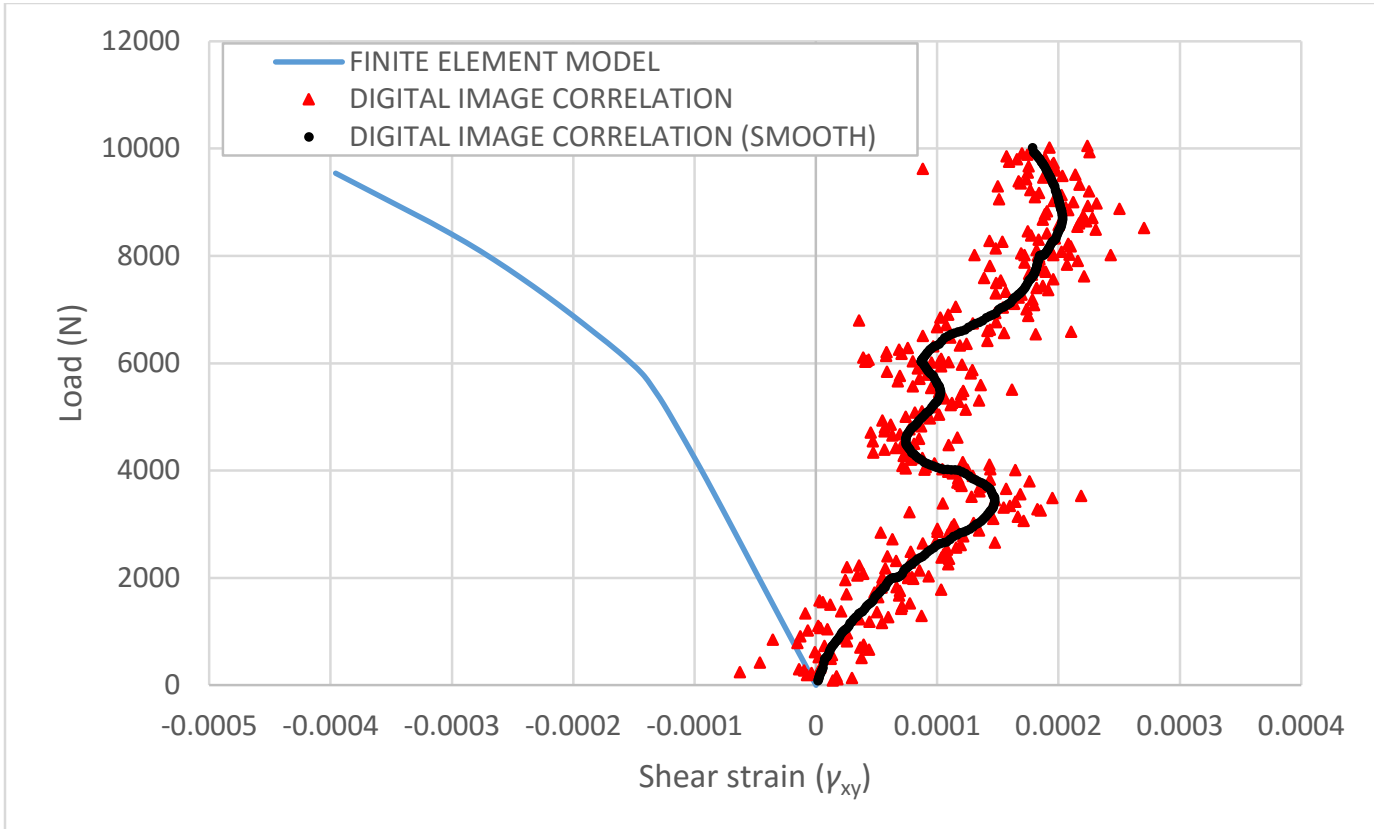

Figure 5.27: Finite Element Analysis vs. Digital Image Correlation (90 $\left.{ }^{\circ}\right)$

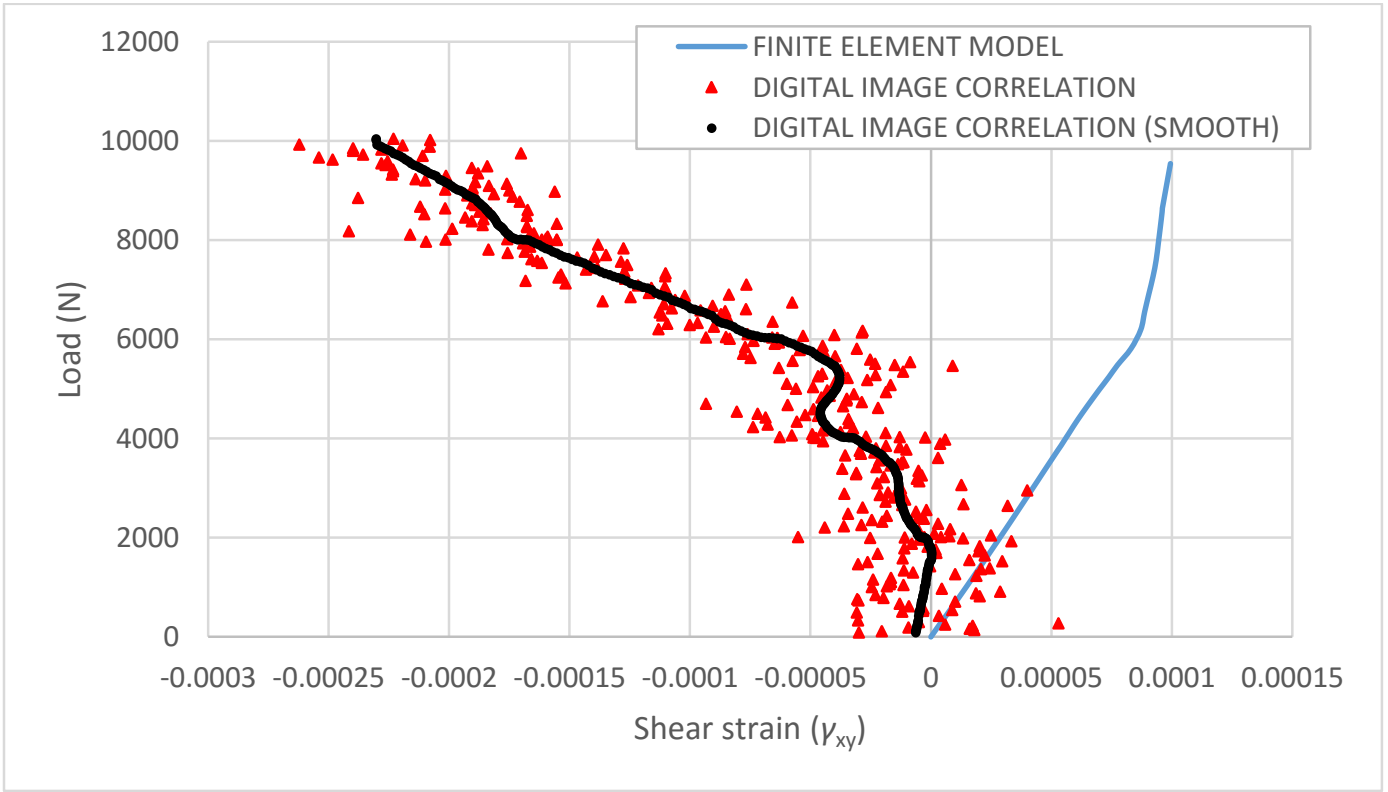

Figure 5.28: Finite Element Analysis vs. Digital Image Correlation $\left(0^{\circ}\right)$ 


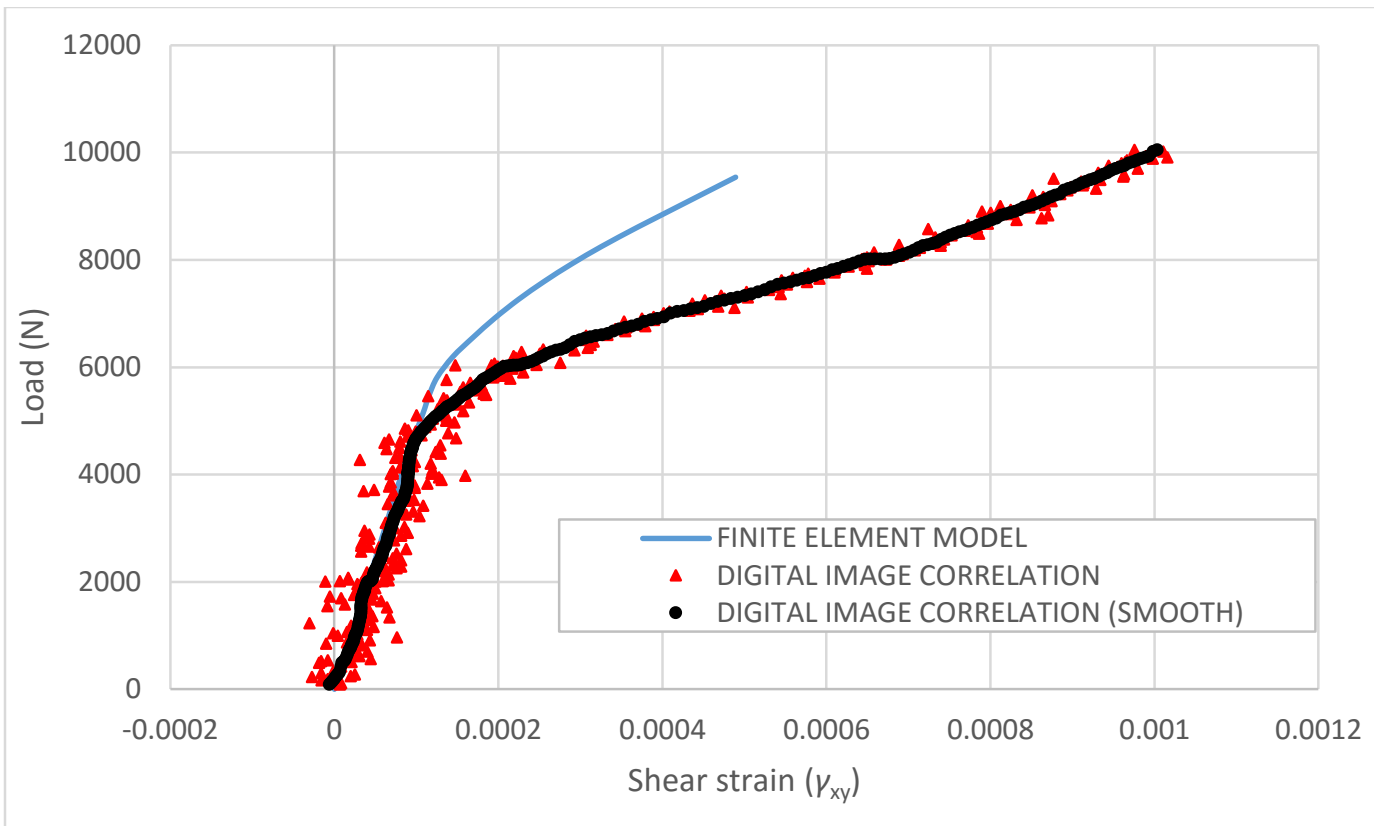

Figure 5.29: Finite Element Analysis vs. Digital Image Correlation $\left(60^{\circ}\right)$

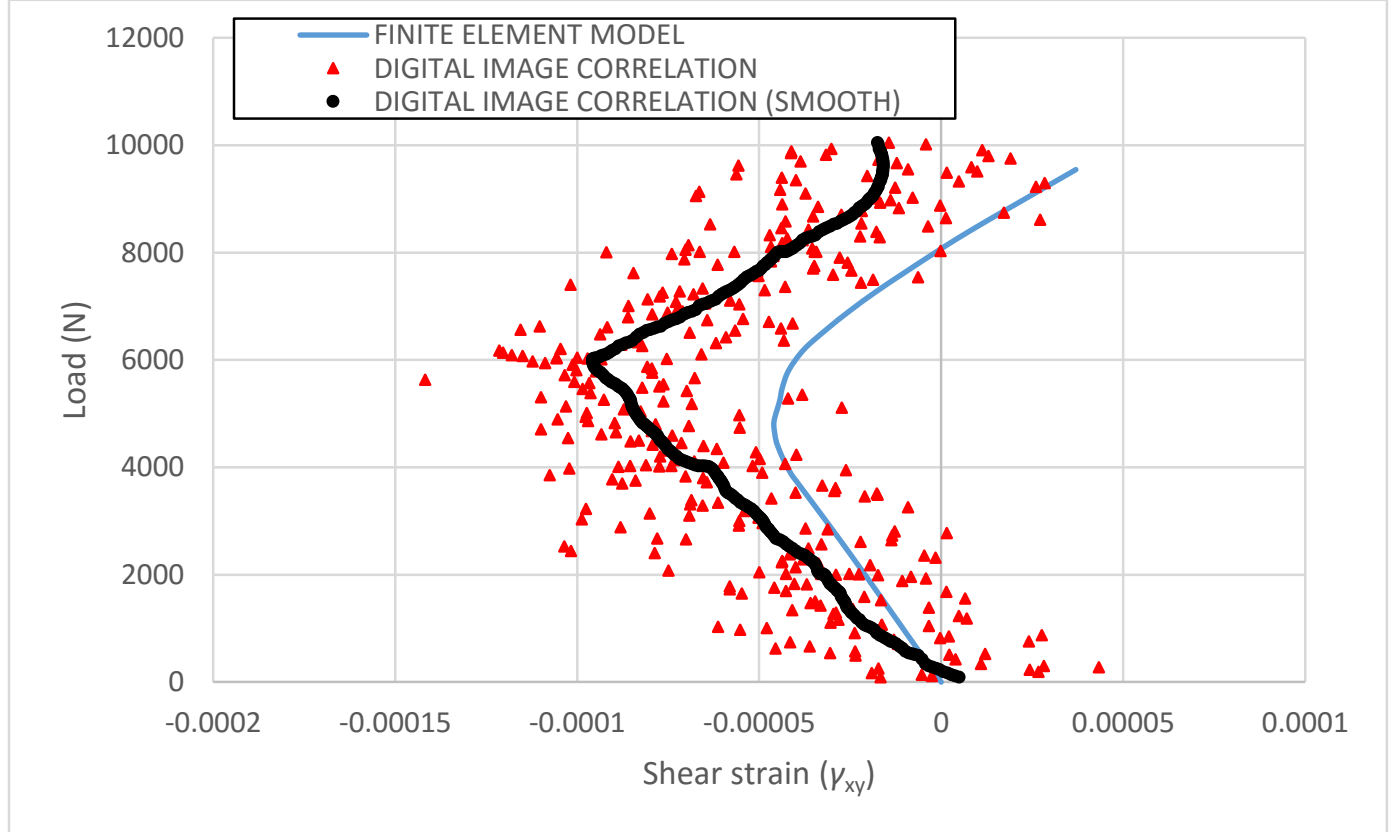

Figure 5.30: Finite Element Analysis vs. Digital Image Correlation (30 ${ }^{\circ}$ 


\subsection{TEST SERIES 3}

\subsubsection{FIRST ATTEMPT}

The original plan for Test Series 3 was to compare different joint configurations with the instrumented bolt. However, two problems were noted during the test. The first problem was a short circuit of the instrumented bolt's wires. A repair to the bolt was attempted, but the bolt soon failed again after re-installation. The other problem with the first trial was that possible manufacturing defects in the composite coupon caused an unexpected brittle failure during the test and resulted in unusable data for the further analysis. During the test, all test coupons used during the first attempt failed within the adherend in a brittle manner. The cause of the failure is assumed to be the carbon fibre partially left from the manufacturing of notches as can be seen in Figure 5.31. This leftover carbon fibre may have induced local fracture, and this local fracture may have initiated failed in the entire adherend.

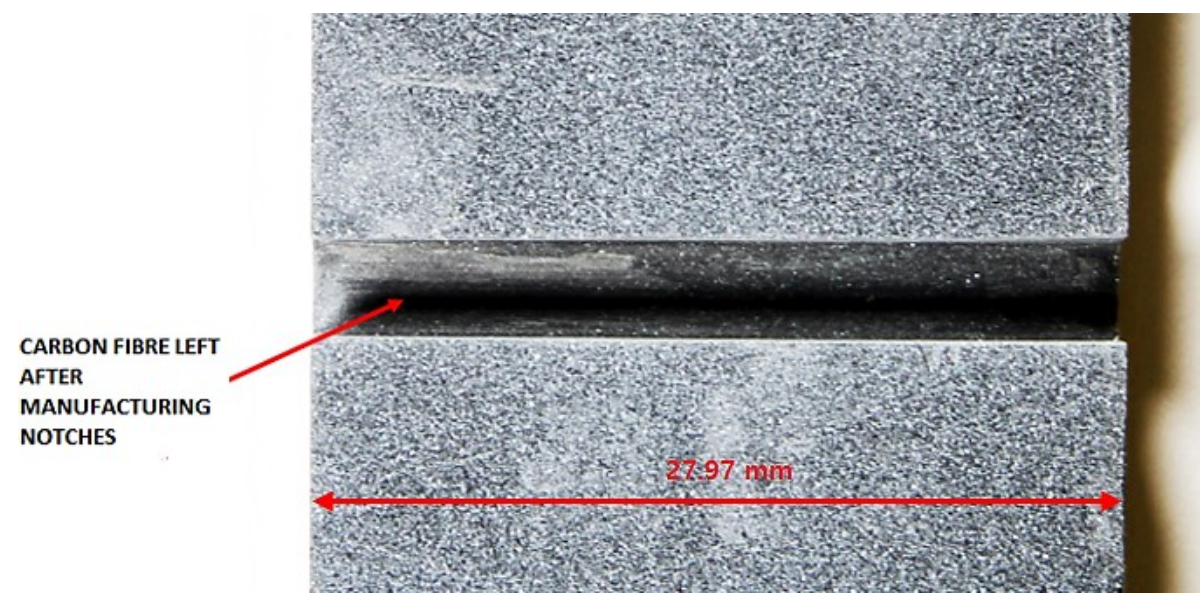

Figure 5.31: Possible manufacturing defects caused unexpected failure behaviour of the joint 
As shown in Figure 5.32, the joint failed just after passing $10000 \mathrm{~N}$, which was well below the load that the test coupon used in the Test Series 2 was able to sustain. It can be seen the sudden stroke increase after the load reached 10000 N. Interestingly, the instrumented bolt did not act at all until the failure happened as can be seen in Figure 5.33. This result contradicted to the result from Test Series 2. The photos of the failed surfaces were collected, and they can be seen in Figure 5.34. As shown in the figure, all three coupons failed in the adherend within the overlap region, which indicates that the failure was not categorized as the bonded joint failure. Also, the failure in all three test coupons occurred at the interface between $0^{\circ}$ and $45^{\circ}$ plies. Ji and Ong observed that the failure between $0^{\circ}$ and $45^{\circ}$ plies was caused by the failure of adjacent $90^{\circ}$ ply (Ji \& Ong, 1994). Hence, the probable reason for this failure mode is that the $90^{\circ}$ ply remnant that was left after machining the notch may have caused the failure between $0^{\circ}$ and $45^{\circ}$ plies. The test coupon with a hole had an additional failure in the $0^{\circ}$ ply. This is assumed to be due to stress concentration around a hole.

In conclusion from the first trial, the instrumented bolt was not reliable due to the delicacy of the equipment. The major overhaul would be required to avoid a short-circuit of the wire. Furthermore, the instrumented bolt will require more testing materials just to check its function after every major overhaul. The entire maintenance process is timeconsuming, and it will limit the number of repeatable tests in the limited time. The findings suggest that alternative approaches need to be found to save time and costs. Also, it was found that more careful manufacturing process is required to produce test 
coupons without defects.

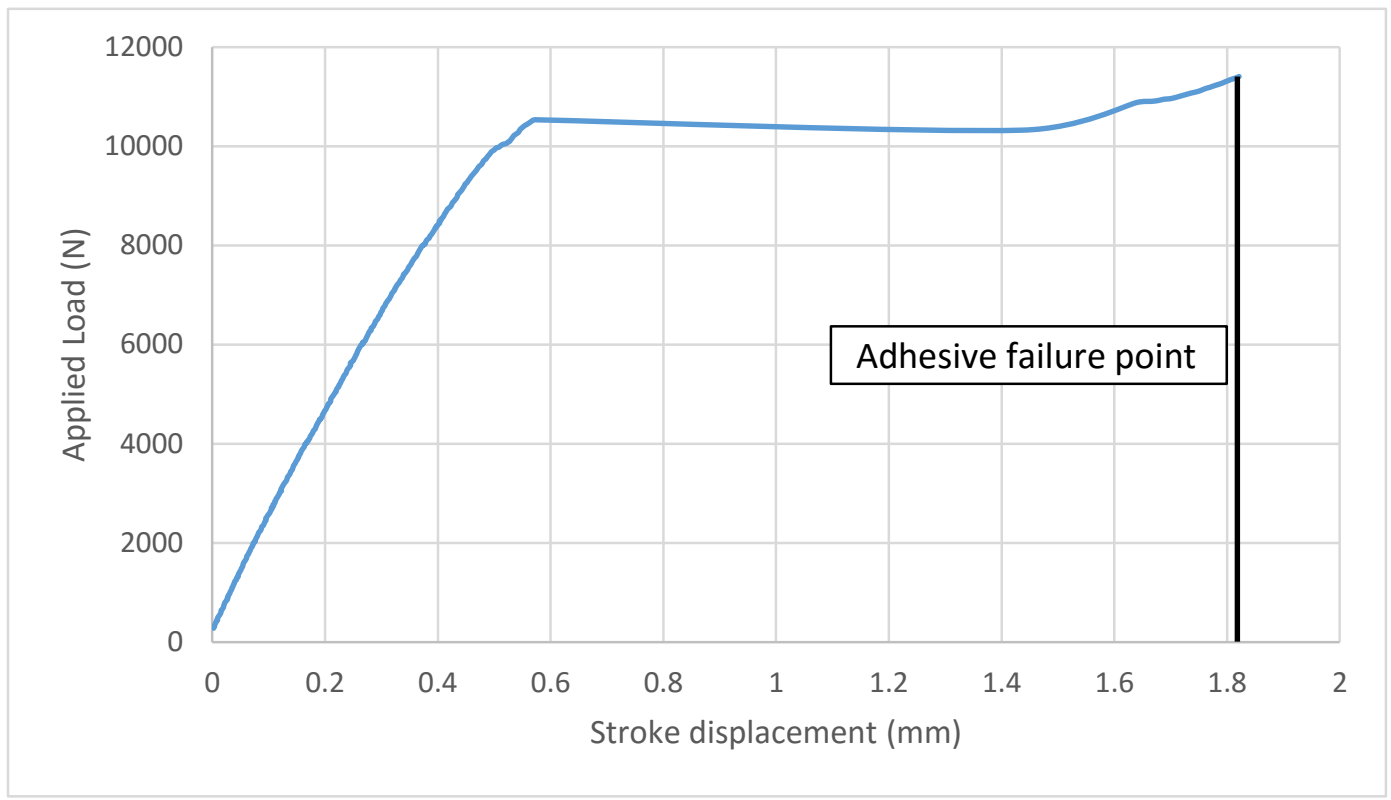

Figure 5.32 Load versus stroke curve of the failed specimen (CFRP bolted/bonded joint)

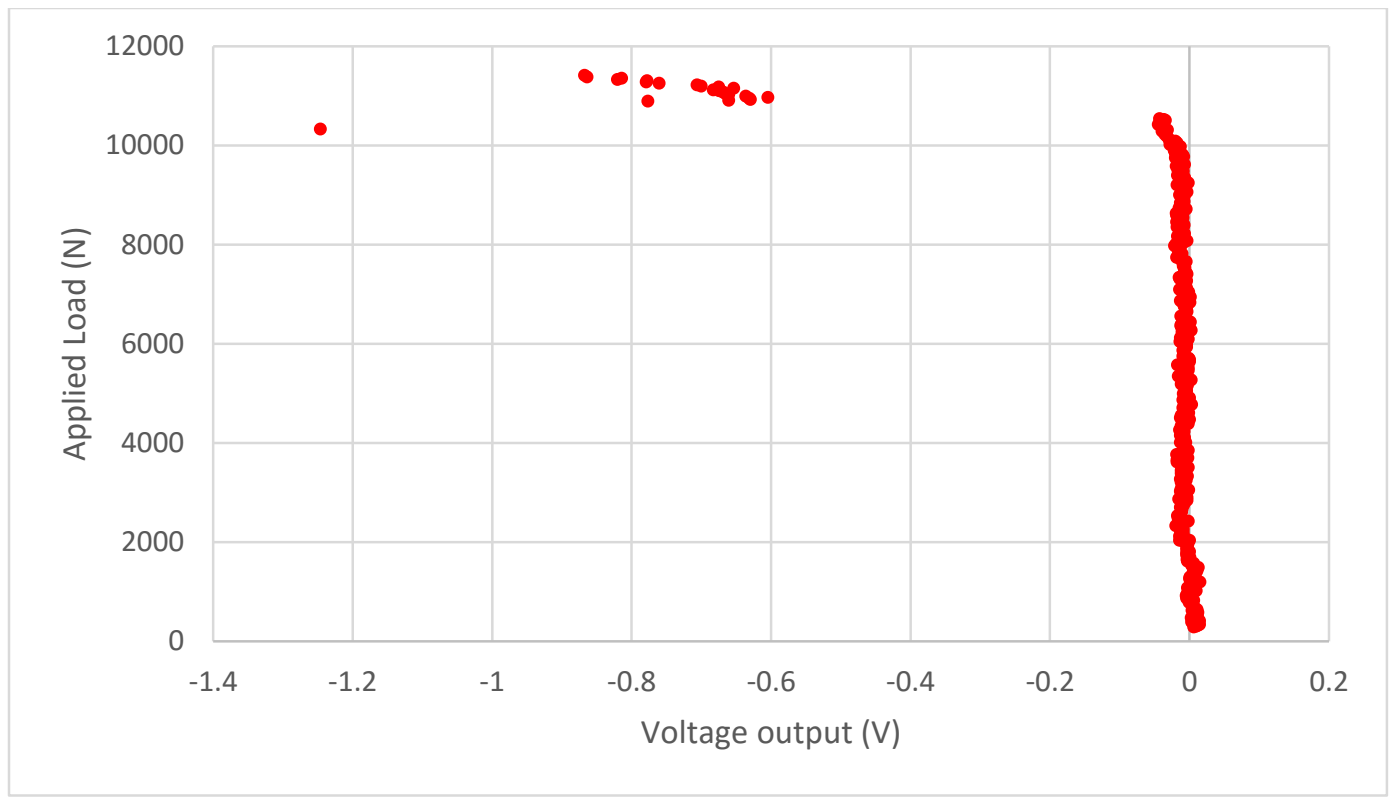

Figure 5.33: The bolt response from the first attempt (CFRP bolted/bonded joint) 


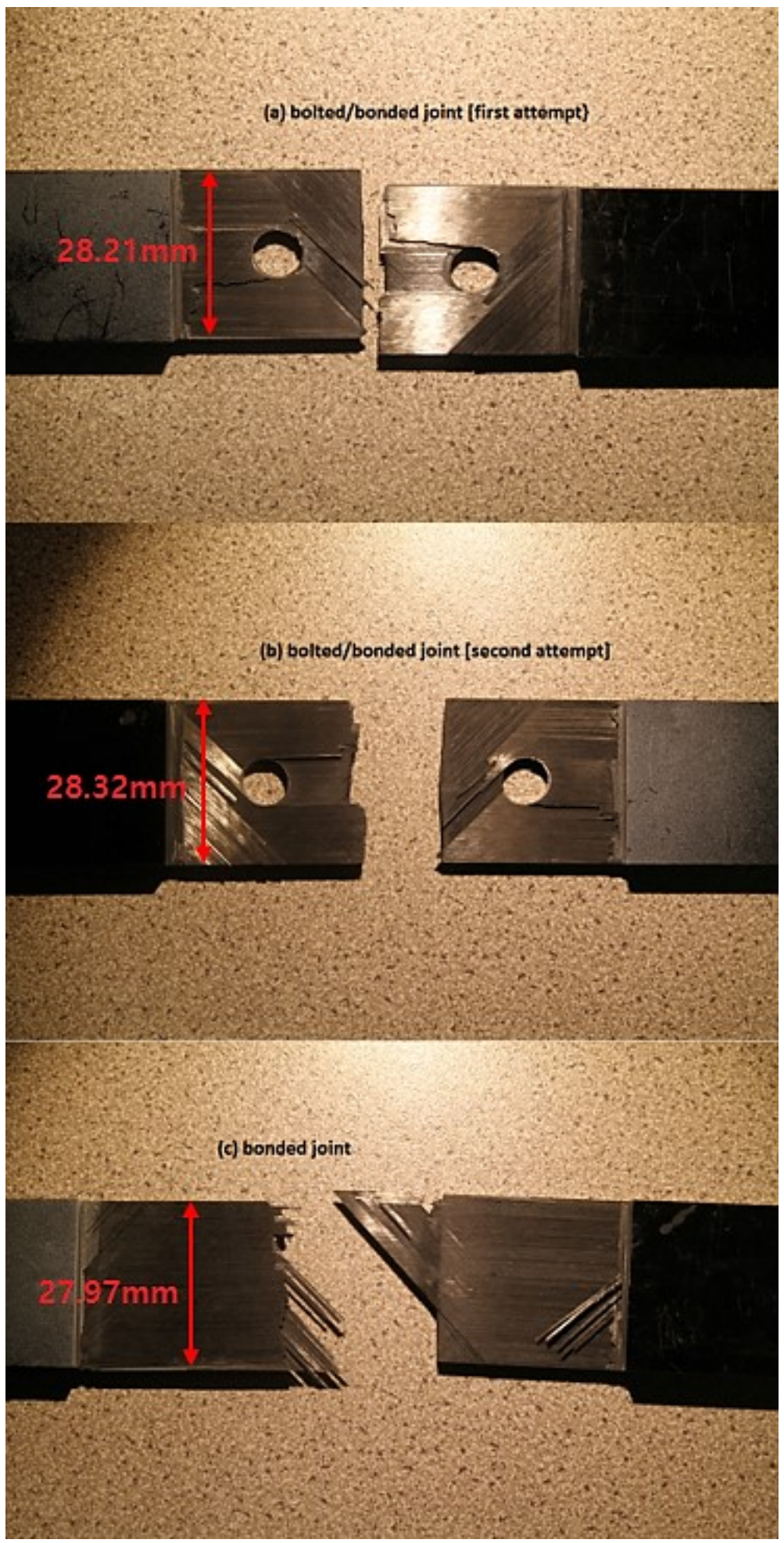

Figure 5.34: Failed surface of the joints during the first attempt 


\subsubsection{SECOND ATTEMPT}

The second attempt in Test Series 3 was successfully completed without unexpected failure. According to the pictures taken during the test for the DIC analysis, the first failure on the surface of the bolted joint was observed at 320 seconds after the test began. The load at this moment was about $9930 \mathrm{~N}$. Other joints did not fail until the tests were completed. According to the load versus stroke curve seen in Figure 5.34, the bolted joint has $200 \%$ higher stroke at the moment of the failure than the bonded joint. In the figure, there are points where the load was held constant even while the stroke increased. This happened due to the sustained load causing creep in the low stiffness adhesive layer.

At $12000 \mathrm{~N}$, the difference in the stroke between the bolted/bonded joint and the bonded joint was about $0.2 \mathrm{~mm}$, which means $20 \%$ lower overall stroke in the bolted/bonded joint. It was assumed that the difference was purely due to the different configuration only. The slippage issue was assumed to be negligible because the same load frame and the same upper, and lower grips were used. Figure 5.35 shows that the stroke difference between the bolted/bonded joint and the bonded joint was negligible until 100 seconds or $4000 \mathrm{~N}$; then it increased slowly. Although it was not visually confirmed, Figure 5.36 indicates the bolt started to act as the load path at 100 seconds or $4000 \mathrm{~N}$, so the deformation of the adhesive layer in the bolted/bonded joint was slower from this point. The possible reason for the effect of the bolt load transfer occurred quicker than the Test Series 2 would be the clearance between the hole and the bolt since 
this clearance delays the load transfer through the bolt until the bolt touches the surface of the adherends.

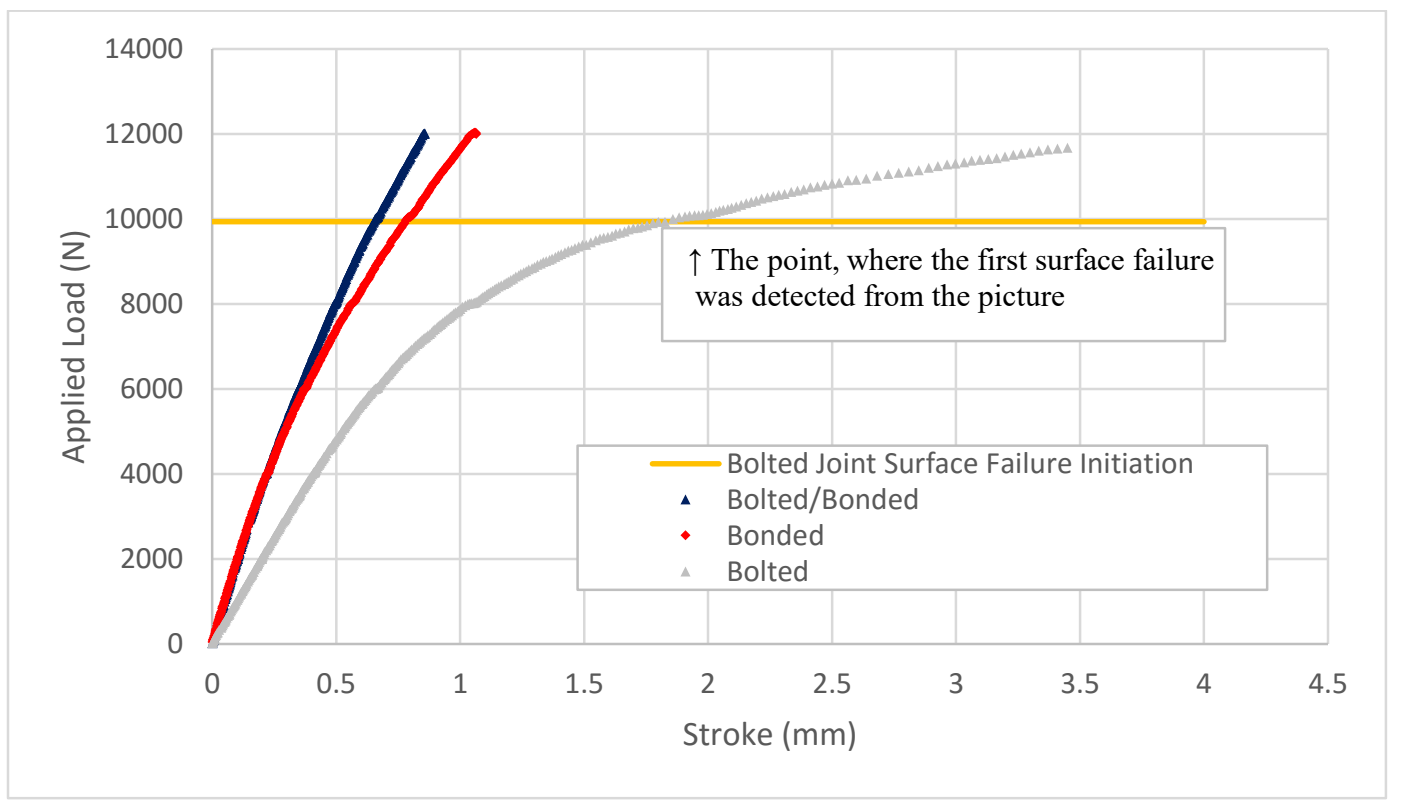

Figure 5.35: Applied load versus stroke curve of three test coupons 


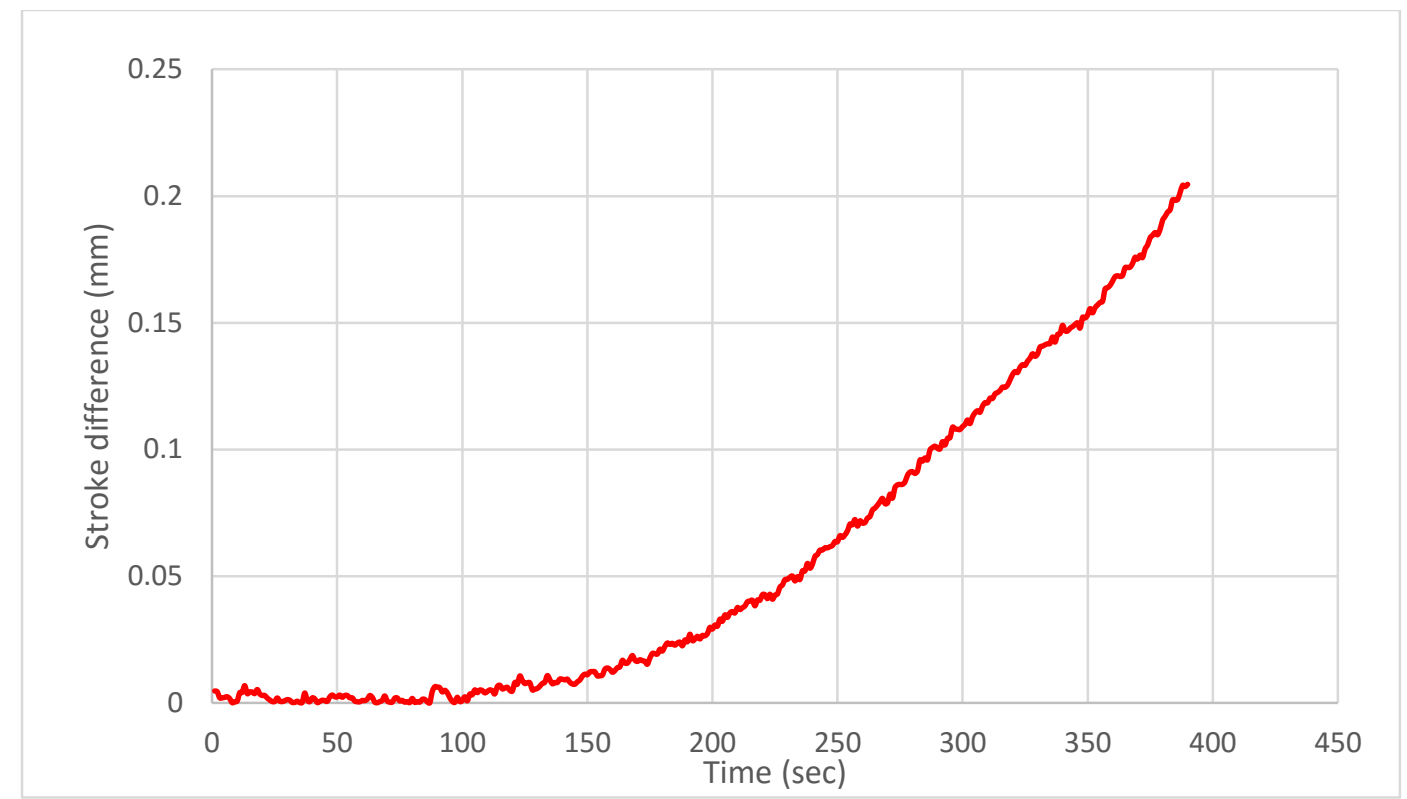

Figure 5.36: The difference in the stroke between the bonded joint with a hole and the bolted/bonded joint

The DIC analysis was performed for all configurations. The FOV and AOI for each test are shown in Figure 5.37. The analysis software provides a ratio between the pixel and the length of the actual specimen. Each pixel was equivalent to $0.03273 \mathrm{~mm}$ in the bolted joint, $0.03256 \mathrm{~mm}$ in the bonded joint, and $0.03136 \mathrm{~mm}$ in the bolted/bonded joint. Each analysis had different DIC parameters to have the best correlations between images for each analysis, and the parameters for each analysis are listed in Table 5.3, 5.4, and 5.5. 

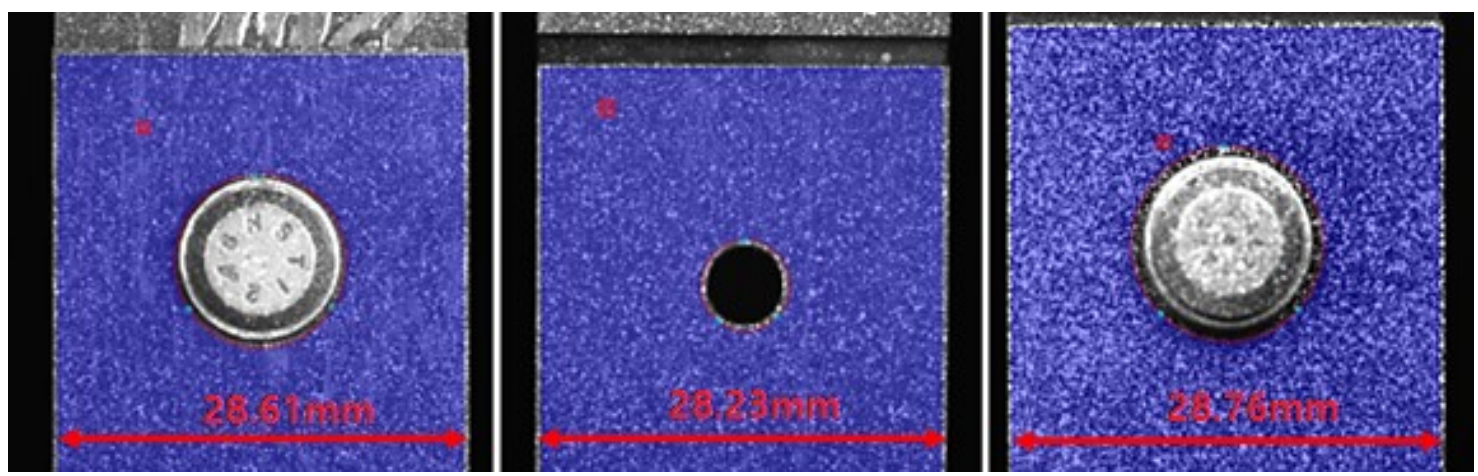

Figure 5.37: FOV, AOI (blue), and the reference subset (red) for the bolted joint (left), the bonded joint with a hole (centre), and the bolted/bonded joint (right)

Table 5.3: DIC analysis setting (CFRP bolted joint)

\begin{tabular}{|c|c||c|c|}
\hline Parameter & Value & Parameter & Value \\
\hline \hline Subset & 23 pixels & Kernel Size & 5 pixels \\
\hline Step & 5 pixels & Strain & Green-Lagrange \\
\hline Criterion & ZNSSD & Strain Window & 29 pixels \\
\hline Interpolation & BCSPLINE & VSG & 163 pixels \\
\hline Shape Function & Affine & Strain Interpolation & Q4 \\
\hline Prefiltering & Gaussian & & \\
\hline
\end{tabular}

Table 5.4: DIC analysis setting (CFRP bonded joint with a hole)

\begin{tabular}{|c|c||c|c|}
\hline Parameter & Value & Parameter & Value \\
\hline \hline Subset & 31 pixels & Kernel Size & 5 pixels \\
\hline Step & 5 pixels & Strain & Green-Lagrange \\
\hline Criterion & ZNSSD & Strain Window & 29 pixels \\
\hline Interpolation & BCSPLINE & VSG & 171 pixels \\
\hline Shape Function & Affine & Strain Interpolation & Q4 \\
\hline Prefiltering & Gaussian & & \\
\hline
\end{tabular}


Table 5.5: DIC analysis setting (CFRP bolted/bonded joint)

\begin{tabular}{|c|c||c|c|}
\hline Parameter & Value & Parameter & Value \\
\hline Subset & 25 pixels & Kernel Size & 5 pixels \\
\hline Step & 5 pixels & Strain & Green-Lagrange \\
\hline Criterion & ZNSSD & Strain Window & 31 pixels \\
\hline Interpolation & BCSPLINE & VSG & 175 pixels \\
\hline Shape Function & Affine & Strain Interpolation & Q4 \\
\hline Prefiltering & Gaussian & & \\
\hline
\end{tabular}

The strain values were extracted from three locations. The first location is in the area with unique strain shape, so called the butterfly region, which can be seen in Figure 5.38. The region was selected because it occurs near the hole. Therefore, the effect of the bolt should be easily detected in this region. The second location is $10 \mathrm{~mm}$ vertically and horizontally away from the centre of the bolt. The numbers were chosen to easily locate the points. This point lies on the axis $45^{\circ}$ away from the horizontal axis that passes through the centre of the bolt. The last point is $10 \mathrm{~mm}$ vertically and $5 \mathrm{~mm}$ horizontally away from the centre of the bolt. This point lies on the axis $60^{\circ}$ away from the horizontal axis. The locations of the extraction areas are shown in Figures 5.39 to 5.41.

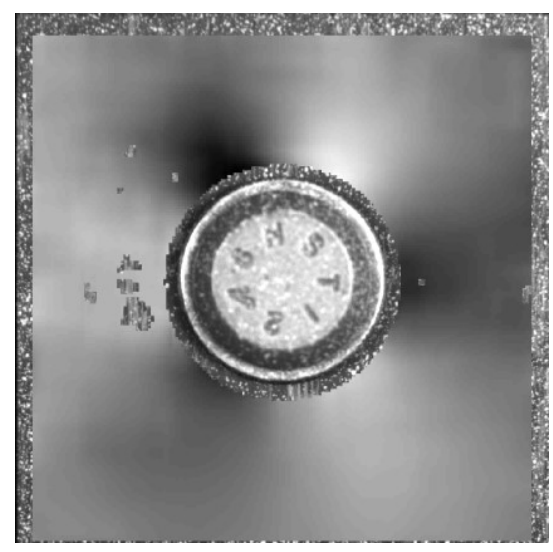

Figure 5.38: Shear strain around the bolt showing the "butterfly" pattern 

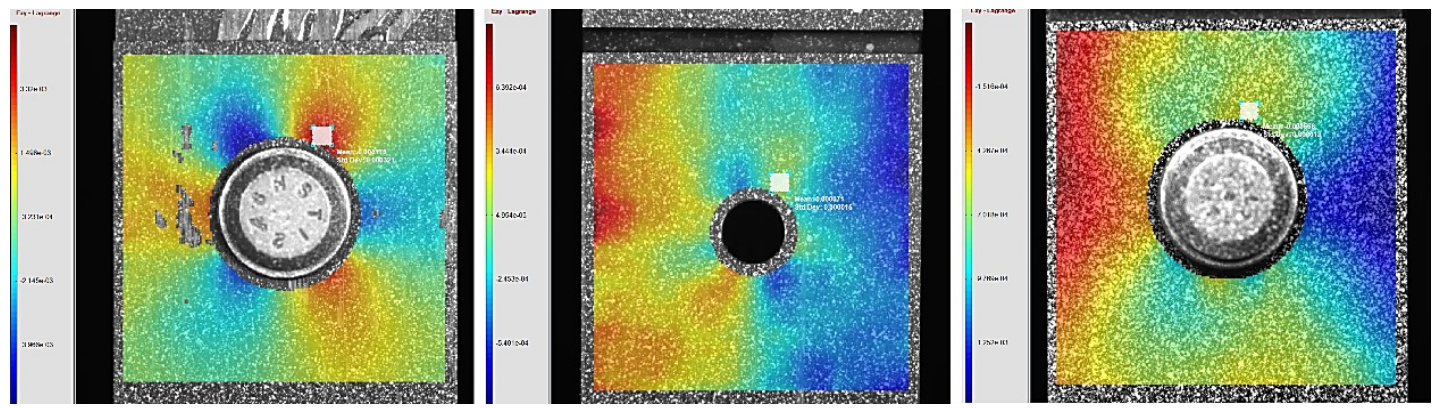

Figure 5.39: The data extraction area for the bolted joint (left), the bonded joint with a hole (centre), and the bolted/bonded joint (right) in the butterfly region
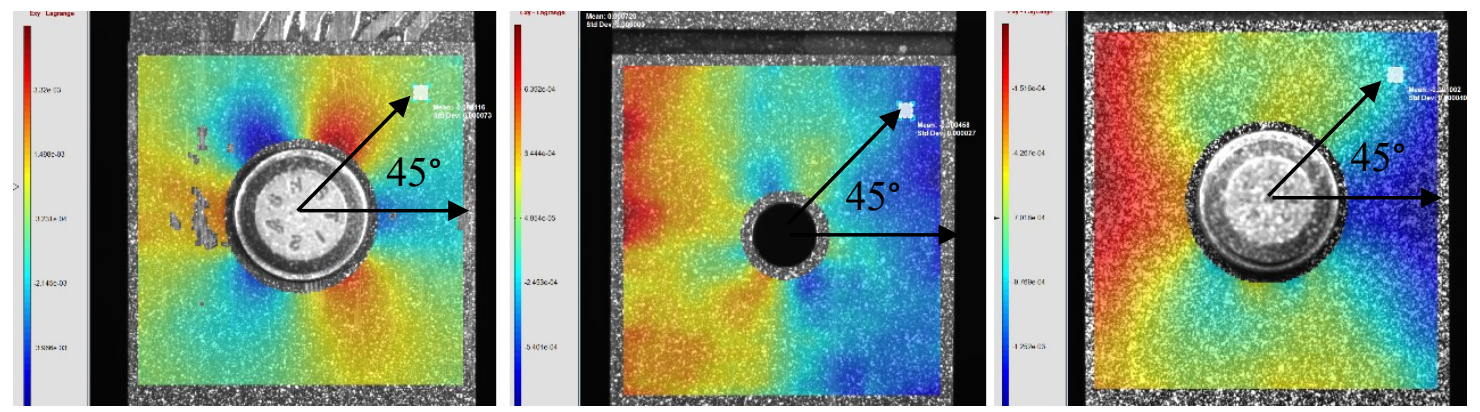

Figure 5.40: The data extraction area for the bolted joint (left), the bonded joint with a hole (centre), and the bolted/bonded joint (right) from the points lying $45^{\circ}$ axis
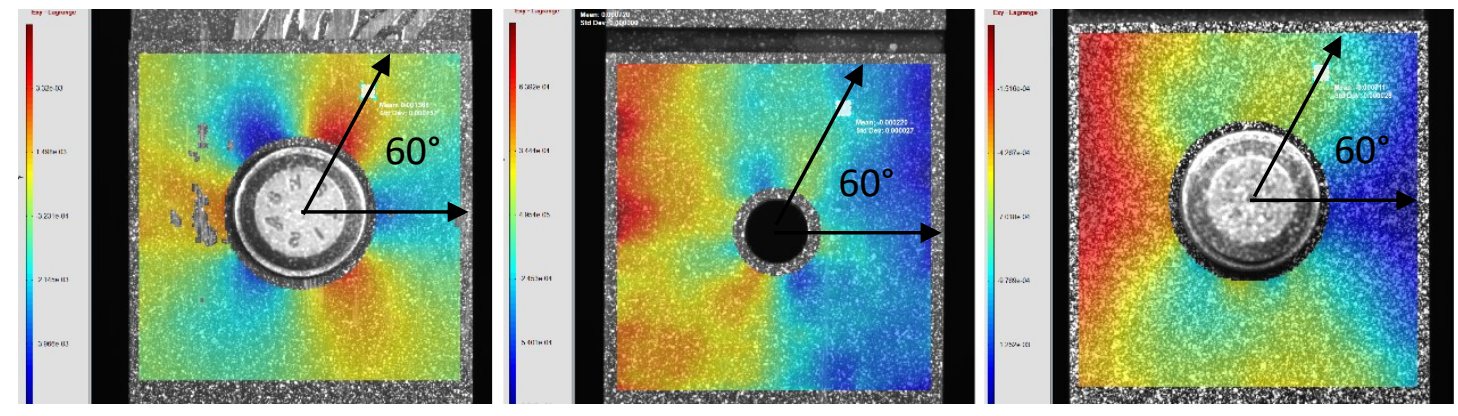

Figure 5.41: The data extraction area for the bolted joint (left), the bonded joint with a hole (centre), and the bolted/bonded joint (right) from the points lying $60^{\circ}$ axis 
The shear strain $\left(\gamma_{x y}\right)$ obtained from the chosen locations can be seen from Figures $5.42,5.43$, and 5.44. The result showed that that the bolted/bonded joint always had larger strain values than the bonded joint in all locations when the same amount of the load was applied. According to Figure 5.42, the shear strain from the bolted joint increased linearly until $6000 \mathrm{~N}$; then it increased with a higher rate. The probable reason the rate increase is that the compressive force from the bolt to the adherends caused the permanent deformation of the adherends. Unfortunately, the moment that the first surface failure was detected in the picture could not be included in the DIC analysis, since the correlation at this displacement dropped significantly. Another interesting observation from Figure 5.42 is that the shear strain of the bolted/bonded joint alone showed negative shear strain.

The analysis software can show the direction of the vector in deformed images. Figures 5.45, 5.46, and 5.47 show the major displacement vector direction in three joint configurations at 300 seconds. Generally speaking, the bolted and the bonded joints had reversed vector fields with respect to the centre of the bolt or the hole while the bolted/bonded joint did not. The imperfect bolted/bonded test coupon may have caused higher loading to one side of the joint and yielded the negative shear strain. Figure 5.43 is the shear strain of three different joint configurations at the $45^{\circ}$ point. Unlike the previous figure, all three joints had negative shear strain. The unique finding is that the bolted joint showed strain decrease after $6000 \mathrm{~N}$. According to Figure 5.42, this is the point where the strain rate started to increase. These two findings may indicate the failure in the bolted joint. The failure was not visually observed during the test and from the pictures after the 
test, so it may not be the definite conclusion. According to Figure 5.44, the bolted joint behaviour was similar to the one in Figure 5.42 while the bonded and the bolted/bonded joint behaviour was closer to the ones in Figure 5.43. Estimating the load transferred by the bolt was not possible because there was no common pattern observed from all plots. At 300 seconds, the shear strain difference between the bonded joint and the bolted joint was 113\% from Figure 5.41, 55\% from Figure 5.43, and 70\% from Figure 5.44.

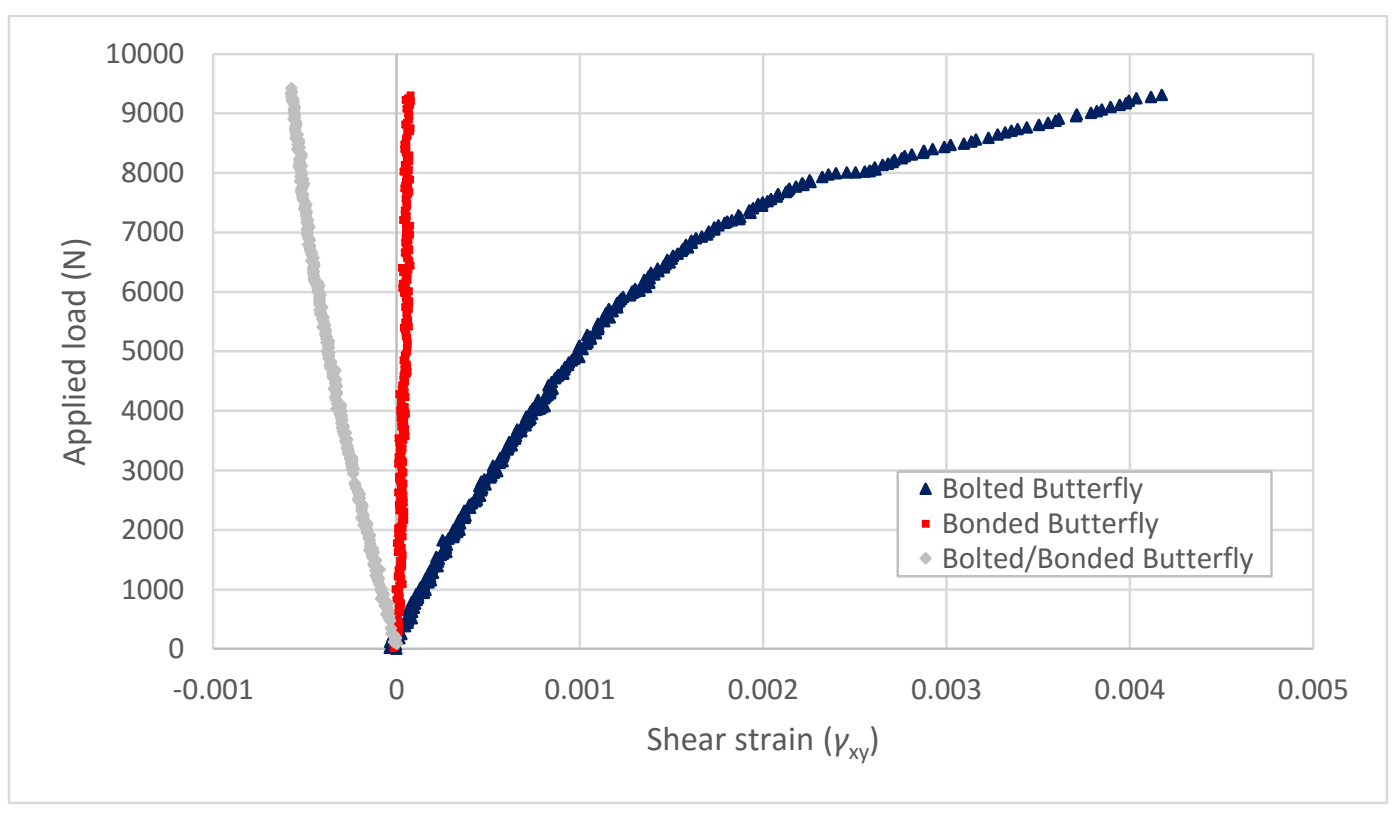

Figure 5.42: Load versus shear strain $\left(\gamma_{\mathrm{xy}}\right)$ comparison of three different joints in the butterfly region 


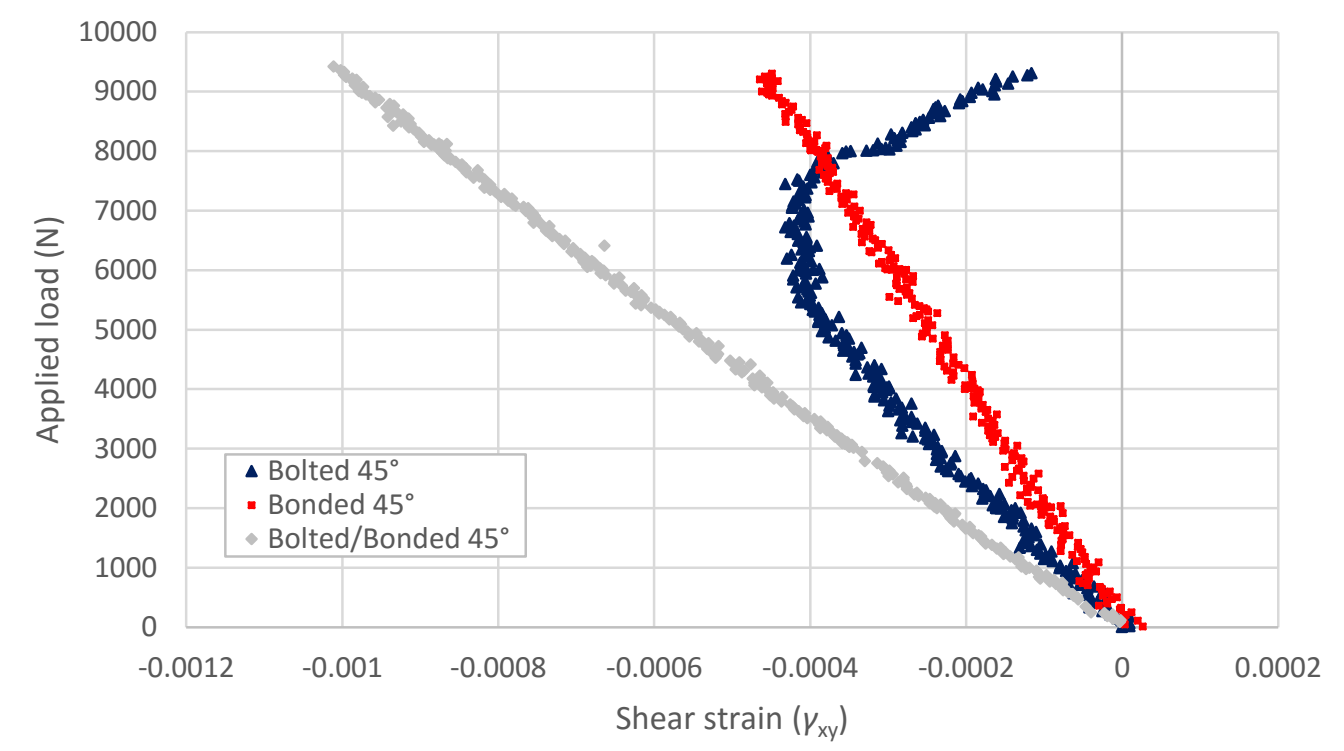

Figure 5.43: Load versus shear strain $\left(\gamma_{\mathrm{xy}}\right)$ comparison of three different joints in the $45^{\circ}$ axis

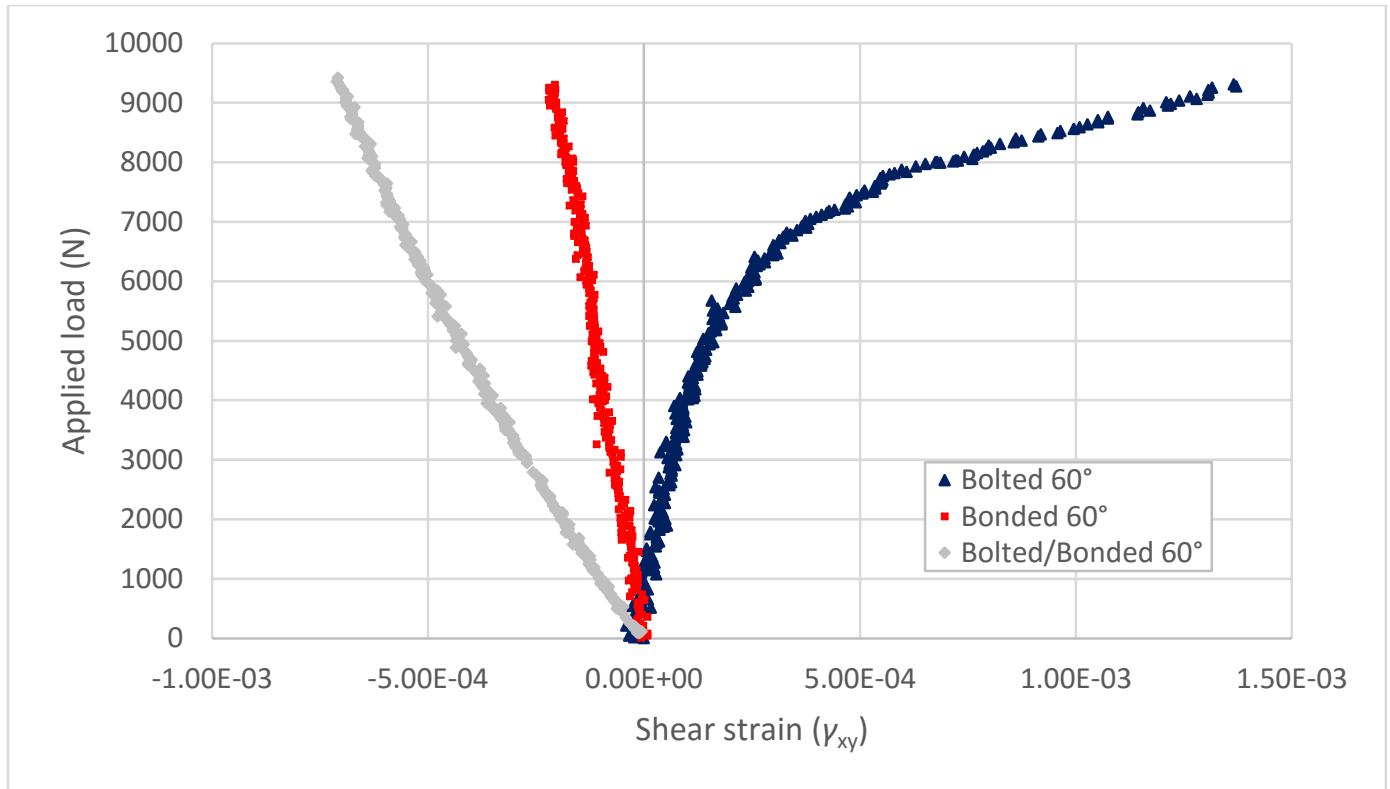

Figure 5.44: Load versus shear strain $\left(\gamma_{x y}\right)$ comparison of three different joints in the $60^{\circ}$ axis 


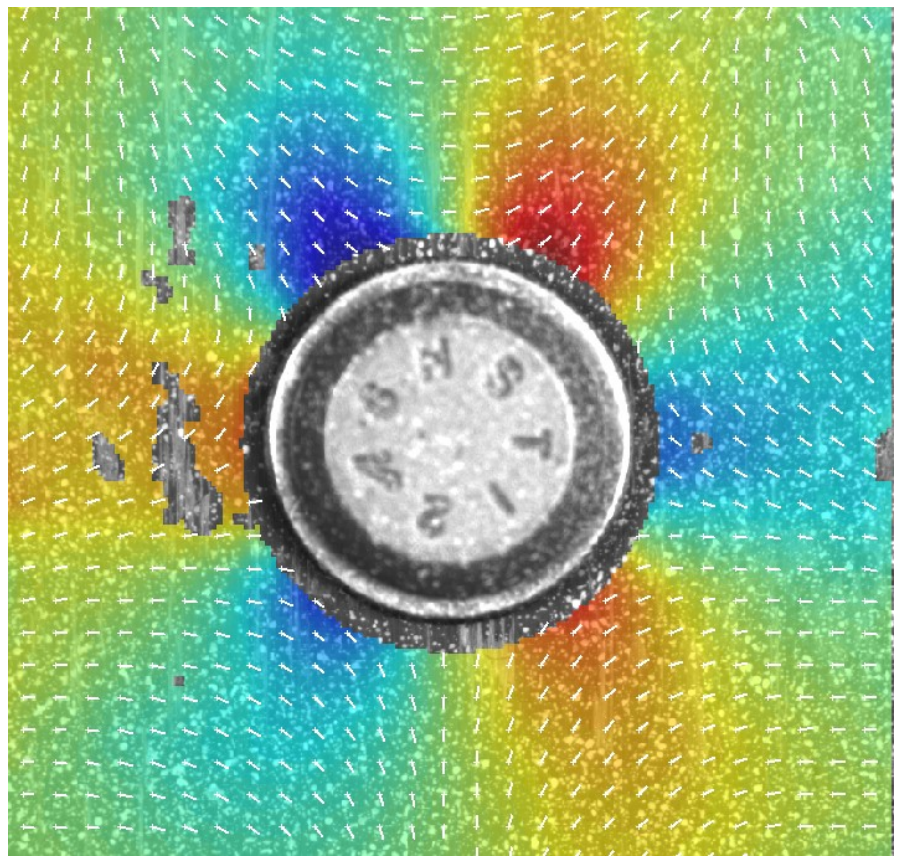

Figure 5.45: Direction of the displacement vector in the bolted joint

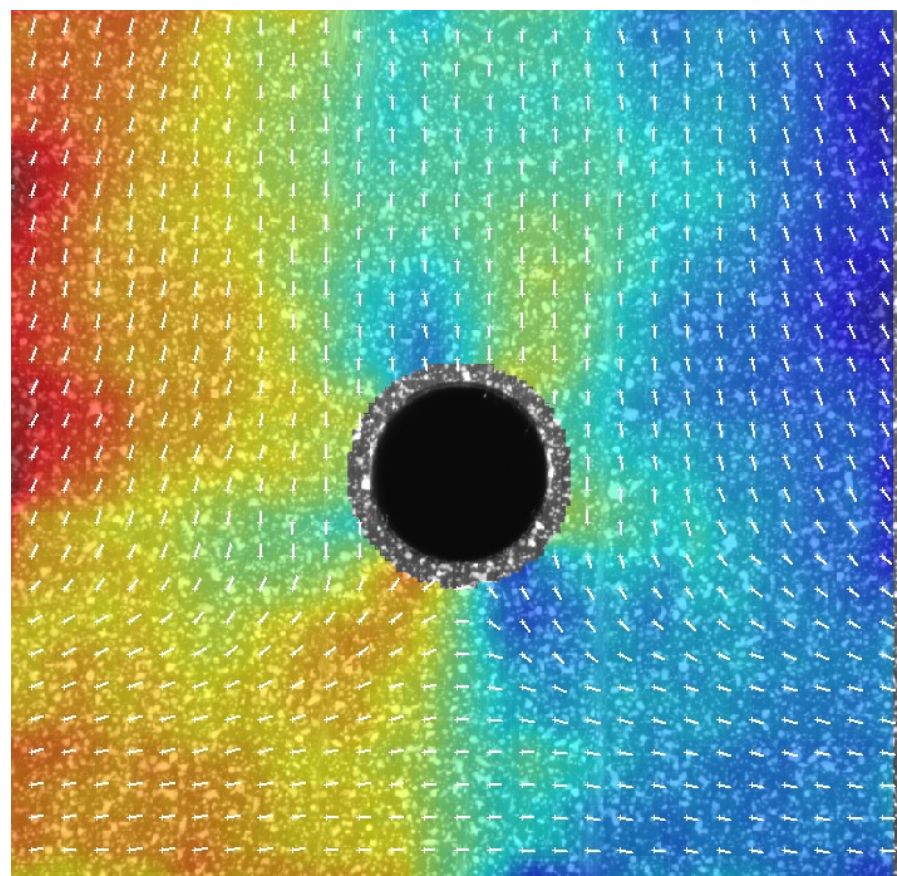

Figure 5.46: Direction of the displacement vector in the bonded joint 


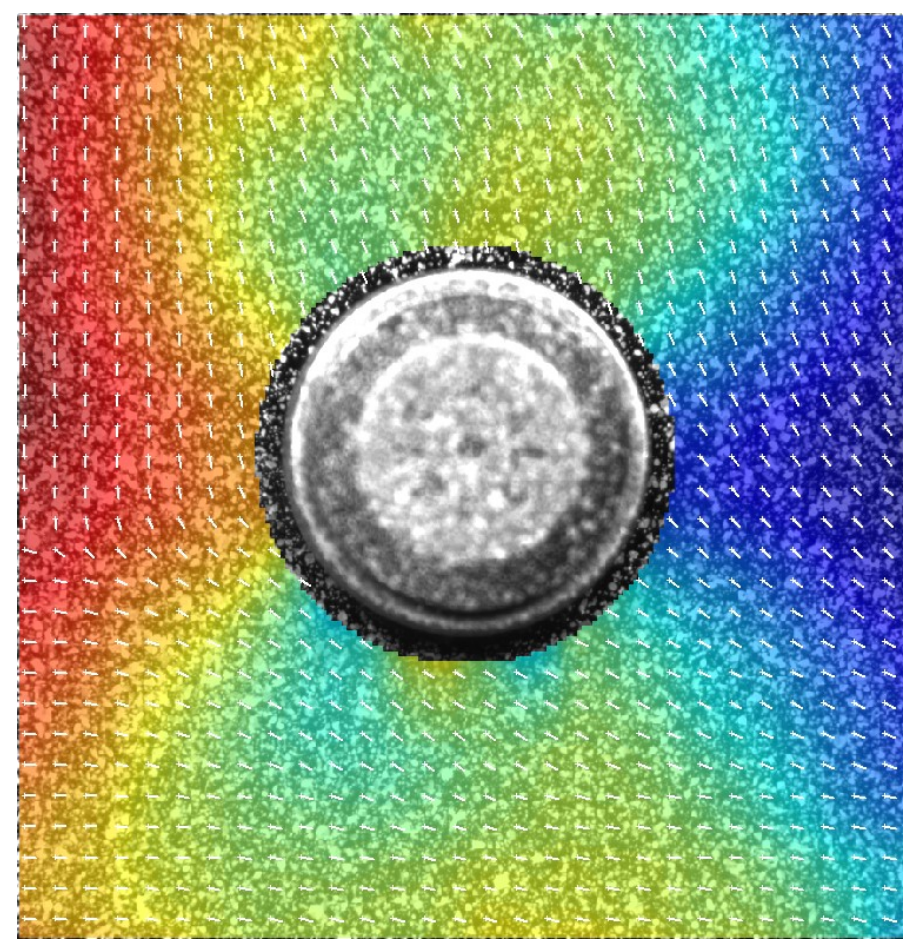

Figure 5.47: Direction of the displacement vector in the bolted/bonded joint

Figures $5.48,5.49$, and 5.50 show the shear strain in various location of each joint. According to Figure 5.48, shear strain is higher as the extraction area is moved closer to the bolt. The farthest extraction area is located where the direction of the vector changes according to Figure 5.45. This region should be less affected by the bolt influence on the adherend.

Figure 5.49 and Figure 5.50 showed a different pattern. As the extraction area becomes farther from the bolt, the shear strain is higher. As both figures have the same pattern, it may indicate that the surface shear strain is more affected by the adhesive layer rather than the presence of the bolt. It is still not possible to find a definite reason for higher strain in the bolted/bonded joint. The probable reason for this is the load path 
change due to the bolt. However, it is not conclusive because higher strain in the bolted/bonded joint means the deformation in the adhesive layer in the bolted/bonded joint will be higher than the deformation in the bonded joint. In other words, the bolt negatively affected the joint configuration. However, this is not a definite conclusion that can be made at this point since the test was performed only once.

In conclusion, the DIC technique was able to help to identify the moment of surface failure and its location. Also, strain results from the DIC technique allowed picking up the moment that something could have happened inside. However, it was still not possible to know what exactly happened inside. From the comparison of the shear strain values in the same joint, the adhesive layer resulted in different strain patterns on the surface. This adhesive layer caused higher strain as the measurement point is farther from the centre of the bolt or the hole. Unusual patterns, such as negative strains near the bolt in the bonded/bolted joints, could not be explained in this thesis. Possible reason is that the torque applied to the bolt for the installation may have caused a different behaviour in the bolted/bonded joint compared to the bonded joint. Strictly speaking, the test coupons do not have same configurations since the bolt installed in the bolted joint is different from the bolt installed in the bolted/bonded joint. The difference may have caused the unusual test results since the geometry parameters of the bolted joint, and the bolted/bonded joints do not match perfectly. Further studies may be required to fully understand the behaviour of joints. Unfortunately, the one of the interests in this thesis, which is to estimate the load sharing by the bolt in the bolted/bonded joint, could not be achieved. Lastly, the axial strains, $\left(\varepsilon_{x x}\right)$ and $\left(\varepsilon_{y y}\right)$, were extracted from the same locations 
as the shear strains were obtained in each joint and these plots can be found in Appendix

D.

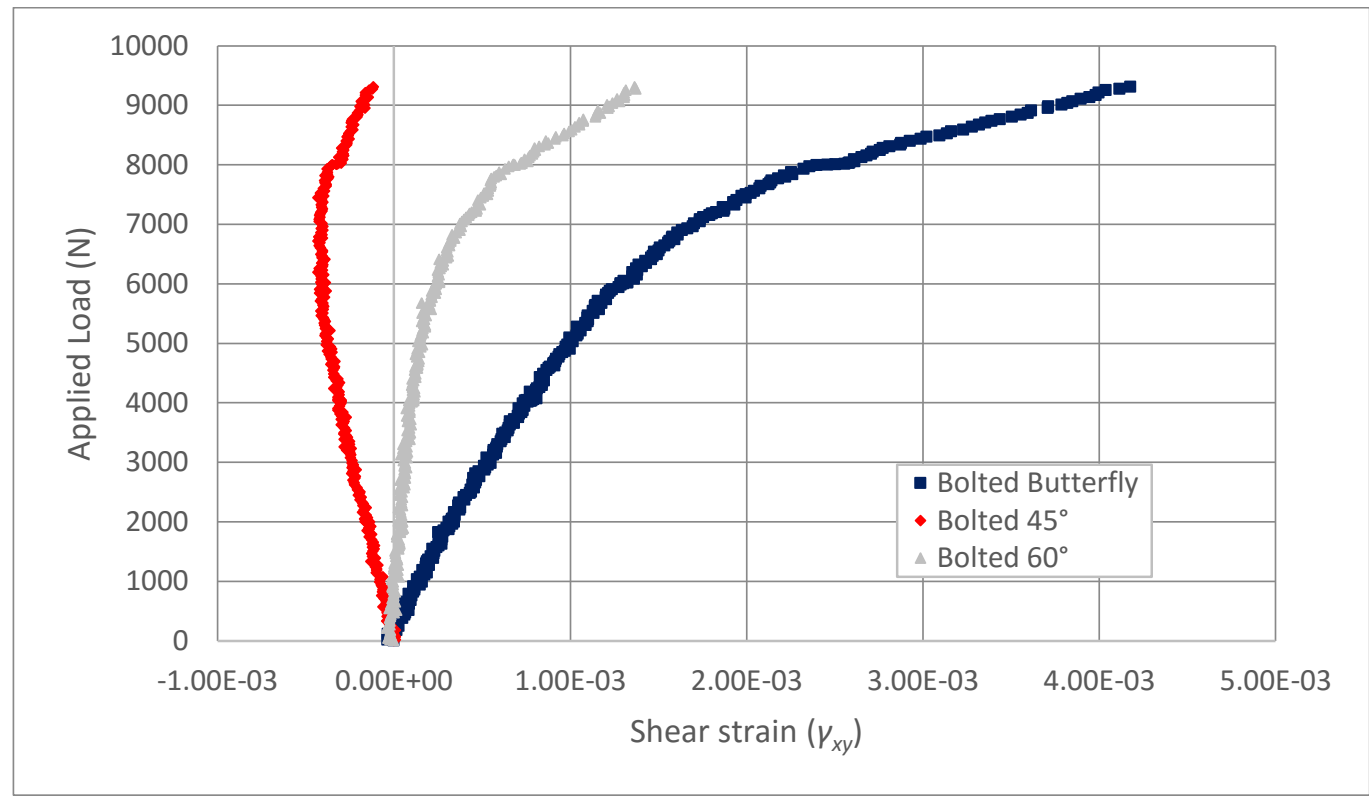

Figure 5.48: Load versus shear strain obtained from various locations in the bolted joint

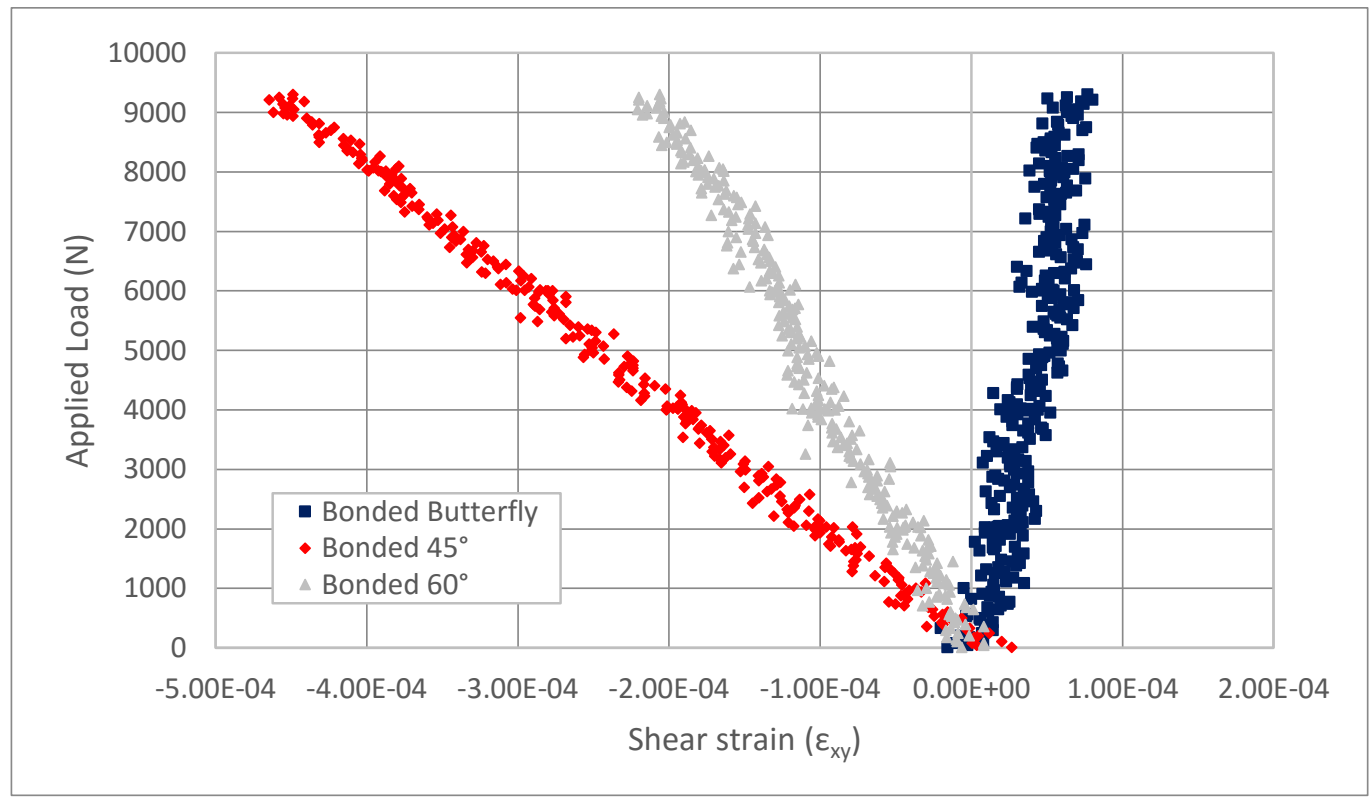

Figure 5.49: Load versus shear strain obtained from various locations in the bonded joint 


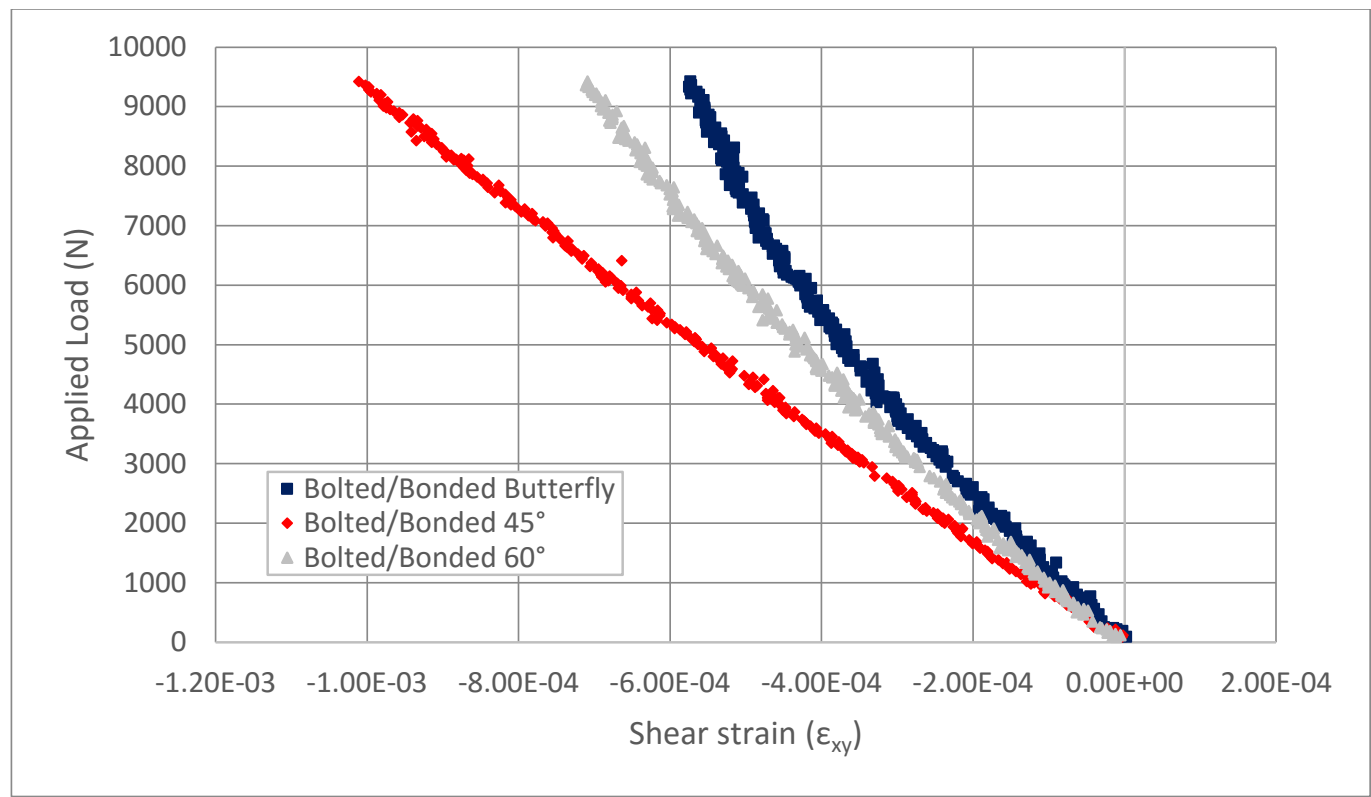

Figure 5.50: Load versus shear strain obtained from various locations in the bolted/bonded joint 


\section{Chapter 6: CONCLUSIONS}

The goal of this thesis was to investigate the DIC measurement technique to assess the behaviour of composite bolted/bonded joints. A number of tests was performed to understand and validate the DIC measurement technique. Additionally, three different joint configurations were attempted to achieve the goal of this thesis. The conclusions made from the projects are:

1) The DIC measurement technique applied to the undamaged aluminum test coupons successfully measured the axial strain. When it was compared to the strain from the extensometer, the percentage difference between two data sets was very large when the stroke values are very small; then the difference reduced to less than 5\%. The strain measure from the DIC analysis uses Green-Lagrange strain while the strain from the extensometer yields engineering strain, the percentage difference is within in the expectation. However, it must be noted that the result is limited to low-level strain. On the equipment side, when higher magnification is unnecessarily used, the strain obtained from the DIC analysis may be higher than the actual value.

2) The DIC measurement technique was used to measure the surface strain on the bolted/bonded joint. The result from the DIC technique detected the strain rate change due to the load path change, and this was confirmed with the instrumented bolt. The shear strain obtained from the DIC technique was compared to the result from the FEA model. There was a difference between two data sets. The possible cause of the gap would be the different material 
behaviour in the adhesive layer, the numerical (or systemic) errors, and the effect of out-of-plane displacement.

3) From Test Series 1, 100 microstrain may be the minimum value that the current DIC equipment can accurately measure. With this finding, the strain values below 100 microstrains in Test Series 2 and Test Series 3 may be incorrect. It indicates that some locations may not be reliable enough for the analysis. The regions that have relatively higher strains or the magnification may be needed to obtain the behaviour of the joint.

4) In Test Series 3, the objective of particular interest in this thesis was to estimate the load transfer through the bolt, could not be achieved due to irregular patterns observed from the surface strain fields in different joint configurations. One of the irregular patterns observed is that the surface of the bolted/bonded joint experienced higher strain values than that of the bonded joint with a hole, which contradicted the load versus stroke curve data. These irregular patterns may be due the variations in the joint configurations. Furthermore, many factors could have contributed the surface strain result. Such factors include preload on the bolt due to torque, or adhesive layer stress distribution. More studies are required to fully explain the behaviour of the joints while minimizing these variations.

5) FAA Advisory Circular 20-107B (2009) states that the fail-safe design is required to permit the certification of bonded joints in primary aircraft structures (Federal Aviation Administration, 2009), and Hart-Smith (1985) 
insisted that the bolted/bonded joints should be used for their fail-safe feature (Hart-Smith, 1985). Hence, it is believed that the bolted/bonded joint configuration is a promising technique to enable the fail-safe design of traditional joints. On the other hand, the improvement in joint strength using softer paste adhesive is still not conclusive since the experimental work in this thesis did not conclusively measure the relative load sharing by the two load paths. 


\section{Chapter 7: RECOMMENDATIONS AND FUTURE WORK}

The goal of this thesis to investigate the mechanical behaviour of bolted/bonded hybrid joints was largely achieved; however, there are more topics to investigate specifically load sharing in hybrid bolted/bonded joint. Below are recommendations for further investigations:

- Although 2D-DIC technique may not be enough to investigate load transfer through the bolt, the surface strain from the DIC analysis helped to observe unexpected behaviours, such as sudden shear strain drops in the bolted joint or higher shear strains in the bolted/bonded joint. There is a lack of information to conclude that these behaviours are normal. More tests are recommended for better understanding.

- The effect of the current hardware to the DIC measurement technique is not fully understood. There is no standard available to obtain the effect. In the long term, routine tests are recommended to be established for understanding the effect of the hardware to the DIC measurement technique.

- Manufacturing of composite test coupons should be more carefully approached. When the coupon includes ductile paste adhesives, even more care should be taken. The paste adhesive, Hysol ${ }^{\circledR}$ EA 9361 (Henkel Co.), caused jamming the diamond blade and stopping the table saw motor rotating. It resulted in applying more pressure to the coupon, and 
ultimately shifting the coupon. Therefore, the more careful approach is recommended to minimize manufacturing defects or errors.

- During this thesis, a tripod was used to hold the camera in position. However, locating the tripod in the best position takes a long time. Also, there was a limitation in placing the tripod due to limited space available near the servohydraulic load frame. A customized camera holder that can be installed directly onto the load frame could allow better positioning of the camera.

- It must be noted that the DIC analysis program that this thesis used does not have a function to calculate engineering strain. The comparison carried on because strain measures do not have much variance when the strain level is low. Therefore, it is recommended to keep in mind that the strain variation is possible when two types of measurement techniques are simultaneously used. Also, a confirmation must be made that the strain measure used in the FEA matches with the DIC analysis.

The following sections present possible future work following this thesis.

\subsection{Three-Dimensional Digital Image Correlation (3D-DIC)}

Although 2D-DIC technique yielded reasonable strain fields in this thesis, the effect of out-of-plane displacement could not be removed from the result. The out-ofplane displacement was observed to be non-linear throughout the overlap length of the 
joint. Therefore, it cannot be simply removed from the 2D-DIC analysis. The 3D-DIC technique should be attempted to obtain in-plane strain fields that are unaffected by the out-of-plane displacement. The 3D-DIC technique is a stereo measurement method, in which deformation is tracked by two cameras as can be seen in Figure 7.1. The 3D-DIC technique requires the sophisticated software to analyze stereo images and time and cost to spend be significantly higher than the 2D-DIC technique. However, the 3D-DIC technique provides in-plane strain fields that are not affected by the out-of-plane displacements.

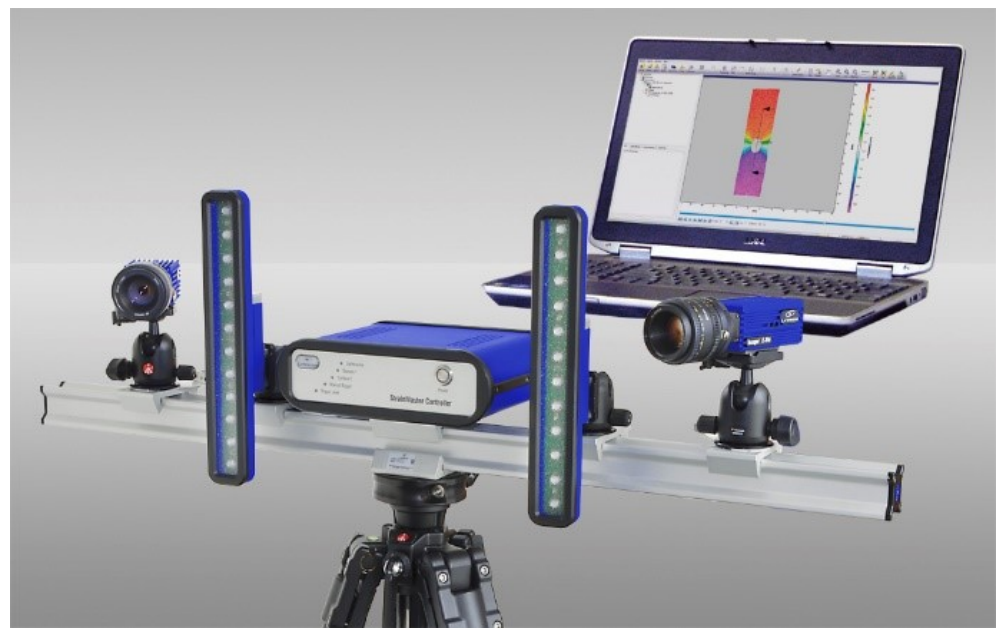

Figure 7.1: 3D-DIC equipment. (LaVision, 2016)

\subsection{D-DIC Technique Measurement on the EdGe of the JoInts}

Although the use of DIC to measure bolt load sharing through the measurement of surface strains with DIC could not be achieved from the experiment, a slightly different approach was performed by Ph.D. candidate Mr. Pedro Lopez-Cruz at Carleton University, who has been working on the same CRIAQ COMP 506 program. His 
approach was to use the DIC technique to measure the strain on the edge side of the joint and compare adhesive shear strain change due to different joint configurations. The example of 2D-DIC analysis result from the edge of the joint can be found in Figure 7.2. The graph in Figure 7.2 shows the adhesive shear strain at the point $1 \mathrm{~mm}$ away from the upper notch. The motivation for measuring the strain from the edge was based on two reasons. First, the edge side of the joint experienced less out-of-plane displacement effect than the front surface. Second, the adhesive is the most ductile component in the joint. Therefore, any change would be easily detectable. With higher magnification, the strain change from the different joint configurations using the DIC technique on the edge side of the joint was able to be identified. Also, the load transfer through the bolt was able to be estimated in the result. If the surface measurement simultaneously with the side measurement using two 2D-DIC measurements, it may be possible to explain unexpected behaviour detected from the surface better and estimate the load transfer through the bolt. Also, additional software for performing 3D-DIC is not required that leads to saving time and expense and providing more valuable data than a single 2D-DIC.
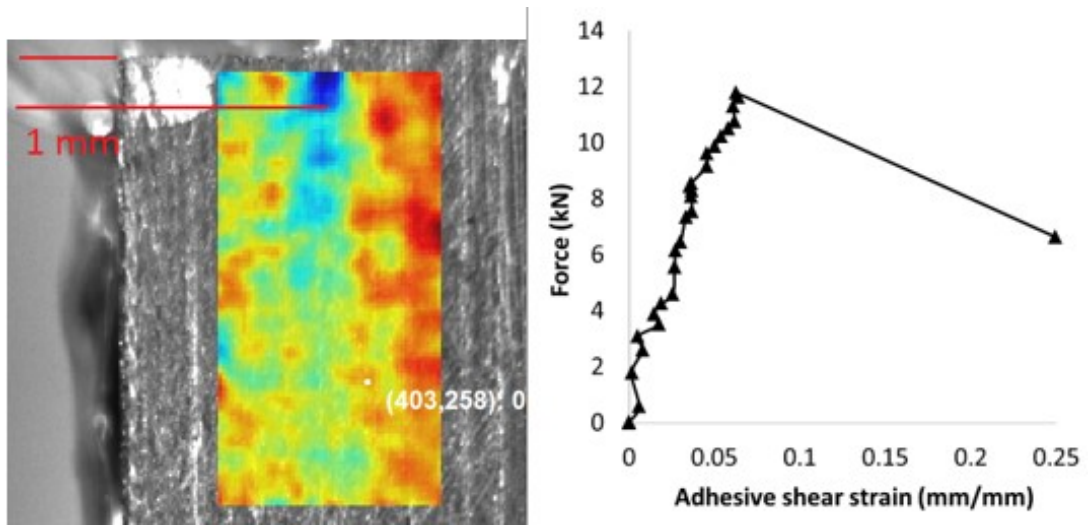

Figure 7.2: Example of DIC technique used on the edge of the joint (Lopez-Cruz, 2016) 


\subsection{Shape Sensing Technique using Fibre Optic Sensors}

A traditional technique to measure the bolt shear load transfer is the instrumented bolt. As mentioned previously, the limitation of the instrumented bolt is the diameter. There is a technology that does not have the size limitation and obtain the bolt strain directly. A development of fibre optic shape sensing technology has allowed obtaining strain various applications including aerospace fields (Polytech $\mathrm{GmbH}$, n.d.). The fibre optic sensing technology measure the deformation of the optical fibre by the beam deflection within the fibre. In certain applications, the fibre with 80 micrometer diameter is used for the shape sensing technique (Fraunhofer Heinrich Hertz Institute, 2015). Furthermore, the strain measurement with nanostrain scale has been studied using this technique (Chow, McClelland, Gray, \& Littler, 2005). If there is a way to embed thin optical fibre to the centre of the titanium bolt, the shape sensing technique should be able to detect even small deformation of the bolt. This technology could not be attempted due to the cost of the equipment. However, if it is available in the future, it would be worthwhile to attempt the application of this technology bolt load sharing measurements. 


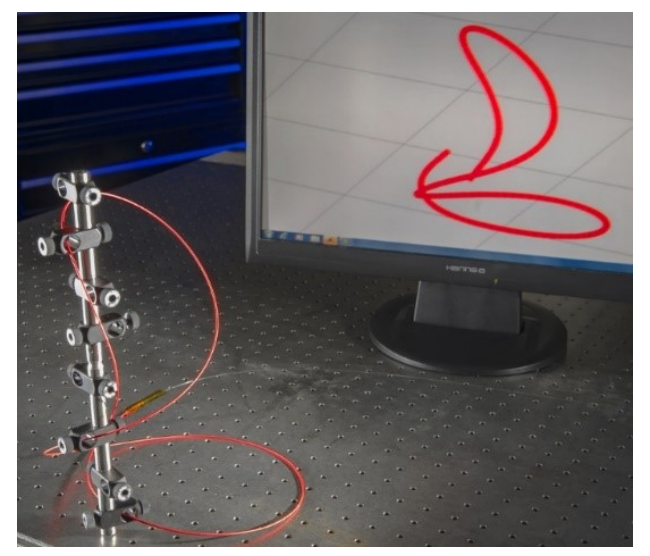

Figure 7.3: Fibre optic shape sensing technology (Beam S., 2014) 


\section{REFERENCES}

ASTM Standard D5961/D5961M - 13. 1996 (2013). "Standard Test Method for Bearing Response of Polymer Matrix Composite Laminates,” ASTM International, West Conshohocken, PA, 2016, DOI: 10.1520/D5961_D5961M-13, www.astm.org

Axis Communications AB. (2010). CCD and CMOS sensor technology. Retrieved from http://www.axis.com/files/whitepaper/wp_ccd_cmos_40722_en_1010_lo.pdf

Ayatollahi, M. R., \& Nejati, M. (2011). Experimental evaluation of stress field around the sharp notches using photoelasticity. Materials \& Design, 32(2), 561-569. doi:10.1016/j.matdes.2010.08.024

Backman, D., Li, G., \& Sears, T. (2011). Determining the Strain Distribution in Bonded and Bolted/Bonded Composite Butt Joints Using the Digital Image Correlation Technique and Finite Element Methods. 401-406. doi:10.1007/978-1-4614-0228-2_48

Beam. S. (2014). Device Feature in Upcoming NASA Webinar. [image] Available at: https://technologygateway.nasa.gov/images/misc/moore-shape-sensing.jpg [Accessed 23 Apr. 2016]

Blanter, Y. M., \& Büttiker, M. (2000). Shot noise in mesoscopic conductors. Physics Reports, 336(1-2), 1166. doi:http://dx.doi.org/10.1016/S0370-1573(99)00123-4

Camanho, P. P., Bowron, S., \& Matthews, F. L. (1998). Failure Mechanisms in Bolted CFRP. Journal of Reinforced Plastics and Composites, 17(3), 205-233.

Camanho, P. P., Tavares, C. M. L., de Oliveira, R., Marques, A. T., \& Ferreira, A. J. M. (2005). Increasing the efficiency of composite single-shear lap joints using bonded inserts. Composites Part B: Engineering, 36(5), 372-383. doi:10.1016/j.compositesb.2005.01.007

Canon Canada Inc. (n.d.). EOS Rebel XTi. [image] Available at:

http://www.canon.ca/inetCA/userfiles/image//CIG/digital\%20cameras/EOS/xti_586x186.gif

Chow, J. H., McClelland, D. E., Gray, M. B., \& Littler, I. C. M. (2005). Demonstration of a passive subpicostrain fiber strain sensor. Optics Letters, 30(15), 1923-1925. doi:10.1364/OL.30.001923

Chow, J. H., McClelland, D. E., Gray, M. B., \& Littler, I. C. M. (2005). Demonstration of a passive subpicostrain fiber strain sensor. Optics Letters, 30(15), 1923-1925. doi:10.1364/OL.30.001923

Collings, T. A. (1977). The strength of bolted joints in multi-directional cfrp laminates. Composites, 8(1), 43-55. doi:http://dx.doi.org/10.1016/0010-4361(77)90027-1

Comer, A. J., Katnam, K. B., Stanley, W. F., \& Young, T. M. (2013). Characterising the behaviour of composite single lap bonded joints using digital image correlation. International Journal of Adhesion and Adhesives, 40, 215-223. doi:http://dx.doi.org/10.1016/j.ijadhadh.2012.08.010

Cooke Co. (2002), SensiCam qe Operating Instructions. Retrived from http://alacron.com/clientuploads/directory/Cameras/COOKE/SensiCam.pdf

Corr, D., Accardi, M., Graham-Brady, L., \& Shah, S. (2007). Digital image correlation analysis of interfacial debonding properties and fracture behavior in concrete. Engineering Fracture Mechanics, 74(12), 109-121. doi:10.1016/j.engfracmech.2006.01.035 
CRIAQ. (2013). Design and Analysis of Hybrid (Bonded and Bolted) Joints for Aerospace Structures. In COMP-506 (Ed.): The Consortium for Research and Innovation in Aerospace in Québec. Retrieved from http://www.criaq.aero/media/articles/COMP-506.jpg

Cytec Solvay Group (2015). CYCOM® 5320-1 Epoxy Resin System. Retrieved from https://www.cytec.com/sites/default/files/datasheets/CYCOM\%205320-1\%20Rev\%20CR5.pdf

da Silva, L. F. M., \& Banea, M. D. (2009). Adhesively bonded joints in composite materials: an overview. Proceedings of the Institution of Mechanical Engineers, Part L: Journal of Materials: Design and Applications, 223(1), 1-18. doi:10.1243/14644207jmda219

da Silva, L. F. M., das Neves, P. J. C., Adams, R. D., Wang, A., \& Spelt, J. K. (2009). Analytical models of adhesively bonded joints-Part II: Comparative study. International Journal of Adhesion and Adhesives, 29(3), 331-341. doi:10.1016/j.jjadhadh.2008.06.007

da Silva, L. F. M., Rodrigues, T. N. S. S., Figueiredo, M. A. V., de Moura, M. F. S. F., \& Chousal, J. A. G. (2006). Effect of Adhesive Type and Thickness on the Lap Shear Strength. The Journal of Adhesion, 82(11), 1091-1115. doi:10.1080/00218460600948511

Di Franco, G., Fratini, L., \& Pasta, A. (2013). Analysis of the mechanical performance of hybrid (SPR/bonded) single-lap joints between CFRP panels and aluminum blanks. International Journal of Adhesion and Adhesives, 41, 24-32. doi:10.1016/j.jjadhadh.2012.10.008

Durão, L., Tavares, J., de Albuquerque, V., Marques, J., \& Andrade, O. (2014). Drilling Damage in Composite Material. Materials, 7(5), 3802-3819. doi:10.3390/ma7053802

Edmund Optics (2016). The Advantages of Telecentricity. Retrieved from http://www.edmundoptics.com/resources/application-notes/imaging/advantages-of-telecentricity/

Federal Aviation Administration (September, 2009). Advisory Circular 20-107B, Composite Aircraft Structure. Retrieved from: http://www.faa.gov/documentLibrary/media/Advisory_Circular/AC20-107B.pdf

Fedele, R., Raka, B., Hild, F., \& Roux, S. (2009). Identification of adhesive properties in GLARE assemblies using digital image correlation. Journal of the Mechanics and Physics of Solids, 57(7), 10031016. doi:10.1016/j.jmps.2009.04.005

Fraunhofer Heinrich Hertz Institute. (2015). 3D fiber optical shape and motion sensing. Retrieved from http://www.hhi.fraunhofer.de/fileadmin/user_upload/Departments/Fiber_Optical_Sensor_Systems/Fiber_O ptical_Microsensors/Fiber_Optical_3D_Shape_Sensing_FiberNavi_/15-06-01_3D-Shape-Sensing.pdf

Goland, M., \& Reissner, S. (1944). The Stress in Cemented Joints. J. Appl. Mech, 11(1), A17-27.

Hale, J. (2006). Boeing 787 from the Ground Up. AERO. Retrieved from

http://www.boeing.com/commercial/aeromagazine/articles/qtr_4_06/article_04_2.html

Hart-Smith, L. J. (1974). Analysis and design of advanced composite bonded joints. Retrieved from NASA, Washington, United States:

Hart-Smith, L. J. (1976). Bolted Joints in Graphite-Epoxy Composites (NASA CR-144899). Retrieved from NASA, Washington, United States

Hart-Smith, L. J. (1985). Bonded-bolted composite joints. Journal of Aircraft, 22(11), 993-1000.

doi: $10.2514 / 3.45237$ 
Hart-Smith, L. J. (2003). Adhesively Bonded Joints for Fibrous Composite Structures. In L. Tong \& C. Soutis (Eds.), Recent Advances in Structural Joints and Repairs for Composite Materials (pp. 173-210). Dordrecht: Springer Netherlands.

Henkel Corporation Aerospace. (2013). LOCTITE EA 9361 AERO Epoxy Paste Adhesive Technical Process Bulletin. Retrieved from https://www.pccomposites.com/wp-content/uploads/2015/07/PCRS9361QT_TDS.pdf

Herring, D. H. (2014, July). The Heat Treatment of Aerospace Fasteners. Fastener World, 147, 309-316.

Heslehurst, R. B. (2013). Design and analysis of structural joints with composite materials / Rikard Benton Heslehurst. Lancaster, Pa: DEStech Publications.

Hild, F., \& Roux, S. (2006). Digital Image Correlation: from Displacement Measurement to Identification of Elastic Properties - a Review. Strain, 42(2), 69-80. doi:10.1111/j.1475-1305.2006.00258.x

Hua, T., Xie, H., Wang, S., Hu, Z., Chen, P., \& Zhang, Q. (2011). Evaluation of the quality of a speckle pattern in the digital image correlation method by mean subset fluctuation. Optics \& Laser Technology, 43(1), 9-13. doi:http://dx.doi.org/10.1016/j.optlastec.2010.04.010

Ji, Y. K., \& Ong, J. W. (1994). A Study on the Acoustic Emission Characteristics of the Carbon Fiber Reinforced Plastics. In R. E. Green, K. J. Kozaczek, \& C. O. Ruud (Eds.), Nondestructive Characterization of Materials VI (pp. 207-214). Boston, MA: Springer US.

Kelly, G. (2005). Load transfer in hybrid (bonded/bolted) composite single-lap joints. Composite Structures, 69(1), 35-43. doi:10.1016/j.compstruct.2004.04.016

Khashaba, U. A., Sallam, H. E. M., Al-Shorbagy, A. E., \& Seif, M. A. (2006). Effect of washer size and tightening torque on the performance of bolted joints in composite structures. Composite Structures, 73(3), 310-317. doi:http://dx.doi.org/10.1016/j.compstruct.2005.02.004

Knauss, W. G., Chasiotis, I., \& Huang, Y. (2002). Mechanical measurements at the micron and nanometer scales. Mechanics of Materials, 35(3-6), 217-231. doi:10.1016/S0167-6636(02)00271-5

Kumar, R. V., Bhat, M., \& Murthy, C. (2013). Experimental analysis of composite single-lap joints using digital image correlation and comparison with theoretical models. Journal of Reinforced Plastics and Composites, 32(23), 1858-1876. doi:10.1177/0731684413500859

Kuphaldt, T. R. Full-bridge strain gauge circuit. In 00431.png (Ed.). Idaho, USA: EETech Media, LLC.

Lava, P. (2015). Practical considerations in DIC measurements. Retrieved from http://www.matchidmbc.be/Presentation/Edinburgh_DIC_2015.pdf

Lava, P., Cooreman, S., \& Debruyne, D. (2010). Study of systematic errors in strain fields obtained via DIC using heterogeneous deformation generated by plastic FEA. Optics and Lasers in Engineering, 48(4), 457-468. doi:10.1016/j.optlaseng.2009.08.013

Lava, P., Coppieters, S., Van Hecke, R., Van Houtte, P., \& Debruyne, D. (2014). Digital Image Correlation in the Classroom: Determining Stress Concentration Factors with Webcams. Experimental Techniques, 38(4), 72-80. doi:10.1111/j.1747-1567.2012.00813.x

LaVision, (2016). Strain Master Portable. [image] Available at:

http://www.lavision.de/cms_images/products/StrainMasterPortable_new.jpg 
Lecompte, D., Smits, A., Bossuyt, S., Sol, H., Vantomme, J., Van Hemelrijck, D., \& Habraken, A. M. (2006). Quality assessment of speckle patterns for digital image correlation. Optics and Lasers in Engineering, 44(11), 1132-1145. doi:http://dx.doi.org/10.1016/j.optlaseng.2005.10.004

Lopez-Cruz, P. (2016). Experimental and Numerical Study on Bolted/Bonded Composite Joints for Aircraft (Unpublished doctoral dissertation), Carleton University, ON: Ottawa.

Lu, H., \& Cary, P. D. (2000). Deformation Measurements by Digital Image Correlation: Implementation of a Second-Order Displacement Gradient. Experimental Mechanics, 40(4), 393-400. doi: $10.1177 / 001448510004000407$

MatchID, (2016). MatchID: Metrology beyond colors. Retrieved from: http://matchidmbc.be/

McCormick, N. D., \& Lord, J. D. (2010). Digital Image Correlation. Materials Today, 13(12), 52-54. doi:10.1016/S1369-7021(10)70235-2

Moroni, F., Pirondi, A., \& Kleiner, F. (2010). Experimental analysis and comparison of the strength of simple and hybrid structural joints. International Journal of Adhesion and Adhesives, 30(5), 367-379. doi:10.1016/j.ijadhadh.2010.01.005

Oluseyi, H. M., Bercovitz, J. H., Karcher, A., Hernikl, C. D., Miller, T., Uslenghi, M., . . Levi, M. E. (2004). LBNL four-side buttable CCD package development.

Olympus America Inc. (n.d.). Olympus SP-350. [image] Available at:

http://www.olympusamerica.com/cpg_section/images/support/product/sup 1188.jpg [Accessed 20 Apr. 2016].

Pan, B., Qian, K., Xie, H., \& Asundi, A. (2009). Two-dimensional digital image correlation for in-plane displacement and strain measurement: a review. Measurement Science and Technology, 20(6), 062001. doi:10.1088/0957-0233/20/6/062001

Pan, B., Xie, H., \& Wang, Z. (2010). Equivalence of digital image correlation criteria for pattern matching. Applied Optics, 49(28), 5501-5509. doi:10.1364/AO.49.005501

Pan, B., Xie, H., Guo, Z., \& Hua, T. (2007). Full-field strain measurement using a two-dimensional Savitzky-Golay digital differentiator in digital image correlation. Optical Engineering, 46(3), 033601033601-033610. doi:10.1117/1.2714926

Pan, B., Xie, H., Wang, Z., Qian, K., \& Wang, Z. (2008). Study on subset size selection in digital image correlation for speckle patterns. Optics Express, 16(10), 7037-7048. doi:10.1364/OE.16.007037

Pantelakis, S., \& Tserpes, K. I. (2013). Adhesive bonding of composite aircraft structures: Challenges and recent developments. Science China Physics, Mechanics and Astronomy, 57(1), 2-11. doi:10.1007/s11433013-5274-3

PCO AG. (2016). SensiCam qe. [image] Available at: http://www.pco.de/fileadmin/user_upload/pcoproduct photos/sensicam blue free 1 1020p.jpg [Accessed 20 Apr. 2016].

Phillips, J. W. (2008). 6. Photoelasticity. Retrieved from

http://www.ifsc.usp.br/ lavfis/images/BDApostilas/ApEfFotoelastico/photoelasticity.pdf

Polytech GmbH. (n.d.). Shape Sensing Application Note. Retrieved from http://www.polytec.com/fileadmin/user_uploads/Products/Faseroptische_Sensorik/documents/PH_TFT_AP PNOTE__Shape_Sensing.pdf 
Post, D. (1979). Photoelasticity. Experimental Mechanics, 19(5), 176-192. doi:10.1007/BF02324263

Pramanik, A. (2013). Problems and solutions in machining of titanium alloys. The International Journal of Advanced Manufacturing Technology, 70(5), 919-928. doi:10.1007/s00170-013-5326-x

Quantum Scientific Imaging, Inc. (2008). Understanding CCD Read Noise. Retrieved from http://qsimaging.com/ccd_noise.html

Ramesh, K., Gupta, S., \& Kelkar, A. A. (1997). Evaluation of stress field parameters in fracture mechanics by photoelasticity—Revisited. Engineering Fracture Mechanics, 56(1), 25-45.

doi:http://dx.doi.org/10.1016/S0013-7944(96)00098-7

Ramesh, K., Kasimayan, T., \& Neethi Simon, B. (2011). Digital photoelasticity - A comprehensive review. The Journal of Strain Analysis for Engineering Design, 46(4), 245-266.

Robert, L., Nazaret, F., Cutard, T., \& Orteu, J.-J. (2007). Use of 3-D Digital Image Correlation to characterize the mechanical behavior of a Fiber Reinforced Refractory Castable. Experimental Mechanics, 47, 761-773. doi:10.1007/s11340-007-9062-8

Robinson, M., \& Kosmatka, J. (2012). Performance of Bonded/Bolted Hybrid Joints. doi:10.2514/6.20121451

Sadowski, T., Kneć, M., \& Golewski, P. (2010). Experimental investigations and numerical modelling of steel adhesive joints reinforced by rivets. International Journal of Adhesion and Adhesives, 30(5), 338-346. doi:10.1016/j.ijadhadh.2009.11.004

Schreier, H. W., \& Sutton, M. A. (2002). Systematic errors in digital image correlation due to undermatched subset shape functions. Experimental Mechanics, 42(3), 303-310. doi:10.1007/BF02410987

Schreier, H. W., Braasch, J. R., \& Sutton, M. A. (2000). Systematic errors in digital image correlation caused by intensity interpolation. Optical Engineering, 39(11), 2915-2921. doi:10.1117/1.1314593

Stelmack, L. (2008, April, 2014-06-10). Surface Preparation for Bonding. Retrieved from http://www.northerncomposites.com/docs/default-source/default-document-library/surface-preparation-forbonding.pdf?sfvrsn=2

Stewart, M., \& Stewart, M. (1997). An experimental investigation of composite bonded and/or bolted repairs using single lap joint designs. doi:10.2514/6.1997-1339

Sutton, M. A., Wolters, W. J., Peters, W. H., Ranson, W. F., \& McNeill, S. R. (1983). Determination of displacements using an improved digital correlation method. Image Vision Comput., 1(3), 133-139.

Sutton, M. A., Yan, J. H., Tiwari, V., Schreier, H. W., \& Orteu, J. J. (2008). The effect of out-of-plane motion on 2D and 3D digital image correlation measurements. Optics and Lasers in Engineering, 46(10), 746-757. doi:10.1016/j.optlaseng.2008.05.005

Tong, W. (2005). An Evaluation of Digital Image Correlation Criteria for Strain Mapping Applications. Strain, 41(4), 167-175. doi:10.1111/j.1475-1305.2005.00227.x

U.S. Government Accountability Office (2011, September). Aviation Safety: Status of FAA's Actions to Oversee the Safety of Composite Airplanes. (Publication No. GAO-11-849). Retrieved from:

http://www.gao.gov/assets/590/585341.pdf 
Vallée, T., Tannert, T., Meena, R., \& Hehl, S. (2013). Dimensioning method for bolted, adhesively bonded, and hybrid joints involving Fibre-Reinforced-Polymers. Composites Part B: Engineering, 46, 179-187.

doi:10.1016/j.compositesb.2012.09.074

Volkersen, O. (1938). Die nietkraftverteilung in zugbeanspruchten nietverbindungen mit konstanten laschenquerschnitten. Luftfahrtforschung, 15, 41-47.

Wang, Z. Y., Li, H. Q., Tong, J. W., \& Ruan, J. T. (2007). Statistical Analysis of the Effect of Intensity Pattern Noise on the Displacement Measurement Precision of Digital Image Correlation Using Selfcorrelated Images. Experimental Mechanics, 47(5), 701-707. doi:10.1007/s11340-006-9005-9

Yao, X. F., Meng, L. B., Jin, J. C., \& Yeh, H. Y. (2005). Full-field deformation measurement of fiber composite pressure vessel using digital speckle correlation method. Polymer Testing, 24(2), 245-251. doi:10.1016/j.polymertesting.2004.05.009

Yavari, V., Rajabi, I., Daneshvar, F., \& Kadivar, M. H. (2009). On the stress distribution around the hole in mechanically fastened joints. Mechanics Research Communications, 36(3), 373-380.

doi:10.1016/j.mechrescom.2008.10.005 


\section{Appendix A. TeChNICAL SPECIFICATION OF CAMERAS}

Table A.1: Technical specifications of cameras

\begin{tabular}{|c||c|c|c|}
\hline & Olympus SP 350 & Canon Rebel XTi & Cooke SensiCam qe \\
\hline \hline Sensor & 8.0 Megapixel CCD & 10.1 Megapixel CMOS & 1.3 Megapixel CCD \\
\hline Sensor size & $7.18 \mathrm{~mm}$ by $5.32 \mathrm{~mm}$ & $22.4 \mathrm{~mm}$ by $14.8 \mathrm{~mm}$ & $8.8 \mathrm{~mm}$ by $6.6 \mathrm{~mm}$ \\
\hline Shutter Speed & $1 / 2000 \mathrm{sec}-15 \mathrm{sec}$ & $1 / 4000 \mathrm{sec}-30 \mathrm{sec}$ & $500 \mathrm{~ns}-3600 \mathrm{sec}$ \\
\hline $\begin{array}{c}\text { Maximum Image } \\
\text { Size }\end{array}$ & $3264 \mathrm{px}$ by $2448 \mathrm{px}$ & $3888 \mathrm{px}$ by $2592 \mathrm{px}$ & $1376 \mathrm{px}$ by $1040 \mathrm{px}$ \\
\hline Lens Mount & N/A & Canon EF and EF-S & C-Mount \\
\hline Maximum FPS & 2.4 FPS up to 2 frames & 3 FPS up to 27 frames & $10 \mathrm{FPS}$ \\
\hline Trigger & N/A & $\begin{array}{c}\text { Soft-touch } \\
\text { electromagnetic release } \\
\text { Remote control } \\
\text { Wireless remote control }\end{array}$ & $\begin{array}{c}\text { Software } \\
\text { TTL (Transistor }- \\
\text { Transistor Level) }\end{array}$ \\
\hline Sensor cooling & No & No & Yes down to $-12^{\circ} \mathrm{C}$ \\
\hline $\begin{array}{c}\text { Recording } \\
\text { Medium }\end{array}$ & $\begin{array}{c}25 \mathrm{MB} \text { internal memory } \\
\text { xD memory card }\end{array}$ & $\begin{array}{c}0 \mathrm{MB} \text { internal memory } \\
\text { CF memory card }\end{array}$ & $\begin{array}{c}900 \mathrm{MB} \text { internal memory } \\
\text { no expansion }\end{array}$ \\
\hline Weight & $0.195 \mathrm{~kg}$ & 0.510 kg (body only) & 1.6 kg (body only) \\
\hline
\end{tabular}




\section{Appendix B.DIMENSIONS Of TEST COUPONS}

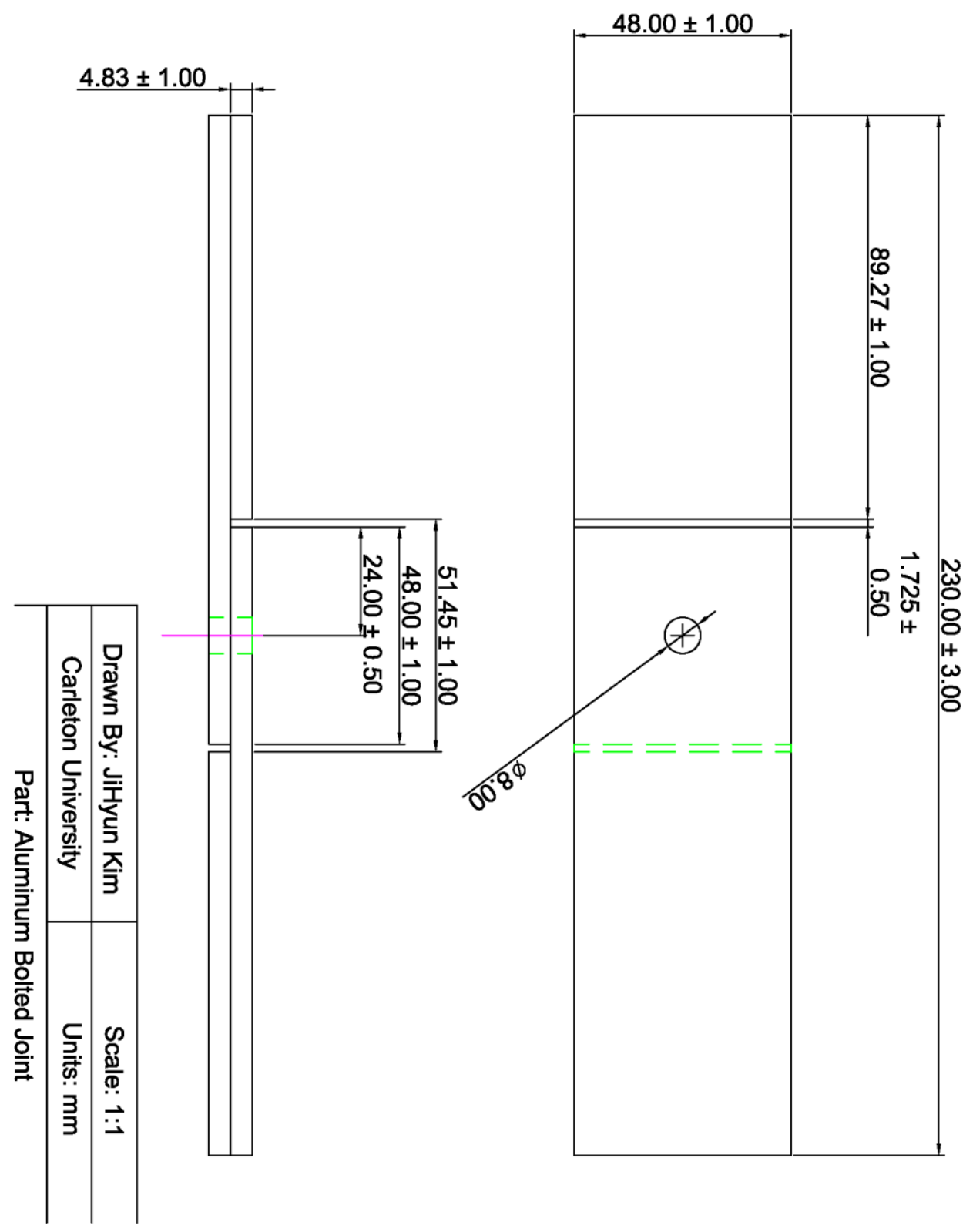

* The drawings are $60 \%$ of the actual size due to spacing 


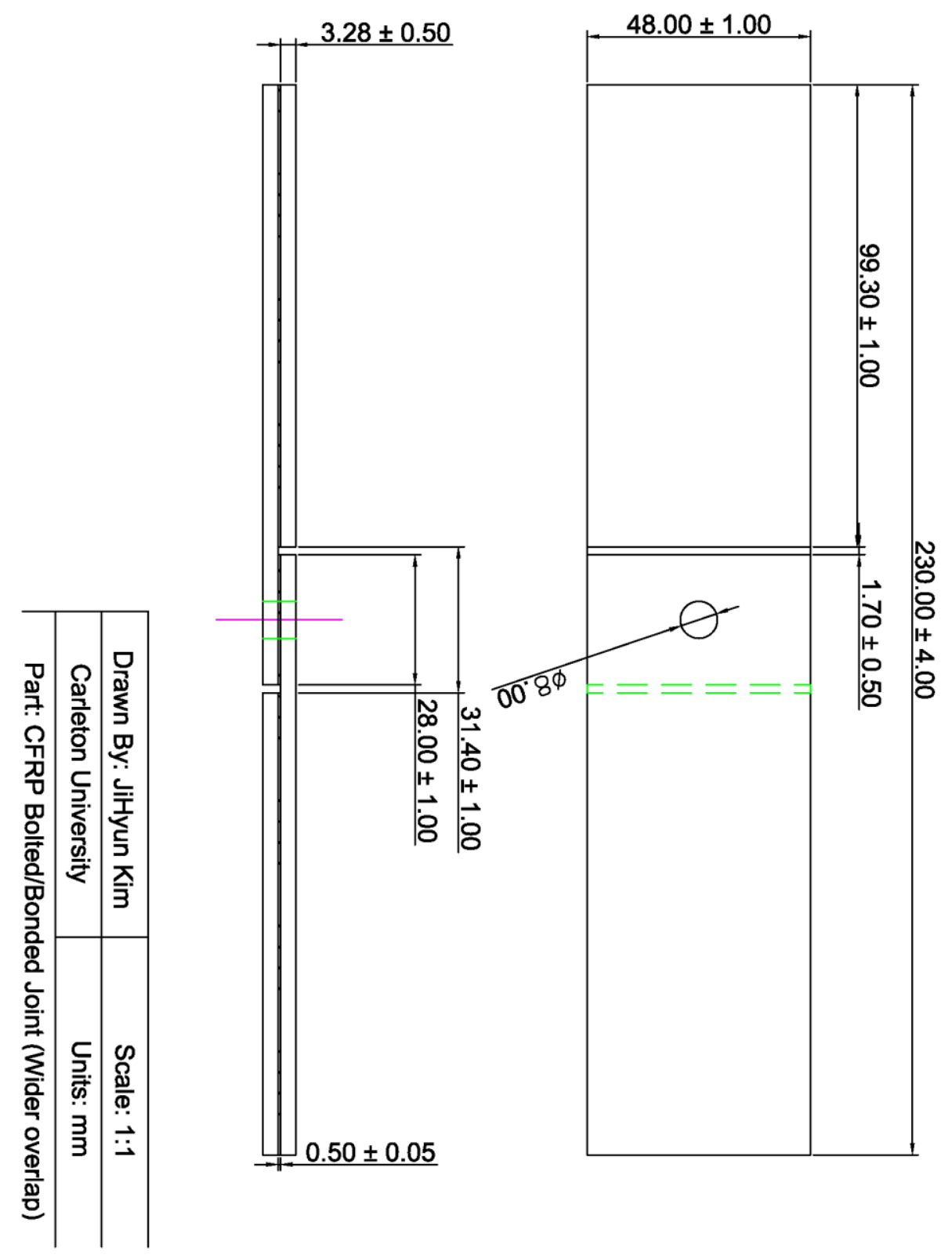

* The drawings are $60 \%$ of the actual size due to spacing 


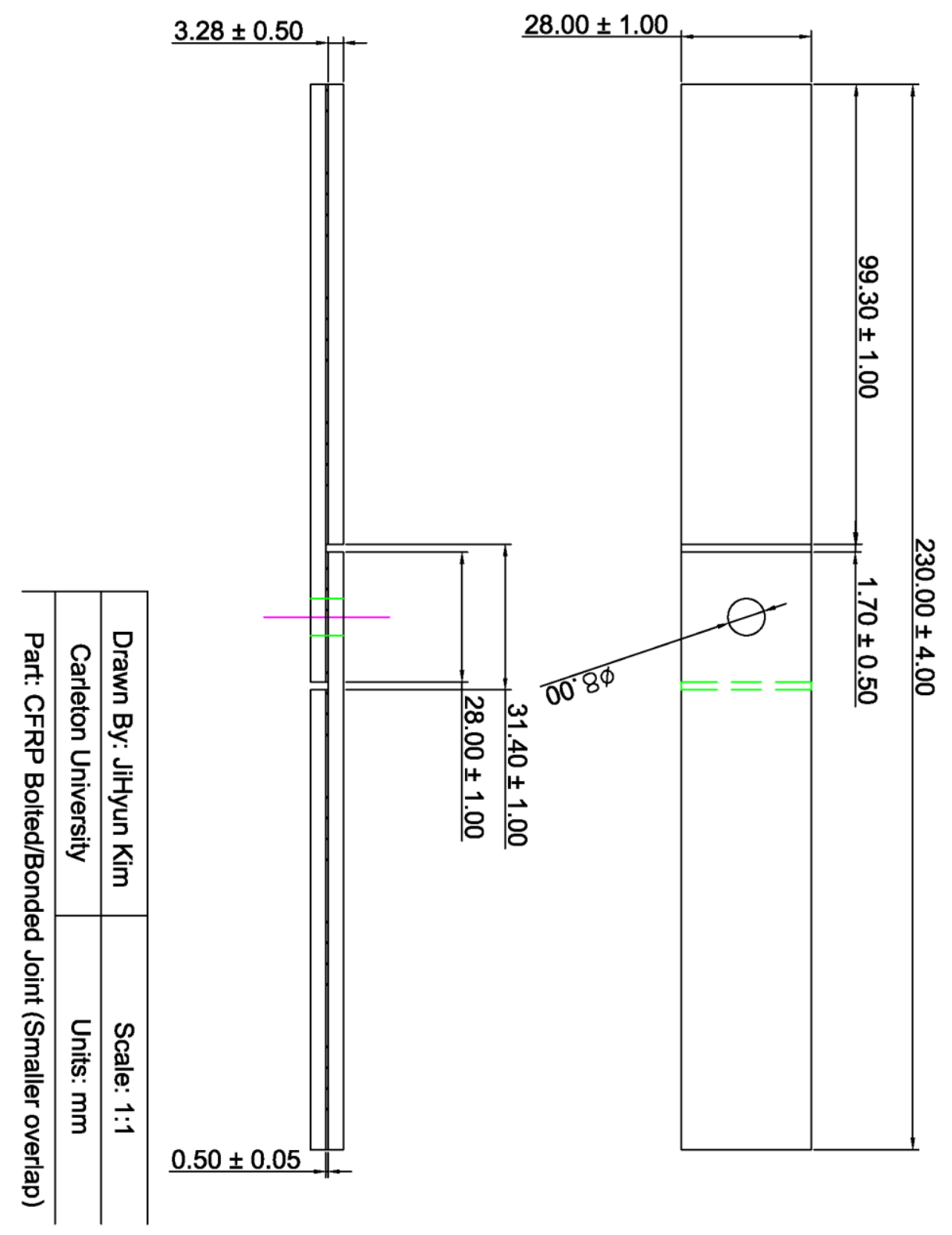

* The drawings are $60 \%$ of the actual size due to spacing 


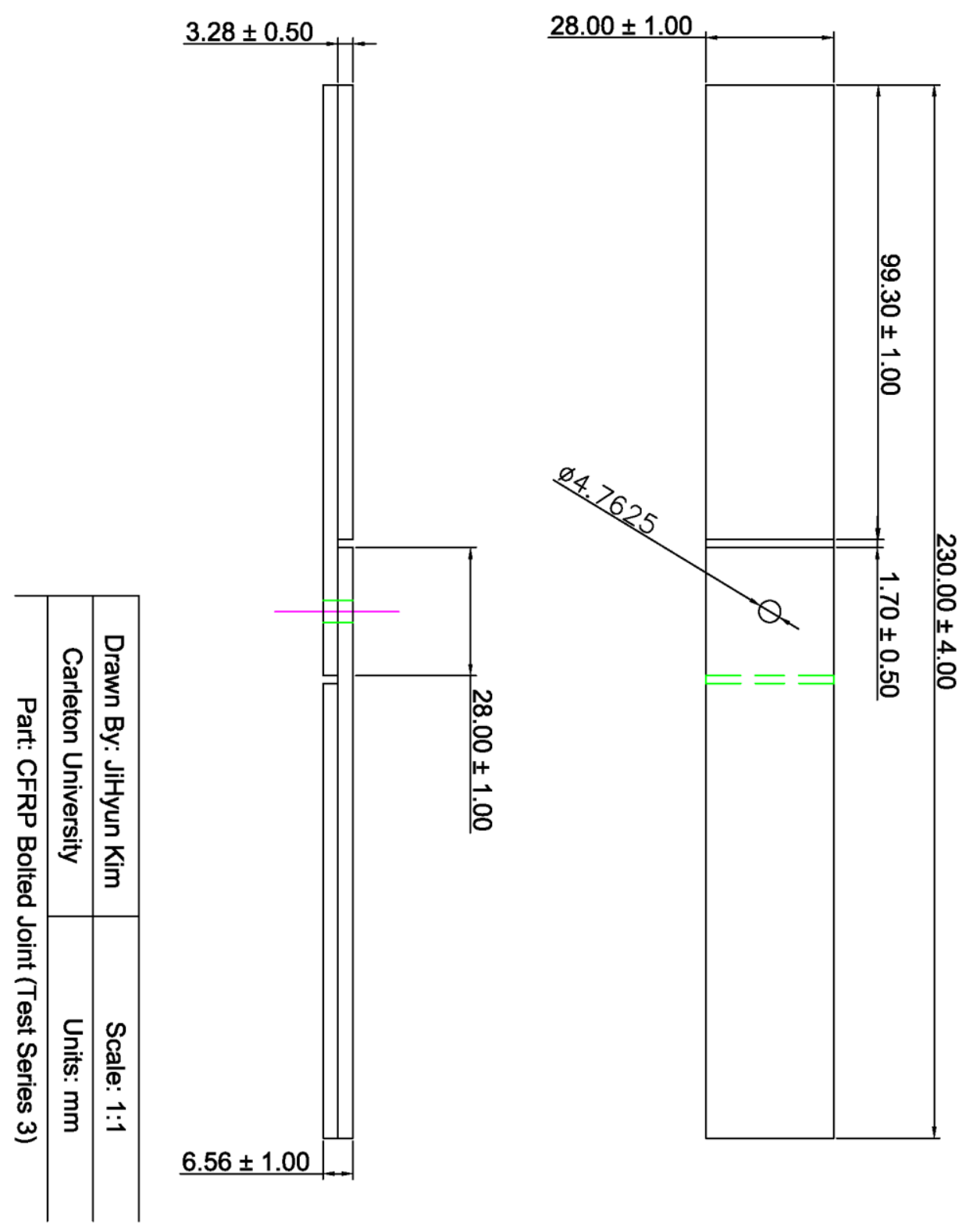

* The drawings are $60 \%$ of the actual size due to spacing 


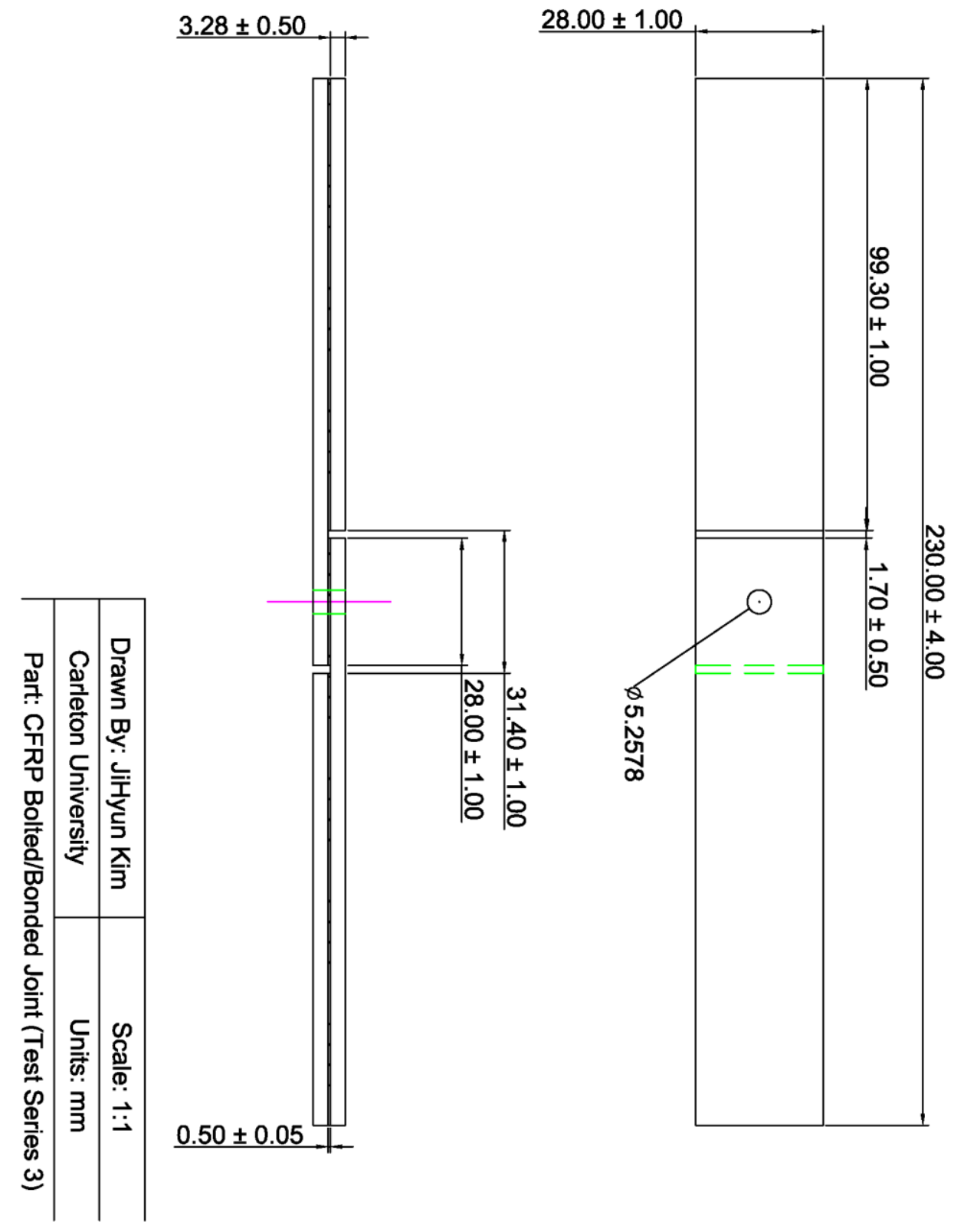

* The drawings are $60 \%$ of the actual size due to spacing 

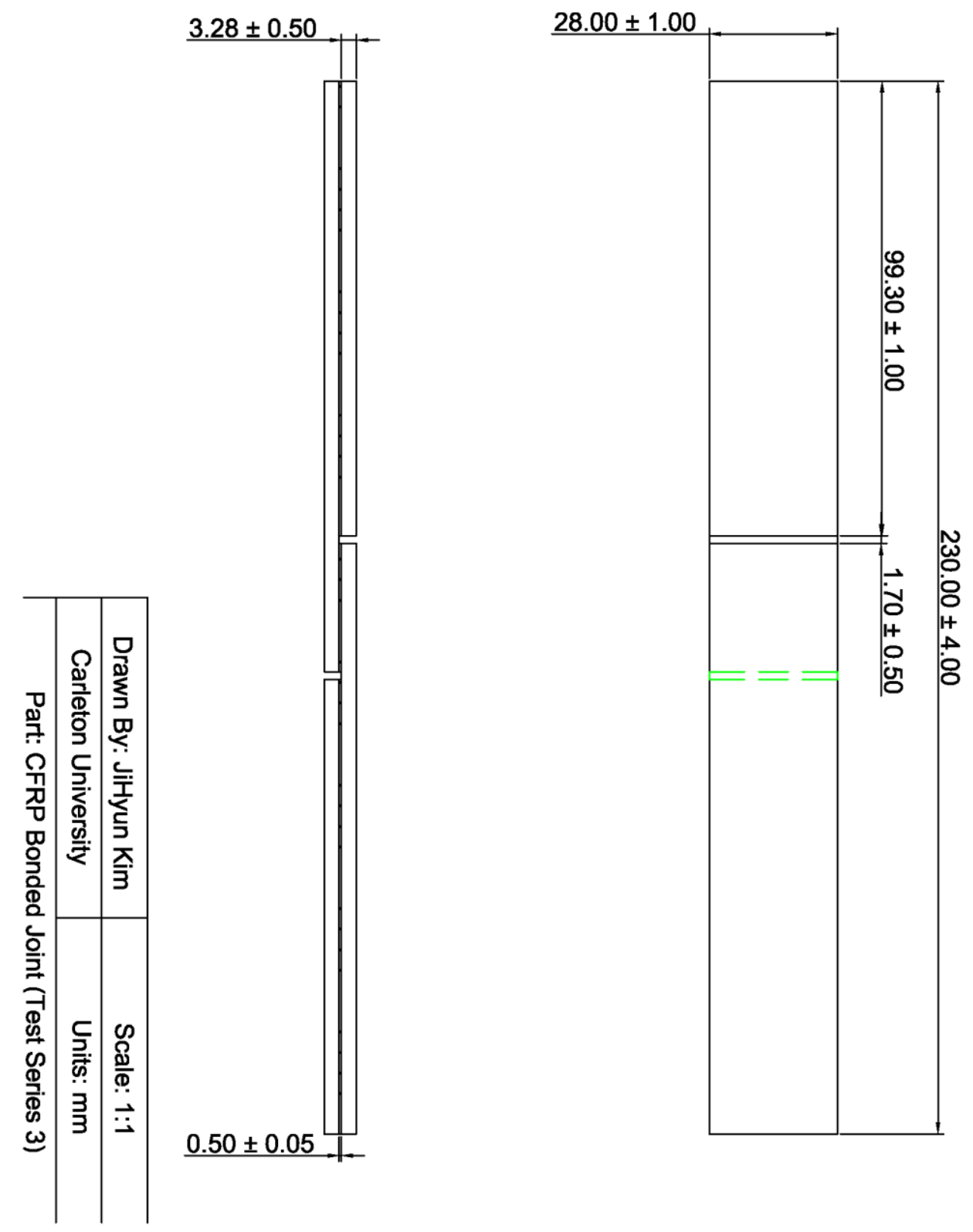

* The drawings are $60 \%$ of the actual size due to spacing 


\section{Appendix C.Model Numbers AND SERIAL NumBERS}

Table C.1: Equipment model number and serial number

\begin{tabular}{|c||c|c|c|}
\hline Equipment & Manufacturer & Model Number & Serial Number \\
\hline Load Unit & MTS Systems Co. & 318.10 & 1308366 \\
\hline 647 Hydraulic Wedge Grips & MTS Systems Co. & $647.02 \mathrm{~B}$ & $1026067 \mathrm{~B}$ \\
\hline 661 Axial Load Cells & MTS Systems Co. & $661.20 \mathrm{E}-01$ & 232973 \\
\hline FlexTest SE Controller & MTS Systems Co & 493.02 & $02007519 \mathrm{D}$ \\
\hline 634 Axial Extensometer & MTS Systems Co & $634.12 \mathrm{E}-24$ & $10212345 \mathrm{~B}$ \\
\hline SensiCam qe & Cooke Co. & N/A & 370 KL 1050 \\
\hline
\end{tabular}




\section{Appendix D. BOLt Shear LoAd CALCUlation}

The voltage recorded by the P-3 Strain Indicator (Vishay Co.) with a medium analogue output setting has the strain range of \pm 3200 -microstrains. In this strain range, the voltage output also is $\pm 1.25 \mathrm{~V}$. The strain value and the voltage output have a linear relationship. Hence, the strain can be obtained from the voltage output with the following equation:

$$
\varepsilon_{\text {bolt shear }}=\left(\left(1.25+V_{\text {out }}\right) \times 2560-3200\right) \times 10^{-6}
$$

Using the strain values obtained from the above equation and the known modulus of elasticity of the bolt material, the stress due to the bolt shear can be estimated as:

$$
\sigma_{\text {bolt shear }}=E_{\text {bolt material }} \times \varepsilon_{\text {bolt shear }}
$$

The load can be estimated by multiplying the bolt shear stress by the bolt crosssectional area. Assuming that the material removed to install the strain gage rosettes is small; the bolt shear load can be obtained using the following equation:

$$
F_{\text {bolt shear }}=\sigma_{\text {bolt shear }} \times A_{\text {bolt cross-sectional area }}
$$




\section{Appendix E. Applied LoAd VERsus AXIAL Strain From TEST}

\section{SERIES 3}

\section{Appendix E-1. AXIAL STRAIN IN X-Directions}

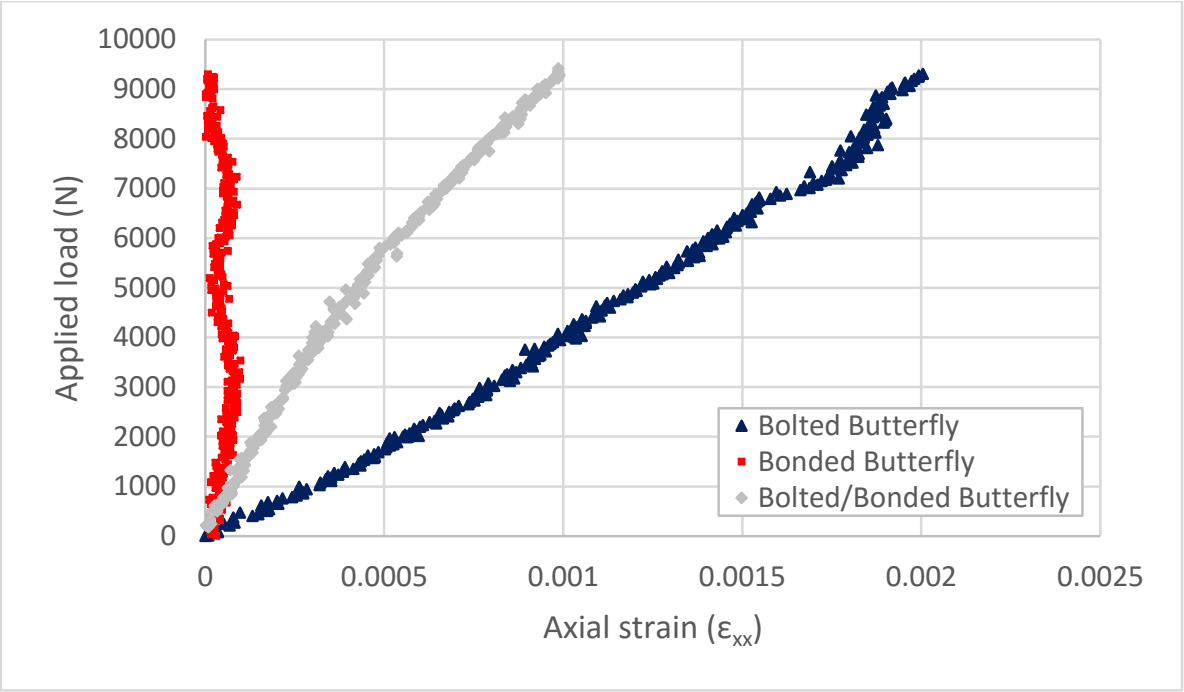

Figure E.1: Applied load versus axial strain $\left(\varepsilon_{x x}\right)$ of three different joints in the butterfly region

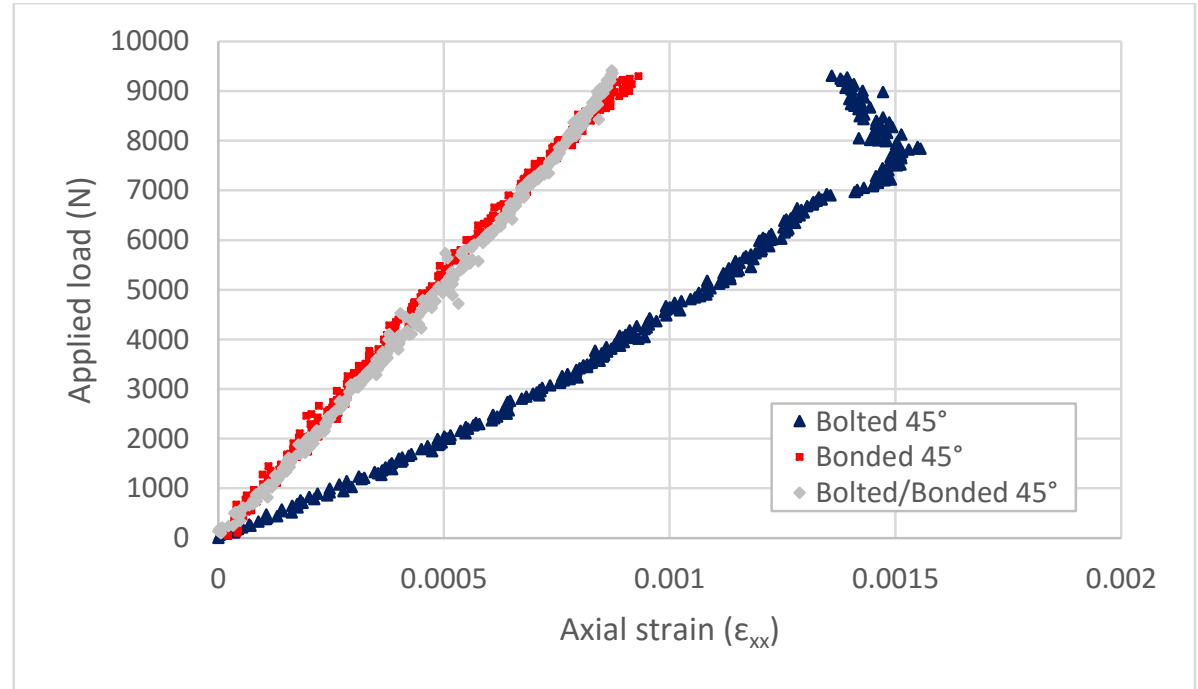

Figure E.2: Applied load versus axial strain ( $\left.\varepsilon_{x x}\right)$ of three different joints in the $45^{\circ}$ axis 


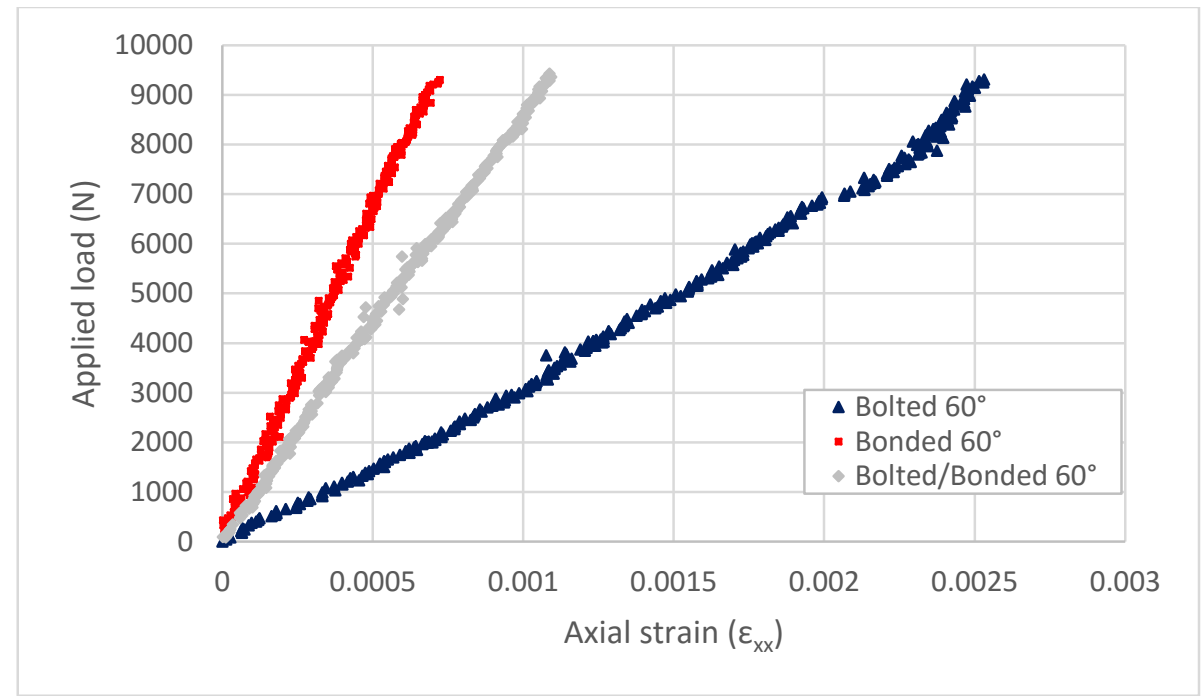

Figure E.3: Applied load versus axial strain $\left(\varepsilon_{x x}\right)$ of three different joints in the $60^{\circ}$ axis 


\section{Appendix E-2. AXIAL STRAIN IN Y-DIRECTION}

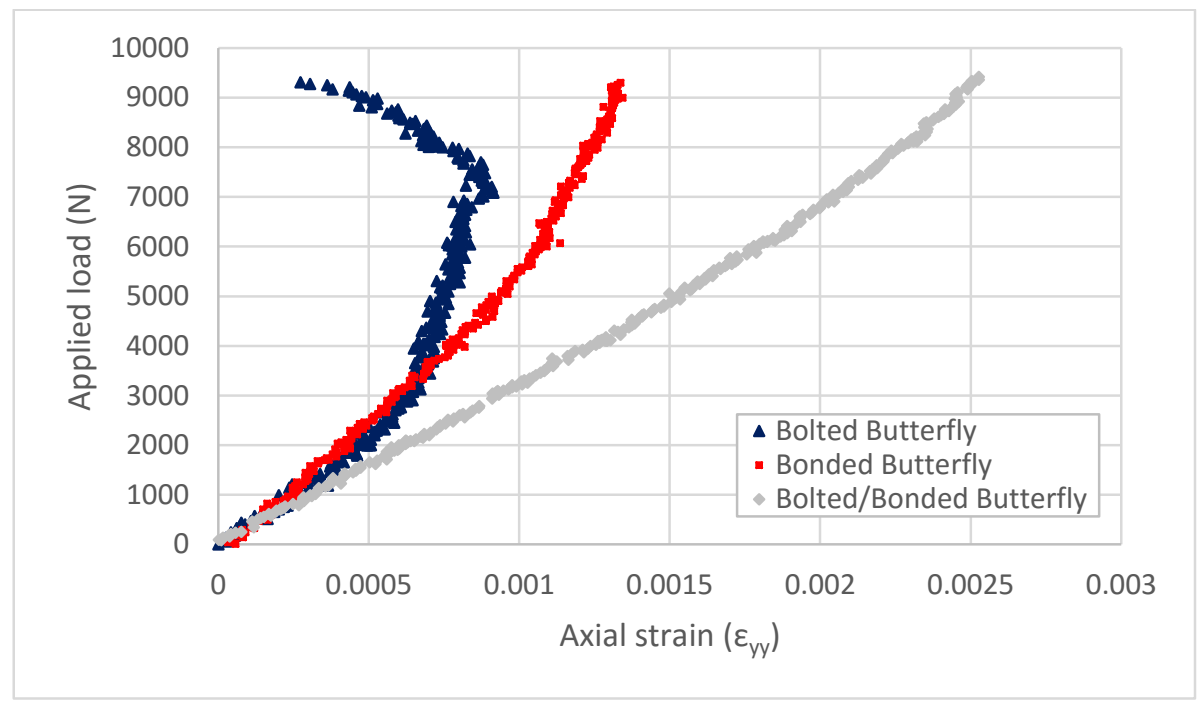

Figure E.4: Applied load versus axial strain ( $\left.\varepsilon_{y y}\right)$ comparison of three different joints in the butterfly region

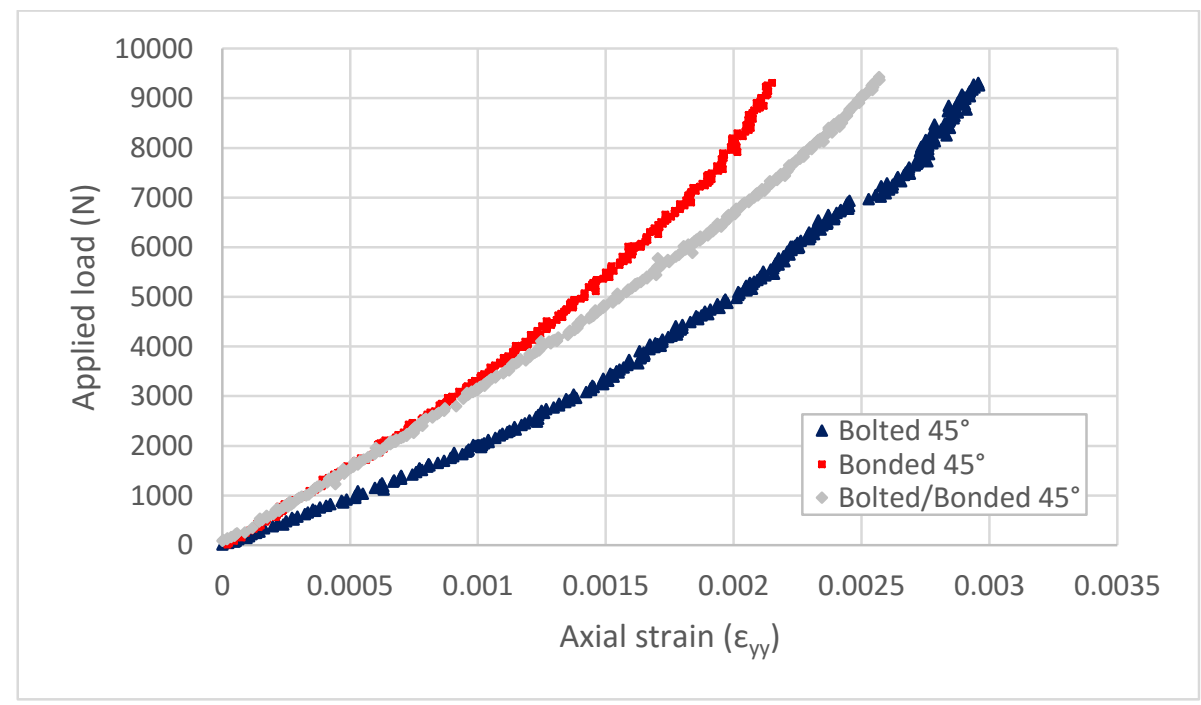

Figure E.5: Applied load versus axial strain $\left(\varepsilon_{y y}\right)$ comparison of three different joints in the $45^{\circ}$ axis 


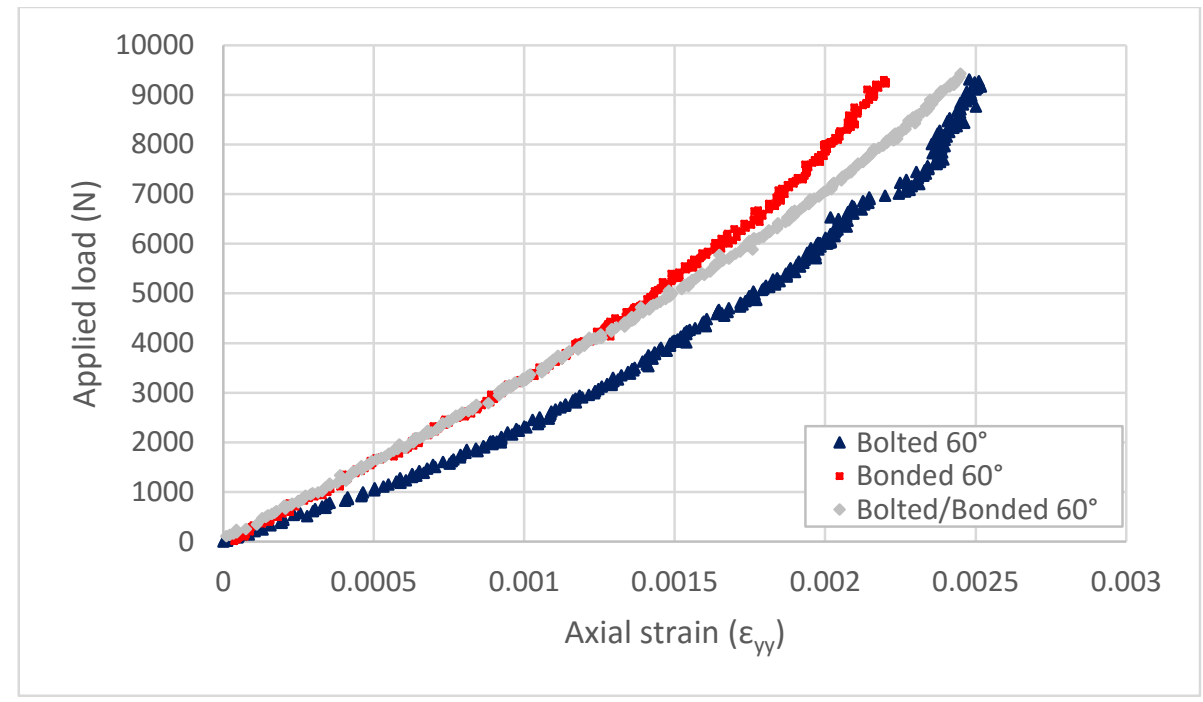

Figure E.6: Applied load versus axial strain $\left(\varepsilon_{y y}\right)$ comparison of three different joints in the $60^{\circ}$ axis 
Appendix E-3. AXIAL Strain From VARIOUs LocATIONS IN THE BOLTED JOINT

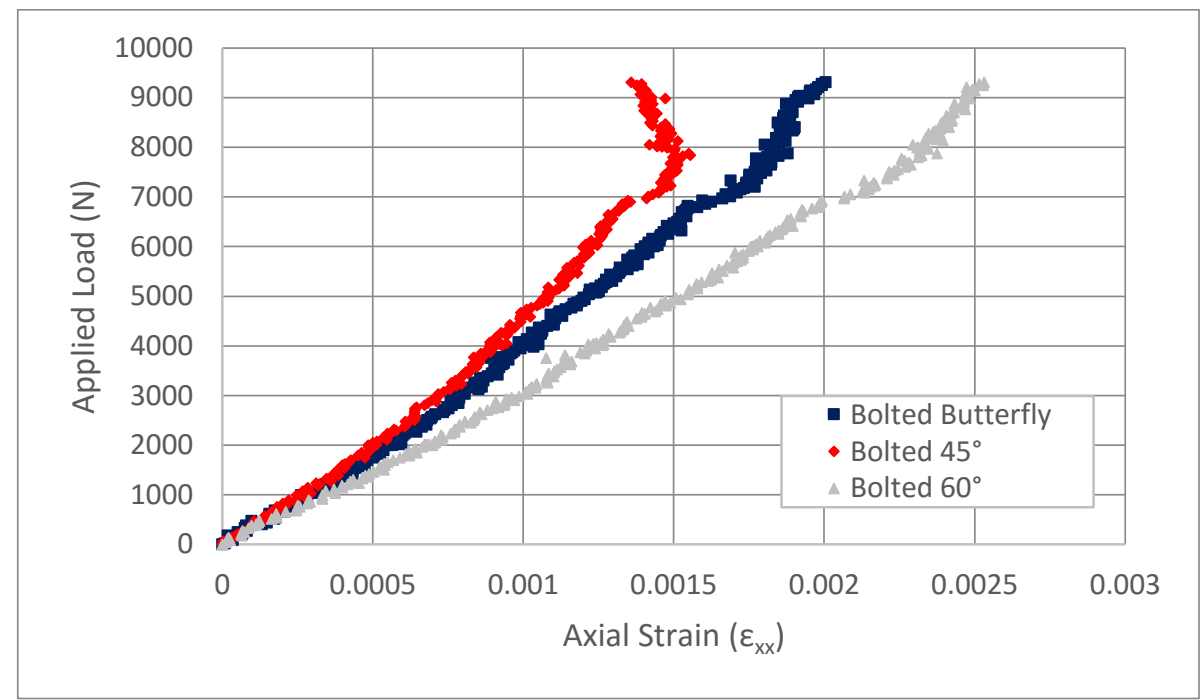

Figure E.7: Applied load versus axial strain $\left(\varepsilon_{x x}\right)$ in the bolted joint

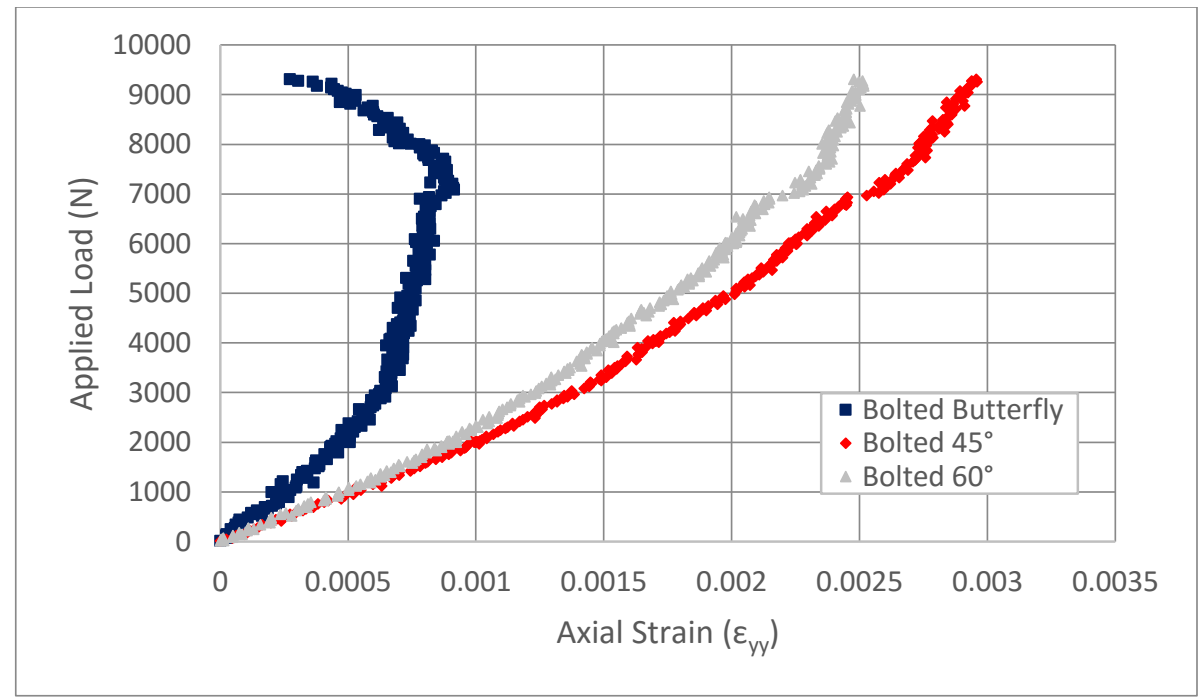

Figure E.8: Applied load versus axial strain $\left(\varepsilon_{y y}\right)$ in the bolted joint

Appendix E-4. AXIAL STRAIN FROM VARIOUS LOCATIONS IN THE BONDED JOINT 


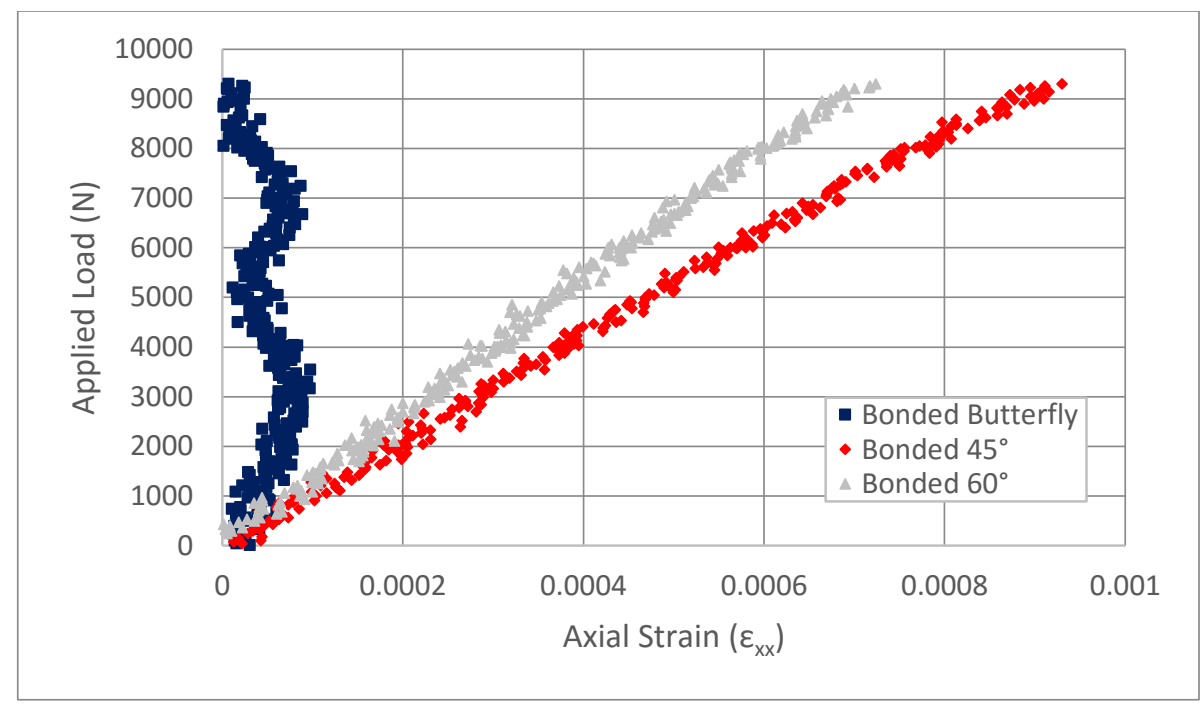

Figure E.9: Applied load versus axial strain $\left(\varepsilon_{x x}\right)$ in the bonded joint

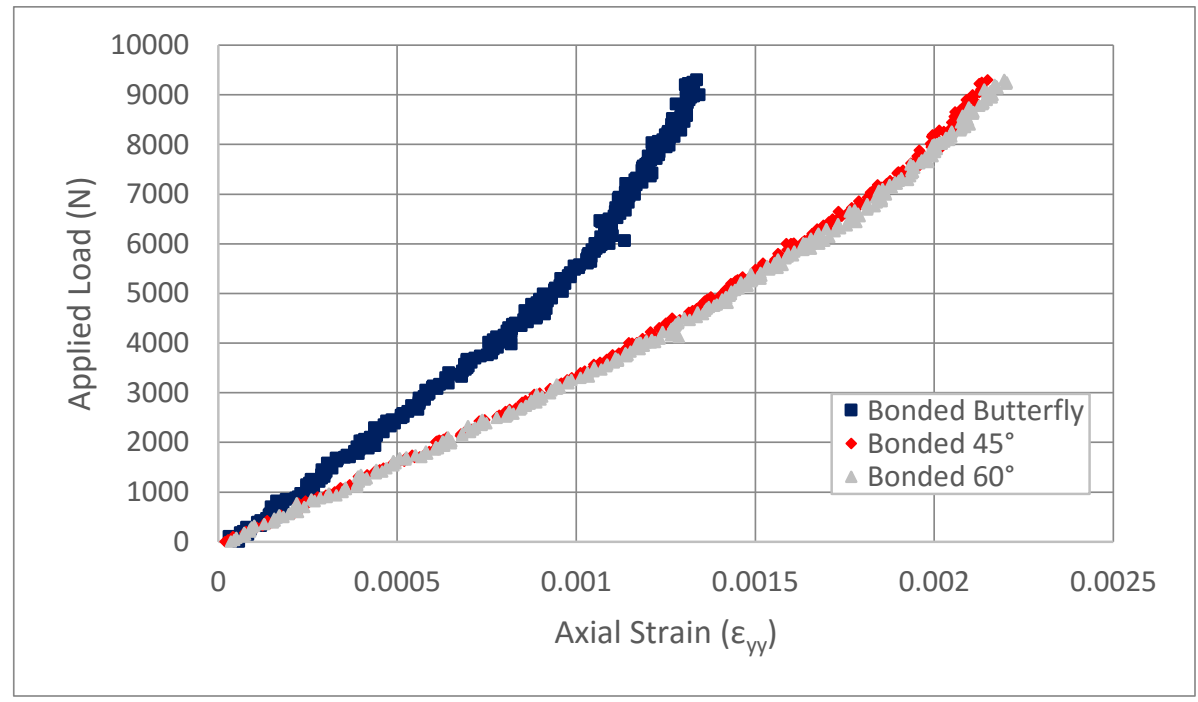

Figure E.10: Applied load versus axial strain $\left(\varepsilon_{y y}\right)$ in the bonded joint

Appendix E-5. AXIAL STRAIN FROM VARIOUS LOCATIONS IN THE

\section{BOLTED/BONDED JOINT}




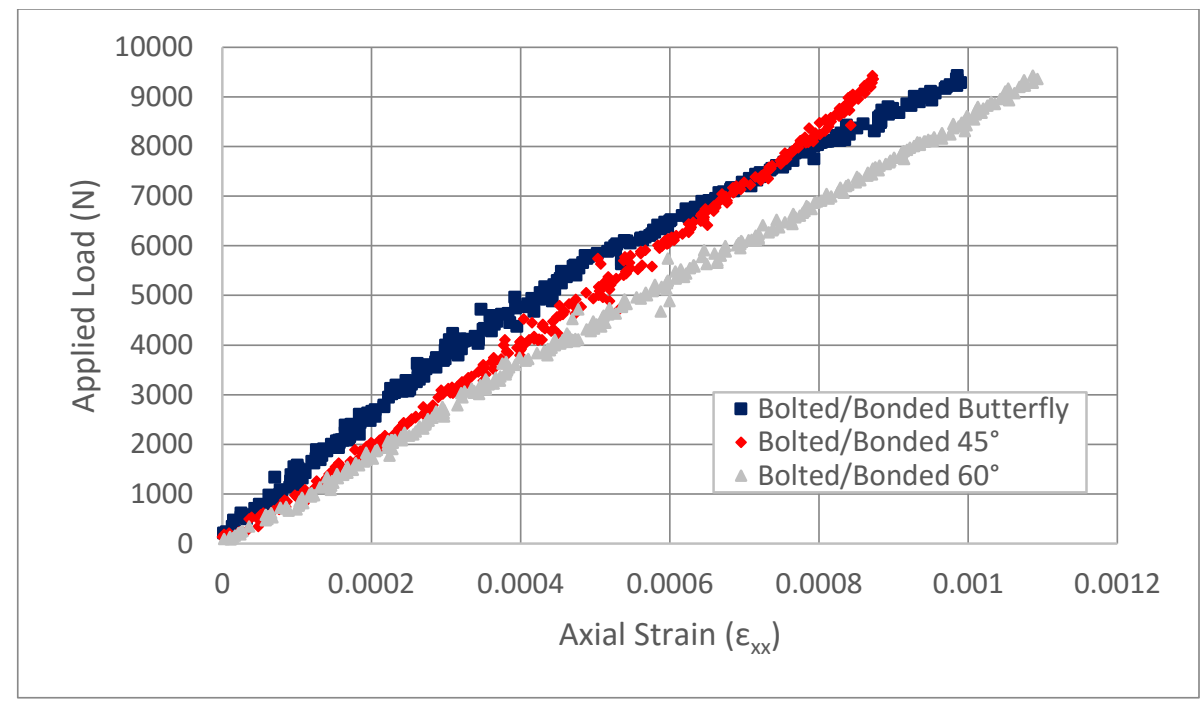

Figure E.11: Applied load versus axial strain $\left(\varepsilon_{x x}\right)$ in the bolted/bonded joint

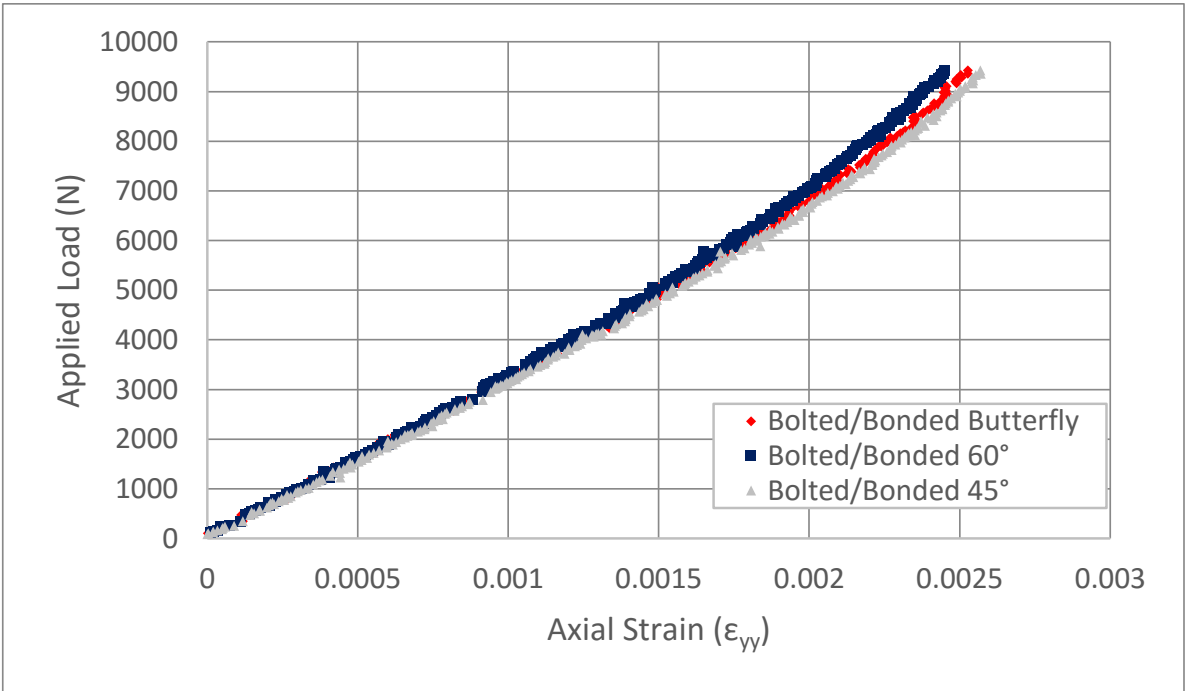

Figure E.12: Applied load versus axial strain $\left(\varepsilon_{y y}\right)$ in the bolted/bonded joint 